\author{
Universidade de São Paulo \\ Instituto de Física
}

\title{
Instabilidades MHD no tokamak TCABR
}

\author{
Tiago Fernandes
}

Orientador: Prof. Dr. Zwinglio Guimarães Filho

Dissertação de mestrado apresentada ao Instituto de

Física para a obtenção do título de Mestre em Ciências.

\section{Banca Examinadora:}

Prof. Dr. Zwinglio de Oliveira Guimarães Filho

Prof. Dr. Dennis Lozano Toufen

Prof. Dr. Francisco Eugenio Mendonça da Silveira 
FICHA CATALOGRÁFICA

Preparada pelo Serviço de Biblioteca e Informação do Instituto de Física da Universidade de São Paulo

Fernandes, Tiago

Instabilidades MHD no tokamak TCABR. São Paulo, 2016.

Dissertação (Mestrado) - Universidade de São Paulo. Instituto de Física. Depto. Física Aplicada.

Orientador: Prof. Dr. Zwinglio de Oliveira Guimarães Filho.

Área de Concentração: Física de Plasmas.

Unitermos: 1. Física de plasmas; 2. Tokamaks; 3. Fusão nuclear; 4. Instabilidades MHD; 5. Análise espectral. 


\title{
University of São Paulo \\ Institute of Physics
}

\section{MHD instabilities in TCABR tokamak}

\author{
Tiago Fernandes
}

Advisor: Prof. Dr. Zwinglio Guimarães Filho

Master's thesis submitted to the Institute of Physics to obtain the title of Master in Science.

Examining Council:

Prof. Dr. Zwinglio de Oliveira Guimarães Filho

Prof. Dr. Dennis Lozano Toufen

Prof. Dr. Francisco Eugenio Mendonça da Silveira 

Dedico este trabalho às minhas irmãs, irmãos e aos meus pais 



\section{Agradecimentos}

Gostaria de expressar meu apreço e gratidão ao meu orientador professor Dr. Zwinglio de Oliveira Guimarães Filho por ter compartilhado este tema de pesquisa, mas também pela disposição, amizade, esmero e compreensão que demonstrou nestes dois anos de trabalho conjunto.

Agradeço ao professor Dr. Iberê Caldas através do qual tive meu primeiro contato com área de física de plasmas e pelo auxílio financeiro que tornou possível a confecção do novo amplificador do diagnóstico de raios $\mathrm{X}$ moles.

Gostaria de expressar meus agradecimentos a um grande amigo, Alexandre Machado, que extrapolou o limite entre trabalho e amizade e me ajudou muito durante estes anos de convivência.

Gostaria de agradecer à secretária Sr. Eleonora Lo Duca que com seu trabalho, dedicação, amizade e respeito ajudou a tornar o trabalho mais agradável.

Agradeço profundamente a todos os professores e técnicos do laboratório pela forma respeitosa pela qual fui aceito no grupo e pelos diálogos produtivos que contribuíram de diversas formas com este trabalho. Agradeço aos técnicos e funcionários da mecânica central do instituto pelas dicas e por seus trabalhos primorosos.

Agradeço aos colegas Bruno, Taymara e Raphael pela leitura de alguns capítulos e pelas sugestões que foram importantes para o resultado final deste trabalho.

Gostaria de agradecer às minhas irmãs Eliza, Lúcia e Maria (em ordem alfabética) pelo auxílio incomensurável que me dispuseram e sem o qual eu não teria chego ao fim do mestrado.

Agradeço aos meus pais Ignês e Timóteo Fernandes pelas incontáveis lições, exemplos de vida e por todo o suporte que tive em minha vida pregressa.

Não poderia deixar de expressar meu reconhecimento aos órgãos de fomento, em especial ao $\mathrm{CNPq}$ que me concedeu a bolsa de mestrado e por toda sua importância no desenvolvimento científico do nosso país.

Agradeço a Deus, por ter me colocado junto dessas pessoas. Espero poder retribuir tudo que tem me proporcionado. 

Perturbo, logo existo "Tirem a matéria ainda tenho o vácuo perturbo os campos $e$ deles tiro ondas Tirem os campos ainda tenho o vazio perturbo o espaço e dele tiro pares

Tirem o espaço ainda tenho o nada perturbo o nada e dele tiro ideias Perturbo a matéria e os campos Perturbo o espaço e o nada

Tiro onda com meus pares e com eles minhas ideias vácuo, vazio e nada Perturbo, logo existo 



\section{Resumo}

Este trabalho descreve o estudo das instabilidades magneto-hidro-dinâmicas (MHD) comumente observadas nas descargas elétricas de plasma no tokamak TCABR, do Instituto de Física da USP. Dois diagnósticos principais foram empregados para observar essas instabilidades: um conjunto poloidal de 24 bobinas magnéticas (bobinas de Mirnov) colocadas próximas à borda do plasma e um medidor de emissões na faixa do Ultra Violeta e de raios X moles com 20 canais (sistema SXR), cujo circuito de condicionamento de sinais foi aprimorado como parte deste trabalho. Esses diagnósticos foram escolhidos porque fornecem informações complementares, uma vez que o sistema SXR observa a parte central da coluna de plasma, enquanto as bobinas de Mirnov detectam as instabilidades MHD na região mais externa da coluna. As informações coletadas por esses diagnósticos foram submetidas à análise espectral com resolução temporal e espacial, possibilitando determinar a evolução das características espectrais e espaciais das instabilidades MHD observadas. Essas análises revelaram que durante a etapa inicial da formação do plasma (quando a corrente de plasma ainda está aumentando) ilhas magnéticas com números de onda decrescente, identificadas como sendo modos kink de borda, são detectadas nas bobinas de Mirnov. Após a formação do plasma, quando os parâmetros de equilíbrio estão relativamente estáveis (platô), oscilações são detectadas tanto nas bobinas de Mirnov quanto no sistema de SXR, indicando a presença de instabilidades MHD em toda a coluna de plasma. Em geral as oscilações medidas nas bobinas de Mirnov tem baixa amplitude e correspondem a pequenas ilhas magnéticas que foram identificadas como sendo modos de ruptura (modos tearing). Por outro lado, as instabilidades na região central foram identificadas como dentes de serra, que correspondem a relaxações periódicas da região interna à superfície magnética com fator de segurança q=1 e que são acompanhadas de oscilações precursoras, cuja amplitude depende da fase do ciclo de relaxação. Devido à essa modulação de amplitude, aparecem picos de frequência satélite nos espectrogramas dos sinais do SXR. Além disso, devido ao fato dos ciclos de relaxação não serem sinusoidais, os harmônicos da frequência de relaxação também aparecem nesses espectrogramas. No entanto, em muitas descargas do TCABR, a intensidade das oscilações medidas nas bobinas de Mirnov aumentam significativamente durante o platô, com efeitos sobre a frequência de todas as instabilidades MHD, até mesmo sobre os dentes de serra localizados na região central da coluna. Em todos os casos, observou-se que durante o platô a frequência das ilhas magnéticas coincide com a frequência das oscilações precursoras do dente de serra, apesar de serem duas instabilidades distintas, localizadas em posições radiais muito diferentes. Essa coincidência de frequências possibilitou descrever a evolução em frequência de todas as oscilações detectadas em diversos diagnósticos com base em apenas duas frequências básicas: a dos ciclos de relaxação dente de serra e a das ilhas magnéticas.

Palavras-chaves: Física de Plasmas, Tokamak, Instabilidades MHD, Análise espectral. 



\section{Abstract}

This work describes the study of magneto-hydro-dynamic instabilities (MHD) commonly observed in plasma discharges in tokamak TCABR (at Instituto de Física da USP). Two main diagnostics were employed to observe these instabilities: a poloidal set of 24 magnetic coils (Mirnov coils) placed near the plasma border and a detector of emissions in the Ultra Violet and soft X-ray range with 20 channels (SXR system) which improvement of the signal conditioning circuit was done as part of this work. These diagnostics were chosen because they provide complementary information, since the SXR system measures the central part of the plasma column, while the Mirnov coils detect the MHD instabilities in the outer part of the column. The information collected by these diagnoses was submitted to spectral analysis with temporal and spatial resolution, making it possible to determine the evolution of the spectral and spatial characteristics of the observed MHD instabilities. These analyzes revealed that during the initial stage of the plasma formation (when the plasma current is still increasing) magnetic islands with decreasing wave numbers, identified as edge kink modes, are detected in the Mirnov coils. After the plasma formation, when the equilibrium parameters are relatively flat (plateau), oscillations are detected in both Mirnov coils and SXR system, indicating the presence of MHD instability in the whole plasma column. In general, the fluctuations measured by the Mirnov coils have low amplitude corresponding to small magnetic islands, which were identified as tearing modes. On the other hand, the instabilities at the central region were identified as sawteeth oscillations that correspond to periodic relaxations in the internal region of the magnetic surface with safety factor $\mathrm{q}=1$ and that are accompanied by precursor oscillations which amplitude depends on the phase of the relaxation cycles. Due to this amplitude modulation, frequency satellite peaks appear in the spectrograms of the SXR signals. Furthermore, due to the fact that relaxation cycles are not sinusoidal, harmonics of the relaxation frequency also appear in the spectrograms. However, in many TCABR discharges, the intensity of the oscillations measured by the Mirnov coils increase significantly during the plateau, with affects the frequency of all MHD instabilities, even over the sawteeth in the central region of the column. In all cases, it was observed that during the plateau the frequency of the magnetic islands coincides with the frequency of the sawtooth precursors, although they are two different instabilities located in separated radial positions. This coincidence of frequencies allowed describing the frequency evolution of all measured oscillations by considering only two basic frequencies: the cycles of sawtooth relaxation and the magnetic islands.

Key-words: Plasma Physics, Tokamak, MHD instabilities, Spectral analysis 



\section{Lista de ilustrações}

Figura 1 - (a) Seções de Choque em função da energia e (b) Taxa de reação média em função da temperatura para as principais reações de fusão com interesse na produção de energia. . . . . . . . . . . . . . . . . . . . .

Figura 2 - Movimento de uma carga sujeita a ação de um campo magnético B. Adaptado

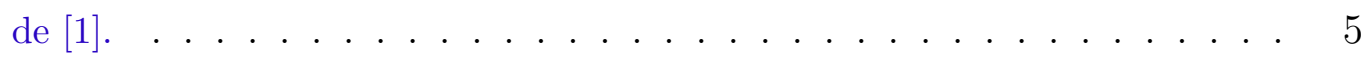

Figura 3 - Campo magnético gerado por bobinas dispostas em um toro. Adaptado de [1]. 6

Figura 4 - Sistema de confinamento aberto. As linhas de campo interceptam as paredes. 9

Figura 5 - (a) Sistema de confinamento toroidal. As linhas de campo são fechadas e não interceptam as paredes do vaso. O sistema de coordenadas está representado sendo $R$ o raio maior, $r$ o raio menor, $\phi$ o ângulo toroidal e $\theta$ o ângulo poloidal. (b) Não-homogeneidade do campo toroidal devido ao espaçamento linear não uniforme das bobinas toroidais. . . . . . . . . . . . . . . . . . 10

Figura 6 - (a) Eixos de referência e componentes do campo magnético na configuração tokamak. $\mathbf{B}_{\phi}$ é o campo toroidal e $\mathbf{B}_{\theta}$ é o campo poloidal. (b) Aspecto do campo magnético resultante da sobreposição das componentes toroidal e poloidal. . . . . . . . . . . . . . . . . . . . 11

Figura 7 - Superfícies Magnéticas. As linhas de campo de $\mathbf{B}$ e de $\mathbf{j}$ estão contidas nestas superfícies e o $\nabla p$ é perpendicular a superfície.

Figura 8 - (a) Aspecto tridimensional de uma ilha magnética em um tokamak e (b) projeção em um plano da seção transversal. . . . . . . . . . . . . . . . . . . 14

Figura 9 - (a) Linhas de campo antes da ruptura e (b) linhas de campo após ruptura e reconexões. . . . . . . . . . . . . . . . . . . . . . 16

Figura 10 - (a) Perfil de equilíbrio da densidade de corrente usando o modelo dado pela expressão (2.17) para diversos valores de corrente de plasma, típicos do TCABR e (b) perfil radial do fator de segurança calculados para os mesmos valores de corrente, $q_{0}=0.9$ e $B_{\varphi}=1.1 T$. O valor de $q_{a}$, em $r=a=0.18$, é determinado pelo valor $I_{p} \ldots \ldots \ldots \ldots$. . . . . . . . . . 17

Figura 11 - Exemplo da influência das perturbações nas grandezas de equilíbrio do plasma. Perfil de equilíbrio da temperatura em (a), deslocamento em degrau em (b), valor da perturbação da temperatura devido ao deslocamento em (c) e perfil perturbado da temperatura sobreposto ao perfil original $(\mathrm{d}) . \quad$. . . . . . . . 19

Figura 12 - Exemplos de instabilidades MHD: (a) modo tearing e (b) modo kink. Para o modo tearing a perturbação radial $\xi_{0}(r)$ apresenta inversão do sinal enquanto que para o modo kink não há inversão.

Figura 13 - Aspecto da perturbação dente de serra devido ao processo de relaxação do centro da coluna de plasma. . . . . . . . . . . . . . . . . . . . . . 
Figura 14 - Modelo de reconexões magnéticas de Kadomtsev mostrando o processo de formação das ilhas magnéticas até atingir no novo estado de equilíbrio. A linha pontilhada em vermelho indica a posição da superfície $q=1 . \quad$. . . . . 23

Figura 15 - Vista em perspectiva mostrando um corte da câmara de vácuo e o posicionamento das bobinas. . . . . . . . . . . . . . . . . . . . .

Figura 16 - (a) Aspecto visual das bobinas de Mirnov instaladas no TCABR e (b) circuito de filtragem e interligação das bobinas de Mirnov com uma entrada analógica diferencial do sistema de aquisição de dados no TCABR. . . . . . . . . . . . 28

Figura 17 - (a) Sinal temporal típico de uma bobina de Mirnov e (b) Espectrograma de potência do sinal típico. . . . . . . . . . . . . . . . . . . .

Figura 18 - (a) Visualização simultânea dos sinais das bobinas de Mirnov poloidais para um disparo típico e (b) Valor instantâneo da perturbação para $t=70.5 \mathrm{~ms}$. É possível visualizar em (a) que existe uma pequena defasagem temporal entre os canais e que os valores se repetem de instante de tempo à instante de tempo em (b), a menos de um deslocamento no número do canal. . . . .

Figura 19 - (a) Sistema de referência do laboratório e do centro da coluna de plasma (b) Posições angulares medidas em ambos os referenciais. . . . . . . . . . . . . 30

Figura 20 - (a) Arranjo experimental do sistema SXR mostrando a disposição dos sensores, das fendas e do filtro de berílio e (b) aspecto físico do encapsulamento dos arrays sensores modelo AXUV20EL. . . . . . . . . . . . . . . . . .

Figura 21 - (a) Esquema eletrônico simplificado de um dos canais do amplificador do sistema SXR e (b) aspecto físico de um dos módulos amplificadores montados. 32

Figura 22 - Montagem do novo sistema de amplificação do sistema SXR no TCABR. . . 32

Figura 23 - (a) Sinal temporal típico de um canal central do SXR (b) Espectrograma de potência do sinal típico do SXR. . . . . . . . . . . . . . . . . 33

Figura 24 - Sinais de todos os canais ativos para os canais com filtro de berílio em (a) e sem filtro em (b).

Figura 25 - (a) Visualização simultânea dos sinais dos canais do SXR sem filtro para um disparo típico e (b) Valor instantâneo dos sinais para três instantes de tempo. 34

Figura 26 - Alocação dos parâmetros de impacto para as cordas do SXR em função dos canais. . . . . . . . . . . . . . . . . . . 35

Figura 27 - Evolução da diferença de fase a cada realização da medida entre dois sinais coerentes numa frequência $\omega_{j}$. A soma de todas as realizações tende a um ponto próximo a circunferência de raio unitário. . . . . . . . . . . . . . . . 4

Figura 28 - Evolução da diferença de fase a cada realização da medida entre dois sinais não coerentes numa frequência $\omega_{j}$. A soma de todas as realizações tende a zero. 42 
Figura 29 - Exemplo de análise de um sinal sintético utilizando a FFT simples e STFT. Em (a) o sinal original composto por duas frequências bem definidas de $50 \mathrm{~Hz}$ e $100 \mathrm{~Hz}$ e os resultados da transformada de Fourier simples e a magnitude de STFT do sinal em (b) e (c), respectivamente. . . . . . . . . . . . . .

Figura 30 - Exemplo de análise de um sinal sintético com ruído gaussiano utilizando a FFT simples e STFT. Em (a) o sinal original composto por duas frequências bem definidas de $50 \mathrm{~Hz}$ e $100 \mathrm{~Hz}$ e os resultados da transformada de Fourier simples e a magnitude de STFT do sinal em (b) e (c), respectivamente. Mesmo com nível de ruído elevado as componentes de frequência do sinal original são discriminadas. . . . . . . . . . . . . . . . . . . . . . . . . .

Figura 31 - Exemplo da aplicação de janelas para STFT. Em (a) o sinal sintético de $23.31 \mathrm{~Hz}$ e $100,23 \mathrm{~Hz}$ acrescido de um ruído gaussiano e o resultado da DFT do sinal em (b). Em (c) e (e) estão janela retangular e a janela Hamming com as respectivas DFT em (d) e (f). Em (g) e (i) estão o produto do sinal original pela janela retangular e de Hamming. Em (h) e (j) estão representados os espectros finais após o janelamento para a função retangular e de Hamming, respectivamente. A utilização de uma janela adequada diminui o alargamento dos picos do espectro. . . . . . . . . . . . . . . . . . . . . . . 444

Figura 32 - Representação matricial de um sinal multicanal. . . . . . . . . . . . . . . . 46

Figura 33 - Diagrama esquemático da análise espectral em sinais multicanais. . . . . . . 47

Figura 34 - Diagrama esquemático do cálculo da potência espectral em sinais multicanais. 47

Figura 35 - Diagrama esquemático do cálculo da fase relativa em sinais multicanais. . . 47

Figura 36 - Formas de visualização das análises espectrais multicanais. . . . . . . . . . 48

Figura 37 - Variáveis de equilíbrio para o disparo \#28661 do TCABR. Com corrente de plasma em (a), densidade central em (b), sinal da bobina de Mirnov de referência em (c) e sinal da emissão de raios-X duros em (d) . . . . . . . . . .

Figura 38 - Número de onda poloidal e frequência do modo para o disparo \#28661 do TCABR. Em (a) o espectrograma de potência médio de todas as 24 bobinas, em (b) até (e) frequência por modo de oscilação para os valores de $\lambda$ indicados. 51

Figura 39 - Determinação dos número de onda poloidal para o disparo \#28661 do TCABR. Em (a) o espectrograma de potência médio de todas as 24 bobinas, em (b) até (e) histogramas de amplitude relativa por modo de oscilação para os valores de $\lambda$ indicados. . . . . . . . . . . . . . . . . . . . .

Figura 40 - Determinação do parâmetro $\lambda$ para correção dos ângulos no referencial do plasma, utilizando o modelo parabólico para densidade de corrente da expressão (2.18). Em (a) curva da posição das superfícies magnéticas $r$ em função do fator de segurança $q$ e em (b) os valores da correção de Merezhkin $\lambda$ em função de $q \ldots$. . . . . . . . . . . . . . . . . . . . . . . 5 53 
Figura 41 - Variáveis de equilíbrio para o disparo \#27000 do TCABR. Com corrente de plasma em (a), densidade central em (b), sinal da bobina de Mirnov de referência em (c) e sinal da emissão de raios-X duros em (d). . . . . . . . . 54

Figura 42 - Número de onda poloidal e frequência do modo para o disparo \#27000 do TCABR. Em (a) o espectrograma de potência médio de todas as 24 bobinas e em (b) o histograma de amplitude relativa por modo de oscilação para $\lambda=0,25$. A taxa de amostragem do sinal é $f_{s}=250 k H z \ldots \ldots . . . .55$

Figura 43 - Variáveis de equilíbrio para o disparo \#30330 do TCABR. Com corrente de plasma em (a), densidade central em (b), sinal da bobina de Mirnov de referência em (c) e sinal da emissão de raios-X duros em (d) . . . . . . . . . 55

Figura 44 - Número de onda poloidal e frequência do modo para o disparo \#30330 do TCABR. Em (a) o espectrograma de potência médio de todas as 24 bobinas e em (b) o histograma de amplitude relativa por modo de oscilação para $\lambda=0.25$. A taxa de amostragem do sinal é $f_{s}=500 \mathrm{kHz} \ldots \ldots . . .56$

Figura 45 - Variáveis de equilíbrio para o disparo \#28400 do TCABR. Com corrente de plasma em (a), densidade central em (b), sinal da bobina de Mirnov de referência em (c) e sinal da emissão de raios-X duros em (d) . . . . . . . . . 57

Figura 46 - Número de onda poloidal e frequência do modo para o disparo \#28400 do TCABR. Em (a) o espectrograma de potência médio de todas as 24 bobinas e em (b) o histograma de amplitude relativa por modo de oscilação para $\lambda=0,25$. A taxa de amostragem do sinal é $f_{s}=250 k H z \ldots \ldots . . . .57$

Figura 47 - Comportamento médio da frequência e número de onda das perturbações magnéticas medidas pelas bobinas de Mirnov para o disparo \#28661 em 20

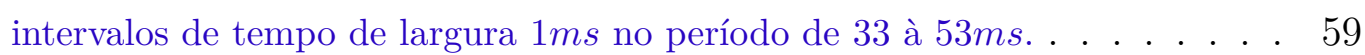

Figura 48 - Estudo dos modos de oscilação durante a rampa de subida da corrente de plasma para o disparo \#28661. Em (a) o espectrograma médio de potência para os sinais das bobinas de Mirnov e em (b) a decomposição dos modos para cada instante de tempo, utilizando $\lambda=0,3 \ldots \ldots$. . . . . . . . 60

Figura 49 - Estudo dos modos de oscilação durante a rampa de subida da corrente de plasma para o disparo \#30330. Em (a) o espectrograma médio de potência para os sinais das bobinas de Mirnov e em (b) a decomposição dos modos para cada instante de tempo, utilizando $\lambda=0,3 \ldots \ldots$. . . . . . . . . 61

Figura 50 - Variáveis de equilíbrio para o disparo \#25911 do TCABR. Com corrente de plasma em (a), densidade central em (b), sinal da bobina de Mirnov de referência em (c) e sinal da emissão de raios-X duros em (d) . . . . . . . . . 62 
Figura 51 - Estudo do acoplamento entre modos de oscilação durante o disparo \#25911 do TCABR. Em (a) o espectrograma médio de potência para os sinais das bobinas de Mirnov, em (b), (c) a decomposição dos modos antes do tempo de $70 \mathrm{~ms}$ para o caminho 1 e 2, respectivamente e em (c) decomposição dos modos após o acoplamento. Análises efetuadas utilizando $\lambda=0,25 \ldots$. . . .

Figura 52 - Variáveis de equilíbrio para o disparo \#27005 do TCABR. Com corrente de plasma em (a), densidade central em (b), sinal da bobina de Mirnov de referência em (c) e sinal da emissão de raios-X duros em (d) . . . . . . . . .

Figura 53 - Estudo do acoplamento entre modos de oscilação durante o disparo \#27005 do TCABR. Em (a) o espectrograma médio de potência para os sinais das bobinas de Mirnov, em (b), (c) a decomposição dos modos antes do tempo de $70 \mathrm{~ms}$ para o caminho 1 e 2, respectivamente e em (c) decomposição dos modos após o acoplamento. Análises efetuadas utilizando $\lambda=0,25 \ldots$. . . .

Figura 54 - Sinais típicos produzidos pelo diagnóstico de raios-X moles, para o disparo \#28661. Da esquerda para a direita e de cima para baixo apresenta os sinais iniciando em um canal periférico (ch\#02), passando pelos canais centrais (ch\#09) e (ch\#10) e chegando no canal de periferia no lado oposto (ch\#14).

Figura 55 - Visualização simultânea dos sinais de todos os canais ativos do SXR para o disparo \#28661 no intervalo de tempo de $76 \sim 80 \mathrm{~ms}$. E (a) o sinal original e em (b) o sinal após a subtração do valor médio dos sinais. A representação em (b) torna mais fácil a visualização das componentes de variação rápida dos sinal. . . . . . . . . . . . . . . . . . . . .

Figura 56 - Visualização simultânea dos sinais filtrados de todos os canais ativos do SXR para o disparo \#28661 no intervalo de tempo de $76 \sim 80 \mathrm{~ms}$. E (a) o resultado da filtragem usando um FPB com frequência de corte superior de $f_{c}=5,0 k H z(b)$ o resultado da filtragem usando um FPA com frequência de corte inferior $f_{c}=7,0 k H z \ldots \ldots \ldots$

Figura 57 - Construção do gráfico de distribuição espacial média de potência espectral. De (a) à (f) os espectrogramas de alguns dos sinais do SXR para o disparo \#26136 e em (g) o gráfico da potência espectral média por componente de frequência para cada canal. O intervalo de tempo de 82 à $90 \mathrm{~ms}$ para o cálculo das médias estão indicados pelas linhas verticais nos espectrogramas. . . .

Figura 58 - Análises da distribuição espacial da potência espectral média dos sinais do SXR para o disparo \#28661 para o intervalo de tempo de 75 à $85 \mathrm{~ms}$ para os canais 4 à 15. Em (a) até (d) estão os resultados referentes à $f_{R E L}$ e em (e) à $(\mathrm{f})$ os resultados referentes à $f_{P R E} \ldots \ldots \ldots \ldots$. . . . . . . . . 
Figura 59 - Efeitos de um pequeno deslocamento da região central da coluna de plasma e do movimento de rotação do centro da coluna de plasma em relação ao eixo magnético original (modo kink interno) e consequências sobre os sinais integrados em linha dos diagnósticos ópticos. . . . . . . . . . . . . . . . . 71

Figura 60 - Variáveis de equilíbrio para o disparo \#26136 do TCABR. Com corrente de plasma em (a), densidade central em (b), sinal da bobina de Mirnov de referência em (c) e sinal da emissão de raios-X duros em (d). . . . . . . . .

Figura 61 - Análises da distribuição espacial da potência espectral média dos sinais do SXR para o disparo \#26136 para o intervalo de tempo de 75 à $85 \mathrm{~ms}$ para os canais 4 à 15 . Em (a) até (d) estão os resultados referentes à $f_{R E L}$ e em (e)

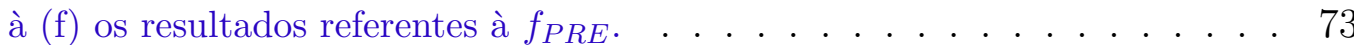

Figura 62 - Análises da distribuição espacial da potência espectral média dos sinais do SXR para o disparo \#28400 no o intervalo de tempo de 75 à $80 \mathrm{~ms}$ para os canais 4 à 15. Em (a) até (d) estão os resultados referentes à $f_{R E L}$ e em (e)

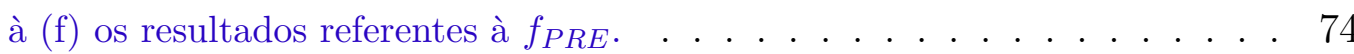

Figura 63 - Refinamento da estimativa da evolução no tempo de uma componente de frequência de um espectrograma. Em (a) espectrograma de um sinal. A linha branca sobreposta constitui uma estimativa manual do valor da frequência no tempo, as linhas pretas delimitam a largura da banda de frequências onde o pico da magnitude será procurado e a linha vertical vermelha especifica o marcador do tempo. Em (b) o histograma de potência espectral para o instante de tempo selecionado e em (c) o valor refinado da componente de frequência no tempo, usando como estimativa a coordenada do ponto de máxima magnitude espectral obtida pelo ajuste parabólico. . . . . . . . . . 77

Figura 64 - Análises comparativas das componentes espectrais dos sinais de referência para o disparo \#30330. Em (a) o espectrograma da bobina de Mirnov 01 e o respectivo caminho no plano frequência $\times$ tempo em cor verde, em (b) o espectrograma do canal 07 do SXR e respectivo caminho em cor vermelha, em (c) o espectrograma do sinal a ser comparado, nestes caso o canal 8 do SXR e em (d) o mesmo espectrograma a ser comparado com a sobreposição dos caminhos de frequência das referências. . . . . . . . . . . . . . . 78

Figura 65 - Análises comparativas das componentes espectrais dos sinais de referência para o disparo \#26136. Em (a) o espectrograma da bobina de Mirnov 01 e o respectivo caminho no plano frequência $\times$ tempo em cor verde, em (b) o espectrograma do canal 09 do SXR e respectivo caminho em cor vermelha, em (c) o espectrograma do sinal a ser comparado, nestes caso o canal 8 do SXR e em (d) o mesmo espectrograma a ser comparado com a sobreposição dos caminhos de frequência das referências. . . . . . . . . . . . . . . . . . 79 
Figura 66 - Variáveis de equilíbrio para o disparo \#29754 do TCABR. Com corrente de plasma em (a), densidade central em (b), sinal da bobina de Mirnov de referência em (c) e sinal da emissão de raios-X duros em (d). . . . . . . . .

Figura 67 - Análises comparativas das componentes espectrais dos sinais de referência para o disparo \#29754. Em (a) o espectrograma da bobina de Mirnov 01 e o respectivo caminho no plano frequência $\times$ tempo em cor verde, em (b) o espectrograma do canal 10 do SXR e respectivo caminho em cor vermelha, em (c) o espectrograma do sinal a ser comparado, nestes caso o canal 9 do SXR e em (d) o mesmo espectrograma a ser comparado com a sobreposição dos caminhos de frequência das referências. . . . . . . . . . . . . . . . . . 80

Figura 68 - Variáveis de equilíbrio para o disparo \#26842 do TCABR. Com corrente de plasma em (a), densidade central em (b), sinal da bobina de Mirnov de referência em (c) e sinal da emissão de raios-X duros em (d) . . . . . . . . . .

Figura 69 - Análises comparativas das componentes espectrais dos sinais de referência para o disparo \#26842. Em (a) o espectrograma da bobina de Mirnov 01 e o respectivo caminho no plano frequência $\times$ tempo em cor verde, em (b) o espectrograma do canal 8 do SXR e respectivo caminho em cor vermelha, em (c) o espectrograma do sinal a ser comparado, nestes caso o canal 10 do SXR e em (d) o mesmo espectrograma a ser comparado com a sobreposição dos caminhos de frequência das referências. . . . . . . . . . . . . . . .

Figura 70 - Análises comparativas das componentes espectrais dos sinais de referência para o disparo \#29754 para outros sinais. Em (a) e (c) os espectrogramas do sinal de emissão de raios-X duros (HARDXRAY) respectivamente com e sem sobreposição da componentes de referência e em (b) e (d) os espectrogramas do sinal de densidade eletrônica a $-1 \mathrm{~cm}$ da posição central da coluna (NE03), respectivamente com e sem sobreposição. . . . . . . . . . . . . . . . . . . 8

Figura 71 - Variáveis de equilíbrio para o disparo \#30920 do TCABR. Com corrente de plasma em (a), densidade central em (b), sinal da bobina de Mirnov de referência em (c) e sinal da emissão de raios-X duros em (d) . . . . . . . . .

Figura 72 - Análises comparativas das componentes espectrais dos sinais de referência para o disparo \#30920. Em (a) o espectrograma da bobina de Mirnov 01 e o respectivo caminho no plano frequência $\times$ tempo em cor verde, em (b) o espectrograma do canal 10 do SXR e respectivo caminho em cor vermelha, em (c) o espectrograma do sinal a ser comparado, nestes caso o canal 12 do SXR e em (d) o mesmo espectrograma a ser comparado com a sobreposição dos caminhos de frequência das referências. . . . . . . . . . . . . 
Figura 73 - Análises comparativas das componentes espectrais dos sinais de referência para o disparo \#30920 para outros sinais. Em (a) e (c) os espectrogramas do sinal de emissão de raios-X duros (HARDXRAY) respectivamente com e sem sobreposição da componentes de referência e em (b) e (d) os espectrogramas do sinal da própria Mirnov 01, respectivamente com e sem sobreposição. O sinal da Mirnov apresenta as frequências de $f_{M I R} \pm f_{R E L} . \quad \ldots . . .86$

Figura 74 - Análises comparativas das componentes espectrais dos sinais de referência para o disparo \#25911. Em (a) o espectrograma da bobina de Mirnov $01 \mathrm{e}$ o respectivo caminho no plano frequência $\times$ tempo em cor verde, em (b) o espectrograma do canal 9 do SXR e respectivo caminho em cor vermelha, em (c) o espectrograma do sinal a ser comparado, nestes caso o canal 10 do SXR e em (d) o mesmo espectrograma a ser comparado com a sobreposição dos caminhos de frequência das referências. . . . . . . . . . . . . . . 88

Figura 75 - Análises comparativas das componentes espectrais dos sinais de referência para o disparo \#27005. Em (a) o espectrograma da bobina de Mirnov $01 \mathrm{e}$ o respectivo caminho no plano frequência $\times$ tempo em cor verde, em $(b)$ o espectrograma do canal 9 do SXR e respectivo caminho em cor vermelha, em (c) o espectrograma do sinal a ser comparado, nestes caso o canal 10 do SXR e em (d) o mesmo espectrograma a ser comparado com a sobreposição dos caminhos de frequência das referências. . . . . . . . . . . . . . . . 89

Figura 76 - Diagrama do circuito eletrônico completo do novo amplificador de sinais do sistema SXR do TCABR. . . . . . . . . . . . . . . . . . . . . . 101

Figura 77 - Desenho em escala natural da parte superior em (a) e inferior em (b) da placa de circuito impresso do novo amplificador do sistema SXR do TCABR. 102

Figura 78 - Lâminas frontais do módulos eletrônicos do sistema SXR do TCABR. . . . 103 Figura 79 - Vista frontal do bastidor do sistema SXR do TCABR.. . . . . . . . . . . . 104 Figura 80 - Vista 3D do bastidor do sistema SXR do TCABR. . . . . . . . . . . . . . 105 


\section{Lista de tabelas}

Tabela 1 - Principais parâmetros do TCABR . . . . . . . . . . . 26

Tabela 2 - Componentes principais do TCABR. . . . . . . . . . . 27 



\section{Lista de abreviaturas e siglas}

$\begin{array}{ll}\text { DDS } & \text { Oscilação Dente de Serra } \\ \text { DFT } & \text { Discrete Fourier Transform } \\ \text { FFT } & \text { Fast Fourier Transform } \\ \text { FPA } & \text { Filtro Passa Altas } \\ \text { FPB } & \text { Filtro Passa Baixas } \\ \text { HFS } & \text { High Field Side } \\ \text { JET } & \text { Joint European Torus } \\ \text { LFS } & \text { Low Field Side } \\ \text { MHD } & \text { Magneto hidrodinâmica } \\ \text { MMQ } & \text { Método dos Mínimos Quadrados } \\ \text { PRE } & \text { Oscilação Precursora de Dente de Serra } \\ \text { REL } & \text { Relaxação da Dente de Serra } \\ \text { STFT } & \text { Short Time Fourier Transform } \\ \text { SXR } & \text { Soft X-ray } \\ \text { TCABR } & \text { Tokamak Chauffage Alfvén Brasilien } \\ & \text { Toroidal'naya Kamera s Magnitnymi Katushkami - Câmara Toroidal } \\ \text { THA } & \text { para }\end{array}$





\section{Sumário}

1 Introdução . . . . . . . . . . . . . . . . . . . 1

2 Confinamento magnético - Tokamaks .............. 5

2.1 Derivas . . . . . . . . . . . . . . . . . . . . 6

2.1.1 Deriva devida ao campo elétrico . . . . . . . . . . . . . . 7

2.1.2 Deriva de polarização . . . . . . . . . . . . . . . 7

2.1.3 Deriva devida à curvatura do campo B . . . . . . . . . . . . . 7

2.1.4 Deriva devida a não homogeneidade do campo B . . . . . . . . . 8

2.2 Tokamaks . . . . . . . . . . . . . . . . . . . . . 8

2.2.1 Equilíbrio do plasma . . . . . . . . . . . . . . . 11

2.2.2 Fator de segurança . . . . . . . . . . . . . . . . . . 13

2.2.3 Eficiência de confinamento . . . . . . . . . . . . . . . . . . 14

2.3 Perturbações e ilhas magnéticas . . . . . . . . . . . . . . . . . . . . . . 14

2.3.1 Origem das perturbações . . . . . . . . . . . . . . . . 15

2.3.2 Localização das perturbações . . . . . . . . . . . . . . . . 16

2.3.3 Influência das perturbações no plasma . . . . . . . . . . . . . . . . 18

2.3.3.1 Rotação e modelo de perturbação . . . . . . . . . . . . . . 19

2.3.3.2 Componente espacial da perturbação $\left(\xi_{0}(r)\right) \ldots . .20$

2.3.3.3 Métodos de deteç̧ão . . . . . . . . . . . . . . . . 21

2.3.4 Oscilações dente de serra e modo kink interno . . . . . . . . . . . . 21

3 Diagnósticos para detecção de instabilidades MHD . . . . . . . . . 25

3.1 O tokamak TCABR . . . . . . . . . . . . . . . . 25

3.2 Bobinas de Mirnov . . . . . . . . . . . . . . . . . . . . . 27

3.3 Sistema SXR . . . . . . . . . . . . . . . . . . 30

4 Métodos para tratamento de dados . . . . . . . . . . . 37

4.1 Transformada de Fourier . . . . . . . . . . . . . . . . . . . . 38

4.2 Correlação cruzada e autocorrelação . . . . . . . . . . . . . . . . . . . . 39

4.3 Densidade de potência espectral e espetral cruzada . . . . . . . . . . . . . 40

4.4 Coerência e fase . . . . . . . . . . . . . . . . . . . 40

4.5 Short Time Fourier Transform - STFT . . . . . . . . . . . . . . . . . . . . 42

4.6 Análise de sinais multicanais . . . . . . . . . . . . . . . . . . . . 45

4.6 .1 Modelo de sinais . . . . . . . . . . . . . . . . 45

4.6.2 Análise espectral de sinais multicanais . . . . . . . . . . . . . . 46

4.6 .3 Visualização de dados multicanais . . . . . . . . . . . . . . . . . . 47

5 Análises e resultados . . . . . . . . . . . . . . . . . 49

5.1 Perturbações magnéticas medidas pelas bobinas de Mirnov . . . . . . . . . 49

5.1 .1 Determinação do parâmetro $\lambda \ldots \ldots$. . . . . . . . . . 52 
5.1 .2 Estudo dos modos múltiplos. . . . . . . . . . . . . . . . . . 53

5.1 .3 Evolução temporal dos modos MHD . . . . . . . . . . . . . . . 58

5.1 .4 Acoplamento entre modos . . . . . . . . . . . . . . . 62

5.2 Estudo das oscilações de centro da coluna . . . . . . . . . . . . . . . . . 64

5.2 .1 Discussão preliminar . . . . . . . . . . . . . . . . . 65

5.2 .2 Disparos com baixa atividade MHD . . . . . . . . . . . . . . . 69

5.2 .3 Disparos com alta atividade MHD . . . . . . . . . . . . . . 74

5.3 Estudo das interferências das oscilações . . . . . . . . . . . . . . . . . . 75

5.3.1 Estimativa da frequência pelo espectrograma . . . . . . . . . . . . 76

5.3 .2 Interferências e batimentos . . . . . . . . . . . . . . . 77

5.3 .3 Interferências em outros sinais . . . . . . . . . . . . . . . . 82

5.3.4 Estudo das frequências durante o acoplamentos de ilhas . . . . . . . 87

Discussões e conclusão . . . . . . . . . . . . . . . . . . 91

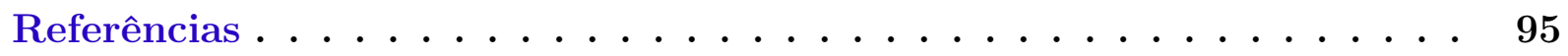

ANEXO A Projeto amplificador do SXR .............. 101

A.1 Desenho da Placa de circuito impresso . . . . . . . . . . . . . . . . . . 102

A.2 Projeto mecânico . . . . . . . . . . . . . . . . . . . . . 103 


\section{Introdução}

O interesse na pesquisa sobre a fusão nuclear cresce, dentre outros motivos, pela possibilidade de produção de energia em larga escala de forma segura e relativamente limpa. No entanto, à despeito dos grandes investimentos e avanços científicos realizados desde a década de 50, ainda não se domina a fusão de maneira controlada para produção de energia, sendo assim, tudo indica que ela não estará disponível na matriz energética num futuro próximo. Os projetos de pesquisa na área demandam um tempo de desenvolvimento da ordem de décadas e o estágio de demonstração de viabilidade técnica e econômica não foi alcançado [2].

São diversas as barreiras que devem ser vencidas antes que esta fonte de energia se torne viável, mas um substancial esforço no desenvolvimento de diversas áreas da ciência, tais como a física e engenharia continuam sendo efetuadas para transpor esses empecilhos.

A maioria dos experimentos e pesquisas na área de fusão nuclear são concebidos utilizando o material combustível em estado de plasma. No que diz respeito a física dos processos de fusão, avanços tem sido alcançados na compreensão teórica e na observação experimental dos fenômenos físicos. A fusão de núcleos leves exige vencer as forças eletrostáticas de repulsão entre os núcleos tal que possamos aproximá-los até a distância característica de alcance da força nuclear forte, visto que abaixo desta distância, esta força sobrepuja a repulsão coulombiana e assim os núcleos leves originais se ligam formando um novo núcleo, mais pesado. Nesta escala de distância os efeitos quânticos de tunelamento tornam-se significativos e mesmo que os núcleos originais não tenham energia suficiente para transpor classicamente a barreira coulombiana a fusão pode ocorrer [3].

Para que a fusão seja factível, devemos produzir um plasma à elevadas temperaturas e densidades utilizando um sistema eficiente de confinamento e aquecimento. Para evitar trocas térmicas e a erosão dos materiais que compõem as paredes internas da máquina, o plasma não pode ter contato com a estrutura mecânica, tornando estes sistemas muito complexos.

$\mathrm{Na}$ natureza as reações de fusão são comuns, ocorrem dentro de todas as estrelas $[4,5]$. Apesar das estrelas apresentarem configurações de campo magnético extremamente complexas e dinâmicas, esses campos não são os principais responsáveis pelo confinamento. Numa estrela, o confinamento do plasma se dá basicamente devido ao intenso campo gravitacional.

O mecanismo primário de geração de energia nas estrelas se dá pela reação de fusão entre dois prótons [4], porém devido a seção de choque próton - próton ser pequena essas reações ocorrem em uma taxa baixa [6]. Devido a quantidade de hidrogênio disponível 
numa estrela as reações não são raras, mas para o emprego em reatores as reações prótonpróton são inviáveis. As principais reações de fusão com interesse para geração de energia são dadas pelas equações (1.1) até (1.4).

$$
\begin{gathered}
D+D \rightarrow T(1.01 \mathrm{MeV})+p(3.03 \mathrm{MeV}) \\
D+D \rightarrow H e^{3}(0.82 \mathrm{MeV})+n(2.45 \mathrm{MeV}) \\
D+T \rightarrow H e^{4}(3.52 \mathrm{MeV})+n(14.06 \mathrm{MeV}) \\
D+H e^{3} \rightarrow H^{4}(3.67 \mathrm{MeV})+p(14.67 \mathrm{MeV})
\end{gathered}
$$

A reação entre entre deutério $\left(D=H^{2}\right)$ e trítio $\left(T=H^{3}\right)$ possui uma grande seção de choque e taxa de reação média se comparadas com as demais reações para uma faixa de energia abaixo de aproximadamente $200 \mathrm{keV}$ [7], conforme mostrado nos gráficos da figura 1 (a) e $1(\mathrm{~b})$, respectivamente. Por esta razão a reação $(D+T)$ é mais adequada para aplicações práticas. Os produtos finais das reações acima são os isótopos $H e^{4}$ e $H e^{3}$ que não são radioativos. Numa estrela, trítio produzido na reação (1.1), que é radioativo, é consumido na reação (1.3). Já em um reator de fusão, como a reação (1.1) não está disponível, o T será obtido pela reação $L i^{6}+n \rightarrow T+\alpha+4.8 \mathrm{MeV}$ e desta forma, nenhum subproduto da fusão em reatores será radioativo, sendo uma grande vantagem da utilização da fusão sobre a fissão para geração de energia. Outra vantagem em relação aos reatores de fissão é que os futuros reatores de fusão somente produzirão radiação enquanto em funcionamento, a menos da radiação residual produzida pela ativação dos elementos químicos que compõe a estrutura mecânica do reator.
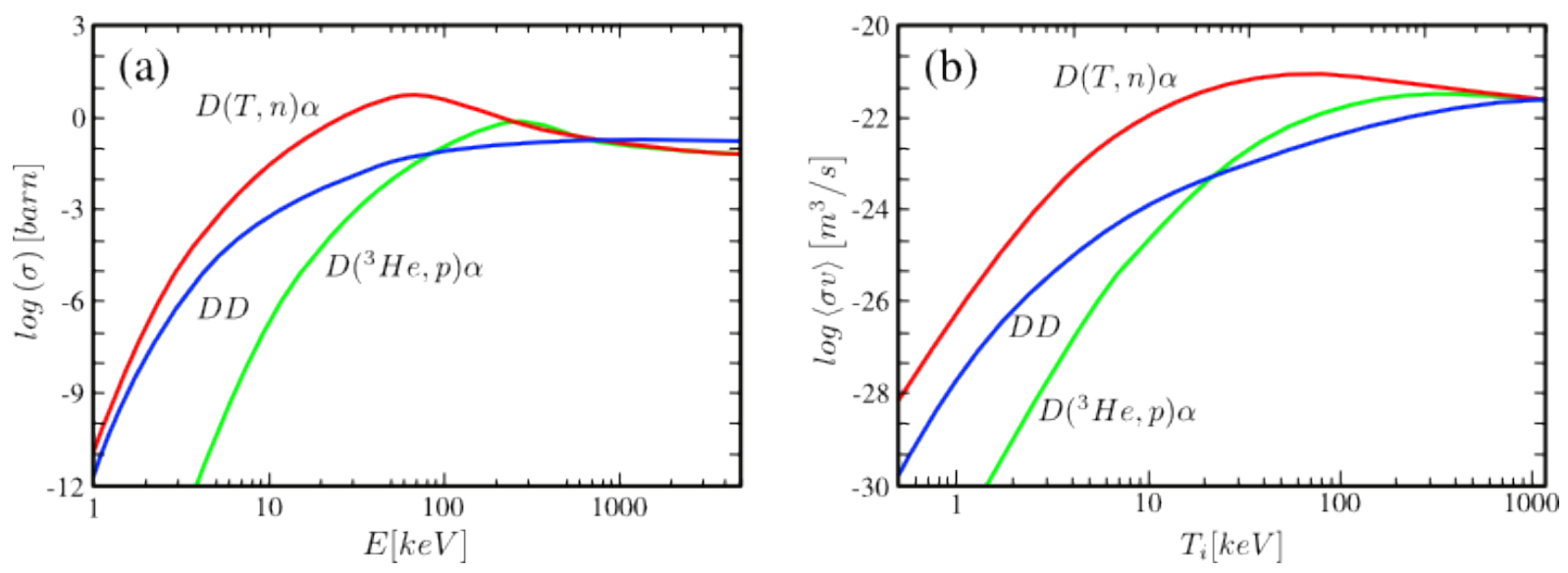

Figura 1 - (a) Seções de Choque em função da energia e (b) Taxa de reação média em função da temperatura para as principais reações de fusão com interesse na produção de energia [7]. 
Evidentemente, o confinamento gravitacional artificial inspirado na natureza não é uma técnica acessível e desta forma outros esquemas de confinamento tem sido testados, tais como o confinamento inercial e magnético. Este último implica em impor ao campo magnético uma geometria tal que mantenha as partículas do plasma livres para percorrer órbitas em torno das linhas de campo, mas com movimento restrito de baixo alcance perpendicularmente ao campo. Dentre os vários tipos de dispositivos geradores de campo confinante implementados, podemos citar os espelhos magnéticos, linear-pinches, toroidalpinches, tokamaks e stellarators [2]. Mas o dispositivo de confinamento que mostrou-se mais promissor em termos da produção de condições favoráveis à fusão são os tokamaks, que produzem um campo em geometria toroidal.

Os tokamaks produzem e confinam o plasma em situações favoráveis de equilíbrio porém, diversos tipos de instabilidades são observadas experimentalmente. Estas instabilidades modificam o transporte de partículas e energia, degradam as condições de confinamento e representam um dos fatores limitantes principais. Outra importante questão está associada ao comportamento do plasma na presença de impurezas, não se limitando a tokamaks, mas em todos os tipos de dispositivos de confinamento. Além de núcleos pesados, oriundos das paredes internas do dispositivo confinante, os próprios produtos da reação de fusão podem ser vistos como impurezas, pois na faixa de energias tipicamente disponíveis em um tokamak, eles não participam de novas reações. Diversos estudos mostram que existe uma relação entre as instabilidades e o transporte de impurezas [8, 9, 10]. Se por um lado a existência das instabilidades prejudicam o confinamento, por outro, elas são responsáveis por modificar o transporte de impurezas e neste sentido podem ser úteis no processo de limpeza do plasma. A compreensão profunda deste tema permanece em aberto e é objeto de pesquisas.

Uma das teorias mais importantes usada para descrever o comportamento do plasma confinado magneticamente, como os produzidos em tokamaks, é a teoria magnetohidrodinâmica. Ela é um modelo macroscópico que trata o plasma como um fluído magnetizado e descreve bem o equilíbrio e as instabilidades. Corriqueiramente nos referimos às instabilidades utilizado os termos "perturbações magnéticas", "instabilidades MHD" ou "atividade $M H D$ ". As instabilidades produzem alterações nas condições locais de equilíbrio, por exemplo na densidade e na temperatura do plasma, que causam perturbações em outras características físicas do plasma, tais como a emissividade óptica, emissão de raios $\mathrm{X}$, entre outras. Utilizando instrumentação adequada podemos detectar essas perturbações e investigar as características das instabilidades MHD.

Tendo em vista a relevância da compreensão dos fenômenos físicos associados às atividade MHD e, em especial em tokamaks, este trabalho tem como foco o estudo experimental detalhado dos diversos tipos de instabilidades MHD observáveis em disparos típicos do tokamak TCABR. Para tanto, serão empregadas técnicas de processamento 
digital de sinais e análise espectral nos sinais provenientes de vários diagnósticos. As principais propriedades a serem estudadas são a frequência, intensidade e características espaciais das perturbações.

Esta dissertação está organizada da seguinte maneira: o capítulo 2 apresenta uma breve revisão sobre confinamento magnético em tokamaks e as principais instabilidades MHD; o capítulo 3 apresenta o tokamak TCABR e os principais diagnósticos utilizados neste trabalho; o capítulo 4 descreve os métodos de análise espectral com resolução espacial empregadas neste trabalho. O capítulo 5 apresenta as análises efetuadas, subdividas em três seções dedicadas às instabilidades na parte periférica da coluna de plasma, às instabilidades na parte central da coluna de plasma e à evolução das propriedades espectrais das instabilidades observadas. O capítulo 6 apesenta uma discussão final e conclusão geral sobre as instabilidades MHD usualmente observadas em disparos do tokamak TCABR. 


\section{Confinamento magnético - Tokamaks}

Para a manutenção das condições propícias à fusão é necessário manter o plasma confinado em uma região do espaço sem que haja contato do mesmo com as paredes internas do dispositivo confinador. O confinamento magnético explora o fato que o plasma é constituído por partículas eletricamente carregadas que interagem com os campos eletromagnéticos segundo a expressão da força de Lorentz $\mathbf{F}=q(\mathbf{E}+\mathbf{v} \times \mathbf{B})$. A parcela da força devido a ação do campo elétrico $\mathbf{E}$ não é desejável, visto que este campo é gerado por distribuições de carga não nulas, causam a aceleração da partícula em órbitas não confinantes. Já com o campo magnético, as linhas de campo podem ser fechadas e a força resultante é perpendicular simultaneamente ao movimento e à direção do campo, possibilitando órbitas fechadas.

Em geral, são utilizados campos magnéticos muito intensos (da ordem de $1 \sim 10 T$ ) e, desta forma, muitas das propriedades de um plasma magneticamente confinado são dominadas pela força $\mathbf{F}=q \mathbf{v} \times \mathbf{B}$, onde $\mathbf{B}$ é o campo magnético macroscópico, resultante da superposição dos campos magnéticos externos e dos campos gerados pelas partículas do plasma coletivamente. A ideia básica é que uma partícula carregada submetida à ação de um campo magnético executa uma órbita helicoidal em torno das linhas de campo B. Ou seja, a partícula gira em torno da linha de campo enquanto se move livremente ao longo da linha, como representado na figura 2. O raio da órbita, chamado de raio de Larmor, é dado por $\rho=m v_{\perp} /|q| B$ e a frequência de rotação é dada por $\omega_{g}=|q| B / m[1]$.

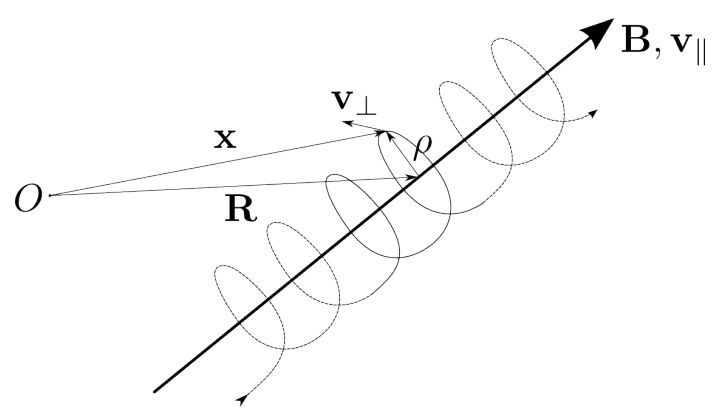

Figura 2 - Movimento de uma carga sujeita a ação de um campo magnético B. Adaptado de [1].

É interessante notar que podemos restringir a órbita da partícula numa região arbitrariamente pequena somente aumentando o valor do campo B [11]. Por exemplo, suponha uma temperatura de um íon da ordem de $T=10 \mathrm{keV}$, usando a velocidade térmica $V_{t h}=(2 T / \mathrm{m})^{1 / 2}$ temos uma velocidade da ordem de $\approx 10^{8} \mathrm{~cm} \cdot \mathrm{s}^{-1}$. Para um campo magnético de $4 T$, temos uma raio de giração da ordem de $\rho_{\text {termico }}(4 T) \approx 5 \mathrm{~mm}$. Aumentando a magnitude do campo magnético para $5 T$ o novo raio de giração fica aproximadamente $\rho_{\text {termico }}(5 T) \approx 4 \mathrm{~mm}$. Para elétrons, como a massa é de 3 ordens de 
grandeza menor que a massa dos íons, o raio de giração do movimento ciclotrônio é muito menor, da ordem de dezenas de $\mu m$. Ademais, o raio de Larmor das partículas carregadas são muito pequenas comparadas com as dimensões do plasma e ao raio de curvatura do campo magnético [12].

A contenção longitudinal das partículas pode ser garantida se as linhas do campo magnético $\mathbf{B}$ forem fechadas. A configuração mais simples que se pode utilizar é usando um campo magnético criado por uma solenoide em forma de toro $[12,11]$, conforme mostrado na figura 3. No entanto, como será visto a seguir, essa configuração magnética simples não permite confinar o plasma de maneira estável, sendo necessário o uso de configurações mais complexas.

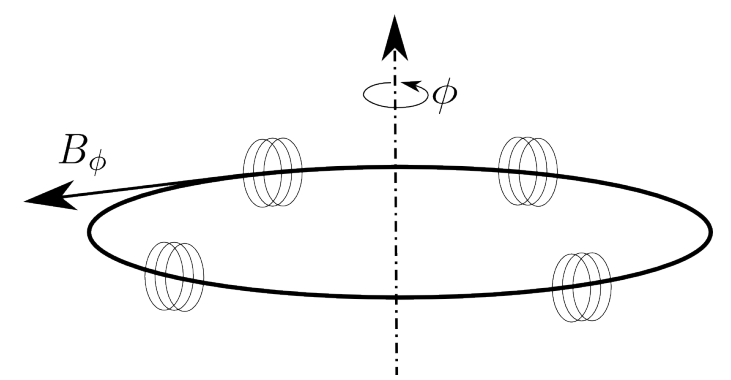

Figura 3 - Campo magnético gerado por bobinas dispostas em um toro. Adaptado de [1].

\subsection{Derivas}

Uma das questões mais importantes para a utilização do confinamento magnético são as ações de forças outras sobre as partículas. De forma genérica, podemos supor uma força qualquer $\mathbf{F}_{g}$ atuando sobre uma partícula, tal que podemos escrever a equação do movimento, compondo com a força de Lorentz devido ao campo magnético, da seguinte maneira:

$$
m \frac{d \mathbf{v}}{d t}=q(\mathbf{v} \times \mathbf{B})+\mathbf{F}_{g}
$$

onde $m$ é a massa da partícula e $\mathbf{F}_{g}$ é a força genérica qualquer que atua sobre a partícula. O movimento devido a $\mathbf{F}$ pode ser separado do movimento de giração ao redor do centro guia de forma que podemos obter:

$$
\mathbf{v}_{g}=v_{\|} \mathbf{b}+\frac{\mathbf{F}_{g} \times \mathbf{B}}{q B^{2}}
$$

onde b é um versor que aponta na direção de $\mathbf{B}$.

A força paralela a $\mathbf{B}$ não produz deriva, porém causa uma aceleração paralela como mostra a equação (2.1), e desta forma podemos escrever:

$$
\mathbf{v}_{g, \perp}=\frac{\mathbf{F}_{\perp} \times \mathbf{B}}{q B^{2}}
$$


De posse da expressão (2.3), podemos analisar casos particulares de forças que podem atuar sobre a partícula e expressar diretamente a deriva por ela causada.

\subsubsection{Deriva devida ao campo elétrico}

Supondo que uma partícula esteja sujeita a ação de um campo elétrico E, então ela sofre a ação de uma força $\mathbf{F}=q \mathbf{E}$, usando a expressão (2.3), segue que:

$$
\mathbf{v}_{E}=\frac{\mathbf{E} \times \mathbf{B}}{B^{2}}
$$

Esta deriva é chamada de deriva $\mathbf{E} \times \mathbf{B}$. Note que ela não depende da massa e da carga da partícula e portanto o efeito produzido é o mesmo, independente da espécie de partícula. Isto produz um fluxo no plasma mas não produz corrente. É interessante notar que, diferente do que ocorreria se não houvesse campo magnético, a deriva se dá em uma direção perpendicular à $\mathbf{E}$, e não paralela.

\subsubsection{Deriva de polarização}

Se o campo elétrico for espacialmente constante mas dependente do tempo $\left(\frac{\partial \mathbf{E}}{\partial t} \neq 0\right)$, a deriva $\mathbf{E} \times \mathbf{B}$ não será constante, resultando numa aceleração perpendicular à $\mathbf{B}$ causada pela força $F=m \frac{d \mathbf{v}_{E}}{d t}=\frac{m}{B^{2}} \frac{d \mathbf{E}}{d t} \times \mathbf{B}$. Essa força, segundo a expressão (2.3) produz uma deriva dada por:

$$
\mathbf{v}_{P}=\frac{\mathbf{F} \times \mathbf{B}}{q B^{2}}=\frac{m}{q B^{2}} \frac{d \mathbf{E}}{d t}
$$

Esta deriva é chamada de deriva de polarização, seus efeitos são muito pequenos visto que em geral a massa das partículas é muito pequena e a magnitude do campo magnético, para aplicações em confinamento, tem um valor muito grande. Comumente esta deriva é expressa na forma de uma densidade de polarização, escrito da forma:

$$
\mathbf{j}_{P}=\frac{\rho_{m}}{B^{2}} \frac{d \mathbf{E}}{d t}
$$

onde $\rho_{m}=m_{e} n_{e}+m_{i} n_{i}$ é a densidade de massa, $m_{\alpha}$ e $n_{\alpha}$ é a massa e a densidade de carga da espécie $\alpha$.

\subsubsection{Deriva devida à curvatura do campo $\mathrm{B}$}

Desprezando o movimento ciclotrônio, o movimento das partículas segue as linhas do campo $\mathbf{B}_{\phi}$ e desta maneira sofrem a ação de uma força centrífuga $\mathbf{F}_{c}=\frac{m v_{\|}^{2}}{R_{c}} \mathbf{r}=\frac{m v_{\|}^{2}}{R_{c}^{2}} \mathbf{R}_{c}$ que dá origem a uma deriva dada pela expressão (2.7). Esta deriva depende da massa e da carga da partícula e então terá magnitude e sentido diferentes para elétrons e íons. 
De onde tiramos que a velocidade de deriva devido a curvatura do campo magnético é dado por:

$$
\mathbf{v}_{c}=\frac{m v_{\|}^{2}}{q B^{2}} \frac{\mathbf{R}_{c} \times \mathbf{B}}{R_{c}^{2}}
$$

\subsubsection{Deriva devida a não homogeneidade do campo B}

Se o campo magnético não é homogêneo, uma partícula executando uma órbita em torno do centro guia experimenta valores de campo magnético dependentes da posição. $\mathrm{O}$ raio de curvatura será menor onde o campo $\mathbf{B}$ for mais intenso e maior onde for menos intenso. Isto leva ao aparecimento de uma deriva perpendicular ao campo magnético e ao gradiente do campo. Essa deriva não é resultante de uma força constante, assim não pode ser aplicada diretamente a expressão (2.3).

Podemos discutir o efeito médio do $\nabla \mathbf{B}$ na órbita considerando uma corrente $I=q \omega_{c} / 2 \pi$ associada com o movimento de giro da partícula carregada. O momento magnético é definido pelo produto da corrente pela área englobada $\left(A=\pi \rho^{2}\right)$, de maneira que obtém-se, por unidade de massa:

$$
\mu=\pi \rho^{2} I=\frac{m q \omega_{c}}{2}=\frac{m v_{\perp}}{2 B}
$$

Dado que a força média sobre o dipolo magnético devido ao gradiente do campo é $\mathbf{F}_{\nabla B}=-\mu \nabla \mathbf{B}$, aplicando na equação (2.3), obtemos a expressão para a deriva como:

$$
\mathbf{v}_{\nabla B}=\frac{m v_{\perp}^{2}}{2 q B^{3}} \mathbf{B} \times \nabla \mathbf{B}
$$

Para íons e elétrons esta deriva apresenta sentidos opostos. Isto causa uma separação de cargas de cargas na direção perpendicular simultaneamente à $\mathbf{B}$ e a $\nabla \mathbf{B}$.

\subsection{Tokamaks}

Historicamente, na pesquisa de fusão nuclear por confinamento magnético, tem sido testadas diversas configurações magnéticas [13] tais como obtidas em dispositivos como espelhos magnéticos, z-pinches, $\theta$-pinches e stellarators. Em geral, para um plasma confinado magneticamente, a primeira consideração a ser efetuada é como são limitados os perfis de pressão, densidade e temperatura em termos das correntes e forças externas necessárias para manter o equilíbrio do plasma. As propriedades do confinamento de muitos destes dispositivos ficam aquém das expectativas devido a inabilidade em manter as instabilidades dentro de níveis aceitáveis.

A medida que cresceu a compreensão teórica das instabilidades do plasma e também ao acumulo de experiencias, foram projetados e construídos novos dispositivos de 
confinamento magnético, que evitam ou suprimem a maioria destas instabilidades. Porém, apesar dos refinamentos dos dispositivos, estes ainda apresentam instabilidades que até o momento inviabilizam o confinamento com propósito de fusão.

A razão para se construir sistemas de confinamento magnético relativamente complexos, como o caso de um tokamak, é que as configurações mais simples, como sistemas abertos ou em linha não garantem condições que evitam a perda de partículas e energia. Em sistemas abertos as linhas de campo magnético inevitavelmente farão contato com as paredes do dispositivo [13], como mostrado na figura 4. A energia e a densidade de partículas confinadas em sistemas abertos caem rapidamente pois as as partículas carregadas se movem livremente ao longo das linhas de campo.

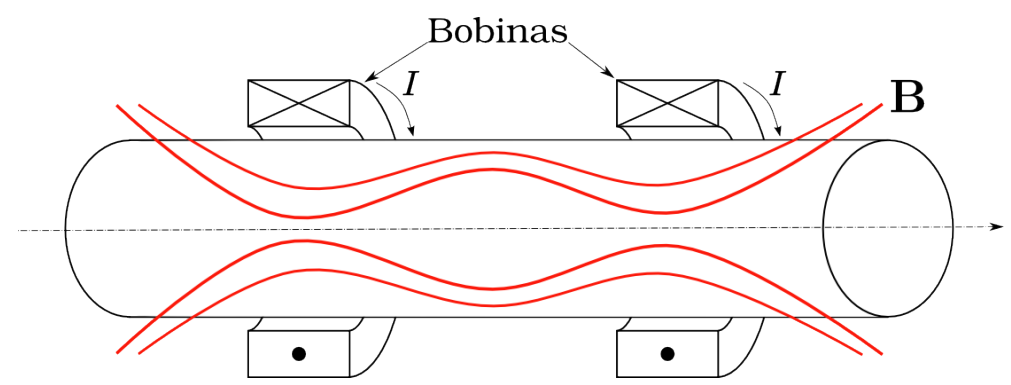

Figura 4 - Sistema de confinamento aberto. As linhas de campo interceptam as paredes.

Uma alternativa a estes tipos de sistemas abertos é o emprego de sistemas de confinamento em que o vaso é fechado, num formato de toro. O campo magnético produzido pelas bobinas distribuídas ao longo do toro são linhas circulares fechadas dentro de um toroide, como mostra a figura 5(a). Na figura não estão representadas as bobinas que geram o campo magnético toroidal mas está representado uma linha de corrente, indicado pela letra $I$. Em vermelho está representado uma das linhas de campo magnético na posição central da secção transversal do toro.

O campo magnético produzido pelas bobinas dispostas toroidalmente apresenta dois tipos de não homogeneidade: uma devida à curvatura e outra devido ao gradiente do campo B. A primeira é inerente a própria geometria do sistema, visto que as linhas de campo são curvadas em forma circular. A segunda é devido ao gradiente do campo, visto que as linhas de campo são mais densas quanto mais próximas do eixo de simetria, tendo em vista que as espiras das bobinas estão mais próximas entre si na região interna do que na região externa do toroide ou seja, o espaçamento linear não é uniforme. Por definição HFS (High Field Side) é o lado da seção transversal com maior intensidade de campo e analogamente para LFS (Low Field Side) é o lado de menor intensidade, como indicado na figura 5(b).

Por causa dessas não homogeneidades, um plasma em um campo magnético toroidal puro estará sujeito ao aparecimento de derivas devidas à curvatura e ao gradiente do campo magnético, como explorado nas seções 2.1 .3 e 2.1.4, respectivamente. O mais 


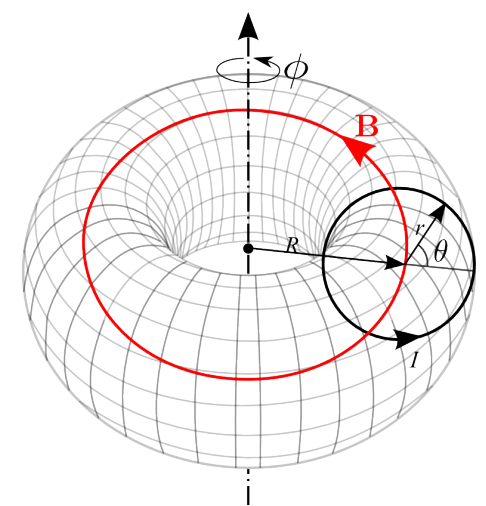

(a)

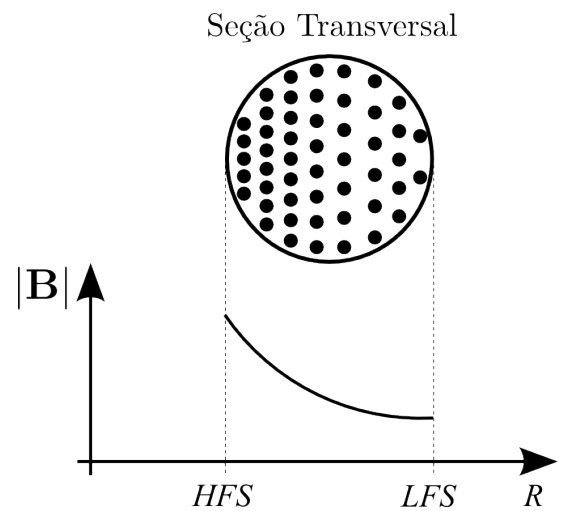

(b)

Figura 5- (a) Sistema de confinamento toroidal. As linhas de campo são fechadas e não interceptam as paredes do vaso. O sistema de coordenadas está representado sendo $R$ o raio maior, $r$ o raio menor, $\phi$ o ângulo toroidal e $\theta$ o ângulo poloidal. (b) Não-homogeneidade do campo toroidal devido ao espaçamento linear não uniforme das bobinas toroidais.

grave com relação ao confinamento é que essas duas derivas causam uma separação de cargas na direção $z$, o que produz um campo elétrico nesta direção (que é perpendicular a $\mathbf{B})$ e consequentemente produz uma deriva do tipo $\mathbf{E} \times \mathbf{B}$ que degrada rapidamente o confinamento pois tende a expulsar as partículas na direção radial (vide seção 2.1.1).

O ponto chave deste problema é que, uma vez estabelecida a separação de cargas, estas iriam se movimentar pelas linhas de campo que são circulares e paralelas. A solução encontrada pelos pesquisadores russos Igor Tamm e Andrei Sakharov foi a de torcer as linhas de campo B para que estas passem tanto na parte superior quanto inferior do vaso. A forma de obter essa nova configuração é fazer com que as linhas de campo circundem o eixo magnético, somando ao campo toroidal $\mathbf{B}_{\phi}$ uma componente na direção poloidal, como indicado na figura 6(a). Assim, cada linha de campo recebe, devido a deriva $\nabla B$, tanto cargas positivas quanto negativas, o que garante a neutralidade do plasma e impede o surgimento da deriva $\mathbf{E} \times \mathbf{B}$. Esta nova configuração do campo magnético se assemelha a uma helicoide conformada sobre uma superfície toroidal e pode ser visualizada na figura $6(\mathrm{~b})$.

Uma forma de gerar este campo poloidal é induzindo uma corrente na direção $\hat{\phi}$. Essa corrente pode ser produzida por condutores tradicionais mas também pode ser induzida diretamente sobre o plasma, visto que ele tem uma resistividade baixa a altas temperaturas e se comporta como um bom condutor. Acrescentando uma bobina central alinhada ao eixo vertical e fazendo variar o fluxo magnético, pela lei de indução o plasma, que age como o secundário de um transformador, será submetido a uma força eletromotriz induzida que produzirá a corrente no próprio plasma, gerando o campo poloidal.

Uma desvantagem importante deste esquema de indução de corrente é justamente 


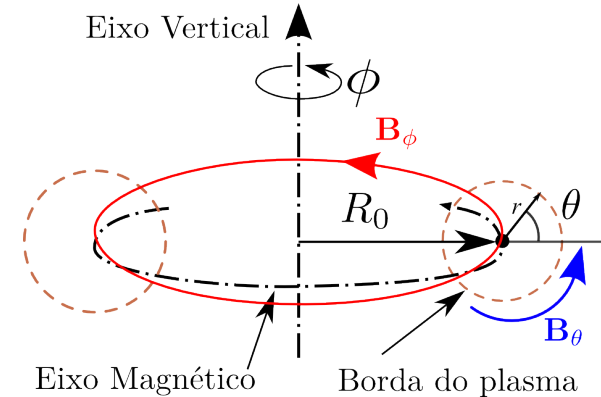

(a)

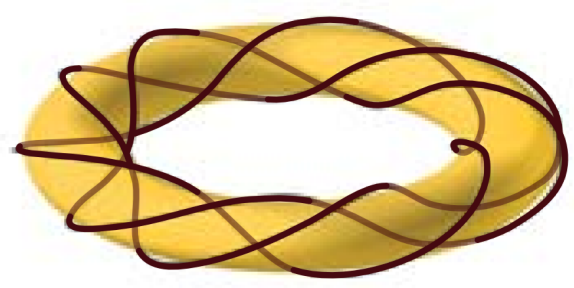

(b)

Figura 6 - (a) Eixos de referência e componentes do campo magnético na configuração tokamak. $\mathbf{B}_{\phi}$ é o campo toroidal e $\mathbf{B}_{\theta}$ é o campo poloidal. (b) Aspecto do campo magnético resultante da sobreposição das componentes toroidal e poloidal.

que a força eletromotriz induzida no plasma é proporcional a taxa de variação do fluxo magnético produzido pelo solenoide central $\varepsilon \propto \frac{d}{d t} \phi_{B_{O H}}$ e não podemos manter a esta taxa sempre constante pois isto implicaria um aumento indefinido do fluxo magnético do solenoide central. Sendo assim, neste esquema, a operação do tokamak é pulsada. Existem outras formas de gerar correntes no plasma que não indutivos, por exemplo por rádio frequência com o uso de ondas hibridas inferiores, que podem operar continuamente.

Em contrapartida, a configuração magnética dos tokamaks é muito robusta e muitos dos modos de oscilação e instabilidades presentes no plasma são naturalmente estabilizados $[13,14]$. Além disto, o acúmulo de experiência operacional nas várias máquinas em operação permitiu que as instabilidades de posição fossem resolvidas, empregando bobinas auxiliares e técnicas automatizadas de controle $[15,16,17]$.

\subsubsection{Equilíbrio do plasma}

Um plasma confinado apresenta um comportamento altamente dinâmico e complexo, mas os processos físicos podem ser analisados e compreendidos considerando escalas de de tempo apropriadas. Para escalas de tempo longas o comportamento do plasma está associado a mudanças gradativas na composição das espécies do plasma ocasionadas por processos de difusão, por transporte de impurezas e alterações na configuração magnética (por exemplo devido as limitações na indução do campo poloidal). Em escalas de tempo curtas, o plasma exibe uma ampla variedade de fenômenos oscilatórios e de turbulências, mas em escalas de tempo intermediárias podemos considerar que o comportamento médio dos fenômenos rápidos é desprezível e os fenômenos lentos são praticamente estacionários. Ou seja, numa escala de tempo apropriada, as forças devido a pressão do plasmas e as forças magnéticas estão balanceadas e pode-se considerar que o plasma está em equilíbrio.

A teoria MHD ideal trata o plasma como um fluído condutor exposto a campos eletromagnéticos e portanto, sujeito a aplicação das leis de Maxwell. Este modelo descreve bem um plasma na situação de equilíbrio como os produzidos em tokamaks. Ademais, 
no regime de baixas frequências, a corrente de deslocamento na lei de Àmpere torna-se desprezível e pode ser escrita como:

$$
\mathbf{j}=\nabla \times \mathbf{B}
$$

onde $\mathbf{j}$ é a densidade de corrente e $\mathbf{B}$ é o campo magnético.

Um plasma em equilíbrio, na teoria MHD ideal, satisfaz a equação de balanceamento de forças, dada por:

$$
\nabla p=\mathbf{j} \times \mathbf{B}
$$

onde $p$ é a pressão do plasma.

Esta expressão, juntamente com as restrições $\nabla \cdot \mathbf{B}=0, \nabla \cdot \mathbf{j}=0$ e $\nabla p \neq 0$ em um volume, definem superfícies de pressão constante e em formato toroidais. Por conseguinte, $\nabla p$ é perpendicular a estas superfícies e que, diretamente da expressão (2.11), as linhas de campo de $\mathbf{B}$ e de $\mathbf{j}$ estão contidas nestas superfícies [18], como mostrado na figura 7.

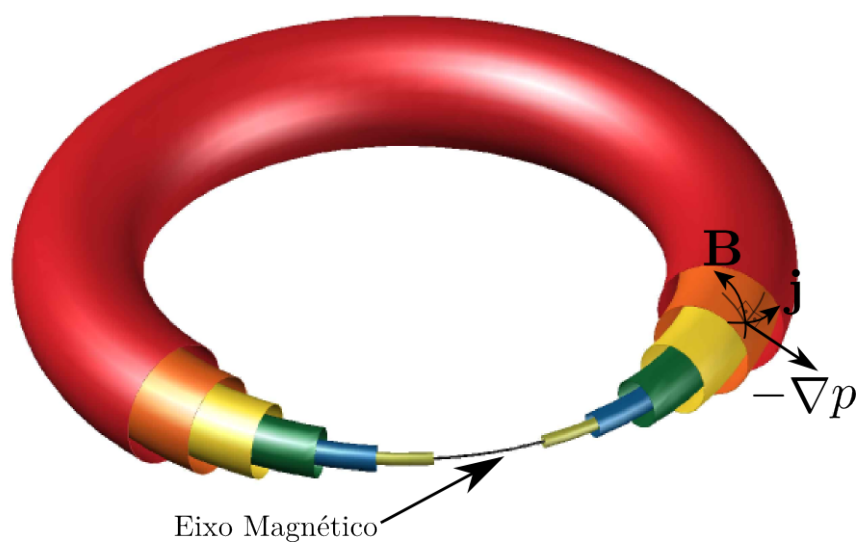

Figura 7 - Superfícies Magnéticas. As linhas de campo de $\mathbf{B}$ e de $\mathbf{j}$ estão contidas nestas superfícies e o $\nabla p$ é perpendicular a superfície.

Mesmo considerando outras configurações fechadas de plasma confinados, estes resultados permanecem válidos e também podem ser generalizados para casos com plasma em rotação ou tensionados anisotropicamente. A conclusão é que as superfícies magnéticas fechadas são necessárias para permitir gradientes de pressão não nulos $(\nabla p \neq 0)$, ou seja, necessárias para a existência e manutenção de plasmas confinados. Do ponto de vista microscópico é esperado que as partículas se mantenham em uma superfície magnética enquanto executam órbitas helicoidais em torno de uma linha de campo contida nesta superfície.

O tratamento teórico do equilíbrio do plasma é feito considerando uma função de fluxo $\psi$, que está relacionada com o fluxo magnético em uma superfície localmente paralelo a um plano orientado pelo eixo vertical do toroide, e leva à uma equação de derivadas parciais em $\psi$ conhecida como equação de Grad-Shafranov. Impondo condições de contorno apropriadas podem ser obtidas como soluções funções $p(\psi)$ que descrevem a pressão do 
plasma em função das superfícies de fluxo. O desenvolvimento da equação de equilíbrio de Grad-Shafranov não faz parte do escopo deste trabalho, mas pode ser encontrado na literatura. Para uma descrição completa, podem ser consultadas as referências [19, 20, 21].

Experimentalmente, a medida da temperatura e densidade eletrônica podem ser usadas para construir o perfil radial destas variáveis e reconstruir o perfil de pressão e, desta maneira, fornecem indicações sobre o equilíbrio do plasma. A medida da corrente de plasma e da posição da coluna também são indicativos do equilíbrio do plasma.

\subsubsection{Fator de segurança}

Como na situação de equilíbrio as linhas de campo magnético pertencem a uma superfície toroidal, existem três possibilidades que podem ser encontradas: 1) as linhas podem se fechar sobre si mesmas após um número finito de voltas poloidais e toroidais, 2) as linhas podem não se fechar e preencher toda a superfície ou 3) não se fechar e preencher todo o volume delimitado pela superfície, mas neste caso só é permitido pela teoria MHD ideal se o gradiente de pressão for nulo. Esta situação onde $(\nabla p=0)$ não é viável do ponto de vista de confinamento, visto que na linha que separa o plasma do vácuo teríamos uma descontinuidade e o gradiente seria infinito. Vale ressaltar que as linhas de campo são curvadas pela geometria dos solenoides e também pelo campo poloidal gerado pela corrente de plasma. Desta forma, não necessariamente as linhas de campo se fecham sobre si mesmas. Isto só ocorre quando uma linha de campo percorre a direção poloidal por um número racional de vezes que percorre a direção toroidal, mas é possível que elas não se fechem e preencham todo o espaço delimitado pela superfície toroidal sem auto-intersecções $[22]$.

Este é um conceito importante que leva a definição usual de um parâmetro chamado de fator de segurança denotado pela letra $q$ que é definido como:

$$
\frac{2 \pi R_{0}}{2 \pi r} q \approx \frac{B_{\phi}}{B_{\theta}} \Rightarrow q \approx \frac{r}{R_{0}} \frac{B_{\phi}}{B_{\theta}}
$$

onde $R_{0}$ é o raio do eixo magnético, $r$ é a distância da superfície ao eixo magnético, $B_{\phi}$ é a magnitude do campo toroidal e $B_{\theta}$ é a magnitude do campo poloidal. Este fator mede a helicidade média das linhas de campo magnético de uma dada superfície, o que corresponde à quantidade de vezes que a linha de campo envolve o eixo magnético na direção poloidal para cada volta completa ao longo do eixo toroidal. Caso as linhas de campo sejam fechadas sobre si mesmas, o valor de $q$ será um número racional. Neste caso, a superfície que contém estas linhas de campo fechadas é chamada de superfície racional. 


\subsubsection{Eficiência de confinamento}

Outro parâmetro importante que mede a eficiência do confinamento é denotado pelo símbolo $\beta$ e é definido pela razão:

$$
\beta=\frac{\text { Energia térmica do plasma }}{\text { Energia do campo magnético }}
$$

Da mesma maneira que o fator de segurança, $\beta$ também é dependente da região do confinamento, visto que cada superfície magnética encerra uma quantidade de energia magnética no volume delimitado pela superfície e, demais, o plasma interno a esta região exibe uma distribuição térmica. Na prática, para os dispositivos de confinamento experimentais disponíveis, o valor máximo de $\beta$ alcançando está em torno de 0,3 citeHazeltine1991. Este é o motivo pelo qual os tokamak de alta performance necessitam de campos magnéticos muito intensos, pois a energia armazenada nos campos magnéticos são proporcionais à $B^{2}$.

\subsection{Perturbações e ilhas magnéticas}

Ilha magnética é o nome genérico dado a perturbações e instabilidades comumente encontradas em plasmas magnetizados. As configurações de campo perturbado se parecem com ilhas quando vistas em corte em alguma secção perpendicular à componente toroidal do campo magnético, mas na realidade são estruturas tridimensionais que se assemelham com helicoides, como representado na figura 8.

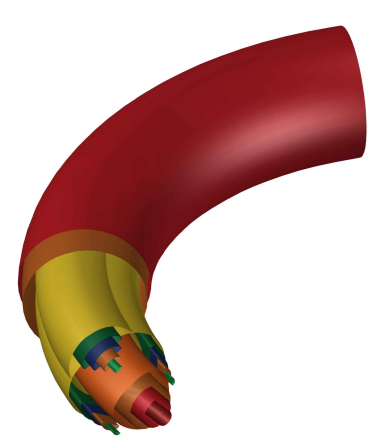

(a)

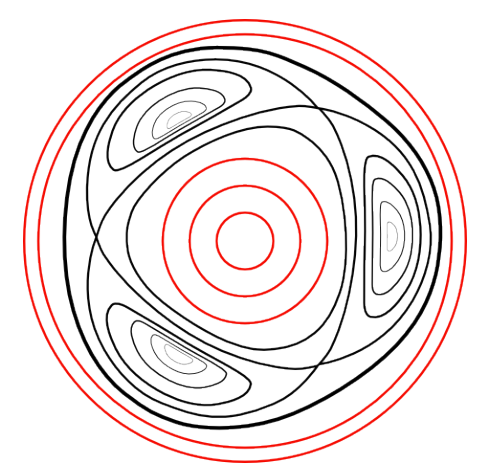

(b)

Figura 8 - (a) Aspecto tridimensional de uma ilha magnética em um tokamak e (b) projeção em um plano da seção transversal.

A presença de ilhas magnéticas em um plasma confinado tem se mostrado como um dos limitadores da performance de confinamento destes dispositivos. Elas alteram substancialmente a configuração magnética de equilíbrio e, em geral, degradam as condições de confinamento. Isso pode, dependendo da intensidade, levar à perda abrupta do confinamento (chamada disrupção do plasma). Mas mesmo que essa situação catastrófica não aconteça, o crescimento das ilhas está relacionada com mudanças no transporte de 
energia e partículas acima dos níveis usualmente observados. Adicionalmente as ilhas modificam os perfis de temperatura, densidade de partículas, pressão e densidade de corrente, visto que "conectam" diferentes regiões do plasma. A interação ilha-plasma é muito complexa visto que mudanças no comportamento de um altera significativamente as características do outro e vice-versa.

O entendimento da dinâmica das ilhas (como surgem, evoluem, se acoplam e como podem ser suprimidas) é de crucial importância para o aprimoramento das técnicas de confinamento e por si só são de grande interesse físico.

\subsubsection{Origem das perturbações}

Para um plasma resistivo temos que o campo elétrico está relacionado com a densidade de corrente por $\mathbf{E} \approx \eta \mathbf{J}$, onde $\eta$ é a resistividade do plasma, $\mathbf{E}$ é o campo elétrico e $\mathbf{J}$ é a densidade de corrente. Tomando o rotacional temos que $\nabla \times \mathbf{E} \approx \eta(\nabla \times \mathbf{J})$, usando a lei de faraday $\nabla \times \mathbf{E}=-\frac{\partial \mathbf{B}}{\partial t}$, a lei de Ampère $\mu_{0} \mathbf{J}=\nabla \times \mathbf{B}$ e relações vetoriais, obtemos:

$$
\frac{\partial \mathbf{B}}{\partial t} \approx \frac{\eta}{\mu_{0}} \nabla^{2} \mathbf{B}
$$

Esta equação relaciona a variação temporal de B com o seu laplaciano, ou seja, uma derivada temporal de primeira ordem com uma derivada espacial de segunda ordem, oque é característico de uma equação de difusão. Sendo assim, o campo magnético pode difundir pelo plasma, alterando a própria topologia.Dependendo da resistividade do plasma, a difusão poder ser suficientemente forte para causar rupturas no campo e posterior reconexões. Por esta razão, instabilidades geradas em plasmas resistivos também são comumente chamados de instabilidades de ruptura, ou do inglês "tearing modes". Caso $\eta=0$ (MHD ideal), não ocorrem alterações na topologia magnética, visto que não há difusão. Desta forma, um plasma quente com resistividade negligenciável, as instabilidades do tipo tearing não causarão danos muito grandes no confinamento. Mas se as instabilidades ocorrem nas superfícies racionais, condições de ressonância induzem correntes altas e mesmo resistividades baixas podem ser suficientes para causar rupturas e reconexões das linhas de campo. A figura 9 mostra o aspecto topológico das linhas de campo antes e depois da ruptura e reconexão.

Para entender melhor o que acontece próximo as superfícies racionais, pode-se considerar o campo $\mathbf{B}_{0}$ acrescido de uma pequena perturbação, de maneira que o campo magnético total pode ser expresso como $\mathbf{B}=\mathbf{B}_{0}+\tilde{\mathbf{b}}$, onde $\mathbf{B}_{0}$ é o campo de equilíbrio não perturbado e $\tilde{\mathbf{b}}$ é a perturbação. Agora considerando uma função $f(\psi)$ qualquer que descreva uma superfície magnética, onde $\psi$ é a função de fluxo e tal que $\mathbf{B} \cdot \nabla f=0$, então temos que $\mathbf{B}$ está nesta superfície. Expandindo $f$ até a primeira ordem, podemos escrever $f=f_{0}+f_{1}$, também temos que $\mathbf{B} \cdot \nabla f_{0}=0$ e $\mathbf{B}_{0} \cdot \nabla f_{1}+\tilde{\mathbf{b}} \cdot \nabla f_{0}=0$. Aplicando estes 


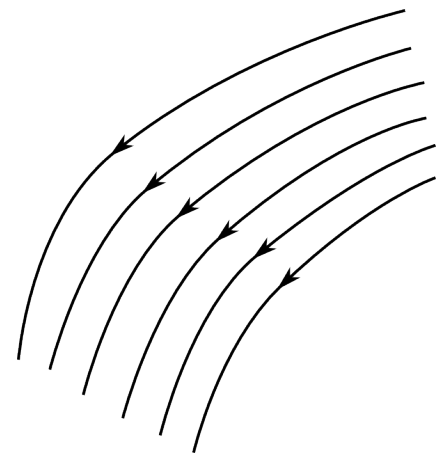

(a)

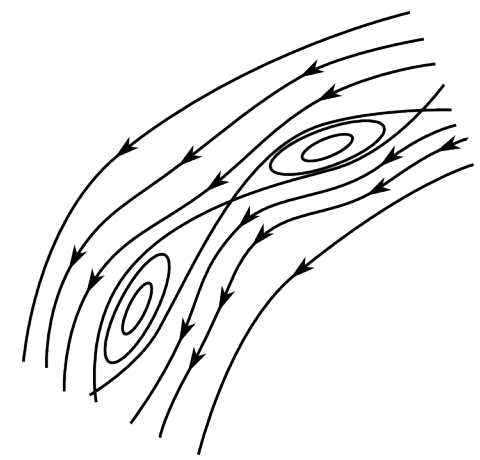

(b)

Figura 9 - (a) Linhas de campo antes da ruptura e (b) linhas de campo após ruptura e reconexões.

resultados na expressão da expansão de $f_{0}$ chega-se à [23]:

$$
f_{1} \sim \frac{d f_{0}}{d \psi} \sum_{m, n} \frac{b_{m, n}(\psi)}{n q(\psi)-m} e^{(i(n q(\psi)-m))}
$$

Quando se aproxima de uma superfície racional temos que $q \rightarrow \mathrm{m} / \mathrm{n}$ fazendo com que a expressão (2.15) tenda a divergir $\left(\left|f_{1}\right| \rightarrow \infty\right)$, fazendo a amplitude da perturbação aumentar, exceto se $\psi$ for aproximadamente constante, pois neste caso, a derivada $\frac{d f_{0}}{d \psi}$ se torna pequena, impedido a divergência de $f_{1}$.

\subsubsection{Localização das perturbações}

O fato das instabilidades crescerem quanto mais próximas das superfícies racionais fornece uma uma indicação de onde devem se localizar as perturbações. Na equação (2.12), $B_{\theta}$ pode ser obtido integrando a lei circuital de Àmpere num caminho na direção poloidal que envolve a corrente, o que fornece $B_{\theta}(r)=\frac{\mu_{0}}{2 \pi} \frac{I(r)}{r}$ e desta forma podemos reescrever a equação (2.12) como:

$$
q(r)=\frac{2 \pi r^{2}}{\mu_{0} R_{0}} \frac{B_{\varphi}}{I(r)}
$$

onde $I(r)=\int_{0}^{r} J\left(r^{\prime}\right) d r^{\prime}$ é a corrente de plasma envolvida por uma circunferência de raio $r$. Essa expressão exige o conhecimento do perfil da densidade de corrente $J(r)$ que é uma medida experimental de difícil obtenção e que num tokamak, em geral, não é constante no tempo. Numa situação de equilíbrio, podemos supor um modelo parabólico para $J(r)$ muito comum na literatura [24], dado por:

$$
J(r)=J_{0}\left[1-\left(\frac{r}{a}\right)^{2}\right]^{\nu}
$$

onde $J_{0}$ é a densidade de corrente no eixo magnético, $a$ é o raio menor do plasma e $\nu$ é um expoente que pode ser determinado experimentalmente. Com isso, integrando a equação da corrente em função da posição radial, obtemos $I(r)=\frac{\pi a^{2}}{\nu+1} J_{0}\left[1-\left(1-\left(\frac{r}{a}\right)^{2}\right)^{\nu+1}\right]$. 
Fazendo $r=a$ nesta expressão, obtemos a corrente total do plasma dada por $I_{p}=\frac{\pi a^{2}}{\nu+1} J_{0} \mathrm{e}$ portanto a expressão final para a corrente em função da posição radial pode ser escrita como $I(r)=I_{p}\left[1-\left(1-\left(\frac{r}{a}\right)^{2}\right)^{\nu+1}\right]$, substituindo na equação (2.16), obtemos a expressão do fator de segurança, para este modelo de perfil de densidade de corrente, como:

$$
q(r)=\frac{2 \pi r^{2} B_{\varphi}}{\mu_{0} R_{0} I_{p}}\left[1-\left(1-\left(\frac{r}{a}\right)^{2}\right)^{\nu+1}\right]^{-1}
$$

Fazendo $r=a$, obtemos o chamado fator de segurança na borda, dado pela expressão $q_{a} \equiv q(a)=\frac{2 \pi a^{2} B_{\varphi}}{\mu_{0} R_{0} I_{p}}$ e no eixo magnético $r=0$ a expressão (2.18) não é bem definida, mas tomando o limite $r \rightarrow 0$ fornece $q_{0} \equiv q(0)=\frac{2 \pi a^{2} B_{\varphi}}{\mu_{0} R_{0} I_{p}} \frac{1}{\nu+1}=\frac{q(a)}{\nu+1}$ que é chamado de fator de segurança no centro da coluna. Desta forma, a expressão anterior fornece uma maneira de calcular o expoente $\nu$ da expressão (2.17) como:

$$
\nu=\frac{q(a)}{q(0)}-1
$$

ou seja, conhecendo o fator de segurança na borda e no centro da coluna, podemos determinar completamente o modelo do perfil de densidade de corrente e obter o perfil radial do fator de segurança. Salienta-se que os valores de $q(a)$ são determinados exclusivamente por parâmetros dimensionais, juntamente com a magnitude do campo toroidal $B_{\varphi}$ e com o valor da corrente de plasma $I_{p}$. A título de exemplo, considerando valores de corrente de plasma entre $70 k A$ e $100 k A$, faixa típica de correntes de plasma do TCABR, um campo toroidal $B_{\varphi}=1.1 T$ e $q_{0}=0.9$, obtemos os perfis de densidade de corrente e do fator de segurança mostrados na figura 10.
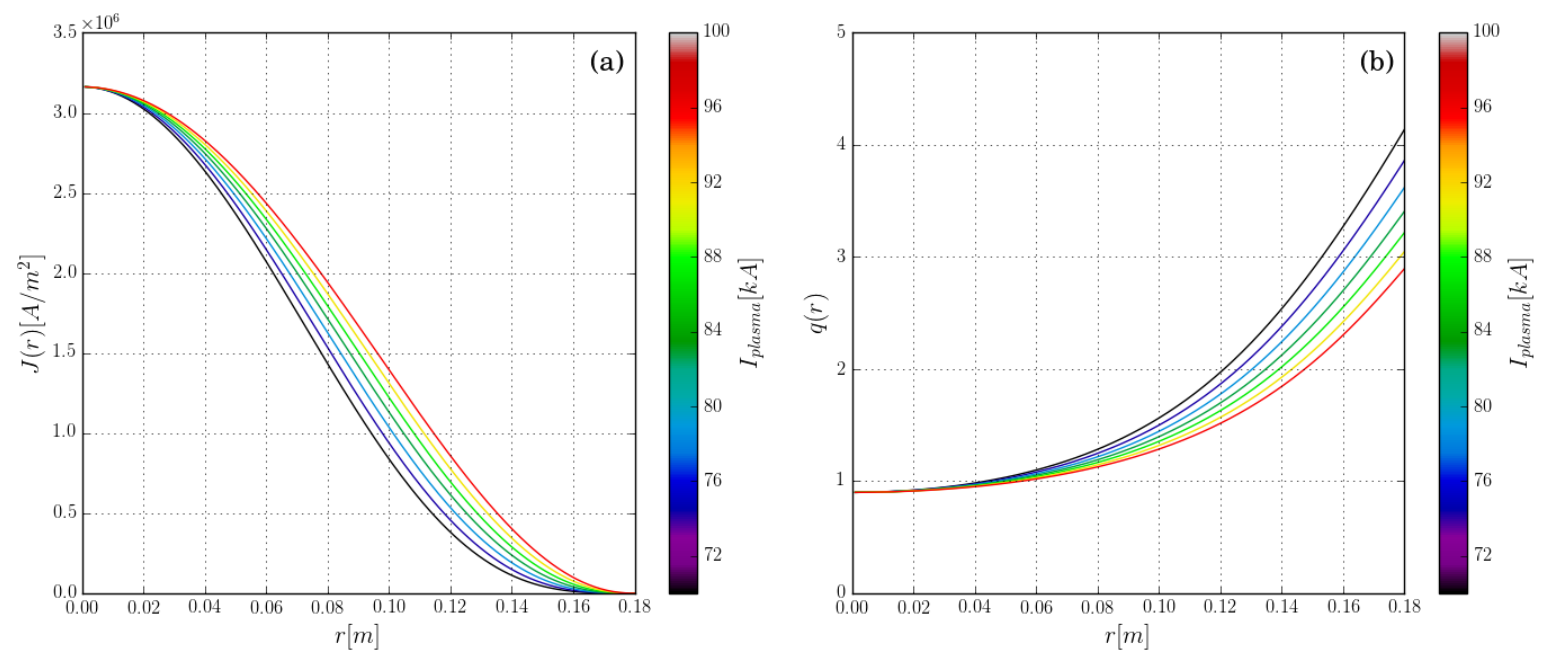

Figura 10 - (a) Perfil de equilíbrio da densidade de corrente usando o modelo dado pela expressão (2.17) para diversos valores de corrente de plasma, típicos do TCABR e (b) perfil radial do fator de segurança calculados para os mesmos valores de corrente, $q_{0}=0.9$ e $B_{\varphi}=1.1 T$. O valor de $q_{a}$, em $r=a=0.18$, é determinado pelo valor $I_{p}$. 
A localização da posição radial das superfícies racionais é dada pela intersecção das retas horizontais $q=m / n$ onde $m$ e $n$ são números inteiros, com as curvas de $q(r)$ para cada corrente de plasma $I_{p}$. É importante ressaltar, como já mencionado, que esse modelo de perfil de densidade de corrente só é admissível numa situação de equilíbrio do plasma, com todas as variáveis de equilíbrio aproximadamente constantes. Na prática, esta situação corresponde a uma parcela do tempo de vida do plasma no tokamak, chamada de região de platô. Outros modelos para perfil de densidade de corrente podem ser encontrados na literatura [25].

\subsubsection{Influência das perturbações no plasma}

É interessante notar que devido à existência de superfícies magnéticas as variáveis relacionadas na teoria MHD podem ser consideradas como funções apenas da posição radial. Desta forma, um deslocamento arbitrário $\xi(\mathbf{r}, t)$ das superfícies magnéticas causam perturbações nessas quantidades quando observadas em uma posição fixa no referencial do laboratório. As perturbações de densidade e temperatura associadas à perturbação radial das superfícies magnéticas são dadas por [26, 27, 28]:

$$
\begin{gathered}
\frac{\delta T_{e}}{T_{e}} \cong-(\gamma-1) \nabla \xi-\xi \cdot \frac{\nabla T_{e}}{T_{e}} \\
\frac{\delta n_{e}}{n_{e}} \cong-\nabla \xi-\xi \cdot \frac{\nabla n_{e}}{n_{e}}
\end{gathered}
$$

onde $\gamma=5 / 3$ é o coeficiente de expansão adiabática [1]. Expressões semelhantes podem ser obtidas para as demais variáveis do plasma como pressão e densidade de corrente. Exemplos de derivações para estas variáveis estão em [29, 30].

Para perturbações radiais de pequena amplitude, as expressões (2.20) e (2.21) podem ser aproximadas por:

$$
\begin{aligned}
& \delta T_{e} \cong-\xi \cdot \nabla T_{e} \\
& \delta n_{e} \cong-\xi \cdot \nabla n_{e}
\end{aligned}
$$

De modo geral, as expressões acima indicam que as perturbações terão efeito mais significativo nas posições radiais onde o perfil de equilíbrio das variáveis apresenta maior variação. A figura 11 mostra um perfil de temperatura aproximado por uma parábola em (a) e um deslocamento $\xi$ em forma de degrau em (b). Próximo ao centro da coluna de plasma o gradiente da temperatura é pequeno e desta forma o deslocamento radial causa pouca variação da temperatura. Porém em regiões da periferia, o gradiente de temperatura é mais alto e as perturbações torna-se significativas, como visto em (c). Acima da linha tracejada o deslocamento decai rapidamente e a perturbação deixa de existir e o perfil da temperatura a partir deste ponto segue o mesmo valor do perfil de equilíbrio (d). 


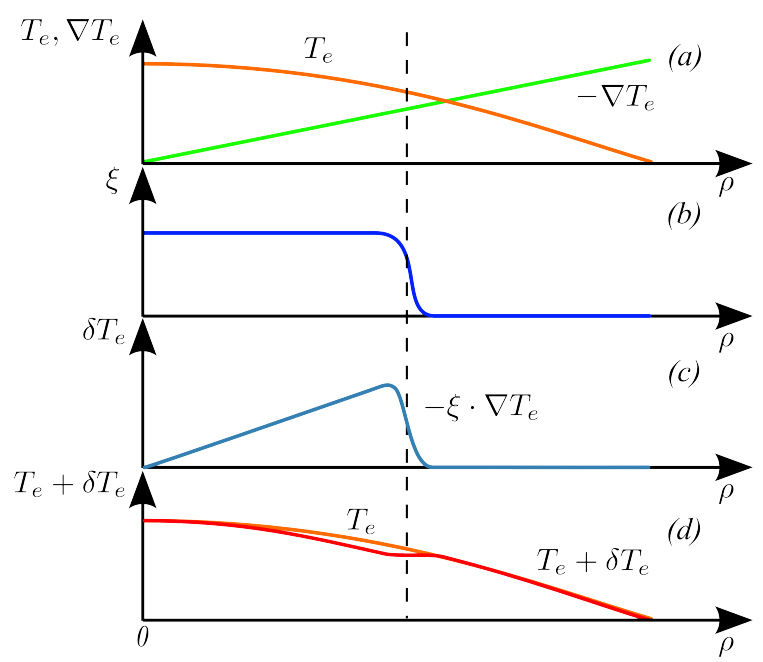

Figura 11 - Exemplo da influência das perturbações nas grandezas de equilíbrio do plasma. Perfil de equilíbrio da temperatura em (a), deslocamento em degrau em (b), valor da perturbação da temperatura devido ao deslocamento em (c) e perfil perturbado da temperatura sobreposto ao perfil original (d).

\subsubsection{Rotação e modelo de perturbação}

A ideia básica da dinâmica do plasma é bem descrita na literatura [21, 1, 14, 31]. Foi discutido anteriormente que a configuração magnética num tokamak é composta por superfícies de fluxo constante. A velocidade do plasma visto como fluído pode ser decomposta nas componentes perpendicular $\left(v_{\perp}\right)$ e paralela $\left(v_{\|}\right)$às superfícies de fluxo. Normalmente a velocidade paralela é identificada como a rotação do plasma, de forma que pode ser decomposta nas componentes na direção toroidal e poloidal, sendo comum expressa-las em termos das frequências angulares $\Omega_{\phi}=v_{\phi} / R$ e $\Omega_{\theta}=v_{\theta} / r$, respectivamente para a a rotação toroidal e poloidal.

Adicionalmente as componentes $v_{\phi}$ e $v_{\theta}$ podem ser expressas pelas componentes perpendicular e paralelas às linhas do campo $\mathbf{B}$ que estão contidas nas superfícies de fluxo. Neste ponto, utilizando a conservação de momento da teoria MHD, pode concluir que ambas as componentes dependem da viscosidade do plasma [32]. Por conseguinte, a viscosidade influencia no perfil de rotação do plasma.

Um estudo bastante completo sobre rotação do plasma em tokamaks pode ser encontrado em [32]. Para o caso da rotação de perturbações e ilhas magnéticas é usual admitir que elas rotam conjuntamente com o plasma. É possível assumir esta hipótese tendo em vista que uma rotação da ilha ou perturbação em relação ao plasma circundante seria rapidamente amortecida devido a efeitos viscosos que agem como uma força restauradora tendendo contra o movimento de rotação relativo da ilha com o vizinhança [33, 34].

Portanto, admitindo que não há escorregamento da perturbação, elas rotam conjuntamente com a superfície e podemos considerar um modelo para uma perturbação genérica 
como:

$$
\xi(\mathbf{r}, t)=\xi_{0}(r) e^{-i(m \theta+n \varphi-\omega t)}
$$

onde $\omega$ é a frequência associada ao modo com números de onda poloidal e torioidal $(m, n)$ e $\xi_{0}(r)$ é a amplitude da perturbação em função da posição radial. Este modelo de perturbação mostra-se útil pois para qualquer outro tipo de perturbação ressonante considerada, pode ser decomposta em série de Fourier e obter uma soma de expressões semelhantes à (2.24), com um conjunto de modos e frequências características.

\subsubsection{Componente espacial da perturbação $\left(\xi_{0}(r)\right)$}

A parcela espacial $\xi_{0}(r)$ da auto-função de deslocamento desempenha um papel importante na modelagem dos diversos tipos de instabilidades encontradas no plasma. Para ilustrar as diferentes formas de instabilidades, a figura 12 apresenta o aspecto dos tipos comuns de instabilidades tearing e kink, juntamente com os gráficos das respectivas componentes espaciais do modelo de perturbação.

No caso apresentado na figura 12 (a) vê-se um modo tearing, que apresentam reconexões magnéticas, com número de onda poloidal $m=3$. Para este tipo de instabilidade a parte radial da perturbação apresenta uma inversão de sinal e o cruzamento pelo zero é precisamente sobre o eixo magnético da ilha. Já no caso da figura 12(b) é mostrado um modo kink $(m=1)$, onde a parte radial da perturbação é dada simplesmente por uma função degrau e não há reconexões do campo magnético. A existência (ou não) de inversão de sinal de $\xi_{0}(r)$ é importante na identificação do tipo de instabilidade, visto que é uma característica das instabilidades MHD resistivas, em contraste com as instabilidades MHD ideais que não apresentam inversão.

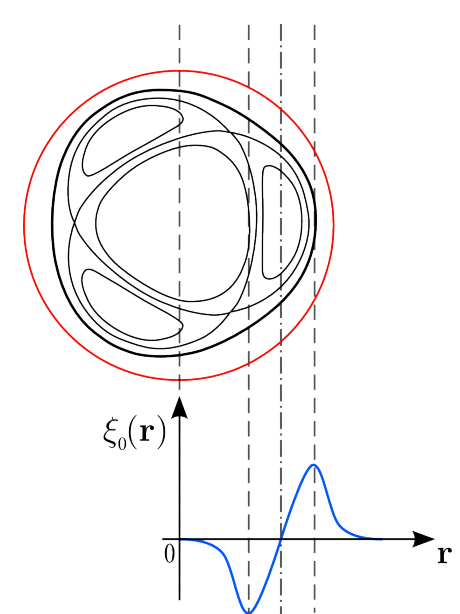

(a)

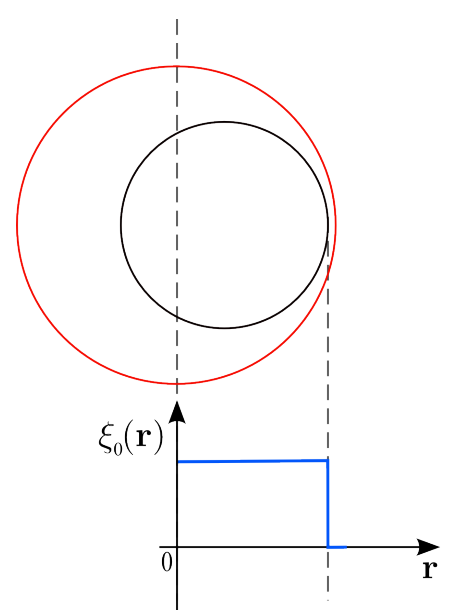

(b)

Figura 12 - Exemplos de instabilidades MHD: (a) modo tearing e (b) modo kink. Para o modo tearing a perturbação radial $\xi_{0}(r)$ apresenta inversão do sinal enquanto que para o modo kink não há inversão. 
Estes são dois tipos de instabilidades MHD muito comuns em plasmas de tokamaks, encontrados em todas as máquinas.

As instabilidades do tipo tearing, se originam da ruptura e reconexões das linhas do campo $B$ no caso MHD não ideal, onde é considerado uma resistividade não nula $(\eta \neq 0)$, surgindo a partir de mudanças na topologia do campo $\mathbf{B}$, como explorado na seção 2.3.1. Elas apresentam taxa de crescimento baixo mas nas superfícies racionais os efeitos da resistividade permitem que as ilhas evoluam e se estabilizem e, desta forma, podemos identificar as ilhas pelo par $(m, n)$ da superfície racional onde ela habita.

Uma explicação mais completa das ilhas magnéticas deve considerar os processos de ruptura e reconexão, mas esta análise teórica é demasiadamente longa e complicada, sendo assim não será considerada neste trabalho e é deixado como referência para consulta em $[35,30,11]$.

\subsubsection{Métodos de detecção}

As perturbações descritas pela equação (2.24) são propagadas para as demais grandezas do plasma como densidade, temperatura, pressão e campo magnético como explicitado pelas equações (2.20) e (2.21). É importante ressaltar que as perturbações carregam as informações dos modos $(m, n)$ e das respectivas frequências de oscilação. Apesar da simplicidade do modelo apresentado em (2.24), ele captura as características mais importantes dos fenômenos associados à atividade MHD num plasma de tokamak.

Utilizando diagnósticos sensíveis às variações destas grandezas, com resolução espacial e temporal, é possível determinar a posição, frequência e estrutura espacial das perturbações.

\subsubsection{Oscilações dente de serra e modo kink interno}

As instabilidades do tipo kink se caracterizam por um deslocamento periódico da coluna de plasma como foi mostrado na figura 12(b), onde a amplitude do deslocamento radial $\xi_{0}(r)$, pode ser modelado (para o caso MHD ideal) como uma função degrau. Neste caso não há reconexões magnéticas e não há mudanças da topologia do campo. Porém, as evidências experimentais mostram que os modos kink internos $(m=1, n=1)$ estão diretamente associados com as chamadas oscilações precursoras de dente de serra [36]. Estas oscilações precursoras estão fortemente associadas ao movimento de rotação toroidal pois apresentam período de oscilação correspondente a uma rotação única da coluna de plasma na direção toroidal [36].

Várias das propriedades físicas do plasma na região central (internas à superfície $q=1$ ) apresentam essa característica oscilatória em forma de dente de serra, tais como a temperatura, densidade e pressão. O comportamento típico destas variáveis segue 
inicialmente um incremento aproximadamente linear do valor da grandeza (fase rampa), seguido de uma fase de oscilação de amplitude (fase precursora) crescente até que ocorre uma queda abrupta do valor da grandeza (fase rápida) e depois o ciclo se repete indefinidamente. Este processo físico é conhecido como relaxação e está representado na figura 13.

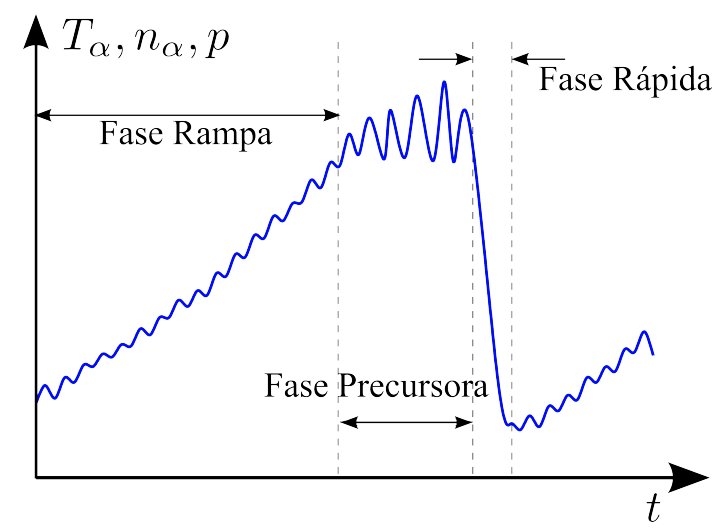

Figura 13 - Aspecto da perturbação dente de serra devido ao processo de relaxação do centro da coluna de plasma. Adaptado de [37].

Essas evidências demonstram que o modelo ideal, onde não há reconexões, não é suficiente para explicar os fenômenos observados. Tendo em vista este padrão de modulação das grandezas no centro e também que as medidas indicam alterações nas superfícies magnéticas internas, naturalmente o modelo MHD não ideal leva a pensar que reconexões magnéticas estariam associadas ao fenômeno. Atualmente várias abordagens teóricas, suportadas por simulações numéricas, vem expandindo o conhecimento de como as pequenas perturbações magnéticas ( $m=1, n=1$ ) evoluem até se tornarem instáveis de maneira que a configuração magnética do centro se modifica de forma abrupta, ejetando material quente do centro para as regiões periféricas. Mas o primeiro modelo que explicou satisfatoriamente as observações foi proposto por Kadomtsev [36].

Um plasma de tokamak é aquecido pela corrente induzida pelo circuito do ôhmico, o mesmo que é responsável pela indução do campo poloidal. Mas outros tipos de aquecimento também são utilizados, como por exemplo aquecimento por injeção de ondas ressonantes com os movimentos ciclotrônicos dos íons ou dos elétrons ou por ondas de Alfvèn. Independentemente do método de aquecimento utilizado, tem-se que a resistividade do plasma é uma função inversa da temperatura eletrônica $\eta \propto T_{e}^{-3 / 2}$ (chamada de resistividade de Spitzer) e pode ser consultada nas referências $[20,38,21,1]$, desta forma, visto que a temperatura é maior no centro da coluna do que na periferia, a condutividade $(\sigma=1 / \eta)$ no centro da coluna é maior e decai para as bordas. Sendo a condutividade maior no centro há uma tendência da densidade de corrente $J$ em se concentrar nesta região. Como o fator de segurança em $r=0$ é dado por $q_{0}=q(r=0)=2 B_{\varphi} / R_{0} J_{0}$, o aumento da densidade de corrente no centro faz com que o fator de segurança tenha um decréscimo.

Desta forma, a medida que o plasma esquenta, o fator de segurança $q_{0}$ no centro 
fica menor que a unidade e o fator de segurança $q=1$ se localiza em alguma superfície mais externa. Usando a teoria MHD é possível mostrar que as linhas de fluxo internas à superfície $q=1$ serão deslocadas do centro [39], como mostrado na figura 14(b).

Kadomtsev supôs que o campo magnético próximo à superfície $q=1$ é da forma $B^{*}=B_{\theta}\left(1-\frac{n}{m} q(r)\right)$ de maneira que para um modo kink $(m=1, n=1)$ esse campo pode ser escrito da forma:

$$
B^{*}=B_{\theta}(1-q(r))
$$

Isto implica que na superfície ressonante $q=1$ que $B^{*}=0$, para $q<1$ o campo $B^{*}$ é positivo e que para $q>1, B^{*}$ é negativo. Ou seja, há uma inversão do sentido do campo quando se cruza a superfície racional. Sendo assim, o processo de reconexão se dá a medida que as linhas de campo são comprimidas próximas à superfície $q=1$, conforme ilustrado na figura 14.

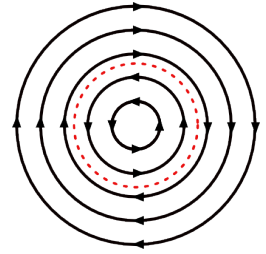

(a)

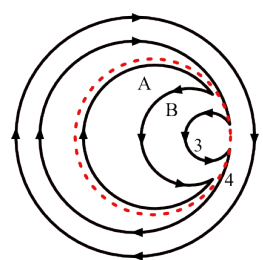

(d)

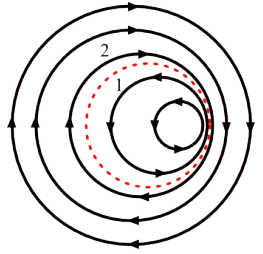

(b)

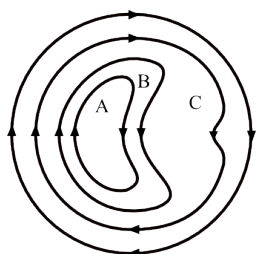

(e)

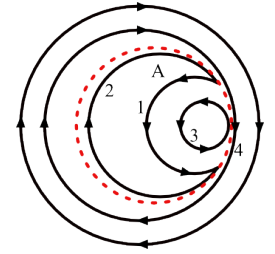

(c)

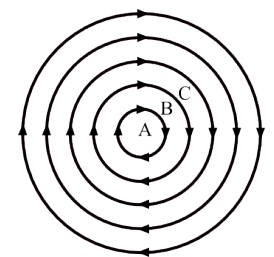

(f)

Figura 14 - Modelo de reconexões magnéticas de Kadomtsev mostrando o processo de formação das ilhas magnéticas até atingir no novo estado de equilíbrio. A linha pontilhada em vermelho indica a posição da superfície $q=1$. Adaptado de [40].

Inicialmente as superfícies magnéticas não perturbadas estão como mostrado na figura 14(a), a medida que vão sendo comprimidas pela evolução das perturbação radial (b) as reconexões começam como indicado para as superfícies 1 e 2 em (c), formando a primeira ilha magnética, nomeada na figura como "A". O processo continua para as linhas 3 e 4 em (d), formando a ilha "B" em (e) e assim por diante até as últimas camadas com sentidos contrários se reconectarem. Ao final todas as linhas estão na mesma direção com $q>1$.

A cada reconexão, uma porção interna do plasma irá acessar uma região mais externa e carregará consigo partículas e energia térmica. Isto causa um aquecimento nas regiões externas à posição da superfície $q=1$ e um resfriamento da região central do plasma. Com a mudança repentina de temperatura no centro a condutividade diminui, 
em contrapartida o aquecimento por efeito joule no centro faz com que a temperatura volte a subir lentamente, o que explica o padrão de dente de serra visto nesta grandeza, como mostrado na figura 13. Um processo análogo ocorre com as demais grandezas físicas citadas anteriormente.

A deteç̧ão experimental dos modos kink internos é normalmente efetuado por medidas indiretas, como temperatura, emissividade óptica e medidas pontuais de densidade. A medição direta das perturbações magnéticas na superfície $q=1$ não é possível, visto que essas perturbações são internas ao plasma e chegam à borda muito atenuadas. Desta maneira, sondas magnéticas, como bobinas de Mirnov, dispostas na periferia da câmara de vácuo não são capazes de se sensibilizar com essas perturbações.

Por outro lado, a emissividade óptica do plasma depende da densidade eletrônica, da temperatura eletrônica e da distribuição de número atômico dos íons (essa última é dependente da concentração de impurezas no plasma). Para os valores típicos destas grandezas num tokamak, o plasma apresenta emissões concentradas na região dos comprimentos de onda da luz visível, infravermelho, UV e na faixa de raios X de baixa energia. O diagnóstico sensível ao UV (denominado de SXR no TCABR) será tratado em um tópico específico neste trabalho, pois é o principal instrumento utilizado no TCABR para investigação das oscilações do centro da coluna. 


\section{Diagnósticos para deteç̧ão de instabilida- des MHD}

Em um tokamak típico, uma variedade grande de diagnósticos é utilizada para medir os parâmetros físicos do plasma, tais como a temperatura e a densidade de espécies eletrônicas (ions e elétrons), a corrente de plasma entre outras. Como visto na seção 2.3, os deslocamentos das superfícies magnéticas causam perturbações nos perfis de equilíbrio dos parâmetros do plasma.

Essas alterações produzem uma mudança na emissividade óptica do plasma de forma localizada e que podem ser detectadas por instrumentos com resolução espacial, tais como o sistema SXR e o bolômetro. Além disto, as próprias perturbações magnéticas nas superfícies magnéticas mais externas podem ser detectadas diretamente, utilizando instrumentos sensíveis à variação do campo magnético poloidal, tais como as bobinas de Mirnov.

Neste capítulo fazer-se-á uma breve explanação sobre o tokamak TCABR e os diagnósticos disponíveis atualmente, especificamente utilizados no presente estudo sobre instabilidades MHD observadas no plasma na região mais externa (bobinas de Mirnov) e na região do centro da coluna (diagnóstico SXR), enfatizando as características temporais e espaciais do sinal produzido por cada um deles.

Também será dado um destaque ao sistema SXR, cujo conjunto eletrônico de condicionamento de sinais foi atualizado, com o desenvolvimento e construção de um novo módulo amplificador para correção de problemas encontrados no decorrer das tomadas de dados. Serão fornecidas visões gerais sobre os demais diagnósticos utilizados, chamando a atenção para pontos importantes e indicando referências para fontes de informações complementares.

Além de apresentar os instrumentos utilizados para diagnóstico da atividade MHD no TCABR, um dos objetivos principais deste capítulo é ampliar a noção intuitiva da composição espectral dos sinais produzidos pelos instrumentos para facilitar a compreensão das análises e resultados a serem apresentados nos próximos capítulos.

\subsection{O tokamak TCABR}

O TCABR é um tokamak de pequeno porte e alta razão de aspecto $(A=R / a \approx 3)$ instalado no Instituto de Física da Universidade de São Paulo. Originalmente foi projetado e construído na Suíça, na École Polytecnique Fédérale de Lausanne, foi primariamente 
desenvolvido com o objetivo de estudar o aquecimento do plasma por ondas de Alfvèn.

No Brasil, onde se encontra em operação desde 1999, tem sido usado para o estudo de melhorias no confinamento e aquecimento do plasma [41], desenvolvimento de instrumentação e diagnósticos, estudo de turbulências e instabilidades [42, 43, 44], pesquisas sobre rotação do plasma [45, 46], além de ser utilizado para a formação de pesquisadores qualificados para a área de física de plasmas.

Nestes quase 20 anos de operação foi usado na formação de diversos doutores e mestres [47], o que representa um papel importante e de destaque no cenário científico nacional. Já no contexto internacional, o grupo de pesquisa do TCABR produz pesquisa localmente e em colaboração com grupos da Inglaterra, Estados Unidos, França, Portugal, Alemanha, entre outros. Tem demonstrado importância do desenvolvimento de diagnósticos de plasma com destaque para o sistema de excitação de ondas de Alfvén [48], aprimorado no laboratório e que foi exportado para a Inglaterra vários destes equipamentos encontram-se atualmente instalados no JET, maior tokamak em operação no mundo.

O plasma produzido pelo TCABR apresenta, de forma relativamente bem controlada, instabilidades MHD de grande intensidade sem que hajam disrupções. Isso o torna interessante para o estudo dessas instabilidades, visto que podemos obter ilhas magnéticas relativamente intensas por praticamente todo o tempo do disparo. Adicionalmente, podemos exitar instabilidades com a injeção de gás durante o disparo ou perturbando o plasma com o emprego de eletrodos polarizados.

As principais características físicas e dimensionais do TCABR encontram-se sumarizadas na tabela 1 .

Tabela 1 - Principais parâmetros do TCABR

\begin{tabular}{lr}
\hline Parâmetro & Valor \\
\hline \hline Corrente de Plasma $\left(I_{p}\right)$ & $100 \mathrm{kA}$ \\
Campo Magnético Toroidal $\left(B_{\phi}\right)$ & $1,1 \mathrm{~T}$ \\
Densidade Eletrônica $\left(n_{e}\right)$ & $1,0 \sim 2.4 \times 10^{19} \mathrm{~m}^{-3}$ \\
Raio Maior $(R)$ & $615 \mathrm{~mm}$ \\
Raio Menor $(a)$ & $180 \mathrm{~mm}$ \\
Temperatura iônica de pico $\left(T_{i}\right)$ & $200 \mathrm{eV}$ \\
Temperatura eletrônica de pico $\left(T_{e}\right)$ & $600 \mathrm{eV}$ \\
Duração do disparo & $120 \mathrm{~ms}$ \\
\hline
\end{tabular}

A figura 15 mostra o aspecto simplificado do TCABR. Ele é composto basicamente de uma câmara de vácuo toroidal de seção transversal retangular ao redor da qual estão montadas as bobinas do campo toroidal e ao centro a bobina do circuito do ôhmico, responsável por induzir o campo poloidal e aquecer o plasma. Conta ainda com diversas bobinas auxiliares de controle de posição. 


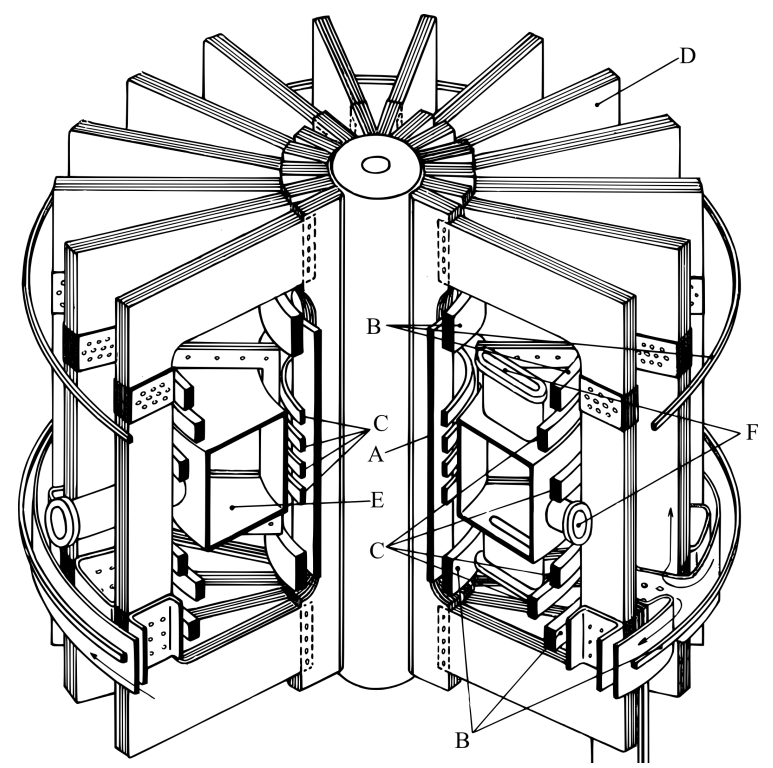

Tabela 2 - Componentes principais do TCABR.

\begin{tabular}{lr}
\hline Identificador & Descrição \\
\hline \hline $\mathrm{A}$ & Bobina de aquecimento ôhmico \\
$\mathrm{B}$ & Bobinas auxiliares \\
$\mathrm{C}$ & Bobina do campo vertical \\
$\mathrm{D}$ & Bobinas do campo toroidal \\
$\mathrm{E}$ & Câmara de vácuo \\
$\mathrm{F}$ & Janelas de diagnósticos \\
\hline
\end{tabular}

Figura 15 - Vista em perspectiva mostrando um corte da câmara de vácuo e o posicionamento das bobinas. Adaptado de [49].

\subsection{Bobinas de Mirnov}

As medidas diretas das perturbações magnéticas da borda do plasma são realizadas por solenoides sensoras distribuídas poloidalmente e toroidalmente no tokamak. O princípio de operação baseia-se na lei de indução do eletromagnetismo:

$$
U_{s o l}=-N A \frac{d B_{\perp}}{d t}
$$

onde $N$ é o número de espiras do solenoide, $A$ é a área da seção transversal da bobina e $B_{\perp}$ é a componente do campo magnético perpendicular à área da bobina. Esta lei diz que a tensão produzida nos terminais da bobina é proporcional à variação do campo magnético e, desta forma, somente perturbações magnéticas que variam no tempo são detectadas.

Atualmente o TCABR conta com um conjunto de 25 bobinas de Mirnov cuja aparência física pode ser vista na figura 16(a) e o circuito de filtragem e interligação com o sistema de aquisição está reproduzido na figura 16(b). Destas bobinas, 24 estão dispostas igualmente espaçadas numa seção poloidal. A outra bobina encontra-se instalada em outra localização toroidal e é utilizada para estudo da dependência toroidal dos modos MHD.

A figura 17(a) mostra um sinal típico produzido pelas bobinas de Mirnov durante um disparo do TCABR e a figura 17(b) apresenta o respectivo espectrograma da potência do sinal. O que pode ser observado como comportamento geral é que as perturbações magnéticas da borda produzem sinais nas bobinas compostos por poucas componentes, 


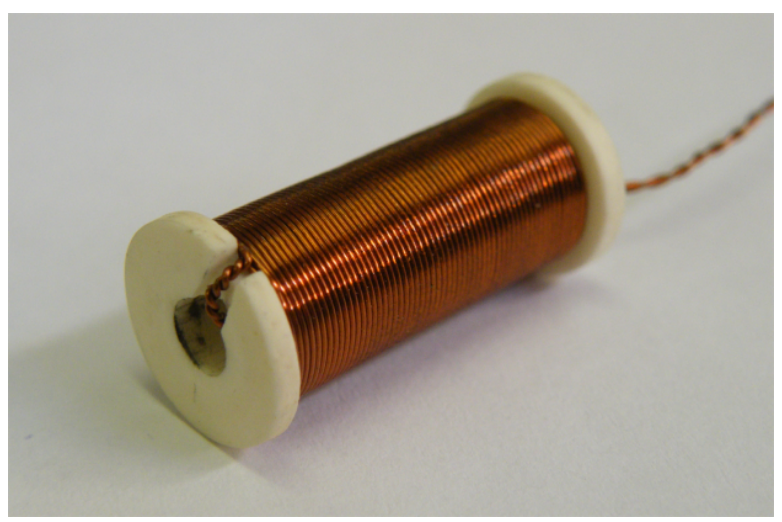

(a)

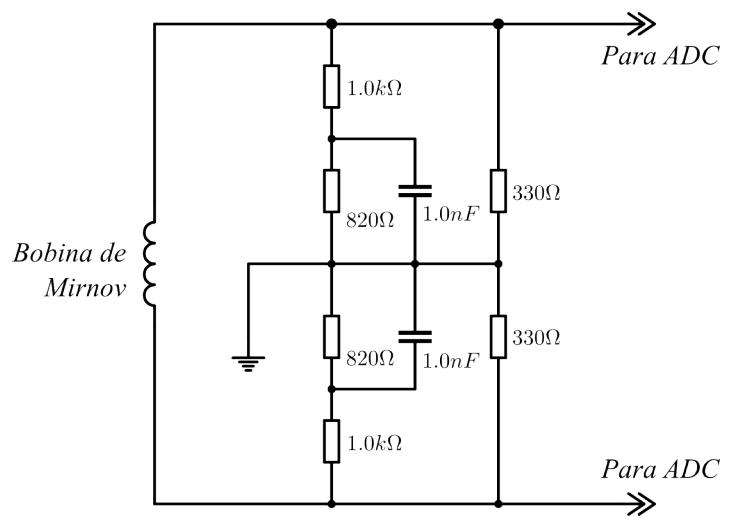

(b)

Figura 16 - (a) Aspecto visual das bobinas de Mirnov instaladas no TCABR e (b) circuito de filtragem e interligação das bobinas de Mirnov com uma entrada analógica diferencial do sistema de aquisição de dados no TCABR.

com frequência da ordem de $(10 \sim 25 k H z)$, o que resulta num espectro relativamente limpo se comparado com outros diagnósticos.
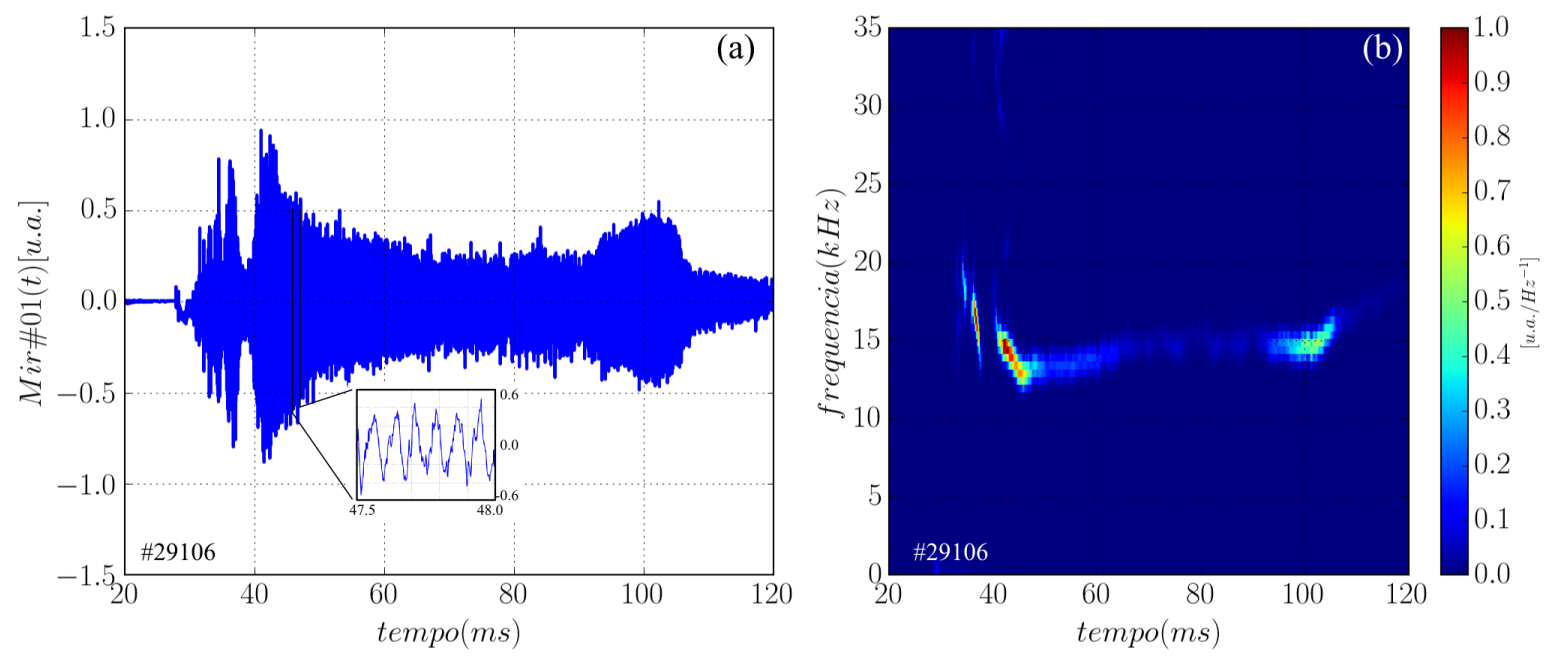

Figura 17 - (a) Sinal temporal típico de uma bobina de Mirnov e (b) Espectrograma de potência do sinal típico.

Uma forma interessante de visualização dos sinais produzidos pelo conjunto das bobinas de Mirnov poloidais é plotar simultaneamente em um mapa de cores, onde o tempo está na horizontal, o número do canal na vertical e a amplitude dos sinais é representado pela barra de cores, conforme métodos explorados na seção 4.6.3. Na figura 18(a) é possível notar que o comportamento entre canais vizinhos é bastante semelhante, a menos de uma defasagem temporal e de mudanças na amplitude. De fato, a diferença de fase entre os canais fornece informações importantes para a análise do modo de oscilação espacial das perturbações. Já a figura 18(b) mostra o valor instantâneo da perturbação magnética por canal para o instante de tempo $t=70.5 \mathrm{~ms}$, que nada mais é que um corte vertical 
no gráfico em (a) para este instante de tempo. Nota-se que os valores instantâneos são repetitivos de amostra temporal para amostra temporal, a menos de um deslocamento no número do canal.
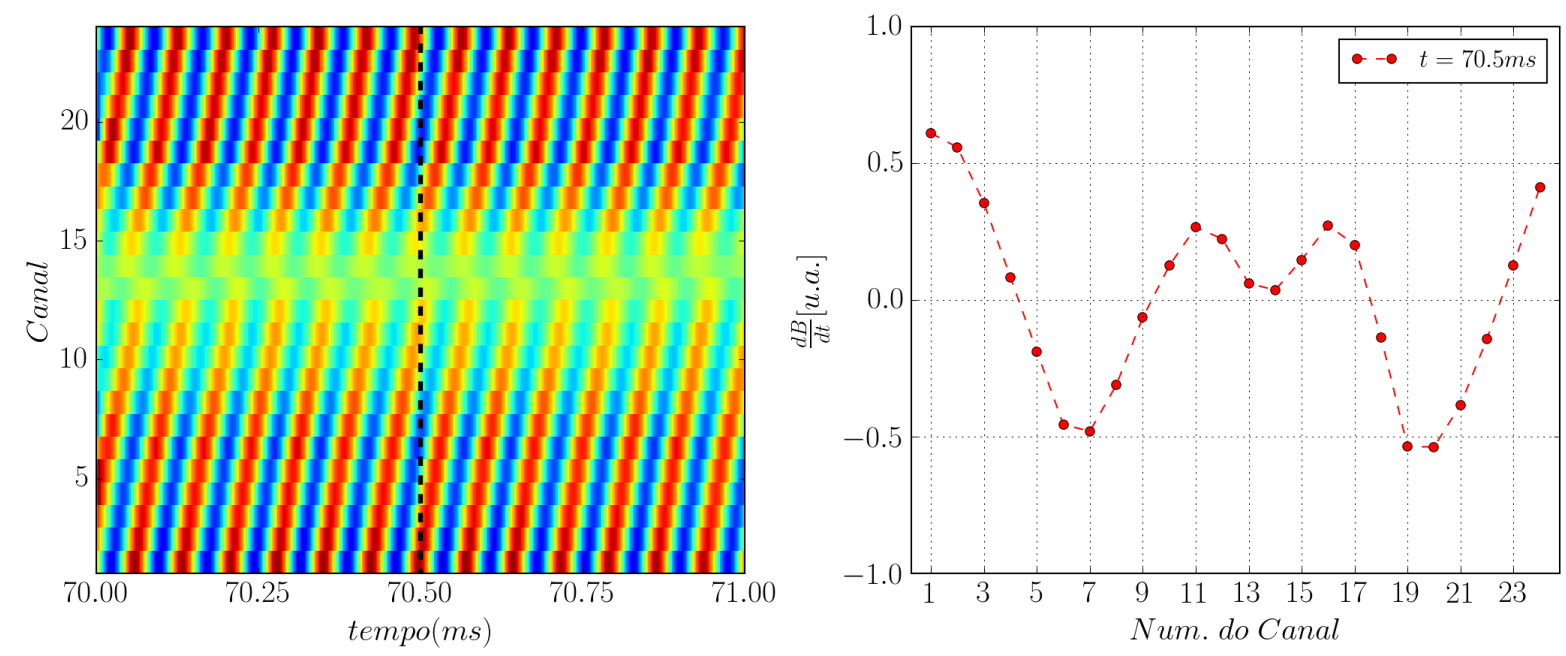

Figura 18 - (a) Visualização simultânea dos sinais das bobinas de Mirnov poloidais para um disparo típico e (b) Valor instantâneo da perturbação para $t=70.5 \mathrm{~ms}$. É possível visualizar em (a) que existe uma pequena defasagem temporal entre os canais e que os valores se repetem de instante de tempo à instante de tempo em (b), a menos de um deslocamento no número do canal.

Com relação às posições das bobinas de Mirnov é necessário ter em mente que dois sistemas de referência estão sendo implicitamente usados. Um deles é o sistema de referência do laboratório, onde as bobinas estão fixas. O outro é o referencial do centro da coluna de plasma. Não necessariamente as origens dos sistemas são coincidentes e de fato, devido a efeitos da toroidicidade do plasma, a origem do sistema de referência do centro do plasma está deslocada no sentido crescente do raio maior [50]. Essa diferença é chamada de deslocamento de Shafranov [14, 19]. Além disso, o campo magnético toroidal é mais intenso na parte interna da coluna do que na parte externa, o que faz com que a helicidade das linhas de campo magnético dependam do ângulo poloidal. Como consequência, as perturbações magnéticas são comprimidas na parte interna da coluna de plasma $(\theta \approx p i$, canais 12 e 13$)$ e expandidas na parte externa $(\theta \approx 0$, canais 1 e 24$)$.

A figura 19(a) ilustra os sistemas de referência e os efeitos com relação ao posicionamento das bobinas em ambos os referenciais [51]. A grosso modo, se as bobinas de Mirnov estão igualmente espaçadas no referencial do laboratório, elas não o estarão no referencial do plasma. Os efeitos podem ser compensados utilizando a correção de Merezhkin [50]:

$$
\theta^{*}=\theta-\lambda \sin \theta
$$

onde $\theta$ é o ângulo medido no referencial do laboratório, $\theta^{*}$ é o ângulo corrigido no referencial do plasma e $\lambda=\lambda(m, n)=\frac{r_{m, n}}{R_{m, n}}\left(\beta_{p}(m, n)+\frac{1}{2} l_{i}(m, n)+1\right)$, com $r_{m, n}$ e $R_{m, n}$ 
sendo as posições da superfície racional $q=m / n, \beta_{p}$ é a razão entre as pressões cinéticas e magnéticas poloidais e $l_{i}$ é a indutância interna do plasma. $\mathrm{O}$ valor de $\lambda$, em primeira aproximação, pode ser dado por $\lambda \approx \frac{r}{R_{0}}$ ou seja, considera-se apenas o efeito da assimetria do campo magnético toroidal. No caso do TCABR, utilizando os dados da tabela 1 , obtemos $\lambda_{T C A B R} \approx 0.29$ na borda e, como para posições mais internas ao plasma $r<a$, tem-se que as correções são menores. O gráfico da figura 19(b) mostra os efeitos da correção de Merezhkin para $\lambda=0.3, \lambda=0.1$ e para o caso sem correção $\lambda=0$.

(a)

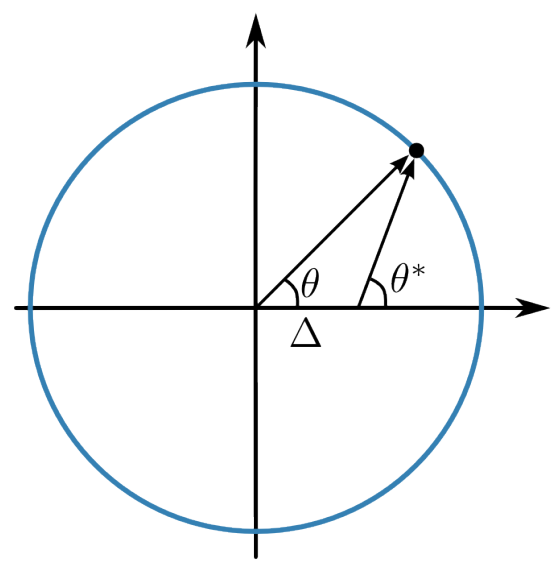

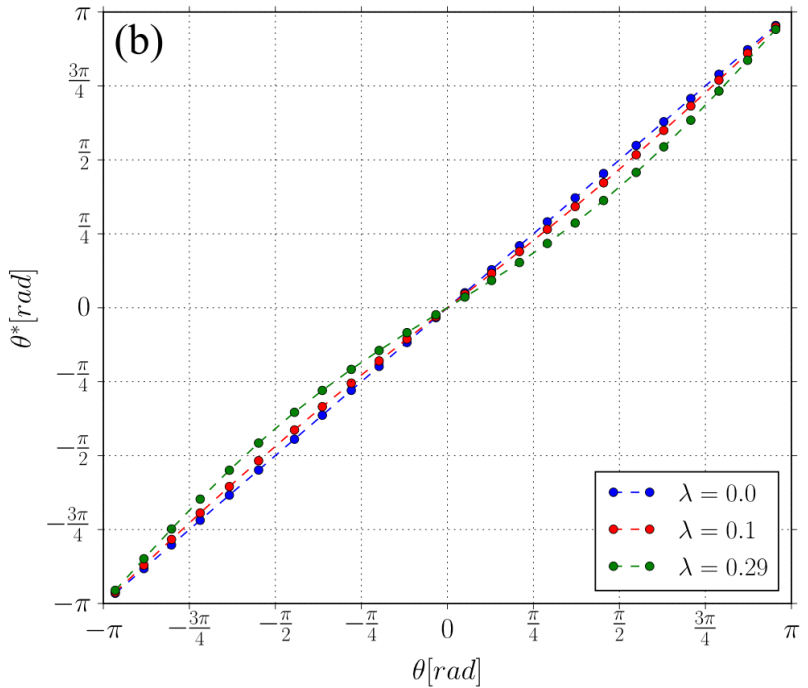

Figura 19 - (a) Sistema de referência do laboratório e do centro da coluna de plasma (b) Posições angulares medidas em ambos os referenciais.

\subsection{Sistema SXR}

O sistema de detecção de raios-X moles (SXR) do TCABR é composto por dois arrays de detectores semicondutores do tipo PIN [52], sendo que um deles é exposto diretamente à radiação emitida pelo plasma e o outro é protegido por um folha de berílio de $7.3 \mu m$ de espessura [53], conforme ilustrado na figura 20(a). O array utilizado no sistema SXR é o AXUV20EL fabricado pela Intenationl Radiation Detectors Inc. (IRD Inc.) e é semelhante ao modelo de detector utilizado no bolômetro, diferenciando principalmente no número de canais. $\mathrm{O}$ aspecto físico do encapsulamento dos sensores é mostrado na figura 20(b).

Do sensor que está sombreado pelo filtro de berílio são adquiridos todos os 20 canais e do outro sensor, os 12 canais mais centrais são adquiridos. Esta restrição no número de canais adquiridos é devido à limitação do número de pinos do conector que interfaceia os sensores, que são internos à câmara de vácuo do tokamak, com o ambiente exterior.

O sistema SXR já era existente no TCABR e havia passado por modernização para a instalação destes detectores porém, devido a instabilidades no sistema eletrônico de 


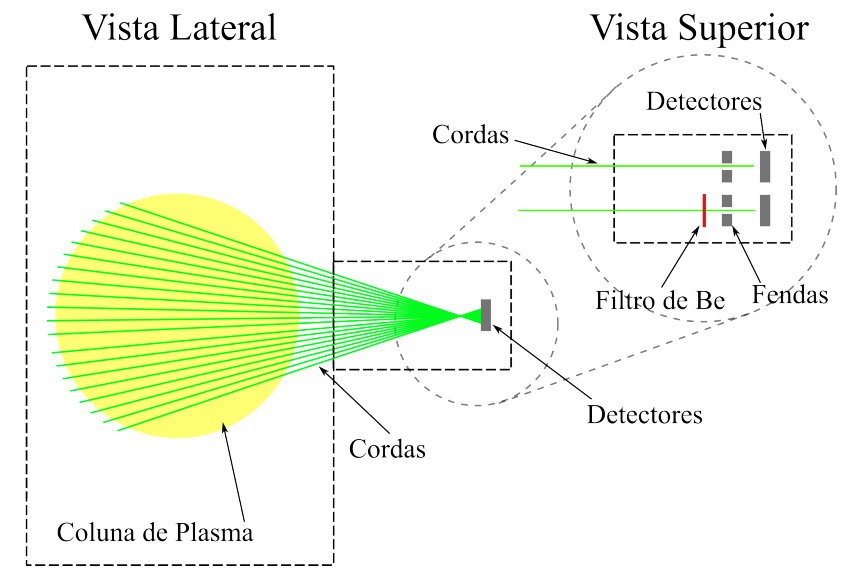

(a)
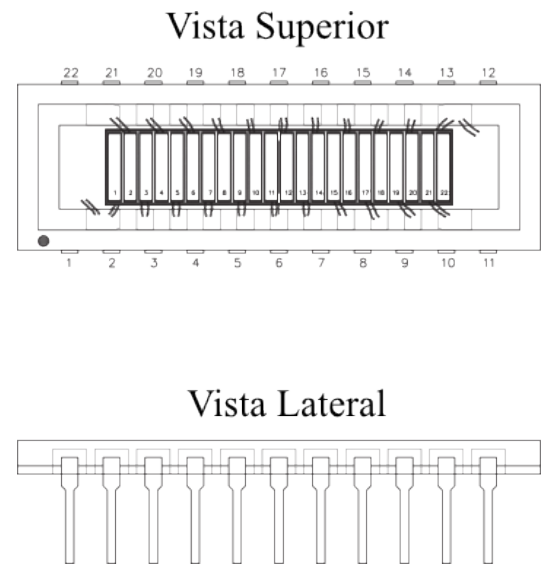

(b)

Figura 20 - (a) Arranjo experimental do sistema SXR mostrando a disposição dos sensores, das fendas e do filtro de berílio e (b) aspecto físico do encapsulamento dos arrays sensores modelo AXUV20EL.

amplificação, foi desenvolvido e construído um novo sistema eletrônico como parte deste trabalho de mestrado. Foram fabricados cinco módulos amplificadores no padrão mecânico europeu para rack 3U [54], sendo que cada módulo possui oito canais. Três módulos são utilizados para amplificação dos sinais provenientes do sensor que está sombreado com o filtro de berílio e outros dois módulos são utilizados para amplificar os sinais do sensor não sombreado.

A figura 21(a) mostra o diagrama eletrônico simplificado de um dos canais do amplificador. Basicamente é construído em torno de um amplificador operacional do tipo JFET de alta impedância de entrada $\left(10^{12} \Omega\right)$, sendo agregados os componentes passivos para fixação do ganho e resposta em frequência. A topologia do circuito é de um amplificador de transimpedância com filtro passa-baixa de primeira ordem, cujo funcionamento detalhado pode ser encontrado na referência [55]. A figura 21(b) mostra o aspecto físico de um dos módulos amplificadores.

Os elementos sensores podem ser modelados, de acordo com os dados do fabricante, como uma fonte de corrente em série com uma resistência e em paralelo com um capacitância, conforme indicado na figura 21(a). Os valores típicos encontrados no manual do fabricante são de $R_{s}=100 M \Omega$ e $C_{p}=40 p F$. O circuito pode funcionar em dois modos de operação, com a chave $S_{1}$ na posição $A$ no modo fototensão e na posição $B$ em modo fotocorrente. No modo fototensão, cada elemento sensor produz uma tensão proporcional à intensidade da radiação incidente. Já no modo fotocorrente os elementos sensores produzem uma corrente na saída, porém a resposta não é linear com a intensidade da radiação. Informações adicionais sobre os modos de operação de fotodiodos podem ser obtidas na referência [56].

Os módulos utilizados para amplificar os canais referentes ao sensor sombreado 


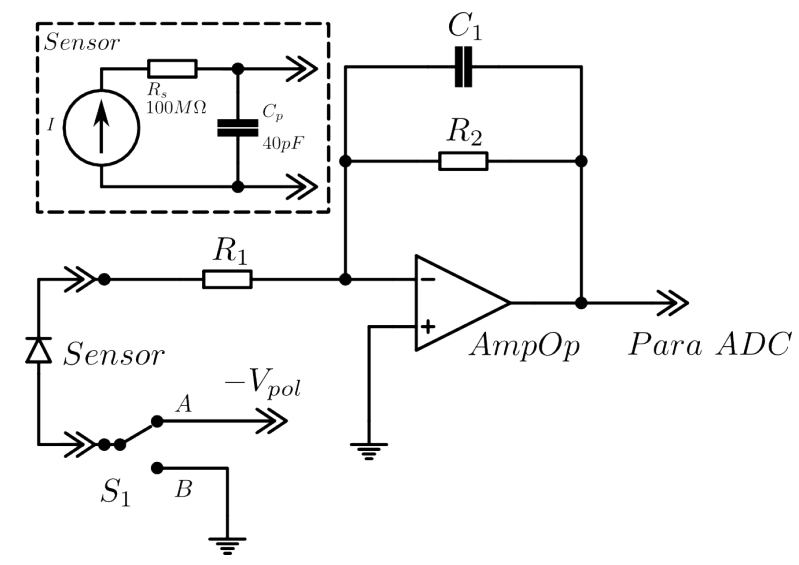

(a)

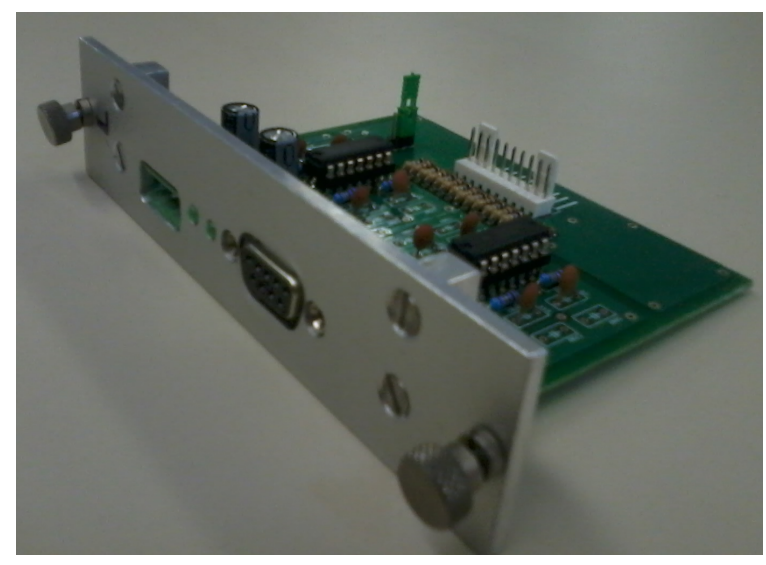

(b)

Figura 21 - (a) Esquema eletrônico simplificado de um dos canais do amplificador do sistema SXR e (b) aspecto físico de um dos módulos amplificadores montados.

foram ajustados com ganho $G=2000$ e os referentes aos demais canais com ganho $G=200$. Em ambos os caso a frequência de corte do amplificador foi ajustado para $f_{c}=150 \mathrm{kHz}$, onde a frequência de corte é calculada por $f_{c}=\frac{1}{2 \pi R_{2} C_{1}}$.

Os desenhos do circuito impresso foram feitos em dupla face com separação dos planos de aterramento, conforme boas práticas de projetos e estão apresentados na figura 77(a) para a face superior e 77(b) para a face inferior, no anexo A. Os protótipos foram montados no laboratório de eletrônica do TCABR e a fabricação das placas virgens finais foram delegadas à uma empresa terceirizada e posteriormente os componentes foram soldados no laboratório de eletrônica do TCABR.

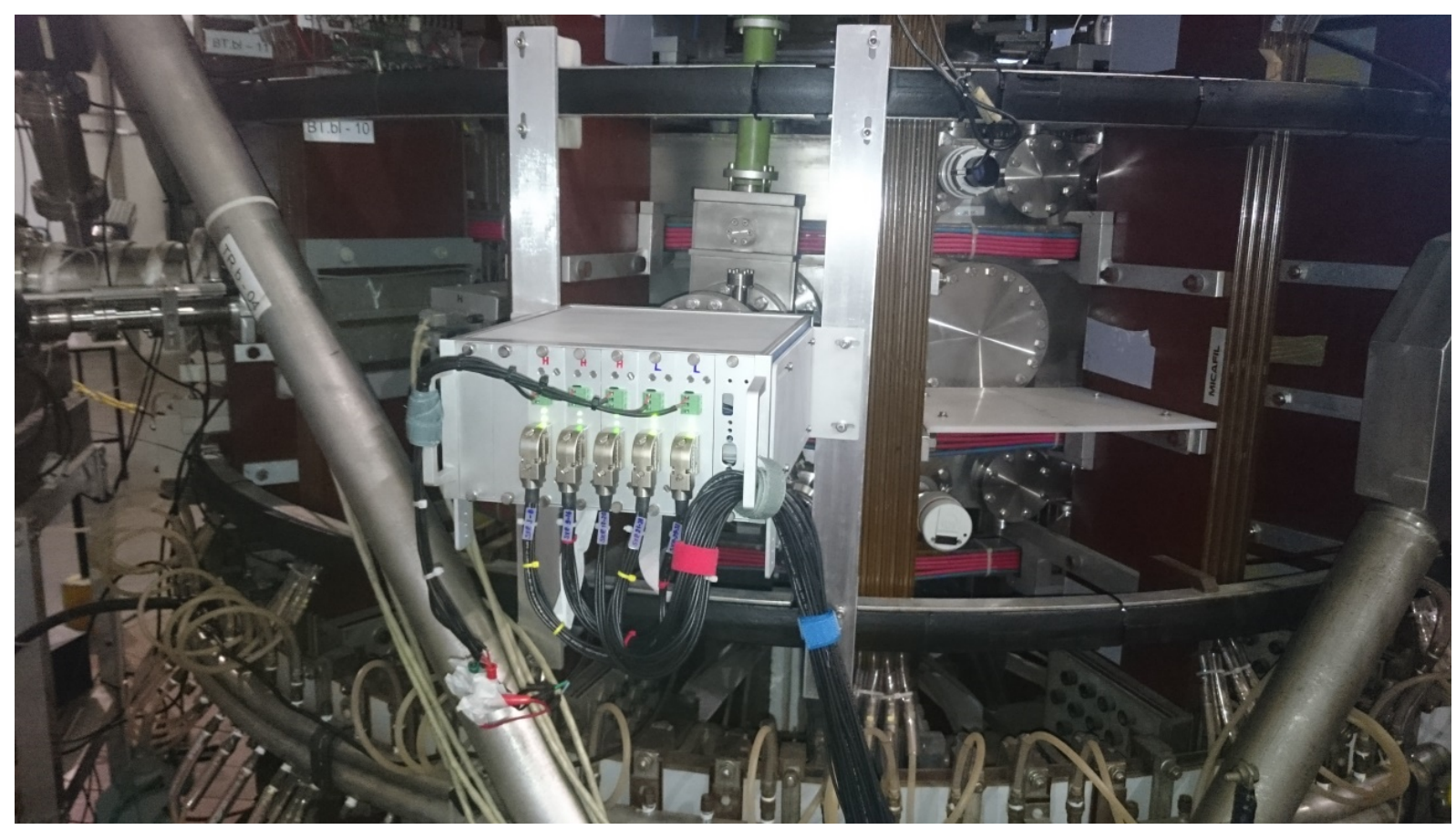

Figura 22 - Montagem do novo sistema de amplificação do sistema SXR no TCABR. 
A montagem mecânica do bastidor foi realizada na oficina mecânica do Instituto de Física e a aparência final, com os módulos eletrônicos instalado no tokamak está mostrada na figura 22. As duas primeiras posições, da esquerda para a direita do bastidor, são reservados para a alocação da futura fonte de alimentação integrada ao sistema. Os três primeiros módulos correspondem ao array com filtro de berílio e as outros dois correspondem ao array que não possui filtro. O bastidor conta com uma posição reserva para permitir futuras expansões do sistema. O anexo A também apresenta o projeto mecânico do bastidor, das lâminas frontais dos módulos eletrônicos e dos suportes mecânicos para a montagem do bastidor no corpo do tokamak.

O sinal típico na saída do sistema SXR para um canal central do array com filtro de berílio está mostrado na figura 23(a) e o respectivo espectrograma de potência do sinal está apresentado na figura 23(b). São nitidamente observáveis duas componentes distintas de frequência no espectrograma, uma da ordem de $2.5 \mathrm{kHz}$, correspondente a frequência fundamental da oscilação dente de serra e outra componente com frequência entre $10 \mathrm{Khz}$ e $15 k H z$ que correspondem as oscilações precursoras do crash da dente de serra.
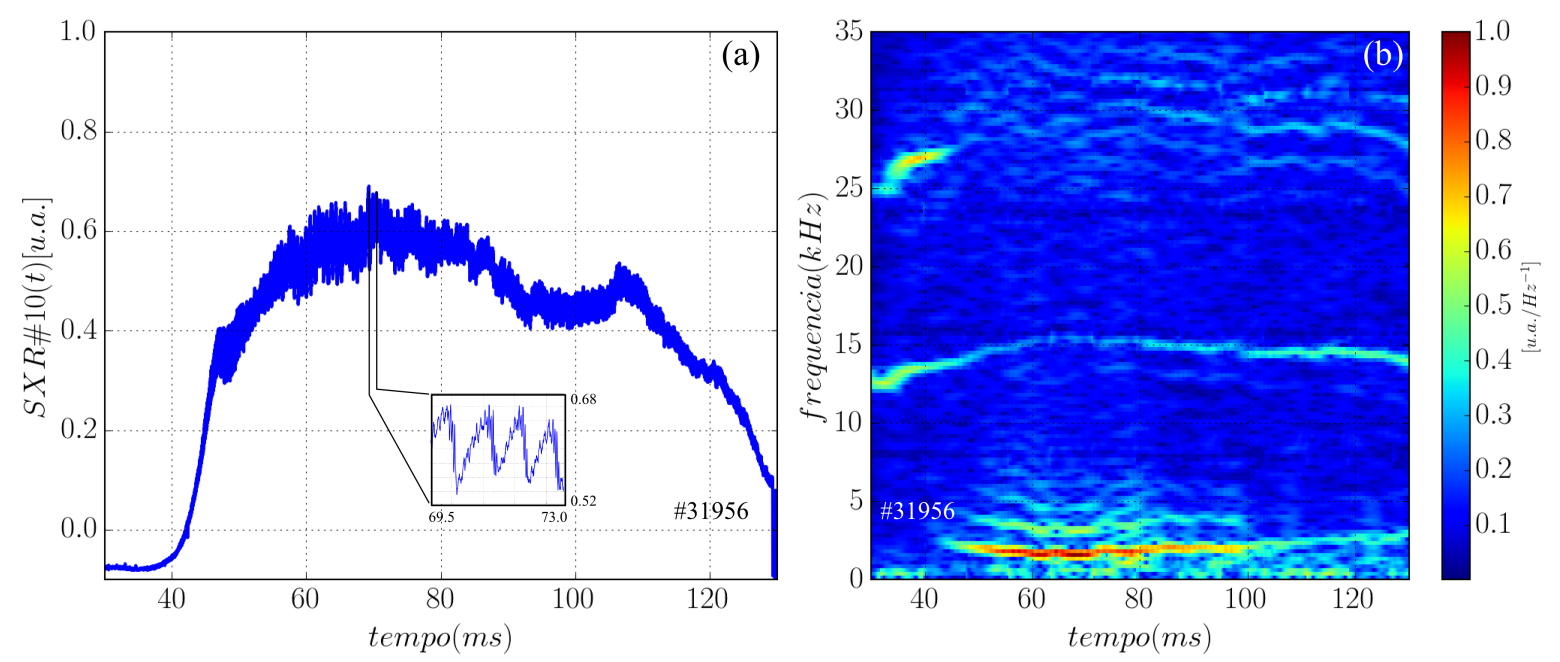

Figura 23 - (a) Sinal temporal típico de um canal central do SXR (b) Espectrograma de potência do sinal típico do SXR.

O sinal do SXR com filtro de berílio apresenta grande amplitude de variação em relação ao nível DC pois, devido ao filtro de berílio que corta a radiação na região do visível, este sensor possui faixa de sensibilidade numa faixa localizada numa região de mais alta energia quando comparado aos canais que não possuem filtro, que enxergam toda a largura do espectro. Isto implica que o SXR é mais indicado para estudar regiões mais quentes do plasma pois estas apresentam maior emissão na região do espectro do U.V. e raios-X moles.

A figura 24(a) e (b) mostram o aspecto dos sinais dos canais ativos do SXR para ambos os arrays com e sem filtro de berílio, respectivamente. Os gráficos mostram a 
presença das oscilações precursoras de dente de serra nas regiões de subida lenta do sinal, seguida do crash característico de relaxação dos ciclos dente de serra. As análises físicas destes fenômenos serão efetuadas no capítulo 5 .
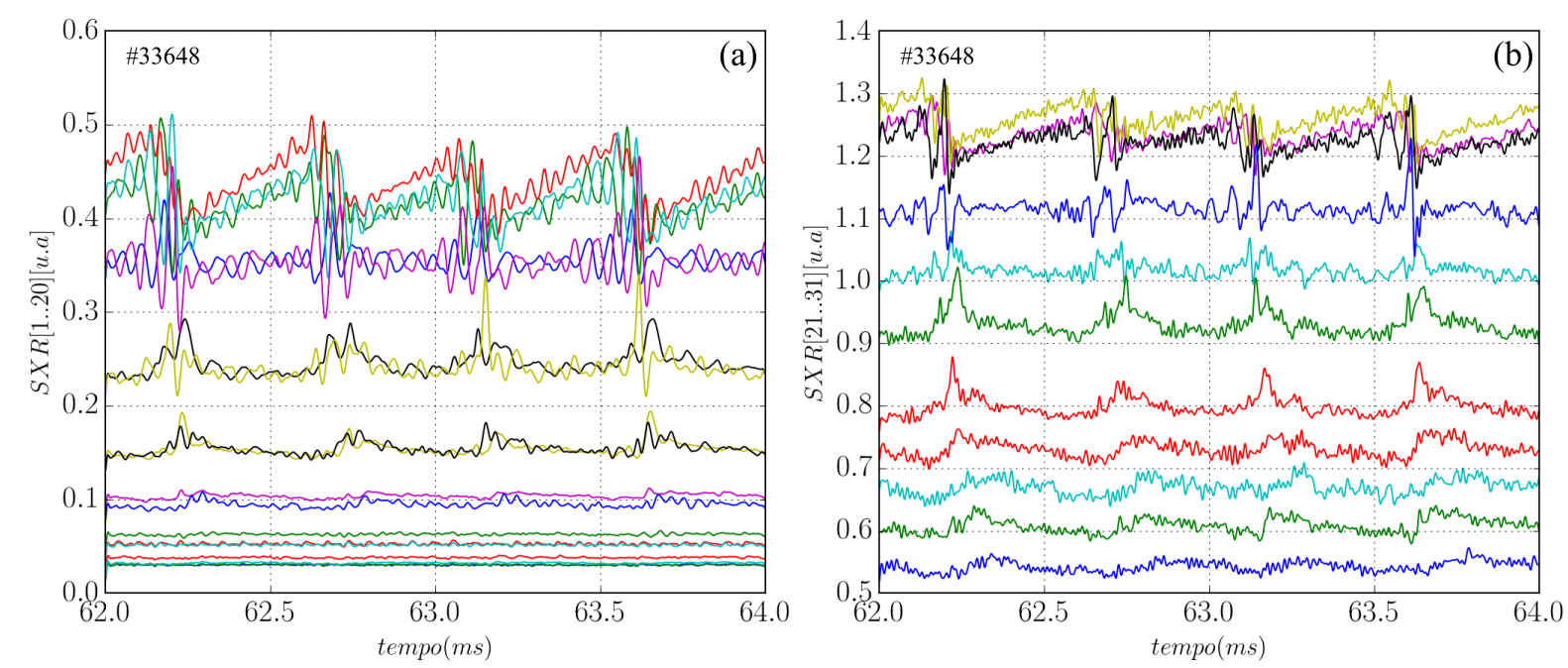

Figura 24 - Sinais de todos os canais ativos para os canais com filtro de berílio em (a) e sem filtro em (b).

A figura 25(a) e (b) mostram respectivamente, todos os sinais correspondentes ao array sem filtro de berílio seguido do corte para três instantes de tempo. Pelo gráfico, percebe-se que emissões mais intensas são detectadas pelos canais centrais $(24 \sim 28)$ e são menos intensas nos demais canais. Isto indica que o perfil de emissão tem um pico no centro da coluna de plasma.
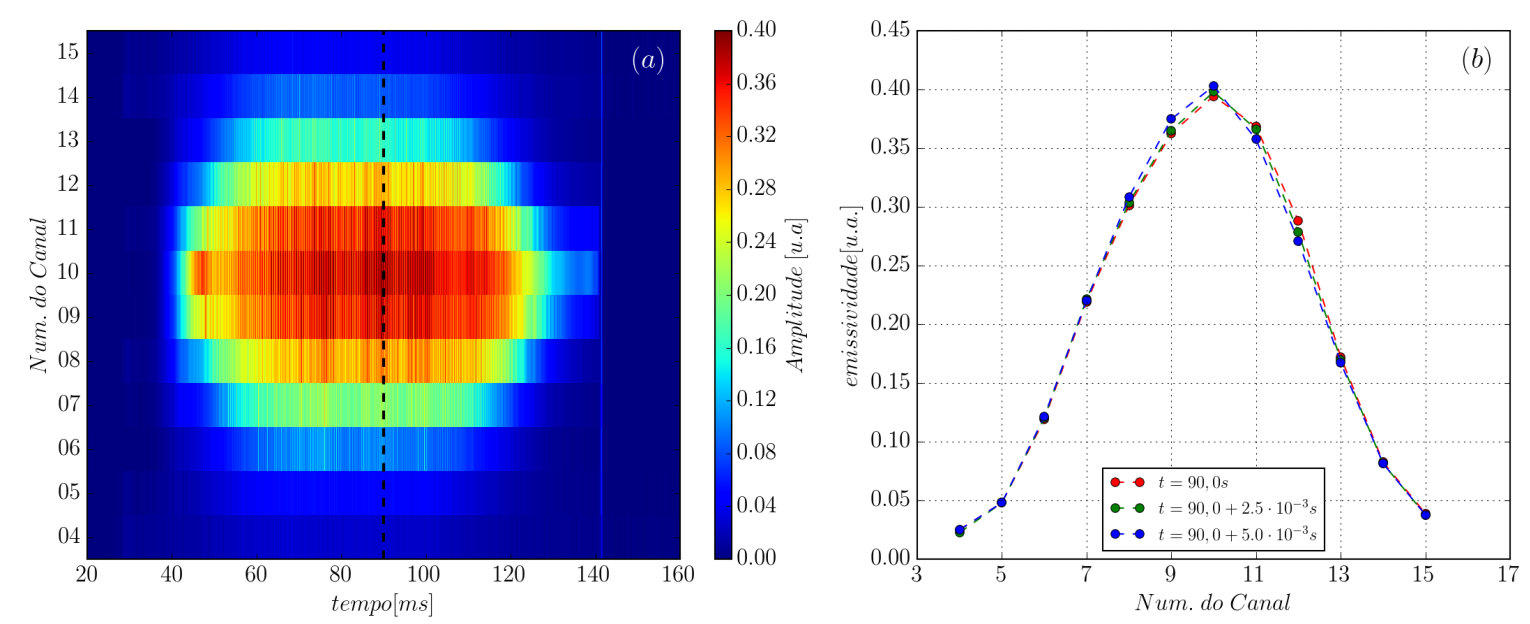

Figura 25 - (a) Visualização simultânea dos sinais dos canais do SXR sem filtro para um disparo típico e (b) Valor instantâneo dos sinais para três instantes de tempo.

Uma definição geométrica comumente empregada para a identificação da linha de visada de cada canal do sistema óptico é o chamado parâmetro de impacto que é a distância entre o centro da coluna de plasma até a linha de visada correspondente. Os 
parâmetros de impacto de cada corda do SXR podem ser obtidas utilizando a geometria mostrada na figura 26(a) e o gráfico da figura 26(b) apresenta o mapeamento do número do canal com o parâmetro de impacto para o SXR.
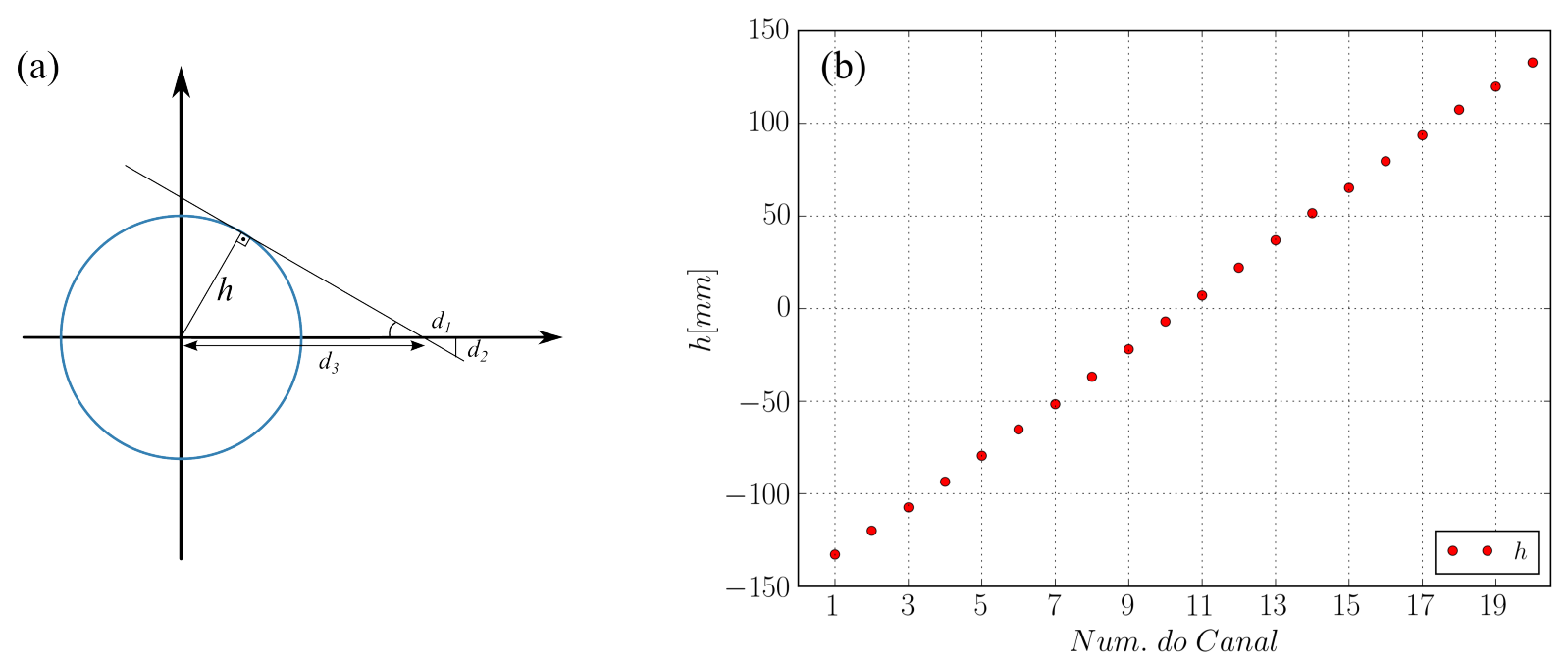

Figura 26 - Alocação dos parâmetros de impacto para as cordas do SXR em função dos canais.

Na figura 26(a), $d_{1}$ especifica a distância do array até a fenda, $d_{2}$ é a distância de um dos elementos sensores do array até o eixo óptico e $d_{3}$ é a distância entre a fenda e o centro da coluna de plasma. 



\section{Métodos para tratamento de dados}

Os sinais experimentais utilizados para estudos das instabilidades MHD são, como os demais diagnósticos de um tokamak, adquiridos por um sistema eletrônico de coleta e armazenamento de dados. Os sinais produzidos são contínuos e passam por um processo de amostragem e digitalização. O sistema de aquisição apresenta elevadas taxas de amostragem para permitir que a ampla variedade de fenômenos físicos produzidos por um disparo típico de um tokamak possam ser devidamente representados por sinais amostrados e discretizados. Por exemplo, no TCABR os sinais provenientes das bobinas de Mirnov são amostrados com taxa de amostragem de $500[\mathrm{kS} / \mathrm{s}]$ e os sinais produzidos pelo diagnóstico do SXR em $1[M S / s]$.

De fato, em termos de análise espectral, duas considerações são importantes quando se adquire sinais através de sistemas de digitalização: 1) a resolução em frequência $(d f=1 / T)$, onde $T$ é o tempo total de aquisição, que impacta diretamente a quantidade de dados gerados a cada sequencia de aquisição e 2) a frequência de Nyquist-Shanon $\left(f_{N}=f_{s} / 2\right)$, onde $f_{s}$ é a frequência de amostragem do sistema, que limita a componente de maior frequência do sinal que pode ser corretamente representada e reconstruída a partir dos dados amostrados.

Num caso típico do TCABR, considerando um intervalo de aquisição total de $T=200 \mathrm{~ms}$, pela primeira consideração, não será possível resolver diferenças de frequência menores que $5 H z$. Sobre a frequência de Nyquist, mesmo sinais com componentes de frequência acima de $f_{s} / 2$ serão amostradas, porém quando reconstruídas, essas componentes aparecerão no espectro como se tivessem frequência menor. Este fenômeno é conhecido como aliasing. O importante é ter em mente que na prática, a frequência máxima observável será menor do que previsto teoricamente pelo teorema de Nyquist pois, para evitar o aliasing, são empregados filtros passa-baixa com frequências de corte menores que $f_{s} / 2$. Uma discussão completa sobre este tema pode ser encontrada nas referências [57, 58, 59].

Ademais, é relevante considerar as escalas de tempo típicas dos fenômenos que se quer observar em tokamaks. Devido ao fato que os processos físicos são rápidos, a análise em tempo real torna-se difícil, sendo preferível coletar os dados na taxa de amostragem adequada e efetuar o armazenamento no banco de dados para análises off-line. No TCABR são armazenadas em um banco de dados MDSPlus para visualização e análises posteriores ao disparo. Isto permite que sejam utilizados uma ampla variedade de algoritmos e métodos de análise para o estudo dos processos físicos associados a um plasma de tokamak.

Neste capítulo trataremos de uma breve revisão das técnicas de análise de sinais empregadas no presente trabalho, com ênfase na análise espectral, tendo em vista que a 
física associada aos modos tearing e kink internos apresentam características espaciais e temporais favoráveis a utilização destas técnicas.

\subsection{Transformada de Fourier}

A transformada de Fourier é uma das técnicas mais utilizadas para modelagem e tratamento de sinais experimentais. Basicamente ela converte a representação de um sinal de um domínio temporal ou espacial para um domínio de frequências ou frequências espaciais, respectivamente. A transformada de Fourier admite operação inversa e o conjunto das operações, direta e inversa, é chamada de par de transformadas de Fourier.

No caso temporal, as definições matemáticas da transformada direta e inversa de Fourier são dadas, respectivamente, por [57]:

$$
\begin{aligned}
& X(\omega)=\frac{1}{\sqrt{2 \pi}} \int_{-\infty}^{\infty} x(t) e^{-i \omega t} d t \\
& x(t)=\frac{1}{\sqrt{2 \pi}} \int_{-\infty}^{\infty} X(\omega) e^{i \omega t} d \omega
\end{aligned}
$$

onde $\omega$ é a frequência angular dada por $\omega=2 \pi f, x(t)$ é o sinal no domínio do tempo, $X(\omega)$ é o sinal no domínio da frequência. Na prática, as definições acima só são úteis para análises teóricas. Para estudos e aplicações com dados experimentais, devido a natureza não-contínua dos sinais amostrados, são empregadas as versões discretas das transformadas.

Na forma discreta, são comumente chamadas de DFT (Discrete Fourier Transforms) e o par de transformadas direta e inversa são definidas, respectivamente, como [57]:

$$
\begin{gathered}
X\left(\omega_{k}\right)=\sum_{n=0}^{M-1} x\left(t_{n}\right) e^{-i \frac{2 \pi}{M} k n}, k=0,1,2, \ldots, M-1 \\
x\left(t_{n}\right)=\sum_{k=0}^{M-1} X\left(\omega_{k}\right) e^{i \frac{2 \pi}{M} k n}, n=0,1,2, \ldots, M-1
\end{gathered}
$$

onde $k$ e $n$ são os índices de frequências e tempos, respectivamente. $x\left(t_{n}\right)$ é a n-ésima amostra temporal e $X\left(\omega_{k}\right)$ é a k-ésima componente de frequência do sinal. As definições referentes ao par de transformadas espaciais são análogas trocando o tempo das definições acima por amostras tomadas no domínio do espaço.

É importante salientar que, pela aplicação da transformada de Fourier em um sinal, nenhuma informação é perdida ou criada. A transformação fornece apenas uma maneira diferente de representar o mesmo sinal em um outro domínio.

Normalmente o cálculo das transformadas é feita utilizando um algoritmo chamado de Fast Fourier Transform ou FFT, sendo que informações sobre como são feitas as operações deste algoritmo podem ser encontradas na literatura [57, 60]. É comum utilizar 
os termos $F F T(x)$ ou $F F T^{-1}(X)$ para denotar operações de transformação direta e inversa, respectivamente. A título de completeza, outra forma de calcular a transformada discreta de Fourier é realizando um ajuste pelo método dos mínimos quadrados (MMQ). Olhando a expressão (4.4) nota-se que o sinal original pode ser entendido por somas de $M$ exponenciais complexas ponderadas pelos fatores $X\left(\omega_{k}\right)$. Ajustando estes fatores tal que minimize a expressão $\sum_{n}^{M-1}\left(x\left(t_{n}\right)-\sum_{k=0}^{M-1} X\left(\omega_{k}\right) e^{i \frac{2 \pi}{M} k n}\right)^{2}$, obtém-se o mesmo resultado que utilizando a FFT. Um estudo completo entre a relação da transformada discreta de Fourier e o algoritmo dos mínimos quadrados segue na referência [61].

Em geral o valor de $X\left(\omega_{k}\right)$ é um número complexo e desta forma pode ser representados na forma retangular $\left(X\left(\omega_{k}\right)=\operatorname{Re}\left\{X\left(\omega_{k}\right)\right\}+i \operatorname{Im}\left\{X\left(\omega_{k}\right)\right\}\right)$ ou na forma polar $\left(X\left(\omega_{k}\right)=\left|X\left(\omega_{k}\right)\right| e^{i \Theta}\right)$ onde $\left|X\left(\omega_{k}\right)\right|=\left(\operatorname{Re}\left\{X\left(\omega_{k}\right)\right\}^{2}+\operatorname{Im}\left\{X\left(\omega_{k}\right)\right\}^{2}\right)^{1 / 2}$ é a magnitude espectral da k-ésima componente de frequência e $\Theta=t g^{-1}\left(\operatorname{Im}\left\{X\left(\omega_{k}\right)\right\} / \operatorname{Re}\left\{X\left(\omega_{k}\right)\right\}\right)$ é chamado de ângulo de fase. A diferença entre o ângulo de fase $\Theta$ entre dois sinais $X\left(\omega_{k}\right)$ e $Y\left(\omega_{k}\right)$ tem o significado físico de defasagem dos sinais na frequência $\omega_{k}$. O conjunto de todas as componentes de frequência de um sinal é chamado de espectro de frequências.

Um conceito importante associado ao espectro de frequências é a densidade de potência espectral, definida como o quadrado da magnitude espectral $S\left(\omega_{k}\right)=\left|X\left(\omega_{k}\right)\right|^{2}$ ou, como consequência, pela expressão:

$$
S\left(\omega_{k}\right)=X\left(\omega_{k}\right) \cdot X\left(\omega_{k}\right)^{*}
$$

onde $X\left(\omega_{k}\right)^{*}$ é o complexo conjugado de $X\left(\omega_{k}\right)$.

\subsection{Correlação cruzada e autocorrelação}

A medida de similaridade entre sinais ou séries temporais é uma aplicação recorrente na análise de dados experimentais, sendo que uma técnica que fornece esta informação é a análise de correlação. A correlação cruzada entre duas séries temporais de amostras em função de um atraso entre as séries é dada por [62]:

$$
r_{x y}(k)=\frac{\operatorname{Cov}_{x y}(k)}{\sqrt{\operatorname{Cov}_{x x}(0) \operatorname{Cov}_{y y}(0)}}
$$

onde $\operatorname{Cov}_{x y}$ é a covariância cruzada amostral entre as séries $x$ e $y$, definida como [62]:

$$
\operatorname{Cov}_{x y}(k)= \begin{cases}\frac{1}{N} \sum_{n=1}^{N-k}\left(x_{n}-\bar{x}\right)\left(y_{n+k}-\bar{y}\right) & k=0,1, \ldots,(N-1) \\ \frac{1}{N} \sum_{n=1-k}^{N}\left(x_{n}-\bar{x}\right)\left(y_{n+k}-\bar{y}\right) & k=-1,-2, \ldots,-(N-1)\end{cases}
$$

A correlação cruzada tem inúmeras aplicações na análise de dados e pode ser utilizada, por exemplo, para a medida do tempo de atraso entre dois sinais, mesmo com 
presença de ruídos. Caso as séries sejam idênticas o resultado da operação é chamada de autocorrelação. A autocorrelação é muito utilizada para identificação de sinais periódicos.

\subsection{Densidade de potência espectral e espetral cruzada}

A densidade de potência espectral cruzada é definida como a transformada de Fourier da função de covariância cruzada, conforme a expressão [63]:

$$
S_{x y}(\omega)=\sum_{k=-\infty}^{\infty} \operatorname{Cov}_{x y}(k) e^{-i \omega k}
$$

Substituindo a definição de covariância cruzada da equação (4.7) na expressão acima, pode ser obtida a seguinte relação:

$$
S_{x y}(\omega)=X(\omega) \cdot Y^{*}(\omega)
$$

onde $X$ e $Y$ são as transformadas de Fourier das séries $x$ e $y$ e o símbolo * denota o complexo conjugado. Diretamente da equação (4.9) conclui-se que se as séries são idênticas, a densidade de potência é equivalente à magnitude quadrática do sinal. Caso as séries sejam diferentes o módulo da potência espectral cruzada é uma medida de potência comum, por componente de frequência, em ambos os sinais.

É usual na literatura denotar a densidade de potência espectral cruzada utilizando as siglas em inglês CSD ou CPSD e no caso das séries $x$ e $y$ serem idênticas a operação é chamada simplesmente de densidade de potência espectral ou pelas siglas PSD ou APSD [64].

Na prática, é comum utilizar o cálculo da densidade de potência espectral em subintervalos dos sinais, além de normalizar pelo quadrado do intervalo de amostragem $\left(1 / f_{s}\right)^{2}$ dividido pela largura total $(T)$ e pelo número total de subintervalos $(K)$. Isto é equivalente a efetuar $K$ medidas ou realizações independentes dos sinais no intervalo $T$, de forma que a relação (4.9) é usualmente expressa como [58]:

$$
\left\langle S_{x y}\left(\omega_{j}\right)\right\rangle=\frac{2}{f_{s}^{2} \cdot T} \cdot \frac{1}{K} \sum_{k=1}^{K} X_{k}\left(\omega_{j}\right) \cdot Y_{k}\left(\omega_{j}\right)^{*}
$$

onde $j$ é o índice da frequência e $k$ é o índice do subintervalo. A constante de normalização não é adimensional e, desta forma, a densidade de potência espectral tem dimensão igual ao produto das dimensões de $X$ e de $Y$, multiplicada por $H z^{-1}$.

\subsection{Coerência e fase}

O espectro de coerência é basicamente uma versão normalizada da potência espectral cruzada, onde esta é dividida pelos espectros de potência individuais dos sinais. A definição 
usual é dada por $[65,63,58]$ :

$$
\gamma_{x y}^{2}\left(\omega_{j}\right)=\frac{\left|\left\langle S_{x y}\left(\omega_{j}\right)\right\rangle\right|^{2}}{\left\langle S_{x x}\left(\omega_{j}\right)\right\rangle \cdot\left\langle S_{y y}\left(\omega_{j}\right)\right\rangle}
$$

Outra definição muito útil é o de espectro de fase entre dois sinais em função da frequência $\omega$ e é dado por [65]:

$$
\Theta_{x y}\left(\omega_{j}\right)=\tan ^{-1}\left(\frac{\operatorname{Im}\left\{S_{x y}\left(\omega_{j}\right)\right\}}{\operatorname{Re}\left\{S_{x y}\left(\omega_{j}\right)\right\}}\right)
$$

Para uma dada frequência, se a diferença de fase entre os sinais em diversas realizações (isto é, em medições distintas ou em intervalos de tempo distintos de uma mesma medição) se mantiver inalterada então a coerência entre os sinais terá um valor elevado (próximo a unidade) e do contrário, se a diferença de fase entre os sinais se altera entre as diferentes realizações, os sinais não serão coerentes nesta frequência [66]. Para uma compreensão intuitiva da relação entre coerência e diferença de fase entre os dois sinais, pode-se considerar as transformadas de Fourier na forma polar, $X_{k}\left(\omega_{j}\right)=\left|X_{k}\left(\omega_{j}\right)\right| e^{i \Theta_{x, k}\left(\omega_{j}\right)}$ e $Y_{k}\left(\omega_{j}\right)=\left|Y_{k}\left(\omega_{j}\right)\right| e^{i \Theta_{y, k}\left(\omega_{j}\right)}$ com amplitudes constantes e iguais em todas as realizações, ou seja, $\left|X_{k}\left(\omega_{j}\right)\right|=\left|Y_{k}\left(\omega_{j}\right)\right|=A_{k}\left(\omega_{j}\right)$. Então a expressão (4.11) pode ser escrita da forma:

$$
\gamma_{x y}\left(\omega_{j}\right) \approx \frac{\left|\frac{1}{K} \sum_{k=1}^{K} A_{k}^{2}\left(\omega_{j}\right) e^{i \Theta_{x, k}\left(\omega_{j}\right)} e^{i \Theta_{y, k}\left(\omega_{j}\right)}\right|}{\sqrt{\frac{1}{K} \sum_{k=1}^{K} A_{k}^{2}\left(\omega_{j}\right) \cdot \frac{1}{K} \sum_{m=1}^{K} A_{m}^{2}\left(\omega_{j}\right)}} \approx \frac{1}{K}\left|\sum_{k=1}^{K} e^{i \Delta \Theta_{x y, k}\left(\omega_{j}\right)}\right|
$$

onde $\Delta \Theta_{x y, k}\left(\omega_{j}\right)=\Theta_{x, k}\left(\omega_{j}\right)-\Theta_{y, k}\left(\omega_{j}\right)$ é a diferença de fase entre os sinais $x$ e $y$ na frequência $\omega_{j}$, na k-ésima realização.

O termo $e^{i \Delta \Theta_{x y, k}\left(\omega_{j}\right)}$ da expressão (4.13) define um ponto no plano complexo com raio unitário. Se a diferença de fase se mantém aproximadamente constante a cada $k$ realização da medida, a soma de todos os termos converge para um ponto próximo à circunferência de raio unitário. Desta forma os sinais estão coerentes na frequência $\omega_{j}$ com uma diferença de fase bem definida. O processo está ilustrado na figura 27.

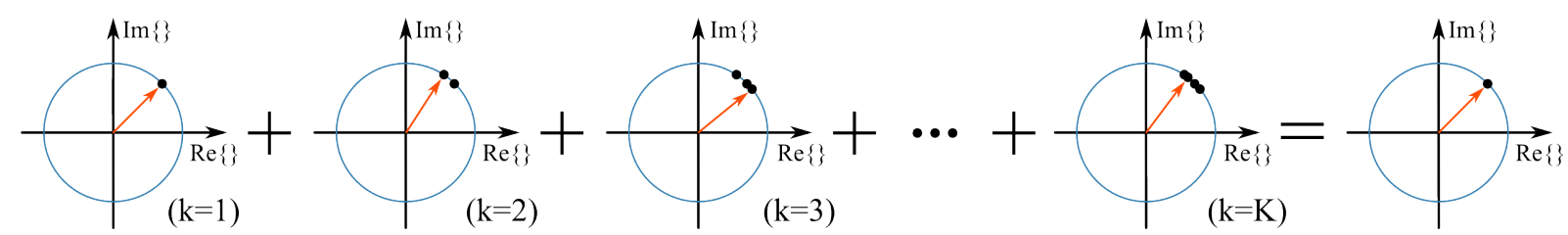

Figura 27 - Evolução da diferença de fase a cada realização da medida entre dois sinais coerentes numa frequência $\omega_{j}$. A soma de todas as realizações tende a um ponto próximo a circunferência de raio unitário. Adaptado de [58].

Mas se as diferenças de fase variam aleatoriamente a cada realização, o somatório dos termos na expressão (4.13) tenderá a se anular, conforme ilustrado na figura 28. Neste caso, os sinais não são coerentes na frequência $\omega_{j}$. 


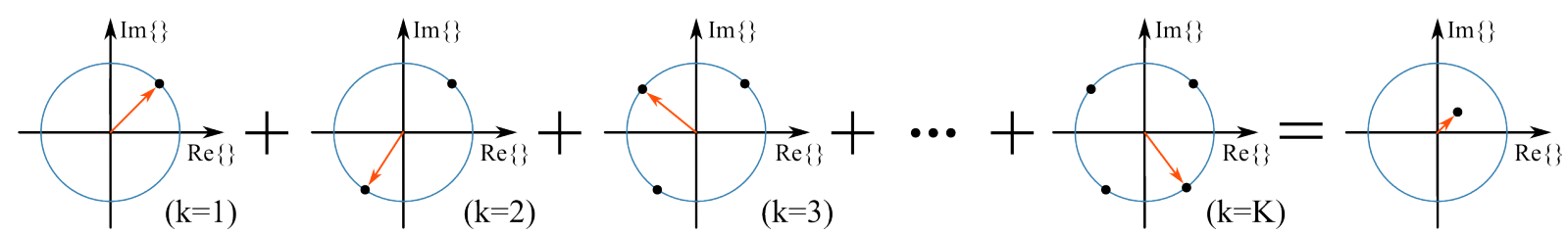

Figura 28 - Evolução da diferença de fase a cada realização da medida entre dois sinais não coerentes numa frequência $\omega_{j}$. A soma de todas as realizações tende a zero. Adaptado de $[58]$.

\subsection{Short Time Fourier Transform - STFT}

Nas aplicações práticas, como o estudo de instabilidades num tokamak, o conteúdo espectral dos sinais não pode ser considerado estacionário no tempo para uma escala de tempo longa (comparável ao tempo do disparo). Desta forma, uma análise por Fourier simples não é capaz de revelar o conteúdo espectral dos sinais ao longo do tempo.

Uma das maneiras de contornar o problema é subdividir o sinal em intervalos de tempo pequenos e consecutivos e aplicar a transformada de Fourier nestes intervalos. Fazendo-os suficientemente pequenos obtém-se uma estimativa da evolução temporal da composição espectral do sinal, desde que, nestes pequenos intervalos o sinal possa ser considerado estacionário. Esta técnica de análise leva o nome de Short Time Fourier Transform e é expressa matematicamente por:

$$
\operatorname{STFT}\{x[n]\} \equiv X(m, k)=\sum_{n=-\infty}^{\infty} x[n] w[n-m] e^{-i 2 \pi k n / N}
$$

onde $m$ é o índice do intervalo de tempo, $x$ é o sinal amostrado, $w$ é a função janela definida no intervalo de tempo considerado e $N$ é o número de amostras da janela $w$. A figura 29 mostra um exemplo de análise de um sinal sintético (a) composto por duas frequências bem definidas de $50 \mathrm{~Hz}$ e $100 \mathrm{~Hz}$, com frequência de amostragem de $1200 \mathrm{~Hz}$ e os resultados da transformada de Fourier simples (b) e a magnitude de STFT do sinal (c) para uma janela de 256 pontos.

A STFT é robusta mesmo quando empregada com sinais que apresentam nível de ruído elevado. A título de comparação, a figura 30 apresenta o mesmo sinal sintético usado no exemplo anterior, acrescido de um ruído gaussiano de média zero. Mesmo numa situação hipotética como esta o espectrograma das magnitudes do novo sinal, que apresentado na figura 30(c), as componentes de frequência do sinal original são muito bem discriminadas.

A largura da janela deve ser curta para que os fenômenos possam ser considerados estacionários e longa o suficiente para que seja possível caracterizar as componentes de mais baixa frequência. Um ponto importante é que a resolução em tempo e frequência estão intimamente ligados pelo princípio da incerteza que diz que $\triangle f \cdot \Delta t=1$. Em geral, a largura da janela deve ser determinada na prática e varia de sinal para sinal, desta forma tem-se uma solução de compromisso. 

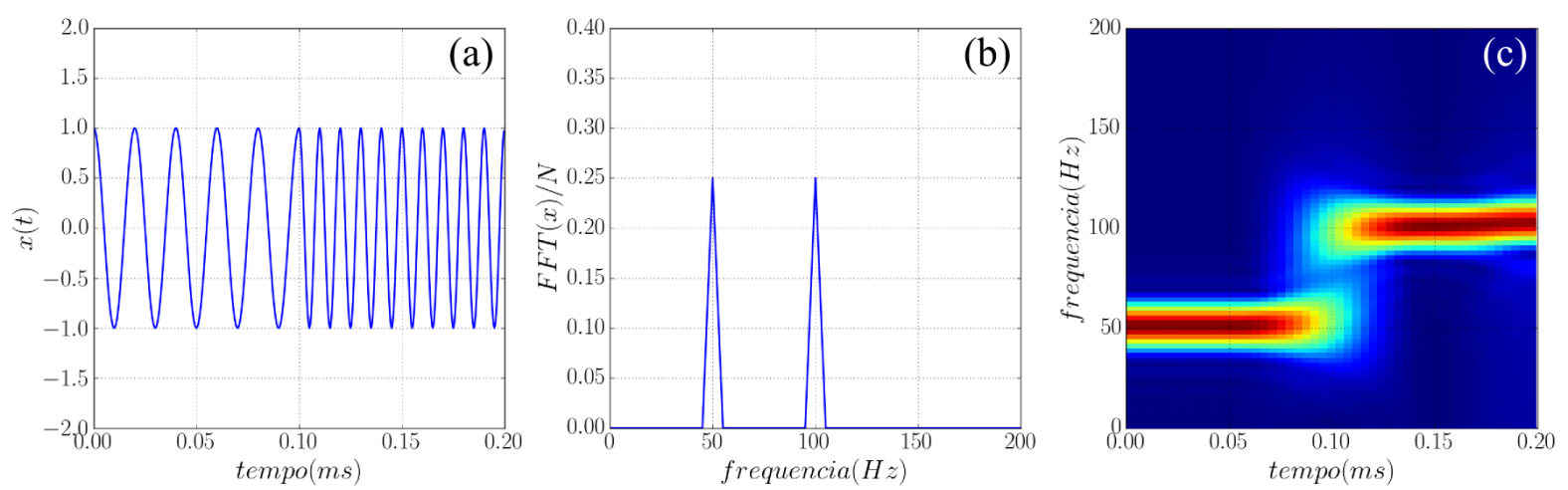

Figura 29 - Exemplo de análise de um sinal sintético utilizando a FFT simples e STFT. Em (a) o sinal original composto por duas frequências bem definidas de $50 \mathrm{~Hz}$ e $100 \mathrm{~Hz}$ e os resultados da transformada de Fourier simples e a magnitude de STFT do sinal em (b) e (c), respectivamente.
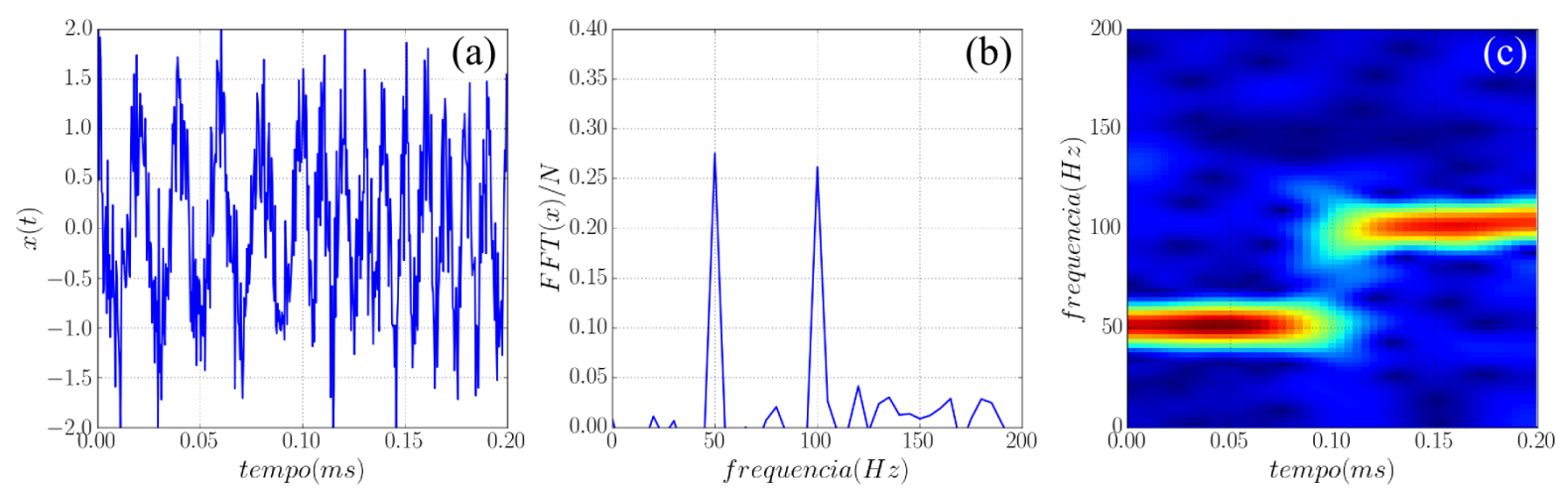

Figura 30 - Exemplo de análise de um sinal sintético com ruído gaussiano utilizando a FFT simples e STFT. Em (a) o sinal original composto por duas frequências bem definidas de $50 \mathrm{~Hz}$ e $100 \mathrm{~Hz}$ e os resultados da transformada de Fourier simples e a magnitude de STFT do sinal em (b) e (c), respectivamente. Mesmo com nível de ruído elevado as componentes de frequência do sinal original são discriminadas.

Deve ser enfatizado que o resultado produzido pela transformada de Fourier aplicadas em janelas é a convolução de duas transformações, uma referente ao próprio sinal e outra referente a transformação da janela. Neste caso, deve-se sempre avaliar o impacto do janelamento sobre os espectros produzidos. Para ilustrar estes efeitos vamos considerar um sinal sintético composto por duas componentes de frequência de igual amplitude e frequências de $23,31 \mathrm{~Hz}$ e $100,23 \mathrm{~Hz}$ amostrados a uma taxa de $10 \mathrm{kS} / \mathrm{s}$. A figura 31(a) e (b) mostram respectivamente o sinal no domínio do tempo e a respectiva DFT.

A forma mais simples de janelamento seria aplicar uma função retangular ao sinal. O aspecto da janela retangular e respectiva DFT estão mostrados na figura 31(c) e (d). Pode-se perceber que a DFT da função retangular produz um espectro disperso no domínio da frequência e caso fosse aplicada no sinal, como mostrado na figura 31(g), produzirá como resultado da convolução um espectro contaminado com alargamento picos das frequências originais do sinal, como mostrado na figura 31(h). Este alargamento dos picos se dá pois 
todas as funções com saltos no domínio do tempo produzem espectros não concentrados no domínio das frequência. Este fenômeno é conhecido em inglês como Spectral leakage.
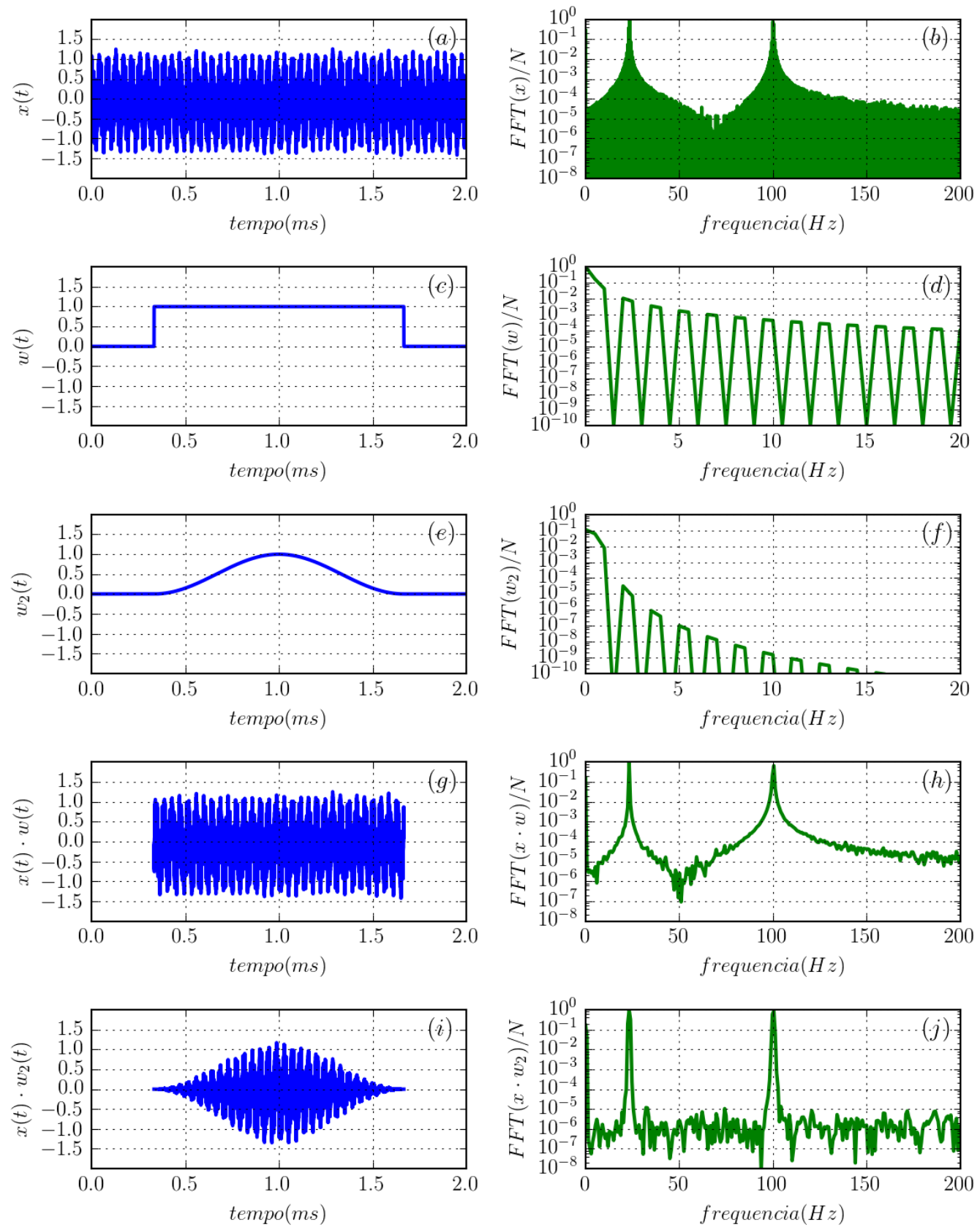

Figura 31 - Exemplo da aplicação de janelas para STFT. Em (a) o sinal sintético de $23.31 \mathrm{~Hz}$ e $100,23 \mathrm{~Hz}$ acrescido de um ruído gaussiano e o resultado da DFT do sinal em (b). Em (c) e (e) estão janela retangular e a janela Hamming com as respectivas DFT em (d) e (f). Em (g) e (i) estão o produto do sinal original pela janela retangular e de Hamming. Em (h) e (j) estão representados os espectros finais após o janelamento para a função retangular e de Hamming, respectivamente. A utilização de uma janela adequada diminui o alargamento dos picos do espectro.

Agora, considerando uma função janela do tipo $w[n]=0.54+0.46 \cos (2 \pi n / N-1)$, onde $n$ é o índice do tempo e $N$ é a largura total do sinal, como mostrado na figura 
31(e). Usualmente esta janela é chamada de janela de Hamming e produz um espectro como mostrado na figura 31(f). O resultado da multiplicação desta janela pelo sinal está mostrado em (i) e a respectiva DFT em (j). Nota-se que o alargamento dos picos é menor do que o caso da janela retangular de mesma largura. Existem vários outros tipos de janelas e um estudo detalhado das propriedades e aplicações está indicado na referência [59].

\subsection{Análise de sinais multicanais}

Diagnósticos multicanais medem a mesma grandeza física em pontos diferentes do plasma de forma simultânea no tempo. Eles permitem a realização de análises do comportamento espacial destas grandezas conjuntamente com a evolução temporal. Em geral esses diagnósticos mapeiam a estrutura espacial da grandeza com resolução limitada e desta forma somente a estrutura macroscópica pode ser identificada. Resolver estruturas pequenas requer resolução espacial grande, o que nem sempre está disponível.

A análise espectral em conjunto com os diagnósticos multicanais permitem a visualização do comportamento das componentes de frequência dos sinais medidos com relação ao tempo e ao espaço, fornecendo uma visão fenomenológica importante da física das instabilidades MHD presentes num plasma de tokamak. As análises de sinais multicanais, como comumente encontradas em tokamaks, podem fornecer uma melhor compreensão das relações entre as grandezas nas posições investigadas e permitem estimar as propriedades espaciais de interesse.

\subsubsection{Modelo de sinais}

A maneira mais simples de modelar um sinal multicanal é considerar que o sinal de cada canal individualmente é composto por amostras tomadas simultaneamente entre todos os canais e distribuídas de alguma maneira fixa no espaço. Desta forma podemos escrever:

$$
x_{j n}=x_{j}(t) \delta\left(t-n T_{s}\right)
$$

onde $x_{j n}$ é a matriz com $j$ linhas e $n$ colunas que representa os dados tal que $j$ é o índice espacial que especifica o canal e $n$ é o índice que especifica a amostra no tempo, $T_{s}$ é o período de amostragem e $x_{j}(t)$ é o valor da grandeza física no instante $t$ para o j-ésimo canal. Essa equação pode ser entendida como uma matriz onde cada linha representa as amostras temporais para um canal específico. A figura 32 mostra esquematicamente a representação matricial de um sinal multicanal. Um elemento $x_{j n}$ representa a n-ésima amostra temporal para o j-ésimo canal.

Sinais de vários instrumentos utilizados para diagnóstico de plasmas em tokamaks podem ser modelados desta forma, como são os casos das bobinas de Mirnov em que a 


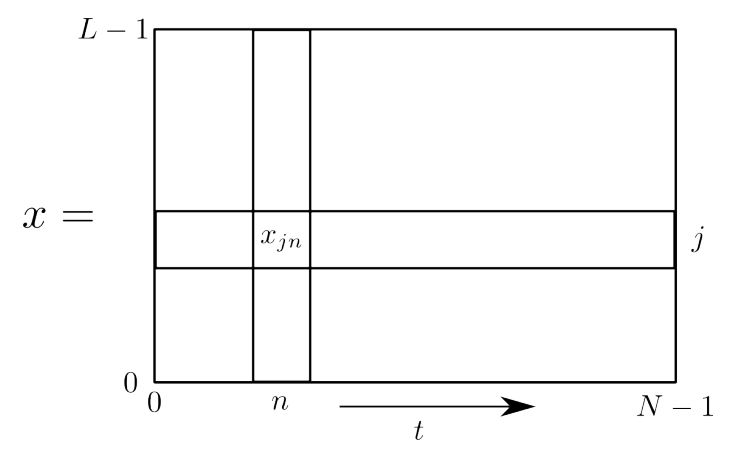

Figura 32 - Representação matricial de um sinal multicanal.

amostragem espacial está distribuída angularmente ao redor do plasma, diagnóstico de raios-X moles e bolômetro que mapeiam pontos do perfil radial da emissividade do plasma em diferentes comprimentos de onda.

\subsubsection{Análise espectral de sinais multicanais}

Uma das práticas comuns na análise de dados multicanais é o emprego de técnicas para análise de sinais simples para cada canal individualmente. Por exemplo, pode-se aplicar a STFT em cada canal independente, conforme ilustrado na figura 33. Um ponto importante é que a aplicação da STFT causa uma explicitação da coordenada de frequência, além do tempo. Desta forma, a matriz que representa o conjunto se torna tridimensional. Salienta-se que, analogamente ao caso de dados simples, nenhuma informação nova é criada, ocorre apenas uma mudança na representação do conjunto de dados.

Utilizando a expressão $\left|X_{j}(\omega, t)\right|=\sqrt{\operatorname{Re}^{2}\left\{X_{j}(\omega, t)\right\}+\operatorname{Im}^{2}\left\{X_{j}(\omega, t)\right\}}$, onde $j$ é o índice da série ou canal, podemos obter os espectros de potência do sinal individualmente para cada canal, conforme representação esquemática mostrada na figura 34.

E de modo análogo, podemos proceder o cálculo da fase relativa entre os sinais para cada índice de tempo e frequência, utilizando a expressão que fornece o ângulo do complexo na notação polar $\Theta_{j}(\omega, t)=t g^{-1}\left(\operatorname{Im}\left\{X_{j}(\omega, t)\right\} / \operatorname{Re}\left\{X_{j}(\omega, t)\right\}\right)$ para obter o argumento do elemento da matriz $X_{j}$. A diferença em relação ao caso da magnitude é que o ângulo do complexo, na notação polar, não tem significado físico. Porém, fixando um canal como referência, a diferença entre $\Theta_{j}$ e $\Theta_{\text {ref }}$ carrega a noção de atraso de fase entre os sinais dos respectivos canais, conforme mostrado na figura 35.

Salienta-se que essa diferença de fase depende da frequência e do tempo. Ou seja, cada componente de frequência tem sua própria defasagem em relação à componente de mesma frequência do canal de referência. Ademais, todas as outras operações definidas para sinais simples podem ser aplicadas a canais individualmente de forma análoga ao exemplificado com a STFT. 


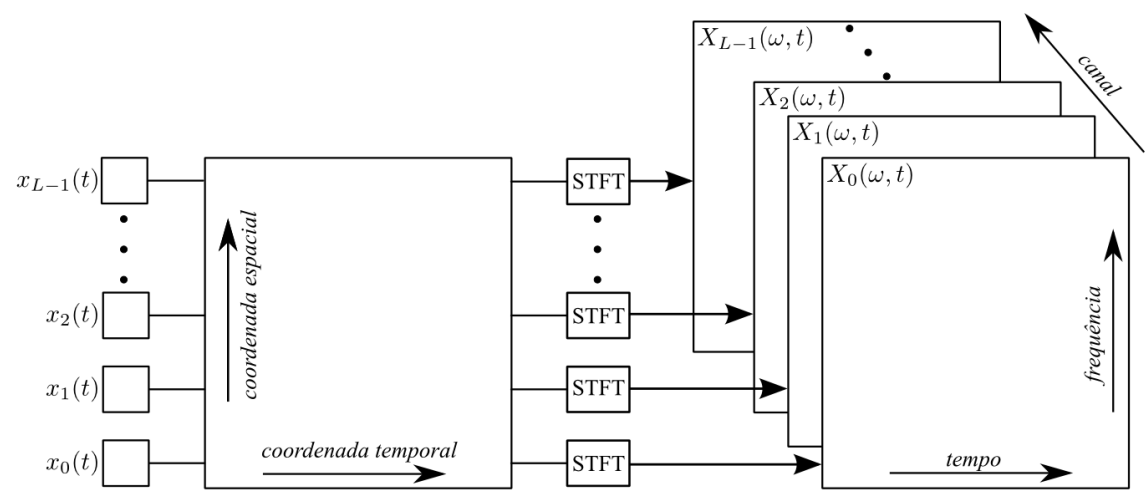

Figura 33 - Diagrama esquemático da análise espectral em sinais multicanais.

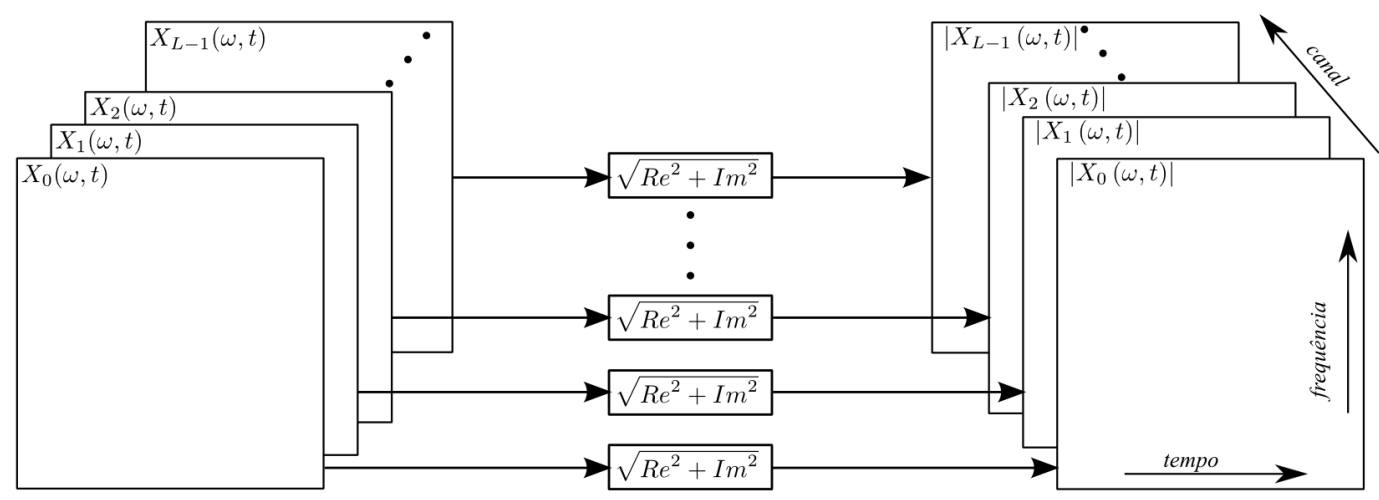

Figura 34 - Diagrama esquemático do cálculo da potência espectral em sinais multicanais.

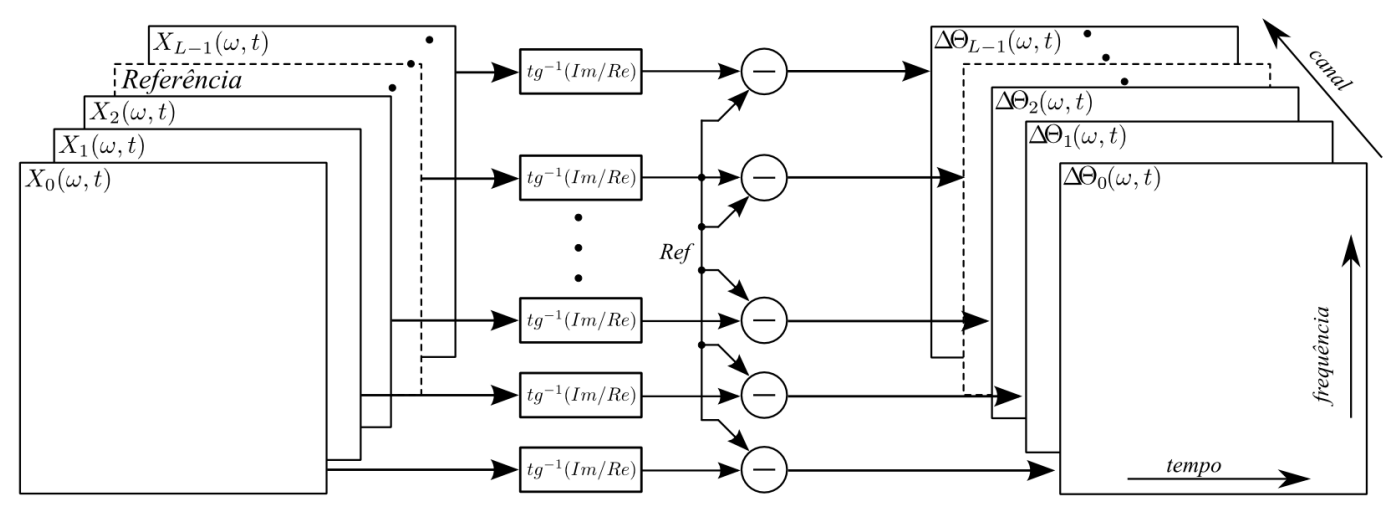

Figura 35 - Diagrama esquemático do cálculo da fase relativa em sinais multicanais.

\subsubsection{Visualização de dados multicanais}

A visualização de dados multicanais não representa um problema quando se está trabalhando no domínio do tempo. Esta tarefa pode ser efetuada plotando simultaneamente todos os sinais em um mesmo gráfico ou plotando em gráficos separados com o eixo do 
tempo sincronizado. Porém, utilizando a STFT ou métodos que forneçam na saída matrizes de valores para cada canal, a visualização conjunta dos dados não é possível.

Uma forma viável de visualização é efetuar a segmentação dos dados de maneira que a informação de interesse possa ser plotada em um gráfico único. Foram empregados neste trabalho quatro formas de visualização, como representadas na figura 36. A segmentação mais simples é aquela efetuada por canal, mostrado em (a) que é equivalente a visualização de uma série de dados única. Outra forma é fixar um parâmetro e tomar todos os dados de todos os espectros que correspondam a este parâmetro. Esta situação está mostrada em (b) para o caso do parâmetro um intervalo de tempo e em (c) para o caso do parâmetro banda de frequências.

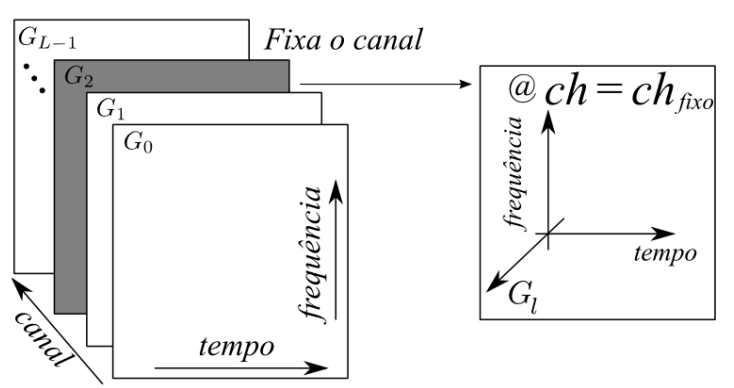

(a)

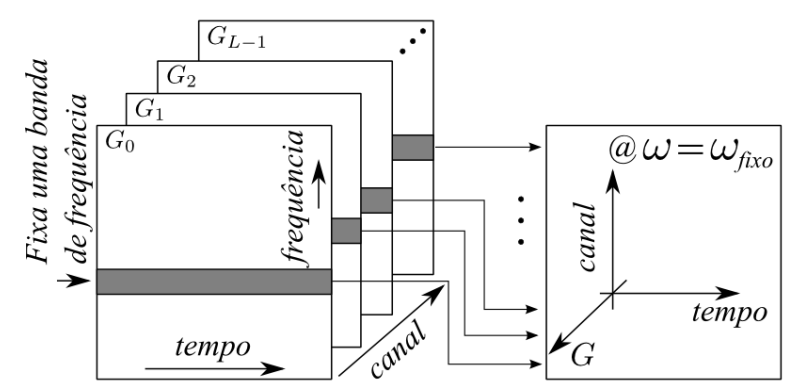

(c)

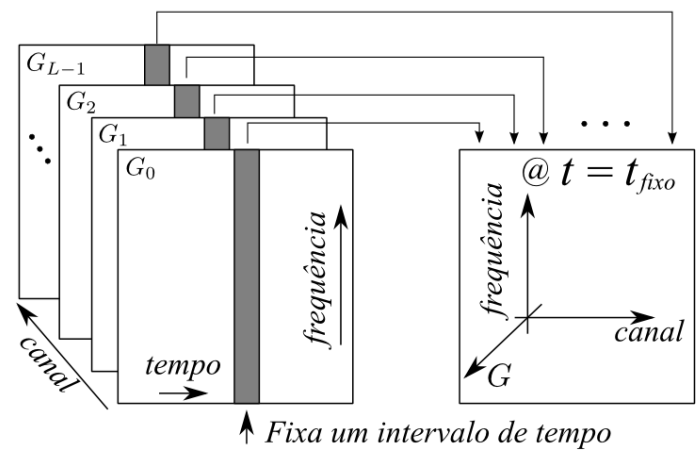

(b)

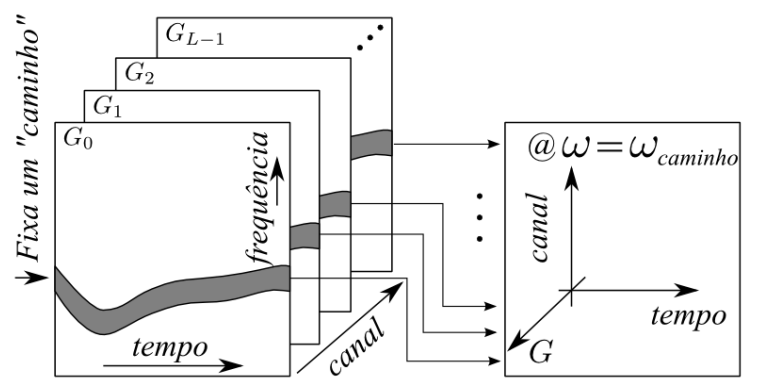

(d)

Figura 36 - Formas de visualização das análises espectrais multicanais.

Uma maneira interessante de segmentação consiste em definir um caminho sobre o plano frequência $\times$ tempo e selecionar os dados dos espectros que correspondam as posições. O termo caminho deve ser entendido como uma banda de frequências que evolui no tempo. O emprego desta forma de segmentação é útil quando a frequência característica do processo físico não é estacionária. 


\section{Análises e resultados}

O estudo experimental da atividade MHD num plasma de tokamak é uma tarefa complexa devido a natureza multicanal dos sinais produzidos pelos diversos diagnósticos e também devido a necessidade de se empregar massivamente técnicas computacionais como as apresentadas no capítulo 4. Em geral, a visualização dos resultados depende da escolha das características de interesse dentro dos dados disponíveis. Entre as principais características estudadas estão a decomposição das oscilações em termos das componentes temporais (frequências) e espaciais (números de onda), intensidade relativa e localização espacial dos sinais produzidos pelos diagnósticos disponíveis no TCABR, apresentados no capítulo 3, juntamente com a interpretação física destas características.

O estudo da frequência e intensidade das perturbações medidas foi efetuado pela construção dos espectrogramas de potência dos sinais produzidos pelas bobinas de Mirnov e SXR, utilizando a STFT. A determinação dos números de onda poloidal foi realizada pelo emprego das técnicas espectrais no domínio do tempo e pelo ajuste pelo método dos mínimos quadrados (MMQ) no domínio espacial, pois este método permite tratar sinais com amostragem não uniforme como é o caso das posições angulares das bobinas sensoras no referencial do plasma, diferentemente dos métodos baseados na transformada de Fourier que exigem que as amostras estejam igualmente espaçadas. Serão discutidos os efeitos da correção devida à geometria toroidal (correção de Merezhkin) e realizada uma estimativa numérica sobre o parâmetro de correção médio que atende satisfatoriamente a maioria das análises para algumas situações de interesse. A partir destes resultados, são apresentados estudos sobre a evolução temporal dos modos MHD poloidais e sobre os acoplamentos dos modos, i.e. ilhas com diferentes números de onda mas mesma frequência, que são corriqueiramente observadas no TCABR e outros tokamaks.

\subsection{Perturbações magnéticas medidas pelas bobinas de Mirnov}

Na seção 2.3.3.1 foi apresentado um modelo de perturbação genérico que pode ser aplicado para o campo magnético poloidal de equilíbrio, de maneira que podemos escrever esta perturbação da forma $\tilde{B}_{\theta}\left(\theta_{k}, t\right)=\left|\tilde{B}_{\theta}\right| e^{-i(m \theta+n \varphi-\omega t)}$, cuja parte espacial apenas na direção poloidal (i.e, para um determinado tempo e posição toroidal) pode ser escrita como um sistema linear na forma $\mathbf{Y}=\mathbf{X A}$, onde $\mathbf{Y}$ é um vetor contendo informações coletadas em diversas posições, $\mathbf{A}$ são os autovalores de pesos da base $\mathbf{X}$, onde $\mathbf{X}$ é a matriz de autovetores da base de Fourier, dado por:

$$
\mathbf{X}_{k l}=e^{-i m_{k} \theta^{\prime} l}
$$


Note que, se $\theta^{\prime}{ }_{l}$ é tomado em intervalos regulares, resolver este sistema linear é equivalente a obter a DFT dos sinais no domínio espacial. De fato, as operações matriciais descritas acima resumem a aplicação do método dos mínimos quadrados, ajustando os valores dos pesos $\mathbf{A}$ que, se multiplicados por $\mathbf{X}$, retornam os valores $\mathbf{Y}$. Considerando a correção de Merezhkin dado pela expressão (3.2), obtemos $\theta_{l}^{\prime}=\theta_{l}^{*}=\theta_{l}-\lambda \sin \left(\theta_{l}\right)$, onde $\theta_{l}$ é a posição da l-ésima bobina de Mirnov no referencial do laboratório. Resolvendo este sistema linear obtemos $\mathbf{A}=\left(\mathbf{X}^{T} \mathbf{X}\right)^{-1} \mathbf{X}^{T} \mathbf{Y}$, que fornece o vetor com as intensidades dos modos $m$. Se o vetor $\mathbf{Y}$ for o vetor da transformada de Fourier dos sinais nas diferentes bobinas para uma dada componente de frequência $f^{\star}$, o resultado obtido para A irá corresponder à decomposição espacial em número de onda $(m)$ para a frequência $f^{\star}$. Fazendo-se o mesmo para todas as frequências obtidas na transformada de Fourier dos sinais, obtêm-se uma matriz $\mathbf{A}=\mathbf{A}(m, f)$, cujos módulos ao quadrado correspondem à densidade espectral associada a cada modo $m$ em cada frequência $f$. Devido à correção de Merezhkin, essas intensidades dependem do valor da constante $\lambda$ adotada. Os critérios para a definição do $\lambda$ e o efeito dessa dependência serão discutidas nas análises a seguir.

Para ilustrar o emprego deste método de análises, considerou-se o estudo das decomposições de modos para o disparo \#28661 do TCABR, cujas variáveis de equilíbrio encontram-se reproduzidas nos gráficos da figura 37. A corrente de plasma é de aproximadamente $I p=83 \mathrm{kA}$, apresentando um platô no intervalo entre $45 \sim 90 \mathrm{~ms}$, com densidade $n_{e}=1,8 \times 10^{19} \mathrm{~m}^{-3}$, apresentando baixa emissão de raios-X duros e intensidade baixa das perturbações magnéticas medidas pelas bobinas de Mirnov.
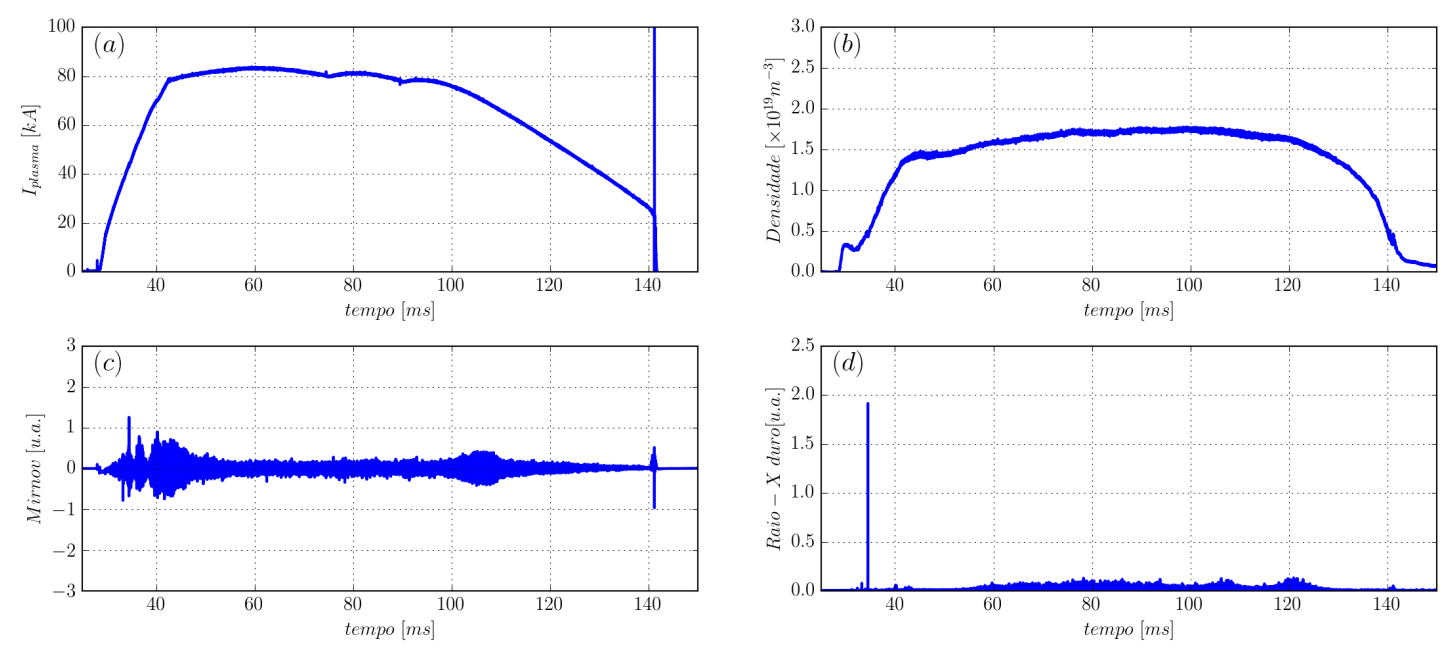

Figura 37 - Variáveis de equilíbrio para o disparo \#28661 do TCABR. Com corrente de plasma em (a), densidade central em (b), sinal da bobina de Mirnov de referência em (c) e sinal da emissão de raios-X duros em (d).

Os gráficos da figura 38 mostram a aplicação da análise da intensidade modal para os sinais das bobinas de Mirnov para o disparo \#28661 do TCABR. 

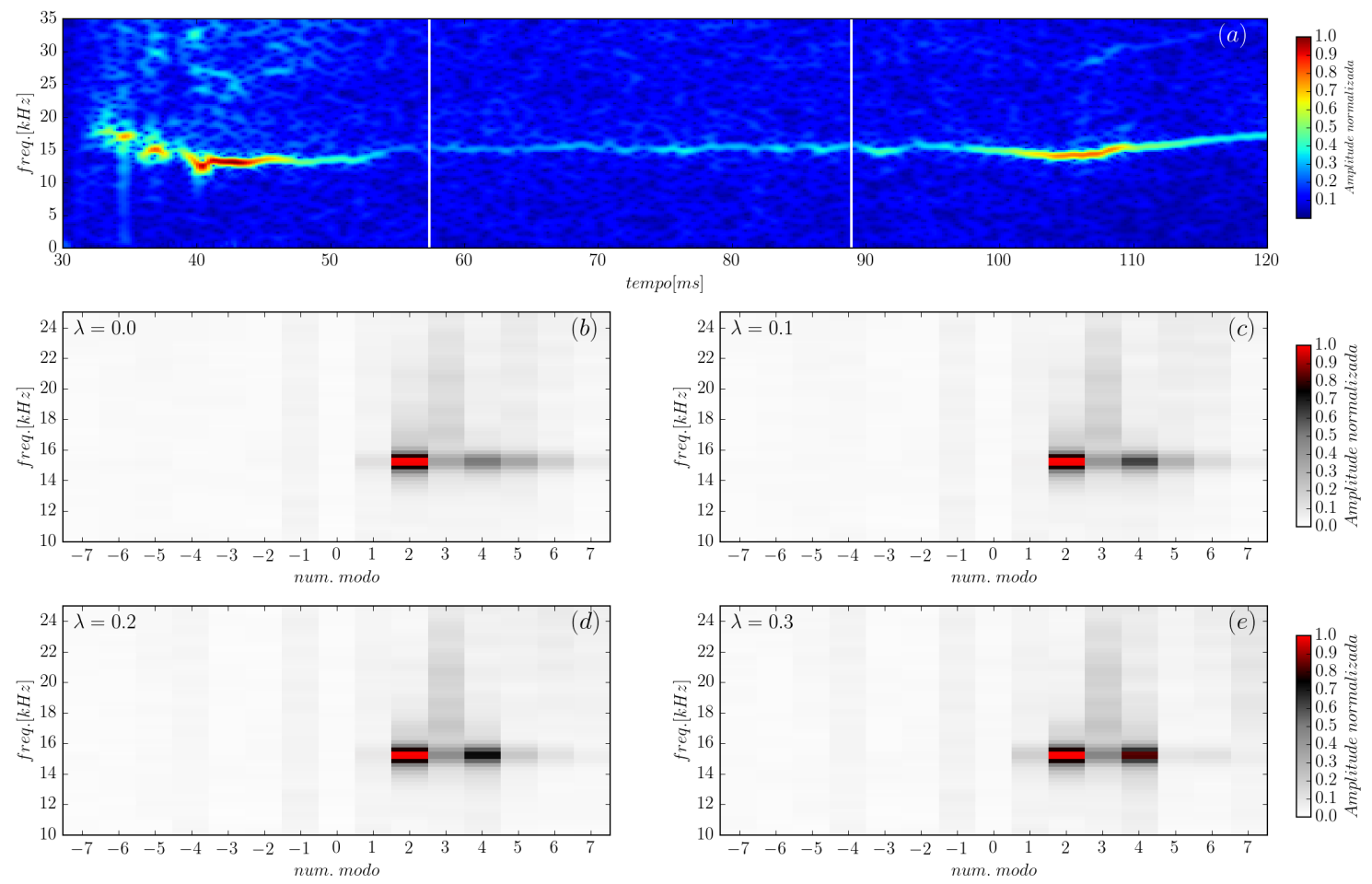

Figura 38 - Número de onda poloidal e frequência do modo para o disparo \#28661 do TCABR. Em (a) o espectrograma de potência médio de todas as 24 bobinas, em (b) até (e) frequência por modo de oscilação para os valores de $\lambda$ indicados.

Em (a) é mostrado o espectrograma das perturbações magnéticas medidas pelas bobinas de Mirnov, cuja característica marcante é a presença de atividade MHD de baixa intensidade, com frequência estimada de $f=(15,4 \pm 0,2) \mathrm{kHz}$, no intervalo de 57 à $89 \mathrm{~ms}$ (correspondente ao platô de densidade e corrente de plasma), conforme indicado pela linhas brancas no gráfico. Em (b) até (e) estão apresentados a distribuições médias dos modos $m$ por frequência de oscilação para valores de $\lambda=0$ até $\lambda=0,3$. Observa-se nas figuras 38(b-e) que estão presentes os modos $m=2$ e $m=4$ e que ambos apresentam a mesma frequência de oscilação. O parâmetro $\lambda$ não influencia na frequência pois age somente sobre a parcela espacial da perturbação. Os gráficos também revelam a ausência dos modos $m<0$ (correspondentes à propagação no sentido de $\theta$ decrescente).

A figura 39 mostra a decomposição em número de onda da amplitude dos modos na faixa de frequência indicada, para o mesmo disparo mostrado na figura 38.Em (a) está repetido o espectrograma médio dos sinais das bobinas de Mirnov, assinalado o mesmo intervalo de 55 à $98 \mathrm{~ms}$. Em (b) até (e) são mostrados os histogramas das amplitudes dos modos MHD médios para valores de $\lambda=0$ até $\lambda=0,3$, no intervalo de tempo considerado e para a banda de frequências assinalada pelas linhas tracejadas em branco no espectrograma.

Os histogramas mostram a presença de uma ilha dominante com $m=2$ e uma ilha de menor intensidade com $m=4$. Para os valores de $\lambda$ considerados, a intensidade relativa 

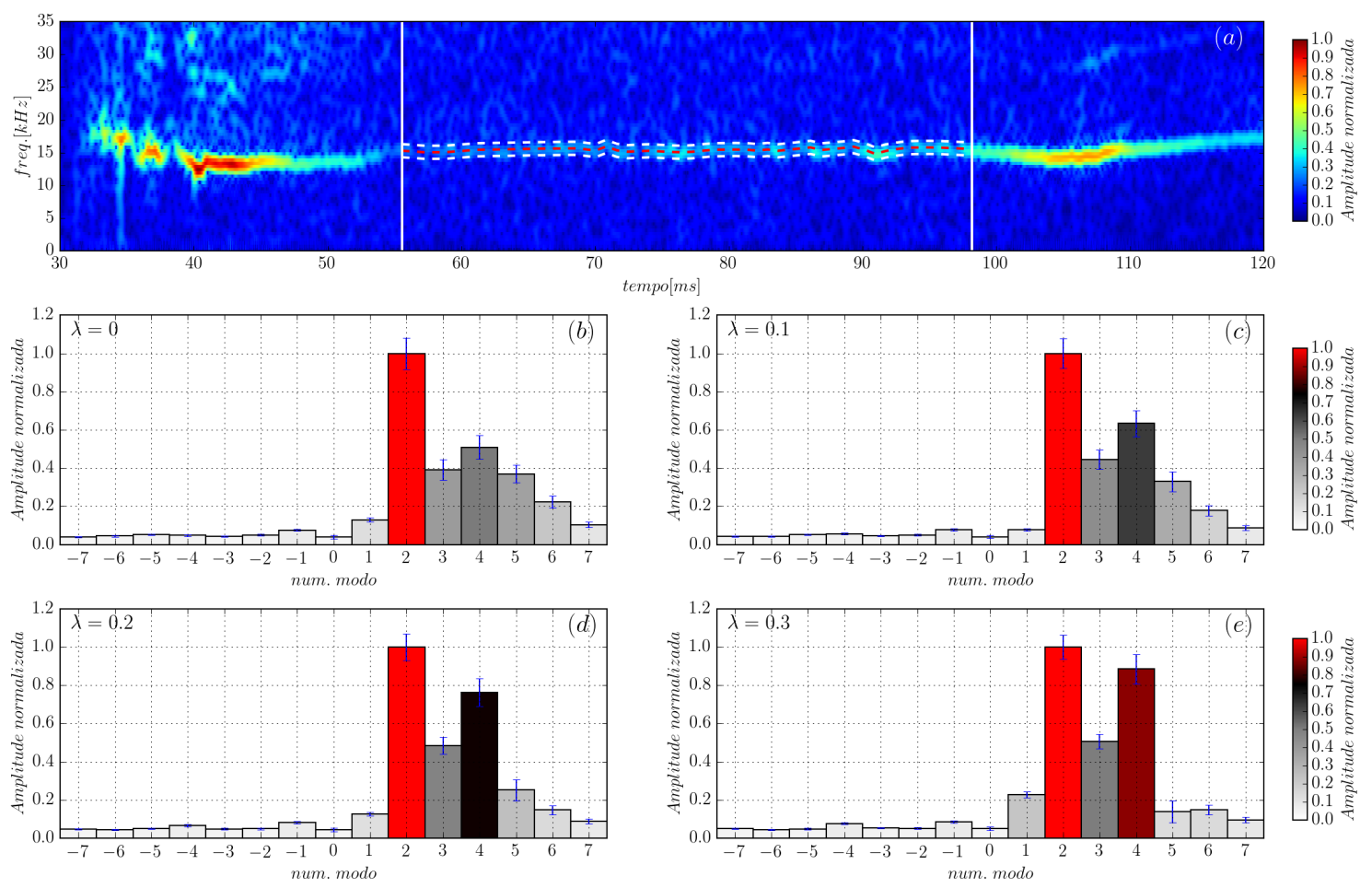

Figura 39 - Determinação dos número de onda poloidal para o disparo \#28661 do TCABR. Em (a) o espectrograma de potência médio de todas as 24 bobinas, em (b) até (e) histogramas de amplitude relativa por modo de oscilação para os valores de $\lambda$ indicados.

entre os sinais referentes à ilha $m=4$ em relação à intensidade do sinal da ilha variam, mas a componente $m=2$ é sempre a dominante. Apesar de não alterar a dominância entre os modos, a variação de $\lambda$ causou uma alteração significativa nas intensidades relativas. Da mesma maneira, como verificado nos modeogramas apresentados na figura 38, não foram detectados modos MHD com $m<0$. O sinal de $m$ é interpretado fisicamente como o sentido de rotação das ilhas na direção poloidal e neste caso, indicam que as ilhas presentes no disparo \#28661 estão girando no mesmo sentido de $\theta$ crescente. As incertezas nas amplitudes dos modos foram obtidas através do desvio padrão da média dos valores de amplitude por modo de oscilação, dentro do intervalo analisado, sendo que ficaram em torno de $5 \%$ do valor da amplitude, para este disparo.

\subsubsection{Determinação do parâmetro $\lambda$.}

Como visto no exemplo do disparo \#28661, o parâmetro $\lambda$ exerce pouca influência sobre a composição dos modos, mas a intensidade relativa entre os modos sofre alterações significativas. Em primeira aproximação, o parâmetro $\lambda$ é dado pela relação $r / R_{0}$, como explorado na seção 3.2. Sabendo que as ilhas habitam as superfícies racionais $q=m / n$, podemos determinar o valor mais adequado para $\lambda$ para cada modo de oscilação conhecendo a posição radial da respectiva superfície magnética, como desenvolvido na seção 2.3.2. 
A figura 40 apresenta um estudo numérico da posição das superfícies racionais utilizando a equação (2.18) no intervalo de $r=0$ até $r=a=0,18$, valores reais para o TCABR (vide tabela 1 ).
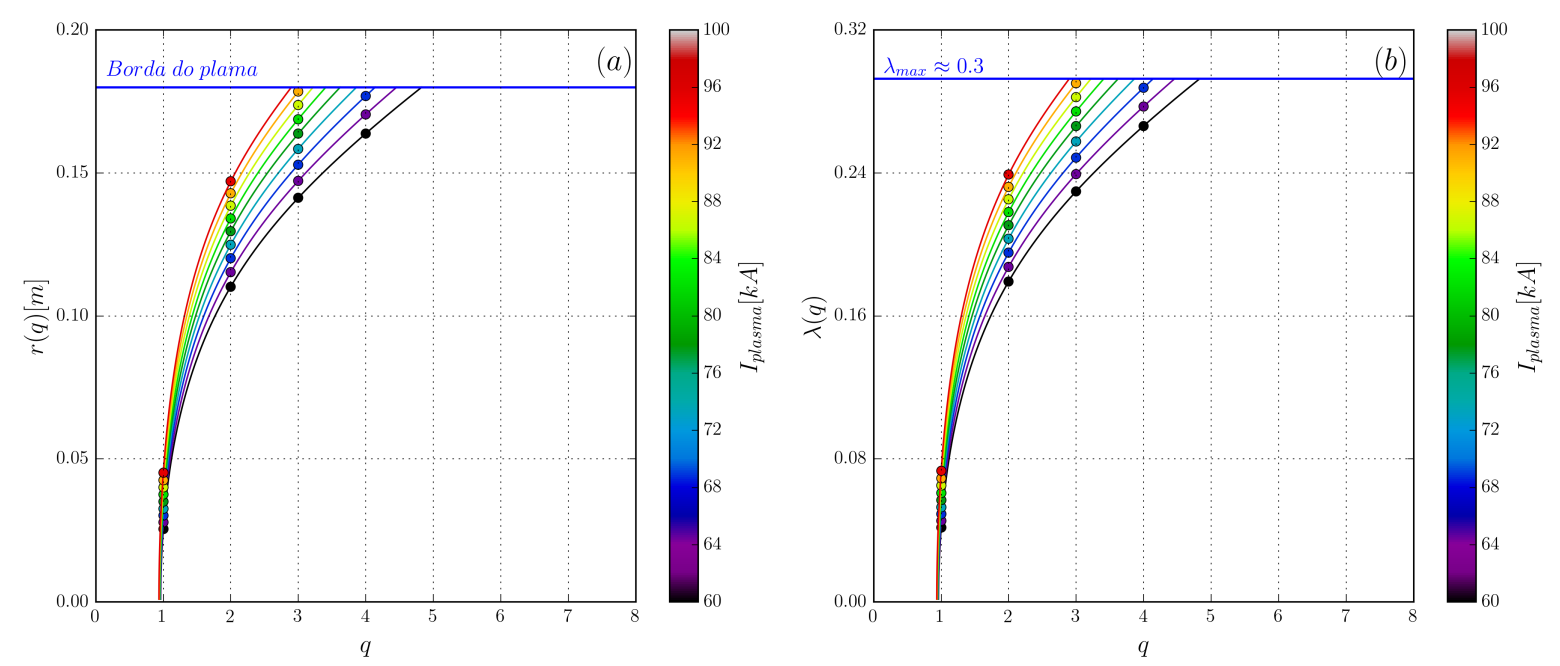

Figura 40 - Determinação do parâmetro $\lambda$ para correção dos ângulos no referencial do plasma, utilizando o modelo parabólico para densidade de corrente da expressão (2.18). Em (a) curva da posição das superfícies magnéticas $r$ em função do fator de segurança $q$ e em (b) os valores da correção de Merezhkin $\lambda$ em função de $q$.

O gráfico em 40(a) mostra a posição das superfícies magnéticas em função do fator de segurança $q$ para uma faixa de correntes típicas do TCABR, codificada pela escala de cores. Os valores das posições radiais das superfícies racionais $\left(r_{s}\right)$ para $q=(1,2,3, \ldots)$ foram obtidos por interpolação na curva $q(r)$ e estão indicadas pelas bolas coloridas no gráfico 40(a). O gráfico 40(b) mostra a curva de $\lambda=r / R_{0}$ com as bolas coloridas nas posições $q_{s}$ referentes às superfícies racionais. Do exposto, conclui-se que o valor da correção utilizando o modelo de perfil parabólico para a densidade de corrente, depende da corrente de plasma e do número de onda poloidal. Desta forma, descartando os valores para a superfície racional $q=1$, cujas perturbações não são detectadas pelas bobinas de Mirnov, podemos estimar o parâmetro de correção tomando a média dos valores de $\lambda$ obtidos para as superfícies racionais $q=(2,3,4, \ldots)$. O valor médio encontrado é de $\lambda_{\text {medio }}=(0,25 \pm 0,03)$ para os modos internos que não estão localizados na borda do plasma. Para os modos de borda, a melhor estimativa da posição radial é o próprio raio do plasma $(r=a)$ e portanto o melhor valor de correção é $\lambda=0,3$.

\subsubsection{Estudo dos modos múltiplos.}

Em algumas situações não podemos afirmar qual é o modo dominante, pois a intensidades das perturbações medidas pelas bobinas de Mirnov para dois ou mais modos de oscilação são semelhantes. Neste caso os modos são co-dominantes, dentro da incerteza experimental. 
Para ilustrar este caso, considerou-se o estudo dos modos para o disparo \#27000 do TCABR, cujas variáveis de equilíbrio encontram-se reproduzidas nos gráficos da figura 41. A corrente de plasma é de aproximadamente $I p=83 k A$, apresentando um platô no intervalo entre $45 \sim 90 \mathrm{~ms}$, com densidade $n_{e}=1,8 \times 10^{19} \mathrm{~m}^{-3}$, apresentando baixa emissão de raios-X duros e intensidade baixa das perturbações magnéticas medidas pelas bobinas de Mirnov.
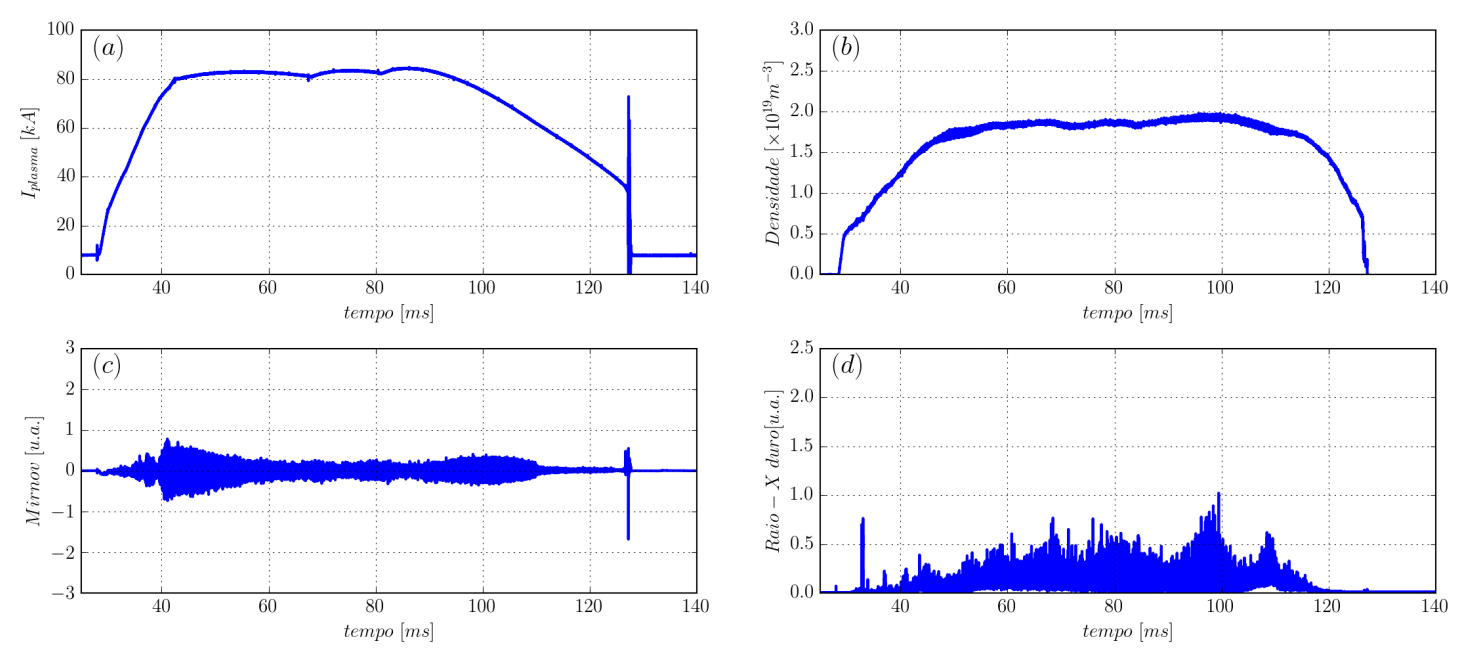

Figura 41 - Variáveis de equilíbrio para o disparo \#27000 do TCABR. Com corrente de plasma em (a), densidade central em (b), sinal da bobina de Mirnov de referência em (c) e sinal da emissão de raios-X duros em (d).

A figura 42(a) mostra o espectrograma médio de potência dos sinais das bobinas de Mirnov, cuja característica marcante é a presença de uma componente de frequência $f=(15,3 \pm 0,5) \mathrm{kHz}$ aproximadamente constante no intervalo $\Delta t=55 \sim 79 \mathrm{~ms}$. Em (b) é mostrado a decomposição dos modos MHD no intervalo considerado e verifica-se a existência dos modos $m=4$ e $m=2$, sendo que a intensidade do modo $m=2$ é muito próxima da do modo $m=4$. A incerteza experimental da intensidade das perturbações medidas pelas bobinas de Mirnov para estes modos ficou em torno de 10\%, no intervalo considerado, de forma que não é possível afirmar que um dos modos é dominante sobre os demais.

O histograma da figura 42(b) também indica a presença de modos com $m=3$ e $m=5$ com intensidades relativas significativamente menores que as do modo $m=4$. O parâmetro utilizado para a correção de Merezhkin foi de $\lambda=0,25$. Novamente não foram encontrados modos com $m<0$, o que indica que a rotação dos modos presentes no plasma estão todos no mesmo sentido.

Uma situação bastante semelhante ocorre com o disparo \#30330, cujas variáveis de equilíbrio encontra-se na figura 43. Este disparo também apresenta um platô da corrente de plasma com valor de $I_{p}=80 \mathrm{k}$, no intervalo de 40 à $90 \mathrm{~ms}$, com densidade central de 

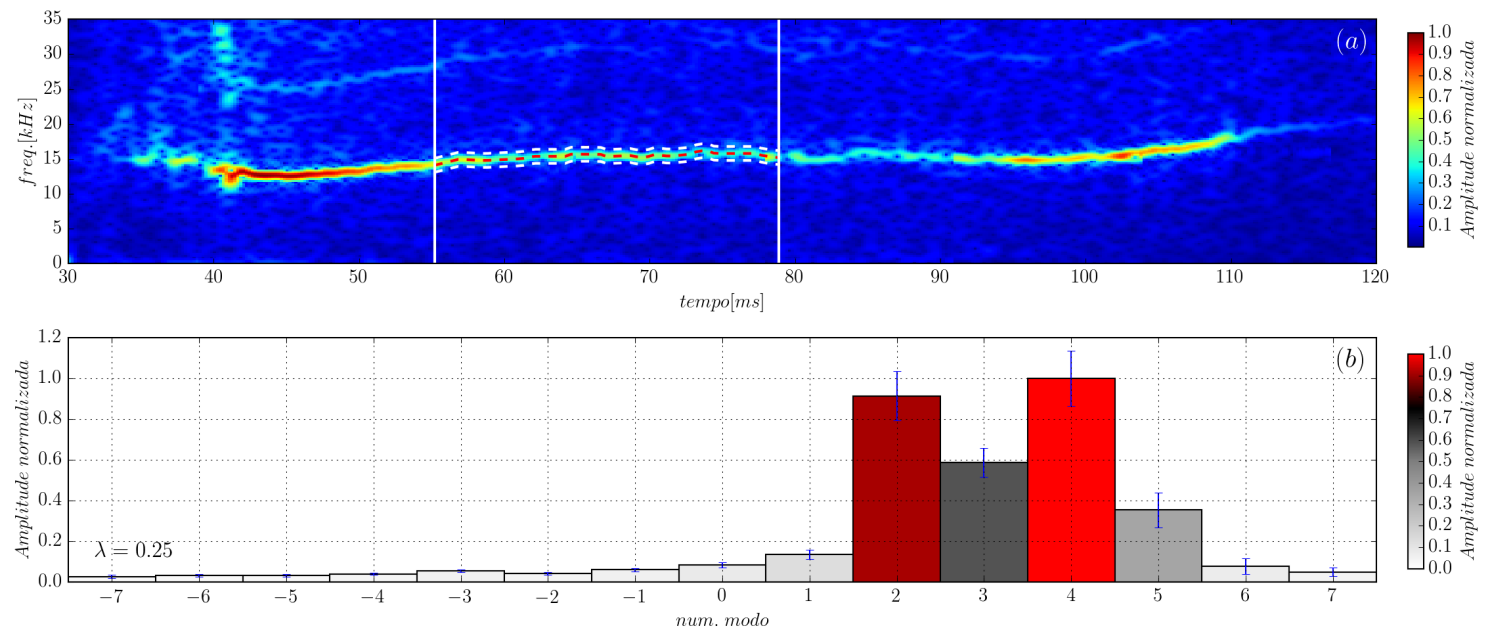

Figura 42 - Número de onda poloidal e frequência do modo para o disparo \#27000 do TCABR. Em (a) o espectrograma de potência médio de todas as 24 bobinas e em (b) o histograma de amplitude relativa por modo de oscilação para $\lambda=0,25$. A taxa de amostragem do sinal é $f_{s}=250 \mathrm{kHz}$.

$n_{e}=2,0 \times 10^{19} \mathrm{~m}^{-3}$, intensidade baixa dos sinais das bobinas de Mirnov e pouca emissão de raios-X moles.
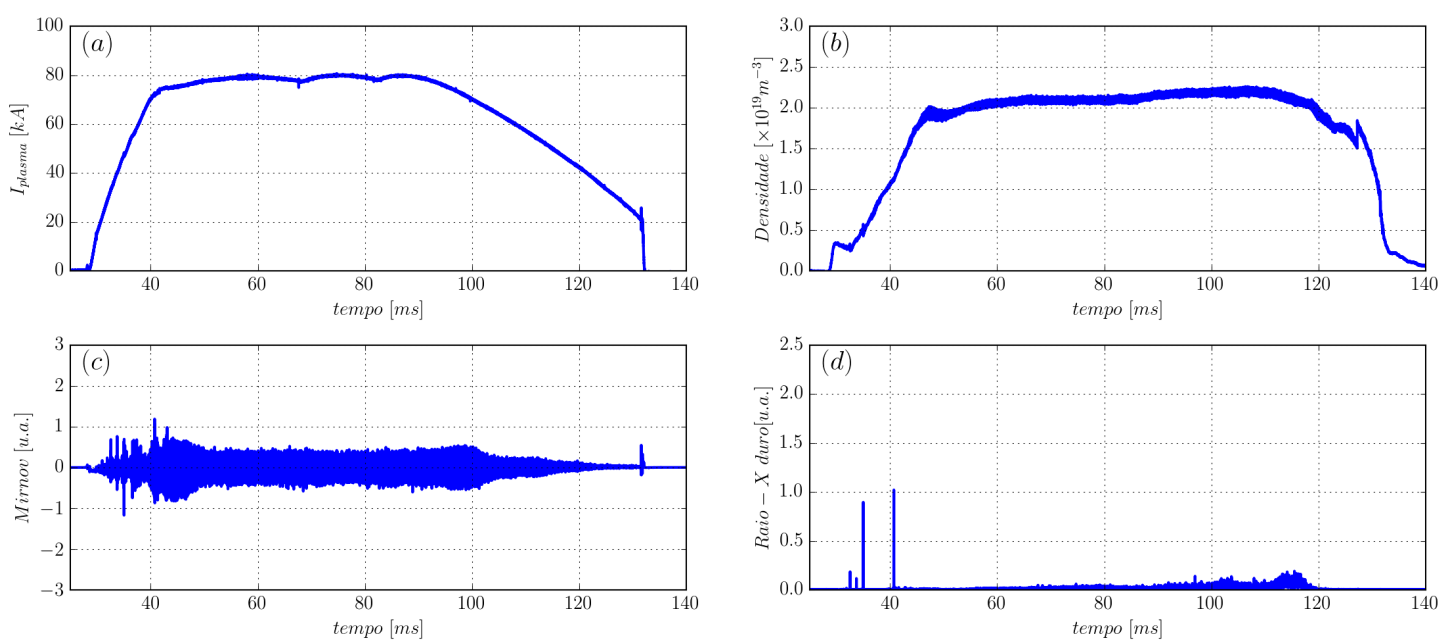

Figura 43 - Variáveis de equilíbrio para o disparo \#30330 do TCABR. Com corrente de plasma em (a), densidade central em (b), sinal da bobina de Mirnov de referência em (c) e sinal da emissão de raios-X duros em (d).

A figura 44 apresenta os resultados das análises de modo. No espectrograma em (a) pode ser notada a presença de uma componente de frequência de $f=(13,8 \pm 0,2) k H z$, aproximadamente constante no intervalo $\Delta t=57 \sim 83 \mathrm{~ms}$. O histograma em (b) indica a presença dos modos $m=2$ e $m=4$, sendo que a intensidade da ilha $m=2$ em relação a intensidade da ilha $m=4$ é cerca de $80 \%$. Também são encontrados os modos $m=3$ e $m=5$ com intensidades relativas bem menores. As incertezas experimentais, calculadas pelo desvio padrão da média das intensidades dos modos no intervalo considerado, ficaram 
em torno de 10\% do valor da intensidade do modo. Da mesma forma que no disparo \#27000, na decomposição dos modos para o disparo \#30330, não foram encontrados modos com $m<0$.
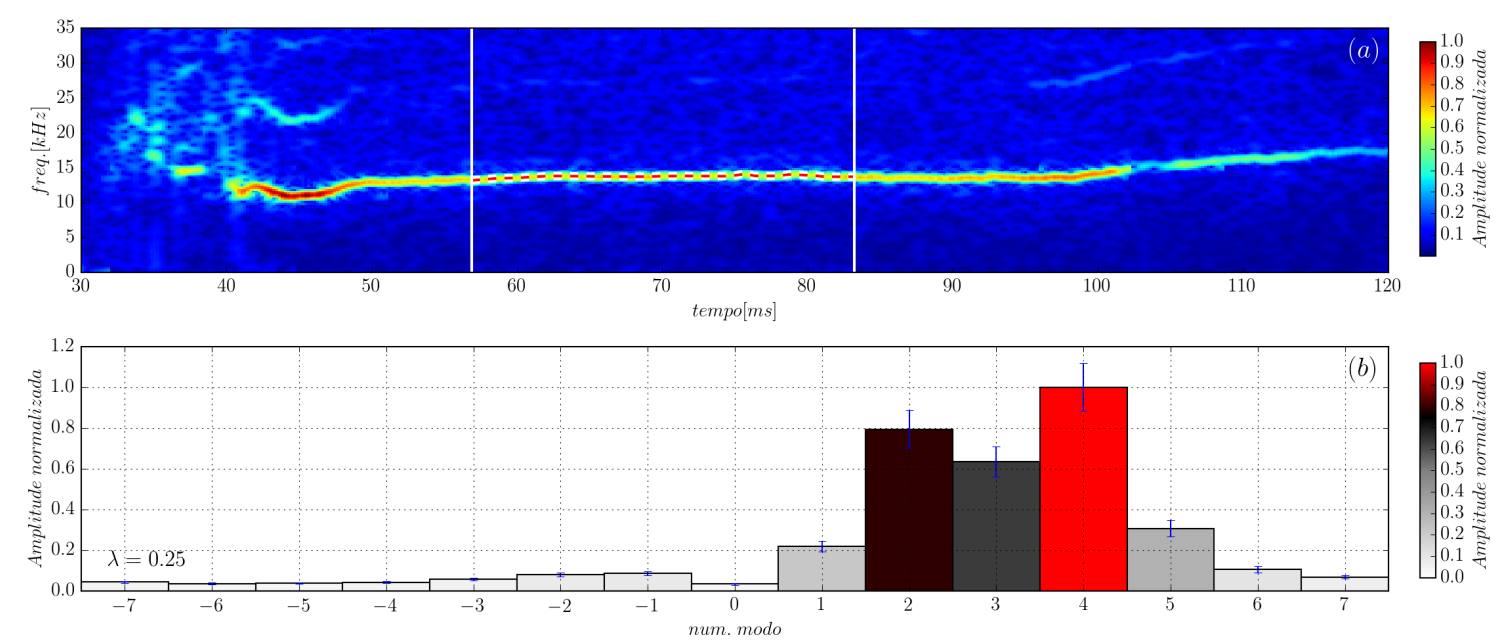

Figura 44 - Número de onda poloidal e frequência do modo para o disparo \#30330 do TCABR. Em (a) o espectrograma de potência médio de todas as 24 bobinas e em (b) o histograma de amplitude relativa por modo de oscilação para $\lambda=0.25$. A taxa de amostragem do sinal é $f_{s}=500 \mathrm{kHz}$.

Os disparos \#27000 e \#30330 são semelhantes nas condições de equilíbrio do plasma pois apresentam correntes, níveis de densidade centrais próximas e intensidades dos sinais das bobinas de Mirnov comparáveis em amplitude. As análises dos modos MHD para ambos os disparos resultaram em um conjunto de modos parecidos em termos de composição e amplitude dos modos.

Por outro lado, o disparo \#28400 apresenta corrente de plasma mais elevada que os disparos analisados anteriormente. As variáveis de equilíbrio para este disparo estão sumarizadas nos gráficos da figura 45. A corrente de plasma é plana no intervalo de 46 à $100 \mathrm{~ms}$ com valor de $I_{p}=90 \mathrm{k}$, densidade central de $n_{e}=0.9 \times 10^{19} \mathrm{~m}^{-3}$, perturbações magnéticas medidas pelas bobinas de Mirnov com forte intensidade e elevada emissão de raios-X duros.

O espectrograma médio dos sinais das bobinas de Mirnov mostram a presença de uma componente de frequência $f=(13,3 \pm 0,3) k H z$ em todo o tempo do platô de corrente, como pode ser visualizado no gráfico da figura 46(a). O espectrograma também mostra a presença de uma harmônica com frequência $f=(26,5 \pm 0,4) k H z$.

Com a análise dos modos de oscilação, obtém-se como resultados a identificação de uma ilha $m=3$ dominante e uma ilha $m=2$ com intensidade relativa à ilha $m=3$ de $80 \%$. As incertezas experimentais na intensidade dos modos ficou em aproximadamente $15 \%$, no intervalo $\Delta t=67 \sim 86 \mathrm{~ms}$. 

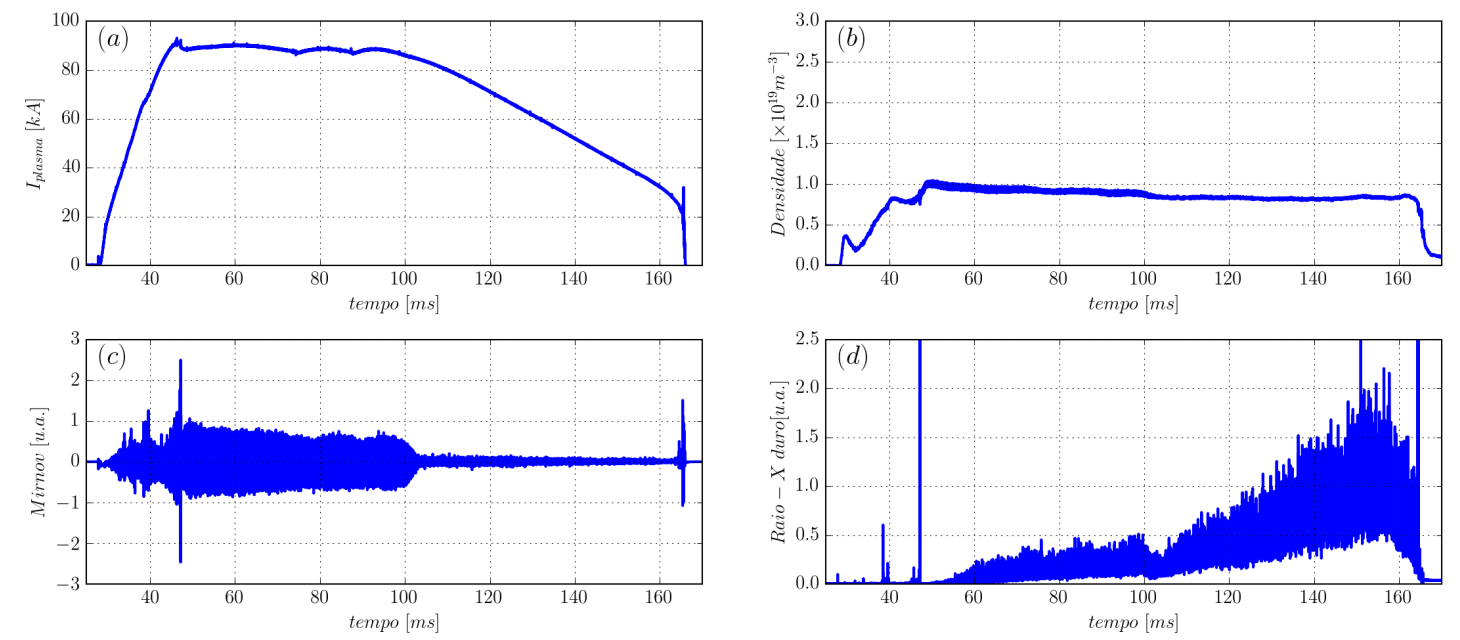

Figura 45 - Variáveis de equilíbrio para o disparo \#28400 do TCABR. Com corrente de plasma em (a), densidade central em (b), sinal da bobina de Mirnov de referência em (c) e sinal da emissão de raios-X duros em (d).
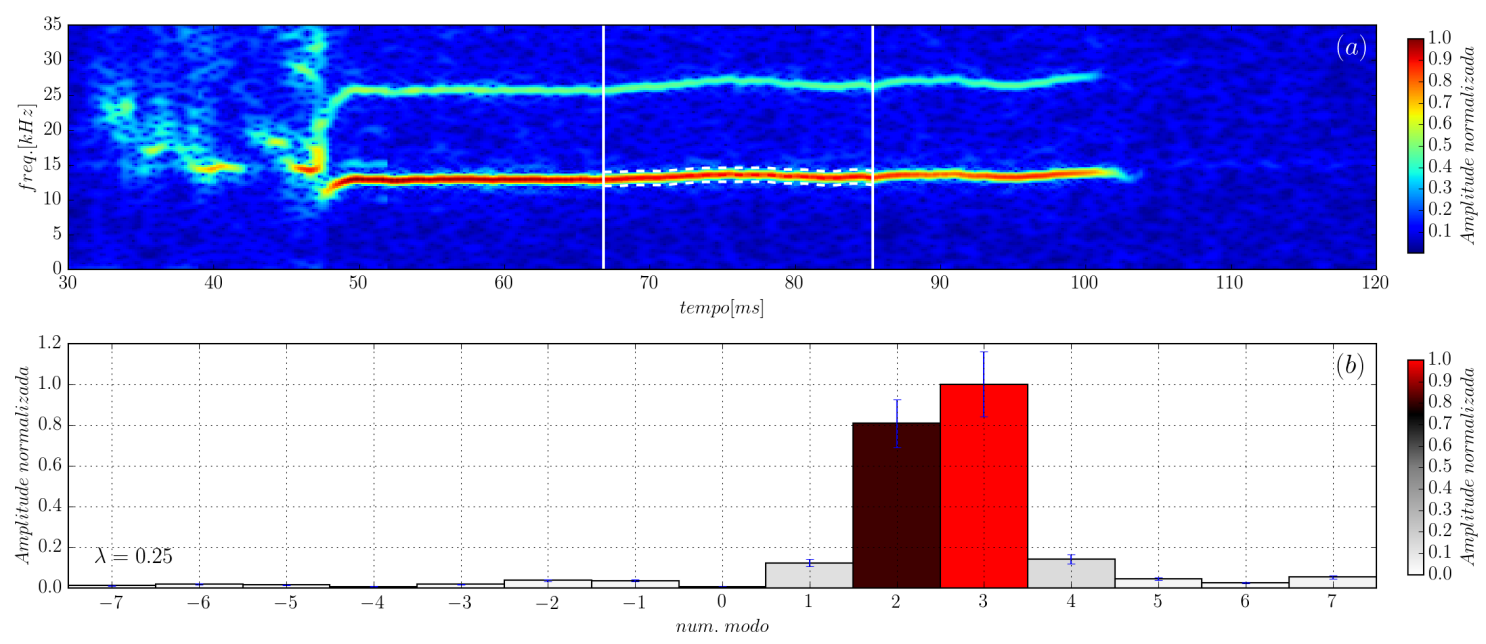

Figura 46 - Número de onda poloidal e frequência do modo para o disparo \#28400 do TCABR. Em (a) o espectrograma de potência médio de todas as 24 bobinas e em (b) o histograma de amplitude relativa por modo de oscilação para $\lambda=0,25$. A taxa de amostragem do sinal é $f_{s}=250 \mathrm{kHz}$.

Em termos de composição dos modos MHD, este conjunto de análises indica que, com o aumento da corrente de plasma, há uma supressão dos modos de oscilação mais altos. Nos exemplos, correntes na faixa de $80 k A$ permitem que a superfície magnética ressonante $q=4$ esteja presente no plasma e desta maneira, ilhas $m=4$ puderam ser detectadas. Com correntes da ordem de $90 k A$ foram detectadas ilhas $m=2$ e $m=3$ e, desta forma, a presença ou não de ilhas magnéticas com número de ondas específicos está em concordância qualitativa com o modelo de perfil de equilíbrio da densidade de corrente do plasma. Como mencionado na seção 2.3.2, vale frisar que o perfil parabólico é um modelo simples para situações de equilíbrio e, como visualizado nos resultados das 
análises dos casos estudados, a região de platô e as condições de equilíbrio do plasma são relativamente estáveis, embora as curvas de corrente de plasma e de densidade não sejam perfeitamente planas.

\subsubsection{Evolução temporal dos modos MHD}

Nos exemplos anteriores foram determinados a composição média dos modos MHD em períodos relativamente longos do disparo, correspondentes a região de platô da corrente de plasma. A partir deste estudo e supondo um modelo do perfil de corrente, foram feitas estimativas razoáveis do parâmetro de correção de Merezhkin e foi verificado que o modo com número de onda mais alto está relacionado com o fator de segurança na borda, este determinado pela corrente de plasma. Os resultados foram apresentados como comportamentos médios para disparos com frequência das ilhas aproximadamente constantes na região de platô. Num contexto mais geral, a frequência das ilhas e a magnitude das perturbações magnéticas medidas pelas bobinas de Mirnov podem variar durante o disparo e, desta forma, a análise média em janelas de tempo longas não fornece uma visão clara dos fenômenos físicos associados.

Para ilustrar a evolução temporal do comportamento dos modos MHD, a figura 47 mostra a decomposição dos modos para o disparo \#28661 fazendo análises médias em 20 janelas de tempo, de mesma largura no intervalo de 33 à $53 \mathrm{~ms}$, o que corresponde a uma largura de janela de $1 \mathrm{~ms}$, mais estreita que as janelas utilizadas nos exemplos anteriores. O intervalo de tempo foi escolhido para que cobrisse o início da formação da coluna de plasma (janela de 33 à $34 \mathrm{~ms}$ ) até a estabilização dos modos de oscilação, perto do início da região de platô de corrente (janela de 52 à $53 \mathrm{~ms}$ ). Os gráficos das variáveis de equilíbrio para este disparo estão mostrados na figura 37.

O comportamento médio na primeira janela, canto superior esquerdo da figura 47 no intervalo de 33 à $34 m s$ uma ilha $m=7$ pode ser observada, com frequência aproximada de $17 \mathrm{kHz}$. A análise do intervalo de tempo seguinte, entre 34 e $35 \mathrm{~ms}$ começa a mostrar a presença de uma ilha $m=6 \mathrm{com}$ frequência de oscilação variando conjuntamente com a ilha $m=7$, próximo à $18 k H z$.

Já no intervalo de 35 à $36 m s$ a ilha $m=7$ não está mais claramente visível, restando a ilha $m=6$ com $f \approx 17 \mathrm{kHz}$. O instante seguinte, de 36 à $37 \mathrm{~ms}$, mostra o surgimento de uma ilha $m=5$ compartilhando a frequência de oscilação com a ilha $m=6$ na frequência de $17 \mathrm{kHz}$, mas com frequência variando dentro do intervalo. Durante o intervalo entre 37 e $38 m s$ a ilha $m=5$ sofre um pequeno decremento na frequência de oscilação para $15 k H z$ e a ilha $m=6$ deixou de ser visível, permanecendo nesta situação no intervalo de 38 e $39 \mathrm{~ms}$. De 39 à $40 \mathrm{~ms}$ surge uma ilha $m=4 \mathrm{com}$ frequência igual a da ilha $m=5 \mathrm{e}$ as manchas escuras no gráfico correspondente indicam que a frequência de oscilação se tornou instável no intervalo. 

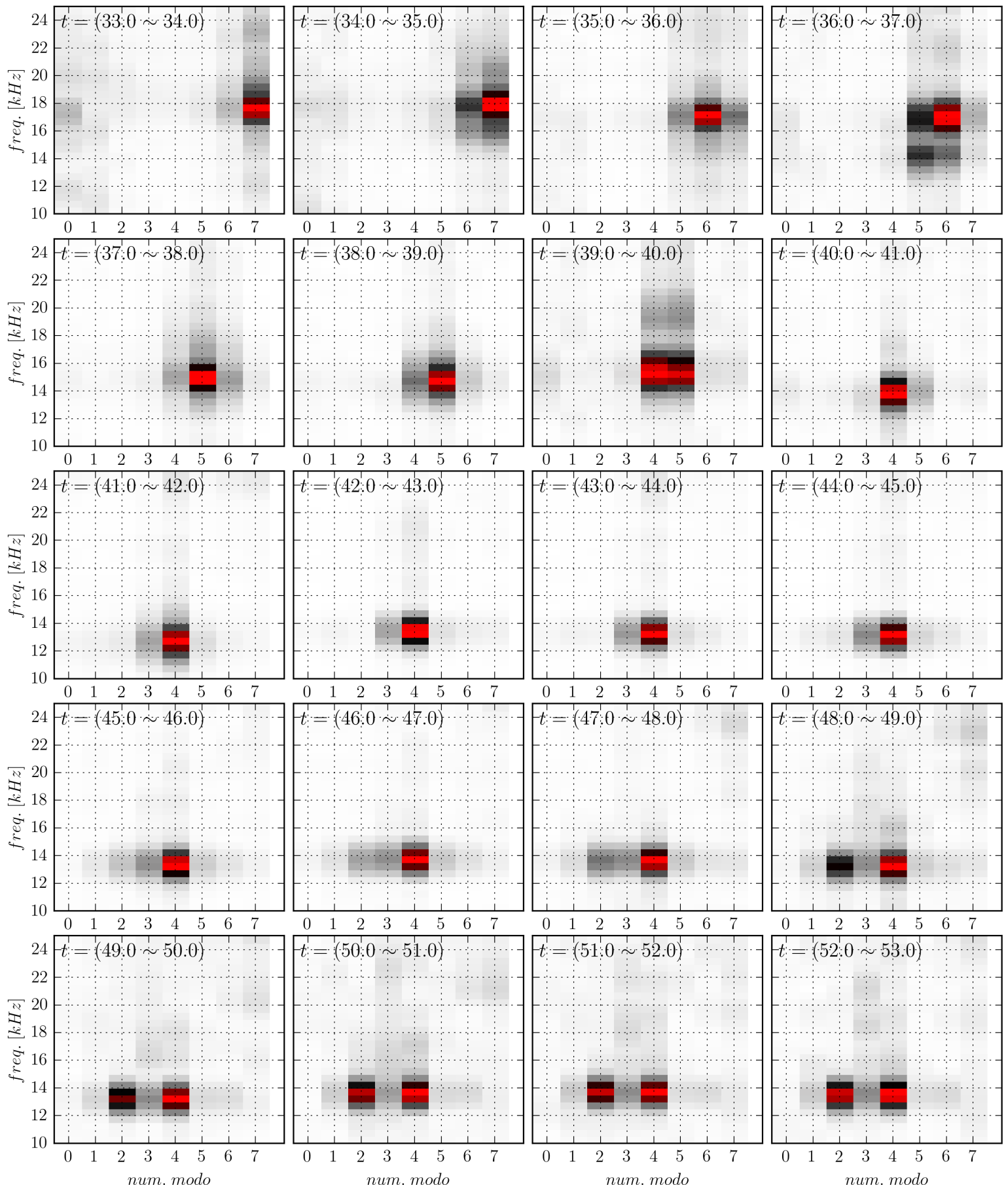

Figura 47 - Comportamento médio da frequência e número de onda das perturbações magnéticas medidas pelas bobinas de Mirnov para o disparo \#28661 em 20 intervalos de tempo de largura $1 \mathrm{~ms}$ no período de 33 à $53 \mathrm{~ms}$.

De 40 à $41 m s$ a ilha $m=5$ desaparece e a ilha $m=4$ sofre uma redução na frequência, caindo para aproximadamente 14khz. Esta composição se mantém estável nos intervalos seguintes até que entre 47 e $48 \mathrm{~ms}$ surge uma ilha $m=2$, sendo que a frequência de ambas as ilhas varia pouco nos intervalos seguintes. No intervalo de 50 à $51 \mathrm{~ms}$ a ilha $m=2$ torna-se co-dominante com a ilha $m=4$ e a frequência de oscilação se mantém 
aproximadamente constante, próxima à $13 k H z$. A partir deste instante, a configuração dos modos se mantém estável durante a região de platô da corrente de plasma, sendo que os gráficos correspondentes a esta situação não estão mostrados na figura 47 apenas por conveniência. Também é possível perceber que a medida que a corrente de plasma se aproxima do valor de platô, há uma tendência em suprimir os modos de oscilação com números de onda mais altos $(m=7,6,5)$ e o surgimento de modos mais baixos, com $(m=4,3,2)$, conforme resultados obtidos nos primeiros intervalos. O significado físico é que a medida com que a corrente de plasma sobe durante a rampa de formação da coluna de plasma o valor do fator de segurança na borda cai, pela expressão 2.16, e as superfícies racionais mais externas tendem a ter números menores, explicando a dinâmica de evolução dos modos. Deste exemplo, percebe-se que as análises médias da frequência $\times$ modo devem ser aplicadas com muito cuidado, visto que podem produzir gráficos confusos. Se a frequência de oscilação do conjunto de ilhas varia dentro do intervalo de análise os resultados produzidos refletem esta situação, mas a interpretação dos gráficos torna-se inviável tendo em vista que a informação temporal da evolução da frequência não é mostrada conjuntamente. Resultados mais significativos podem ser obtidos se as análises forem efetuadas apenas em frequências selecionadas, utilizando o método de seleção de caminhos apresentado na figura 36(d).

A figura 48 mostra a análise dos modos de oscilação na fase de subida da corrente para o disparo \#28661 no intervalo de tempo de 32 à $52 \mathrm{~ms}$ levando em consideração uma banda de frequências pré selecionadas. Em (a) está o espectrograma de potência médio dos sinais das bobinas de Mirnov, onde está demarcado o caminho de frequências analisado, e em (b) a decomposição dos modos para cada instante de tempo.

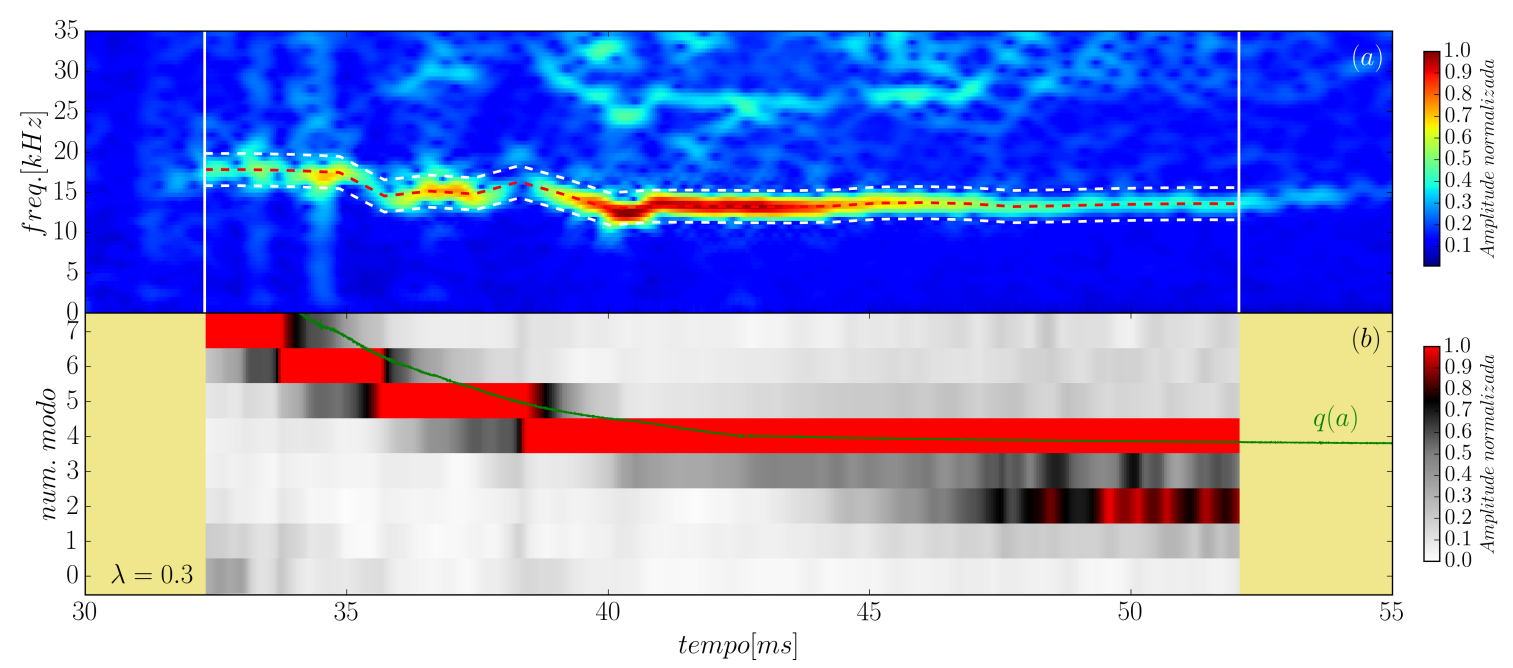

Figura 48 - Estudo dos modos de oscilação durante a rampa de subida da corrente de plasma para o disparo \#28661. Em (a) o espectrograma médio de potência para os sinais das bobinas de Mirnov e em (b) a decomposição dos modos para cada instante de tempo, utilizando $\lambda=0,3$. 
Como discutido na seção 5.1.1, a melhor estimativa do parâmetro de correção de Merezhkin para $r=a$ é de $\lambda=0,3$ e desta forma, podemos usar esse valor de $\lambda$ para analisar a evolução dos modos MHD durante a rampa de subida de corrente, tendo em mente que os modos mais intensos, nesta fase do disparo, estão localizados na borda do plasma. É visível no gráfico 48(b) uma sequência decrescente do número de onda do modo, começando em $m=7$ em $t=32 \mathrm{~ms}$ até chegar em $m=4$ próximo a $40 \mathrm{~ms}$. Também é visível que o modo dominante sempre é igual ou menor ao valor do fator de segurança na borda $q(a)$. O traço em cor verde indica o fator de segurança na borda do plasma, calculado a partir da corrente de plasma instantânea aplicada a equação 2.16.

Estas análises foram repetidas para o disparo \#30330 e estão apresentados nos gráficos da figura 49. As variáveis de equilíbrio para este disparo encontram-se nos gráficos da figura 43. O resultado das análises para este disparo são análogos entre os disparos na região da subida de corrente durante a formação da coluna de plasma. É visível no gráfico da figura 49 que os modos estão numa sequência decrescente do número de onda, começando em $m=7$ em $t=32 \mathrm{~ms}$ até chegar em $m=4$ próximo a $40 \mathrm{~ms}$. De maneira semelhante ao exemplo do disparo \#28661, o modo dominante também é sempre igual ou menor ao valor do fator de segurança na borda $q(a)$.

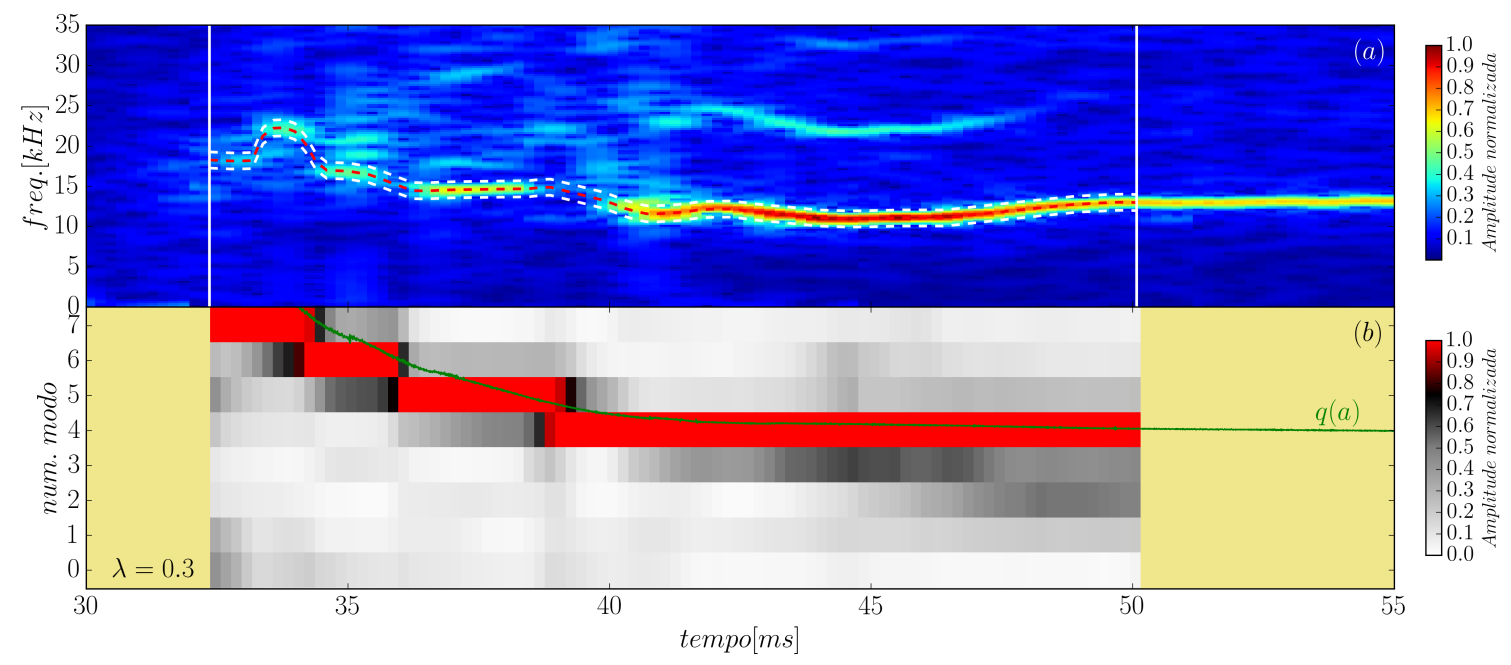

Figura 49 - Estudo dos modos de oscilação durante a rampa de subida da corrente de plasma para o disparo \#30330. Em (a) o espectrograma médio de potência para os sinais das bobinas de Mirnov e em (b) a decomposição dos modos para cada instante de tempo, utilizando $\lambda=0,3$.

Estes resultados são interessantes do ponto de vista experimental, pois são repetitivos na maioria dos disparos do TCABR e também porque revelam uma boa concordância entre as análises dos modos MHD realizados via análise espectral com a evolução do fator de segurança na borda do plasma, calculado pela expressão 2.18, utilizando os dados da tabela 1 e o valor instantâneo da corrente de plasma. 


\subsubsection{Acoplamento entre modos}

No estudo da evolução temporal dos modos MHD pôde ser percebido que ilhas de números de onda diferentes podem compartilhar a mesma frequência de oscilação. No exemplo apresentado na figura 47 para o disparo \#28661 vimos a co-existência de ilhas $m=4$ e $m=2$ para tempos maiores que $47 m s$ e que elas compartilhavam a mesma frequência de oscilação.

Para ilustrar de forma mais clara esse fenômeno, vamos analisar o disparo \#25911 cujas variáveis de equilíbrio encontram-se reproduzidas nos gráficos da figura 50. Este disparo apresenta corrente de plasma aproximadamente plana de $I_{p}=80 \mathrm{k}$ no intervalo de tempo de $50 \sim 95 \mathrm{~ms}$, com densidade eletrônica de $n_{e}=1,5^{19} \mathrm{~m}^{-3}$. A atividade MHD é intensificada devido a um acoplamento de ilhas $m=2$ e $m=4$ com uma perturbação $m=3$. Também apresenta alta emissão de raios-X duros.
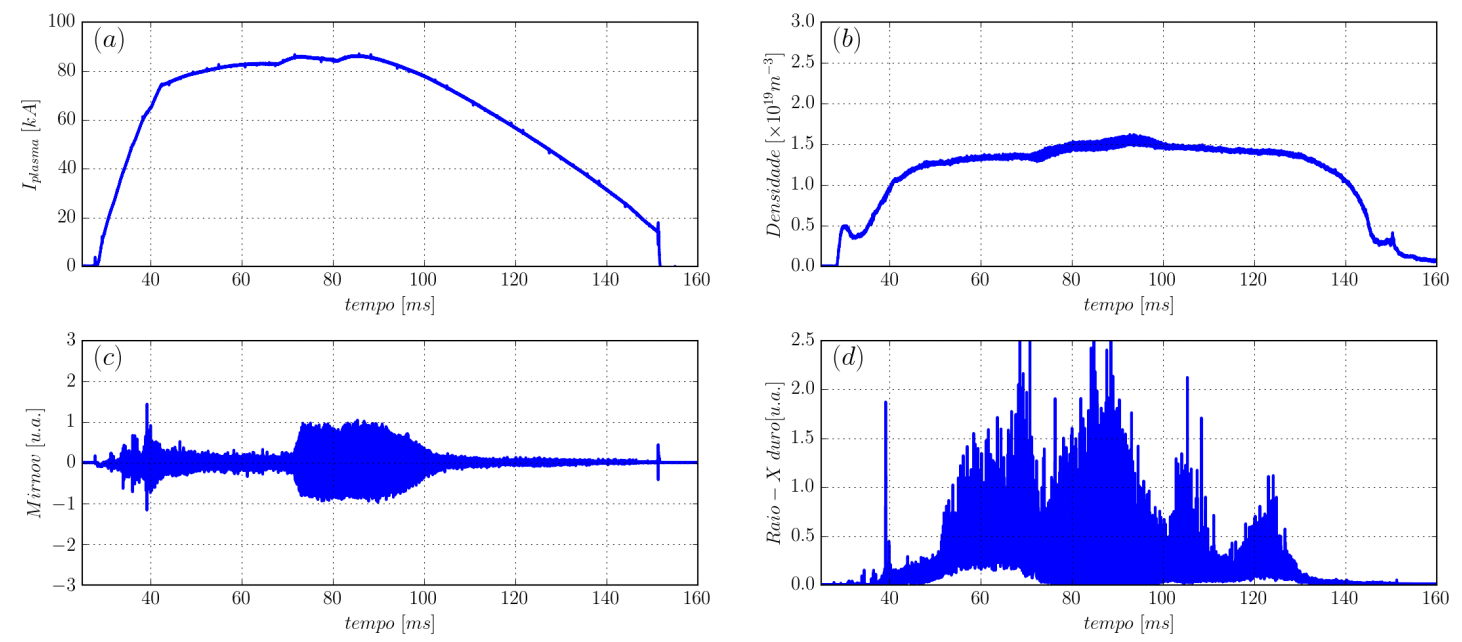

Figura 50 - Variáveis de equilíbrio para o disparo \#25911 do TCABR. Com corrente de plasma em (a), densidade central em (b), sinal da bobina de Mirnov de referência em (c) e sinal da emissão de raios-X duros em (d).

Para este disparo, a figura 51 mostra o espectrograma médio de potência de todos os sinais das bobinas de Mirnov poloidais. A escala de cores foi escolhida para evidenciar os caminhos no plano frequência $\times$ tempo. O gráfico em (a) mostra dois caminhos antes do tempo de 70ms identificados como "Caminho 1" e "Caminho 2", respectivamente nas cores vermelha e amarela. A decomposição dos modos MHD referentes a estes caminhos estão mostradas nos gráficos em (b) e (c). O caminho 1 possui uma combinação dos modos $m=2,3$ e 4 , sendo a ilha $m=2$ dominante sobre as demais. A frequência de oscilação deste conjunto de modos é de $\approx 15 k H z$. O caminho 2 é composto de um modo puro $m=3$ que apresenta o valor da frequência de oscilação variando de 22 para $20 k H z$ durante o percurso. Após o tempo de $70 \mathrm{~ms}$ está assinalado em cor verde no espectrograma um terceiro caminho, cuja decomposição dos modos MHD está representado no histograma 
em (d). Essa decomposição de modos no caminho 3 mostra que ele é a composição dos modos MHD dos caminhos 1 e 2 . Ademais, como visualizado no espectrograma, as ilhas que anteriormente apresentavam frequências de oscilação diferentes passam a oscilar com o mesmo valor de frequência. Logo após o acoplamento o valor da frequência sofreu um decréscimo e se estabilizou em $\approx 13 \mathrm{Khz}$. A intensidade relativa dos modos depois do acoplamento revela que a ilha $m=3$ tornou-se dominante sobre as demais ilhas. É interessante notar que a magnitude dos modos antes do acoplamento eram pequenas e que depois do acoplamento ela cresce substancialmente. Este comportamento pode ser percebido em diversos disparos.
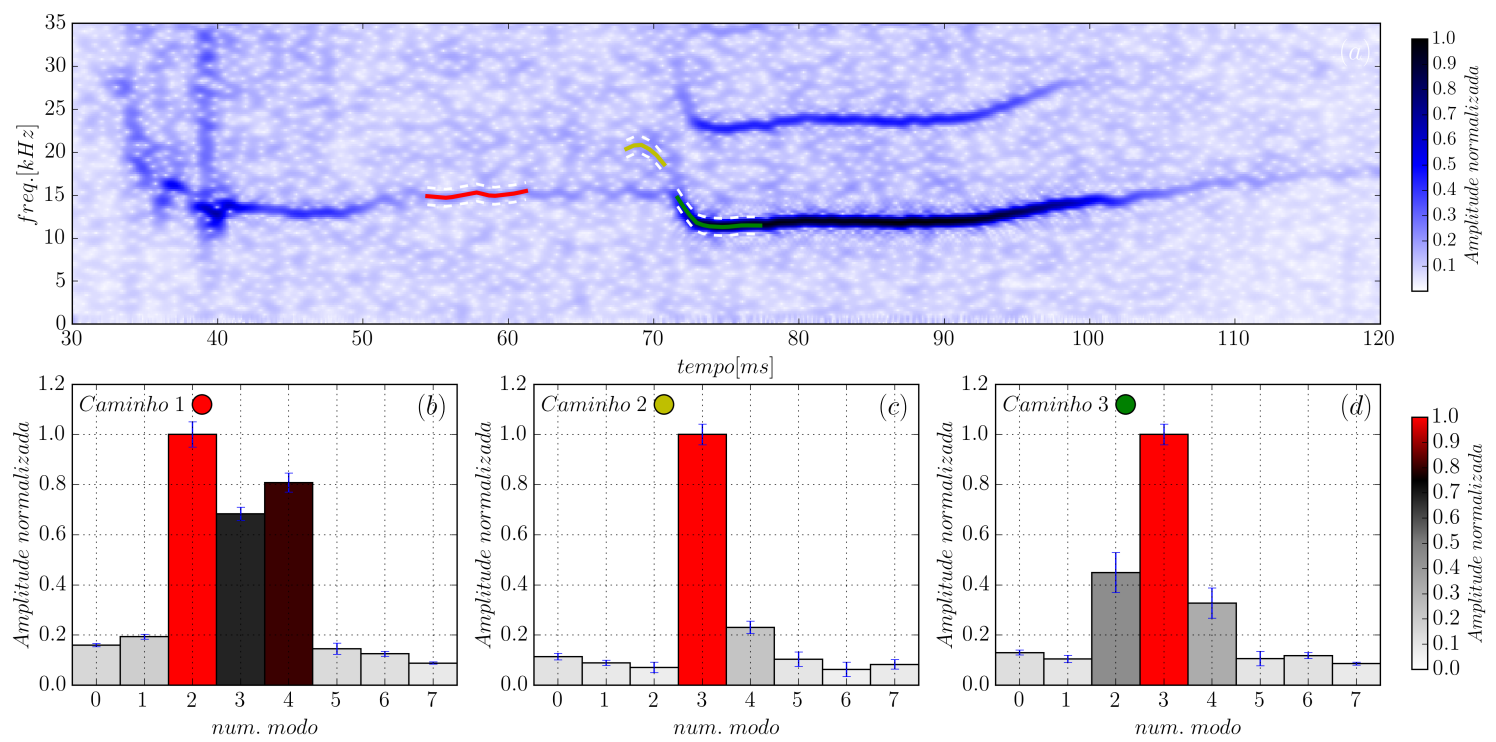

Figura 51 - Estudo do acoplamento entre modos de oscilação durante o disparo \#25911 do TCABR. Em (a) o espectrograma médio de potência para os sinais das bobinas de Mirnov, em (b), (c) a decomposição dos modos antes do tempo de $70 \mathrm{~ms}$ para o caminho 1 e 2, respectivamente e em (c) decomposição dos modos após o acoplamento. Análises efetuadas utilizando $\lambda=0,25$.

Essa mesma análise foi repetida para o disparo \#27005, cujas variáveis de equilíbrio encontram-se reproduzidas nos gráficos da figura 52. Para este disparo a corrente de plasma se manteve plana no intervalo de $50 \sim 100 \mathrm{~ms}$ no valor de $I_{p}=93 \mathrm{kA}$ com densidade eletrônica central de $n_{e}=1,1 \times 10^{19} \mathrm{~m}^{-3}$ e apresentou pouca emissão de raios-X duros.

O resultado das análises de acoplamento de modos encontra-se nos gráficos da figura 53. Para este disparo a configuração de ilhas iniciais era composta por um modo $m=4$ dominante e um modo $m=2$ menos intenso, ambos compartilhando a frequência de aproximadamente $14 k \mathrm{~Hz}$, conforme mostrado na figura 53(b). O caminho mostrado em amarelo na figura 53(a) corresponde a um modo de borda $m=3$ puro, conforme indicado pelo histograma mostrado em (c). Em (d) está mostrado a decomposição dos modos após o acoplamento, sendo que o modo $m=3$ se tornou dominante. 

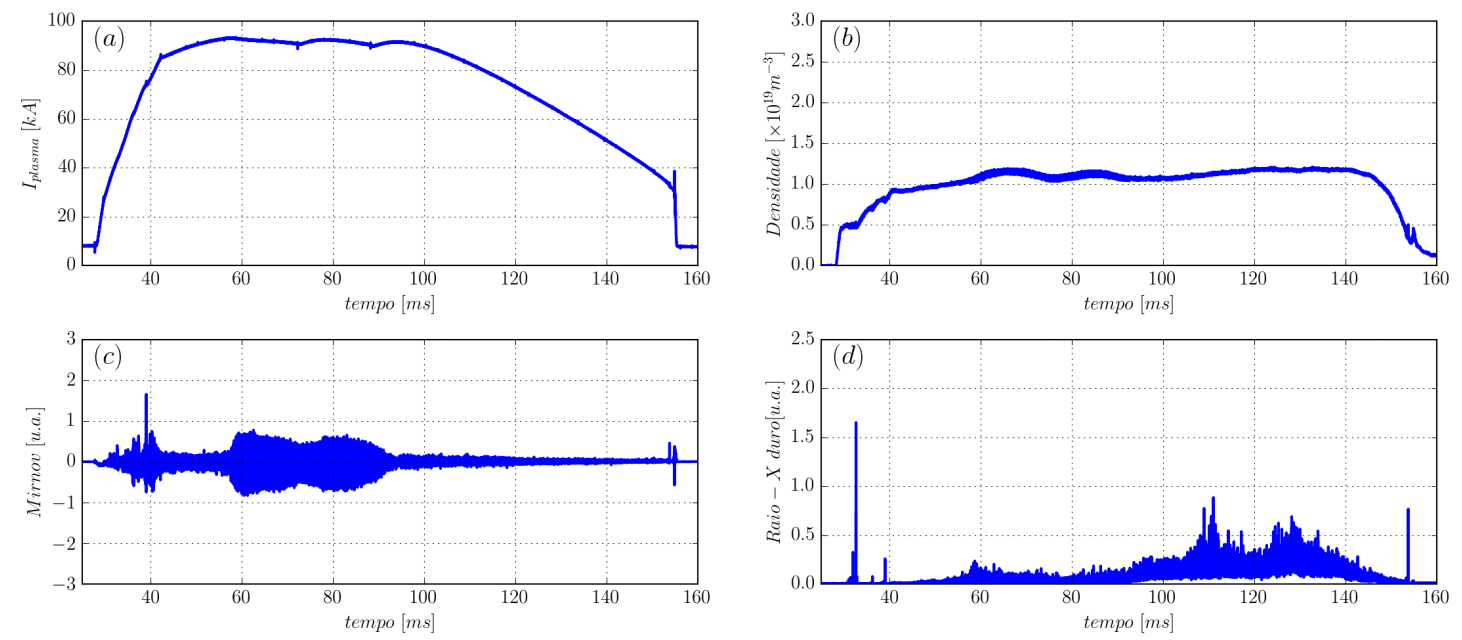

Figura 52 - Variáveis de equilíbrio para o disparo \#27005 do TCABR. Com corrente de plasma em (a), densidade central em (b), sinal da bobina de Mirnov de referência em (c) e sinal da emissão de raios-X duros em (d).
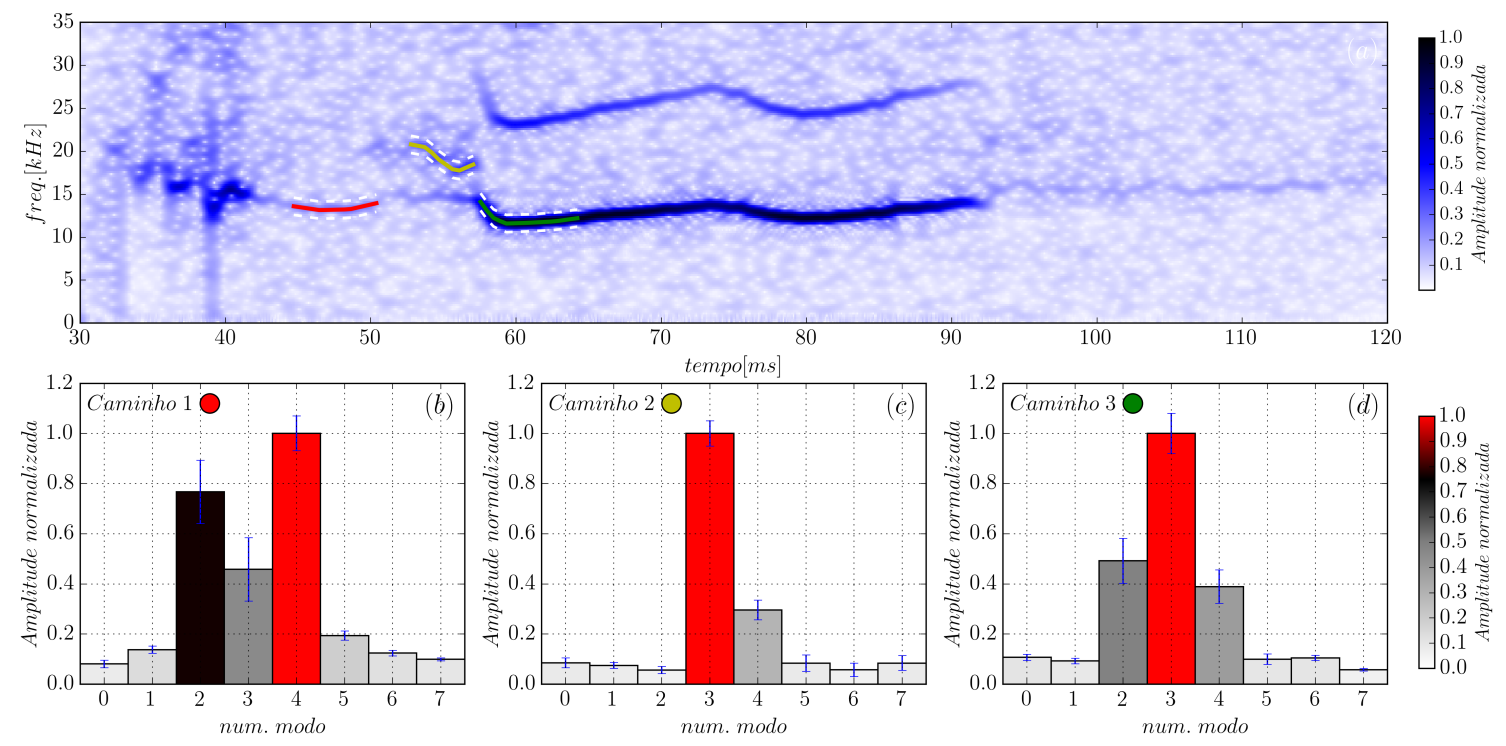

Figura 53 - Estudo do acoplamento entre modos de oscilação durante o disparo \#27005 do TCABR. Em (a) o espectrograma médio de potência para os sinais das bobinas de Mirnov, em (b), (c) a decomposição dos modos antes do tempo de $70 \mathrm{~ms}$ para o caminho 1 e 2, respectivamente e em (c) decomposição dos modos após o acoplamento. Análises efetuadas utilizando $\lambda=0,25$.

\subsection{Estudo das oscilações de centro da coluna}

Na seção 2.3.4 foi apresentado o modelo simplificado de Kadomtsev que explica de forma razoavelmente satisfatória as oscilações dente de serra detectadas por diagnósticos destinados a monitorar as grandezas físicas do centro da coluna de plasma. Como já visto, este modelo supõe que ocorrem reconexões magnéticas próximo a superfície $q=1$ e que esse processo é precedido de modos kinks internos. Ademais, o modelo dá uma explicação 
à dinâmica do fluxo de acesso de plasma quente do centro para às regiões mais externas da coluna.

Como visto na seção 3.3, o sistema do SXR é um dos os diagnósticos ópticos disponíveis no TCABR para monitorar a emissão de radiação do centro do plasma. Nesta seção, tratar-se-á das análises e interpretações físicas dos sinais produzidos por estes diagnósticos e apresentará os resultados obtidos através delas. Inicialmente será efetuado um tratamento qualitativo dos sinais típicos do diagnóstico de raios-X moles, evoluindo até utilizar as análises espectrais dos sinais e estimar a posição radial da superfície $q=1$ e a posição central da coluna de plasma. Um esforço foi feito para a identificação e caracterização das componentes espectrais quanto à localização radial e composição de frequências. Estas características são repetitivas, sendo que as oscilações precursoras e dente de serra ocorrem em todos os disparos do TCABR.

\subsubsection{Discussão preliminar}

O sinal do sistema SXR, conforme já visto na seção 3, fornece um sinal integrado em cada corda do respectivo canal. A aparência dos sinais pode ser visto nos gráficos da figura 54. Esta figura mostra o sinal de alguns dos canais do sistema de raios-X moles para o disparo \#28661 do TCABR cujas variáveis de equilíbrio já foram apresentadas nos gráficos da figura 37. Na figura 54 estão mostrados os canais indo do 2 ao 7 nos gráficos de (a) até (d), respectivamente de um dos lados da região central em direção ao centro da coluna de plasma e de (e) até (h), seguindo do centro até a lado oposto, canais 9 até 14 . A emissão óptica é mais concentrada nos canais centrais, pois estes canais apresentam maior nível de sinal, e menos concentrada nas regiões periféricas. Nestes gráficos a diferença de nível de sinal é de uma ordem de grandeza.

Os gráficos da figura 54 também mostram que os sinais contém oscilações de período bem mais curto que a duração do disparo. A figura 55(a) mostra os sinais de todos os canais ativos do SXR simultaneamente num gráfico em que a escala de cores representa a amplitude, para o mesmo disparo do tokamak no intervalo de $76 \sim 80 \mathrm{~ms}$. Fica facilmente visível a diferença de níveis entre os canais centrais $(8 \sim 12)$ e os canais periféricos $(1 \sim 7)$ e $(13 \sim 20)$.

Mesmo com essa diferença de nível, não é possível notar com clareza os processos temporais apesar de que duas escalas de tempo parecem estar presentes; uma delas da ordem de $0,5 \mathrm{~ms}$ e outra da ordem de $50 \mu \mathrm{s}$. O gráfico na figura 55(b) mostra o resultado obtido pela subtração do valor médio dos sinais originais. Agora, especialmente no caso dos canais mais centrais (canais 8 a 12), é fácil perceber a existência de oscilações do sinal contendo, pelo menos, duas escalas de tempo. Uma maneira qualitativa de avaliar estes dois processos temporais é aplicar uma filtragem passa baixas (FPB) para evidenciar o processo lento e um filtro passa altas (FPA) para salientar o processo rápido. A figura 56 

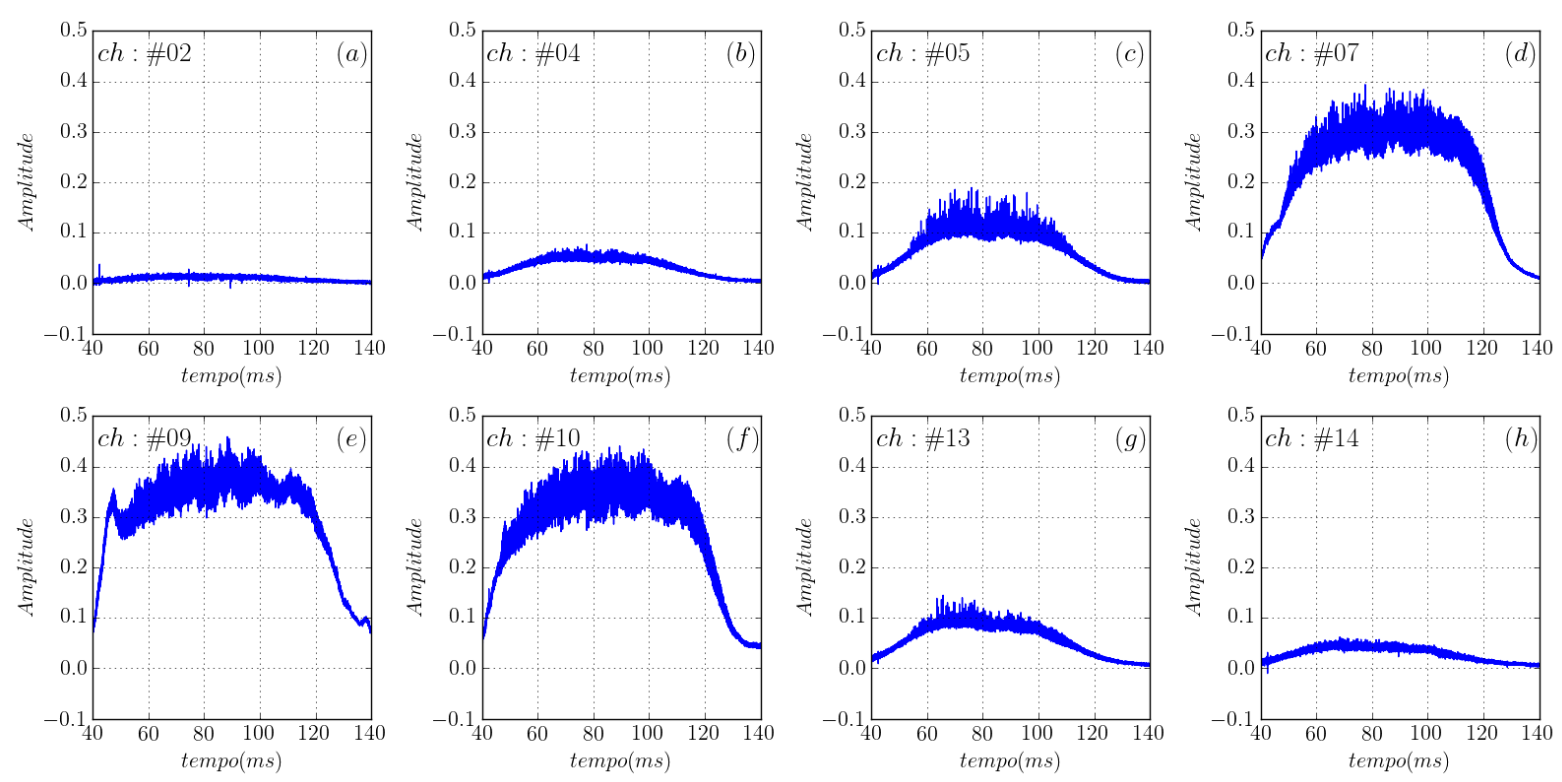

Figura 54 - Sinais típicos produzidos pelo diagnóstico de raios-X moles, para o disparo \#28661. Da esquerda para a direita e de cima para baixo apresenta os sinais iniciando em um canal periférico (ch\#02), passando pelos canais centrais (ch\#09) e (ch\#10) e chegando no canal de periferia no lado oposto (ch\#14).
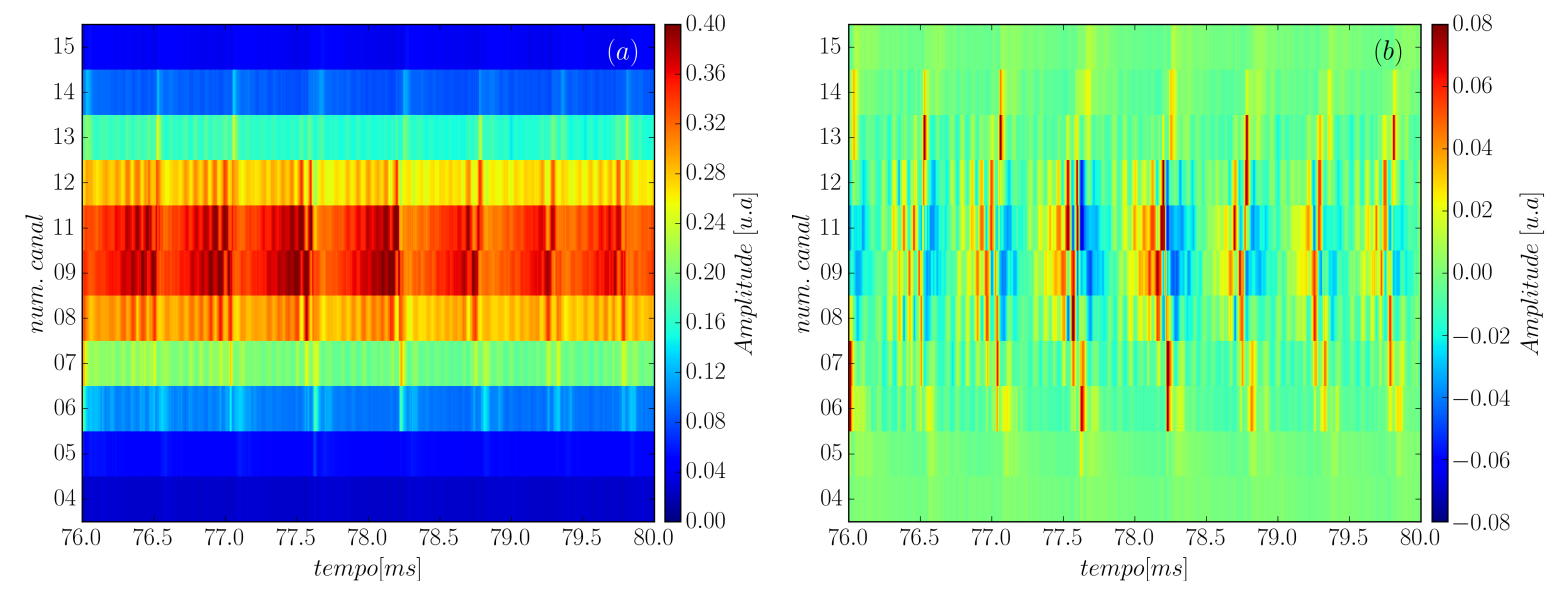

Figura 55 - Visualização simultânea dos sinais de todos os canais ativos do SXR para o disparo \#28661 no intervalo de tempo de 76 80ms. E (a) o sinal original e em (b) o sinal após a subtração do valor médio dos sinais. A representação em (b) torna mais fácil a visualização das componentes de variação rápida dos sinal.

mostra o resultado da filtragem dos sinais, utilizando um filtro passa baixa de primeira ordem com frequência de corte superior de $5 k H z$, cujo resultado esta na figura 56(a) e aplicando um filtro passa altas de frequência de corte inferior de $7 \mathrm{kHz}$, cujo resultado está mostrado na figura 56(b).

O gráfico mostra que os canais centrais $(8 \sim 12)$ o sinal cresce lentamente, partindo de um valor abaixo da média (em azul na escala de cores), passando pelo zero (em branco) e subindo até um valor máximo acima da média (em vermelho). A subida lenta é seguida de um queda abrupta que vai do máximo positivo ao máximo negativo, depois do qual o 

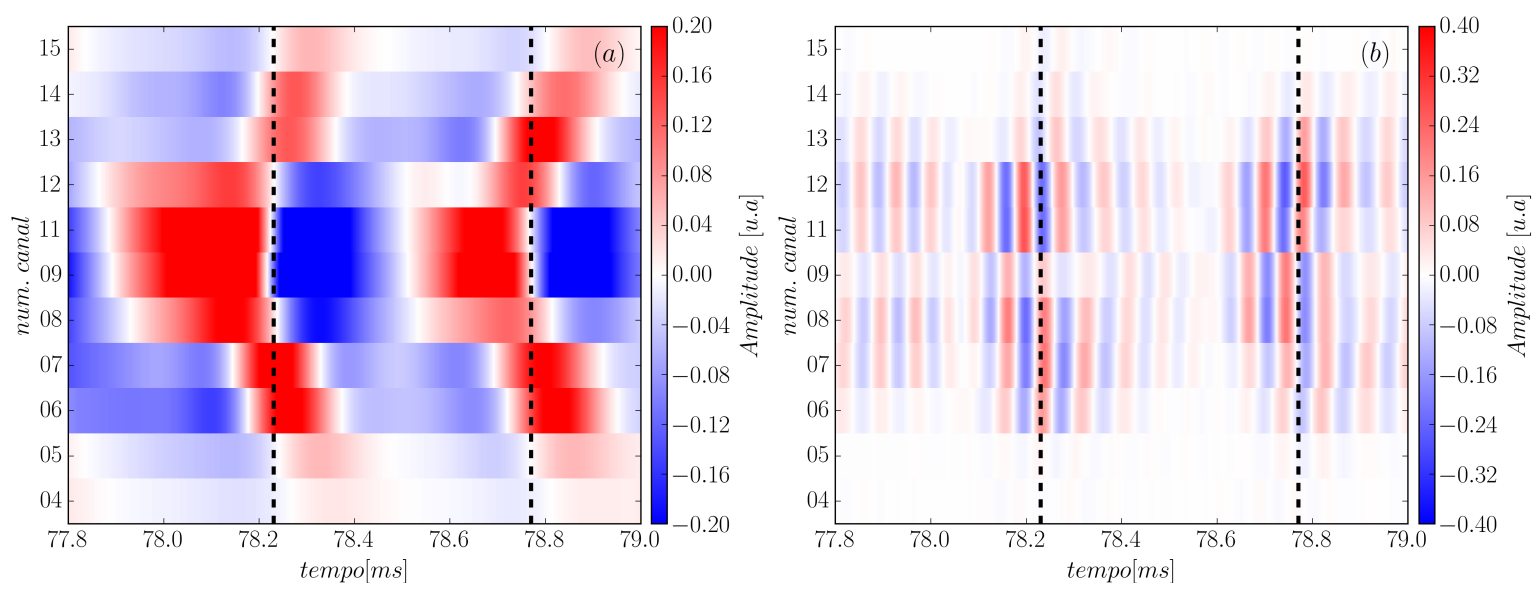

Figura 56 - Visualização simultânea dos sinais filtrados de todos os canais ativos do SXR para o disparo \#28661 no intervalo de tempo de $76 \sim 80 \mathrm{~ms}$. E (a) o resultado da filtragem usando um FPB com frequência de corte superior de $f_{c}=5,0 k H z$ (b) o resultado da filtragem usando um FPA com frequência de corte inferior $f_{c}=7,0 \mathrm{kHz}$.

ciclo recomeça. Um ciclo completo está delimitado nos gráficos da figura 56 pelas linhas verticais tracejadas.

Para os canais mais externos, $(4 \sim 7)$ e $(13 \sim 15)$, o comportamento é o oposto, uma subida abrupta seguida de uma queda lenta. Isto identifica um padrão dente de serra e corresponde ao processo lento. Também é perceptível que a localização temporal das mudanças abruptas está cada vez mais defasado no tempo dos canais mais centrais para os canais periféricos, o que cria a característica visual de uma letra "Y" na imagem mostrada na figura 56(a). Já o gráfico da figura 56(b), referente as componentes de mais alta frequência, mostra que as oscilações são anti-simétricas em relação ao canal central, ou seja, quando a intensidade do sinal é maior que a média de um lado, é menor do outro lado. Este comportamento caracteriza uma oposição de fase entre os sinais dos lados opostos, tomando como o centro alguma posição entre os canais 9 e 11.

Outra característica notável é que a intensidade das emissões em alta frequência apresentam uma modulação de amplitude que acompanha o ciclo das componentes de mais baixa frequência, ou seja, vão de uma amplitude baixa para uma amplitude elevada acompanhando o mesmo intervalo de tempo do ciclo da dente de serra. Radialmente, a intensidade das oscilações diminui a medida que se afasta do centro da coluna. $\mathrm{O}$ crescimento da amplitude dessas oscilações sempre ocorre antes da mudança abrupta da dente de serra e por esta razão são chamadas de oscilações precursoras do crash da dente de serra, que serão identificadas como oscilações PRE.

Devido a periodicidade, podemos analisar estes fenômenos utilizando a análise espectral dos sinais do SXR e, desta forma estamos interessados em avaliar o conteúdo espectral médio dos sinais em cada posição radial referente as cordas ou canais dos diagnósticos ópticos. 
Os gráficos da figura 57 mostram o processo de construção da distribuição espacial média de potência espectral (potência $\times$ frequência $\times$ canal) para o caso alguns canais do SXR que são sombreados pelo filtro de berílio. Do gráfico (a) até (f) um conjunto representativo de espectrogramas para os sinais que cobre a região central da coluna de plasma. O intervalo de tempo utilizado na análise de distribuição espacial está indicado pelas linhas pretas verticais.
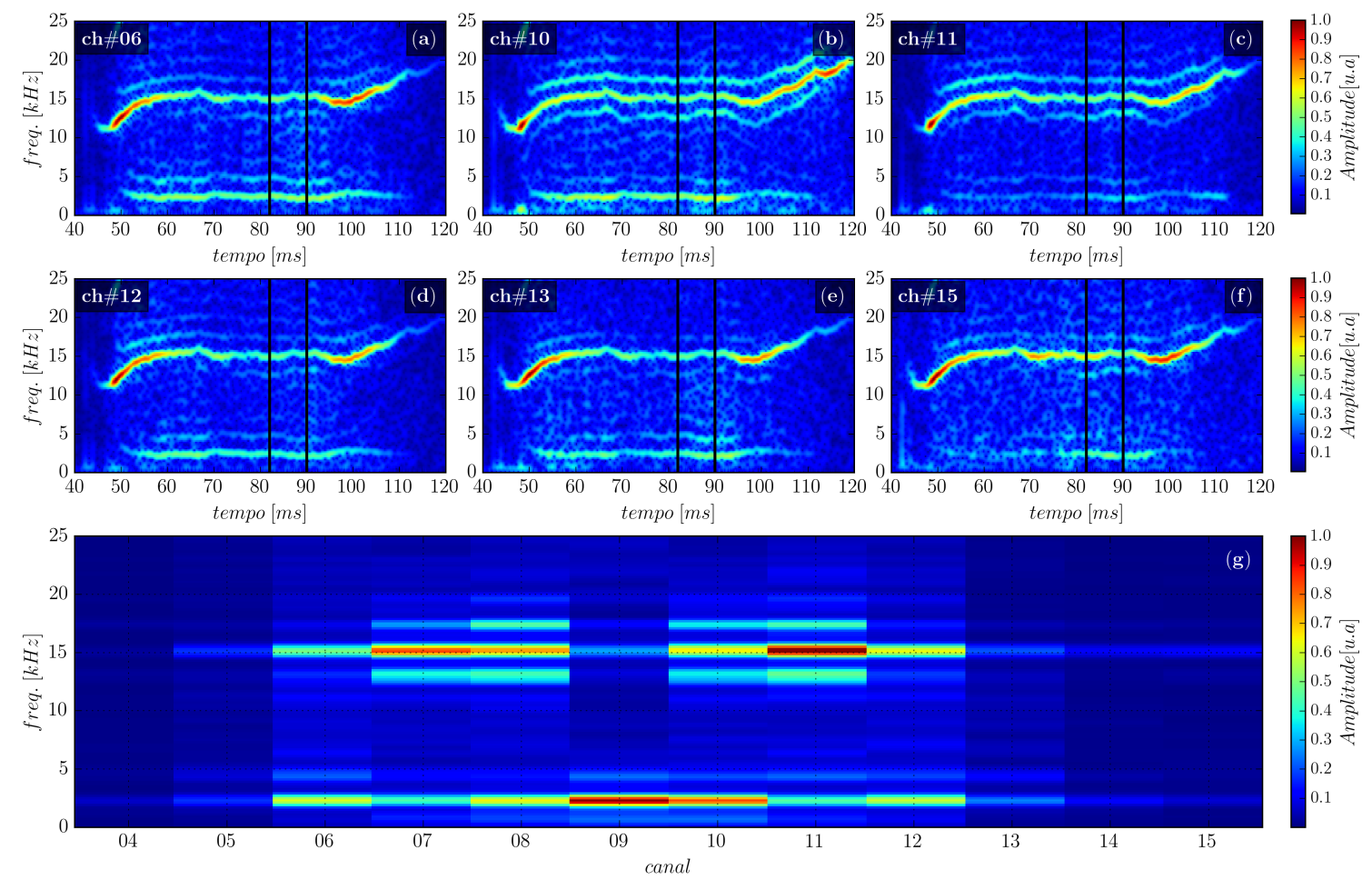

Figura 57 - Construção do gráfico de distribuição espacial média de potência espectral. De (a) à (f) os espectrogramas de alguns dos sinais do SXR para o disparo \#26136 e em (g) o gráfico da potência espectral média por componente de frequência para cada canal. O intervalo de tempo de 82 à $90 \mathrm{~ms}$ para o cálculo das médias estão indicados pelas linhas verticais nos espectrogramas.

Neste intervalo são calculadas as médias temporais da potência espectral por componente de frequência para cada canal. O resultado de cada média corresponde a uma coluna no gráfico mostrado em (g). O significado da figura 57(g) é a de distribuição média de potência espectral por canal num dado intervalo de tempo. No caso, foram utilizados os dados produzidos pelo SXR para o disparo \#26136 no intervalo de tempo de 82 à $90 \mathrm{~ms}$.

Percebe-se que as componentes de baixa frequência $(<5 k H z)$ estão concentradas nas regiões mais centrais da coluna de plasma, referentes aos canais $9 \sim 11$ e que as componentes de frequência mais altas $(10 \sim 15 k h z)$ também estão concentradas nas regiões internas, mas mais espalhadas radialmente, entre os canais $8 \sim 12$. Também são perceptíveis outras componentes de frequência que podem ser identificadas como harmônicas das componentes com amplitudes mais intensas ou que são relativas a fenômenos 
de interferência e modulação que serão discutidos mais adiante neste capítulo. Tendo em vista que os diagnósticos ópticos, como o é o caso do SXR, fornecem sinais integrados ao longo da linha de visada e, desta forma, produzem sinais que carregam informações sobre a emissividade do plasma tanto das regiões internas quanto das mais externas de modo que torna-se interessante estudar separadamente as situações com baixas e altas intensidades de atividade MHD. Desta forma, estaremos isolando (ou não) nas análises as interferências provocadas pela presença de grandes ilhas magnéticas nas superfícies racionais $q=2,3,4$, externas à superfície $q=1$.

\subsubsection{Disparos com baixa atividade MHD}

Um disparo de baixa intensidade de perturbações medidas pelas bobinas de Mirnov já foi analisado na seção 5.1, onde foi discutido as perturbações medidas pelas bobinas de Mirnov para o caso do disparo \#28661, cujas variáveis de equilíbrio se encontram nos gráficos da figura 37. A distribuição espacial da potência espectral dos sinais do detector SXR estão apresentadas no gráfico da figura 58(a) e 58(e), sendo assinaladas as frequências $f_{R E L}=(1,91 \pm 0,12) k H z$ e $f_{P R E}=(15,39 \pm 0,12) k H z$, associadas às relaxações dos dente de serra e as oscilações precursoras, respectivamente.
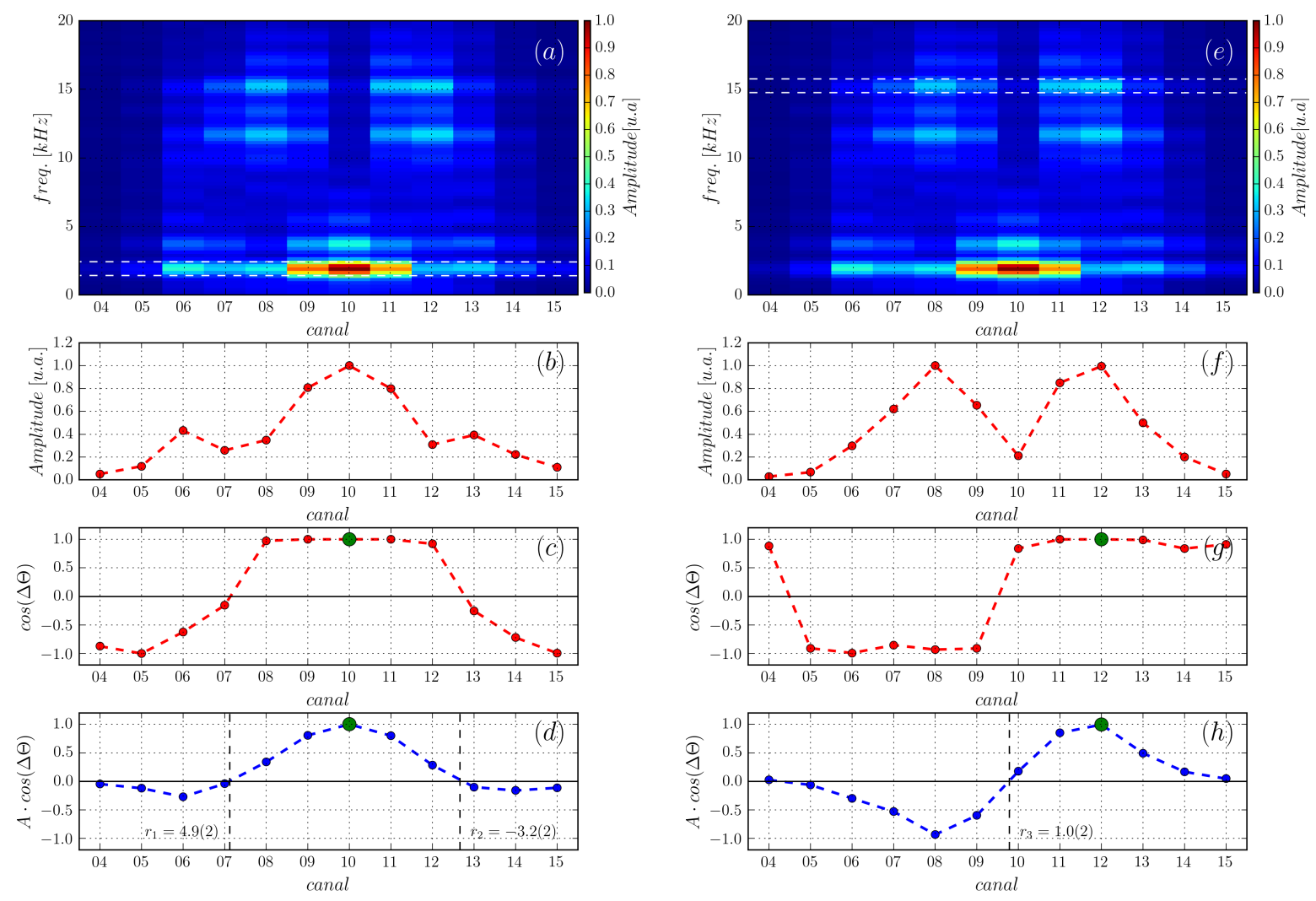

Figura 58 - Análises da distribuição espacial da potência espectral média dos sinais do SXR para o disparo \#28661 para o intervalo de tempo de 75 à $85 \mathrm{~ms}$ para os canais 4 à 15. Em (a) até (d) estão os resultados referentes à $f_{R E L}$ e em (e) à (f) os resultados referentes à $f_{P R E}$. 
A oscilação precursora está acompanhada por duas frequências satélites inferiores de frequências $f_{P R E}^{s a t 1}=(13,45 \pm 0,12 k H z)$ e $f_{P R E}^{s a t 2}=(11,69 \pm 0,12 k H z)$. Estes gráficos foram construídos tomando as médias no intervalo de tempo de 75 à $85 \mathrm{~ms}$. O gráfico em (b) mostra a amplitude média normalizada da componente $f_{R E L}$ e, conforme o gráfico, as amplitudes das oscilações nesta frequência são mais intensas na região mais central da coluna, entre os canais $8 \sim 11$. Em (c) é apresentado o cosseno da diferença de fase $(\Delta \Theta)$ das oscilações em cada canal em relação ao sinal do canal 10, tomado como referência de fase e que está indicado no gráfico pela bola verde. Vale ressaltar aqui que o símbolo $\Theta$ representa o argumento do número complexo da componente de Fourier para a frequência considerada.

Percebe-se que as oscilações referentes aos canais centrais $(8 \sim 11)$ para $f_{R E L}$ estão todas em fase com relação ao canal 10 e que as oscilações referentes aos canais mais externos $(4 \sim 7)$ e $(12 \sim 15)$ estão todas em contra-fase com relação ao sinal de referência. Os pontos de inversão de fase ocorrem entre os canais 6 e 7 e também entre os canais 12 e 13. O gráfico em (d) mostra o produto da amplitude normalizada pelo cosseno da diferença de fase entre cada canal e a referência. As posições radiais dos pontos de inversão de fase foram calculadas por interpolação e estão indicadas no gráfico pelas linhas tracejadas verticais. Novamente, a bola verde no gráfico em (d) identifica o canal utilizado como referência no cálculo da diferença de fase.

Os pontos de inversão de fase referentes a oscilação dente de serra, obtidos por interpolação da curva $A \cdot \cos (\Delta \Theta)$ foram $r_{1}=(4,9 \pm 0,2) \mathrm{cm}$ e $r_{2}=(-3,2 \pm 0,2) \mathrm{cm}$ em relação ao eixo óptico do instrumento, conforme destacado no gráfico em (d). Tomando a metade do intervalo entre estes dois pontos, estima-se o raio de inversão de fase em relação ao centro da coluna de plasma, o que resulta em $r_{s}=(4,05 \pm 0,2) \mathrm{cm}$. Fazendo-se uma análise semelhante para a precursora do dente de serra $58(\mathrm{e}-\mathrm{h})$, obtêm-se para o ponto de inversão o valor o ponto de inversão de fase referente a precursora da dente de serra foi obtido o valor $r_{3}=(1,0 \pm 0,2) \mathrm{cm}$ em relação ao eixo óptico do instrumento, como assinalado no gráfico em $(\mathrm{h})$.

Fisicamente os resultados das análises mostradas na figura 58(a) até (d) estão relacionadas com o ciclo de aquecimento e posterior relaxação do plasma dentro da superfície racional $q=1$. O centro do plasma se aquece lentamente devido ao efeito Joule causado pela corrente de plasma e, com o aumento da temperatura, ocorre um incremento do nível de radiação emitida pelo centro da coluna que por sua vez são detectados de forma simultânea por todos os canais que mapeiam a região central. Já os canais que mapeiam as posições radiais imediatamente fora da superfície racional $q=1$ veem a diminuição da emissão de radiação nesta região, cujos sinais também estão em fase entre si mas em oposição de fase com relação aos canais centrais. Desta forma, o raio de inversão de fase é uma boa estimativa da posição da superfície $q=1$. Este comportamento está de acordo 
com o modelo simplificado de reconexões magnéticas durante as oscilações dos modos kink internos, conforme explorado na seção 2.3.4.

Nos gráficos da figura 58(e) até (h) estão repetidas as mesmas análises anteriores para a componente de frequência mais elevada, com valor em torno de $15 k \mathrm{~Hz}$. O Gráfico em (e) mostra que a distribuição espacial da potência espectral normalizadas desta componente de frequência estão concentradas no canais 8 e 12. O gráfico em (f), que representa a amplitude média desta componente no intervalo de tempo de 75 à $85 \mathrm{~ms}$, reafirma que a potência espectral está concentrada nos canais 8 e 12 e que decai tanto em direção ao centro quanto em direção à periferia do plasma. O gráfico em (g) mostra o cosseno da diferença de fase dos sinais dos canais do SXR em relação ao canal 12, onde é visível que só existe um ponto de inversão de fase, próximo ao centro da coluna de plasma (entre os canais 9 e 10). Este gráfico mostra que os sinais de cada lado em relação ao centro estão em fase, ao passo em que estão em oposição de fase com relação às oscilações do lado oposto. Tendo em vista que a oposição de fase dos sinais na frequência de $f_{P R E}=(15,39 \pm 0,12) k H z$ de um lado para outro do centro da coluna de plasma, essas oscilações podem ser interpretadas como sendo os efeitos de um pequeno deslocamento da região central da coluna de plasma em conjunto com um movimento de rotação da região central como um todo em relação ao eixo magnético original, como mostrado na figura 59 e conforme discutido na seção 2.3.4, onde tratamos do modo kink interno precursor dos dentes de serra.

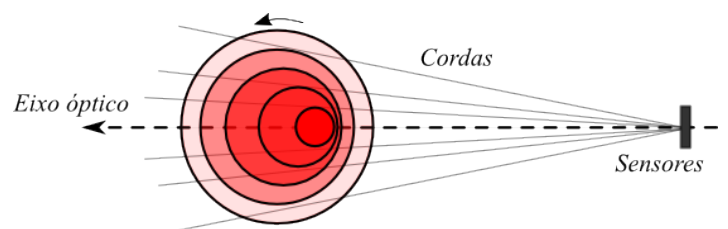

(a)

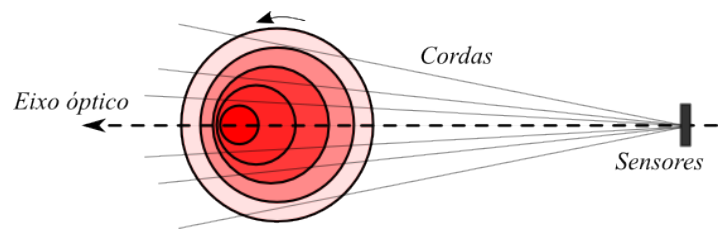

(c)

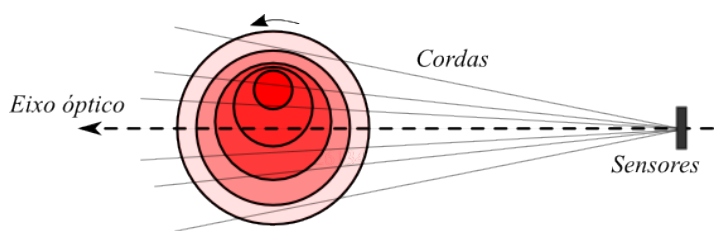

(b)

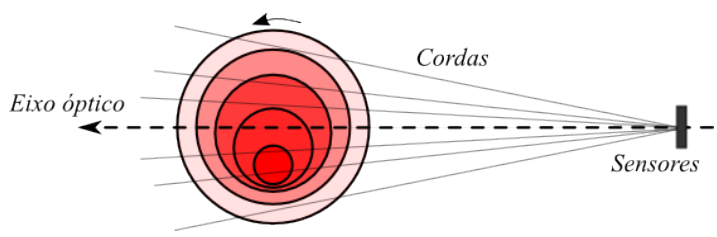

(d)

Figura 59 - Efeitos de um pequeno deslocamento da região central da coluna de plasma e do movimento de rotação do centro da coluna de plasma em relação ao eixo magnético original (modo kink interno) e consequências sobre os sinais integrados em linha dos diagnósticos ópticos.

A medida que a região central da coluna de plasma rota em torno do eixo magnético original, a emissividade integrada pelos canais referentes as cordas acima do eixo óptico variam conjuntamente e em contra-fase com os sinais produzidos pelas cordas que cobrem as posições abaixo do eixo óptico, de forma que podemos associar essa frequência de rotação com a fase precursora da dente de serra, mostrada na figura 13. Essa frequência de 
rotação será identificada pelo símbolo $f_{P R E}$. Aqui vale lembrar que logo após as superfícies magnéticas reconectarem (crash da dente de serra) o plasma na região central fica mais frio e menos denso e, por consequência a emissividade do plasma também diminui. Por esse motivo, as emissões na região central detectadas pelo sistema de SXR irão ter uma menor amplitude, ao passo que as cordas que veem a região externa à superfície $q=1$ observam o comportamento inverso: a intensidade do sinal do SXR aumenta após o crash. A medida com que o plasma volta a se aquecer devido ao efeito Joule causado pela corrente de plasma, a emissividade do plasma também volta a aumentar e, por consequência, o sinal produzido pelo sistema SXR fica mais intenso. Além disso, após o crash as propriedades do plasma na região interna à superfície $q=1$ (temperatura, densidade e pressão) ficam praticamente uniformes e o modo kink interno $\left(f_{P R E}\right)$ se torna estável ou tem sua amplitude (o $\xi_{0}$ da equação (2.24)) drasticamente reduzida. A associação desses dois efeitos (redução dos gradientes e redução da amplitude da perturbação radial associada ao modo) é que explicam a variação da amplitude da componente $\left(f_{P R E}\right)$ durante os ciclos de dente de serra, conforme percebido na figura $56(\mathrm{~b})$.

Para ilustrar o caráter de reprodutibilidade desdes fenômenos oscilatórios do centro da coluna de plasma, as análises anteriores foram repetidas para o caso do disparo \#26136 no intervalo de 75 à $85 \mathrm{~ms}$. As variáveis de equilíbrio para este disparo estão apresentadas na figura 60. A corrente de plasma se manteve plana em aproximadamente $I_{p}=73 \mathrm{kA}$ no período de 42 à $90 \mathrm{~ms}$, com densidade na região central entre 1,7 à $2,0 \times 10^{19} \mathrm{~m}^{-3}$, baixa intensidade de perturbações medidas pelas bobinas de Mirnov e com pouca emissão de raios-X duros.
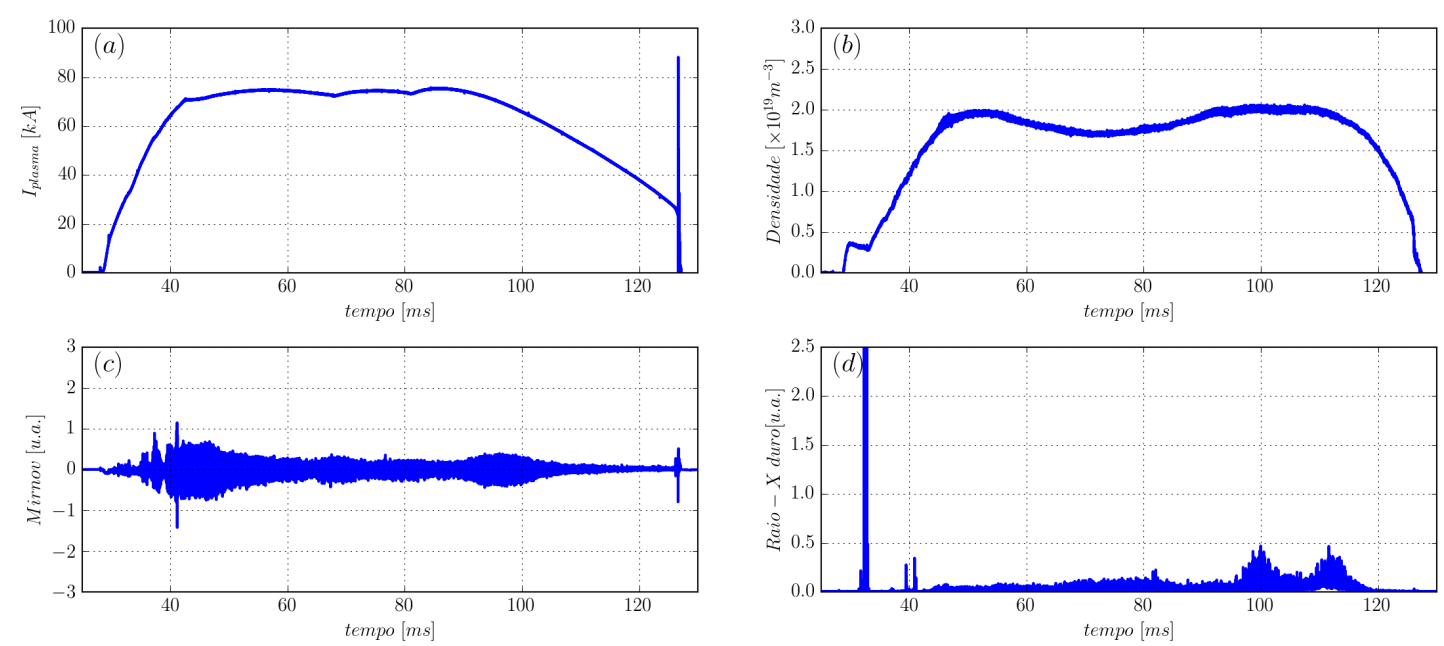

Figura 60 - Variáveis de equilíbrio para o disparo \#26136 do TCABR. Com corrente de plasma em (a), densidade central em (b), sinal da bobina de Mirnov de referência em (c) e sinal da emissão de raios-X duros em (d).

Os resultados das análises para este disparo estão apresentados nos gráficos da figura 61. Para a componente de frequência relativa aos ciclos de relaxação dente de serra 
foi utilizado o canal 10 como referência de fase e para a componente precursora o canal utilizado foi o 12, conforme indicado nos gráficos (c) e (d) para a $f_{R E L}$ e (g) e (h) para a $f_{P R E}$. As frequências encontradas foram $f_{R E L}=(2,52 \pm 0,12 k H z)$ e $f_{P R E}=(15,12 \pm 0,12 k H z)$, sendo que a oscilação precursora está acompanhada por duas frequências satélites de frequências $f_{P R E}^{s a t 1}=(12,78 \pm 0,12 k H z)$ e $f_{P R E}^{s a t 2}=(17,50 \pm 0,12 k H z)$. Ademais, para a componente referente a relaxação dente de serra, a potência espectral está bastante concentrada entre os canais 9 e 10. Já para a componente precursora, as maiores concentrações ocorrem nos canais 7 e 11.
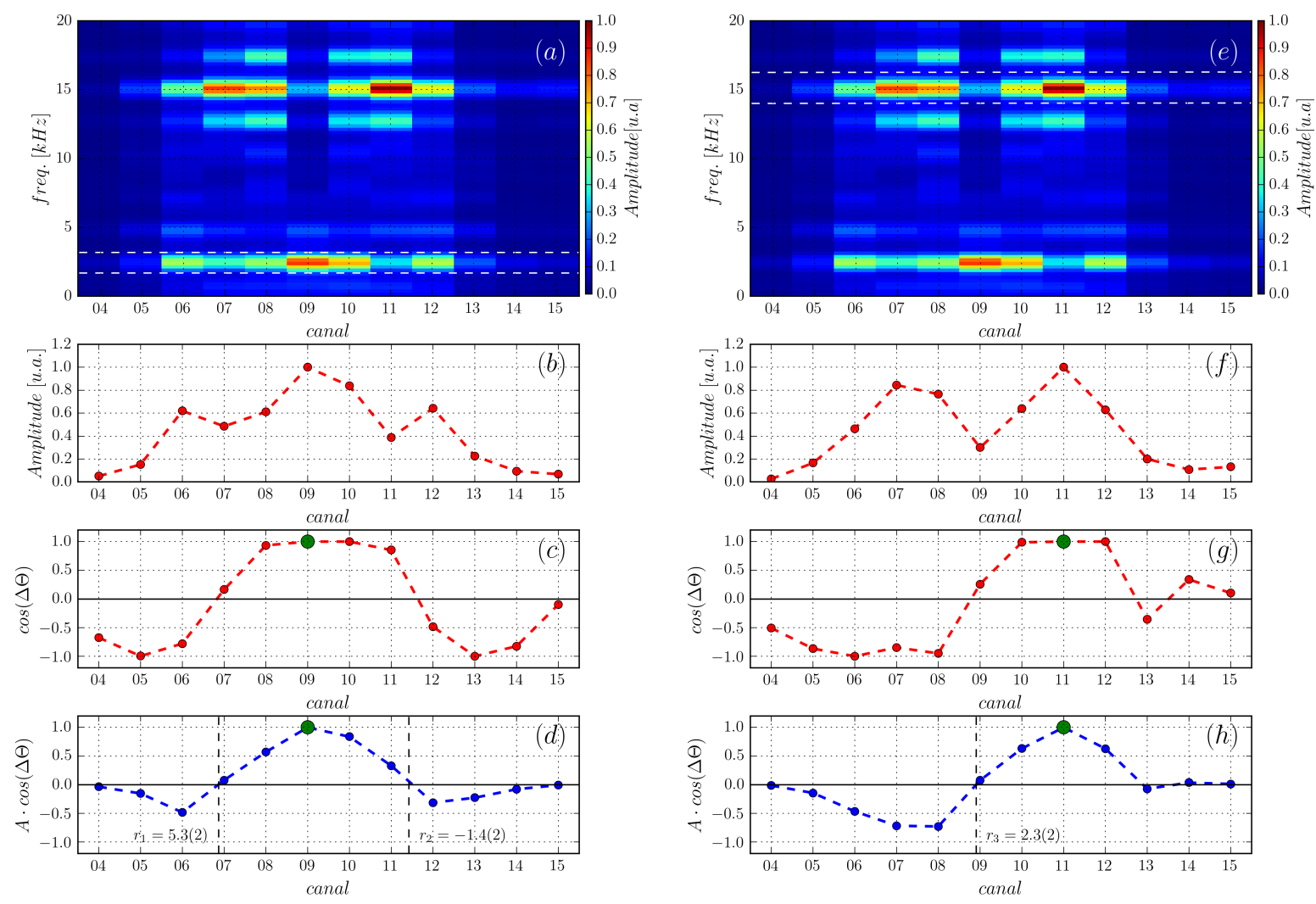

Figura 61 - Análises da distribuição espacial da potência espectral média dos sinais do SXR para o disparo \#26136 para o intervalo de tempo de 75 à $85 \mathrm{~ms}$ para os canais 4 à 15. Em (a) até (d) estão os resultados referentes à $f_{R E L}$ e em (e) à (f) os resultados referentes à $f_{P R E}$.

Os valores interpolados para os pontos de inversão de fase na curva $A \cdot \cos (\Delta \Theta)$ referentes a oscilação dente de serra foram $r_{1}=(5,3 \pm 0,2) \mathrm{cm}$ e $r_{2}=(-1,4 \pm 0,2) \mathrm{cm}$ em relação ao eixo óptico do instrumento, resultando num raio de inversão de fase $r_{s}=(3,4 \pm 0,2) \mathrm{cm}$ e, para o ponto de inversão de fase referente a precursora da dente de serra foi obtido o valor $r_{3}=(2,3 \pm 0,2) \mathrm{cm}$ em relação ao eixo óptico do instrumento, como destacado no gráfico em (h). No exemplo da figura 58, referente ao disparo \#28661 que apresenta atividade MHD muito pouco intensa, é perceptível que as componentes satélites presentes estão abaixo da $f_{P R E}$, não sendo visíveis componentes acima, enquanto na figura 61, referente ao disparo \#26136 que apresenta atividade MHD um pouco mais elevada 
que no caso anterior, as componentes satélites são simétricas com relação à frequência da precursora e que ambas as satélites apresentam potência espectral semelhante. Ademais, o espaçamento entre elas e a $f_{P R E}$ é da ordem da frequência da relaxação da dente de serra $f_{R E L}$.

\subsubsection{Disparos com alta atividade MHD}

Conforme discutido na seção 5.1, a intensidade da atividade MHD associada às ilhas magnéticas na região mais externa da coluna de plasma são medidas pelas bobinas de Mirnov. A presença das ilhas modifica as propriedades de emissividade local do plasma, pois perturbam as variáveis como temperatura e densidade de espécies. Devido à rotação das ilhas magnéticas, os sinais integrados dos diagnósticos ópticos podem detectar as alterações na emissão de radiação ao longo da linha de visada que intercepta a ilha, como já discutido na seção 3.3. Para ilustrar esse fenômeno, foram utilizados os dados do disparo \#28400, cujos parâmetros de equilíbrio já foram apresentados nos gráficos da figura 45. A análise da distribuição espacial da potência espectral para os sinais do SXR estão mostradas nos gráficos da figura 62. Em termos gerais, vê-se um comportamento análogo aos casos estudados anteriormente.
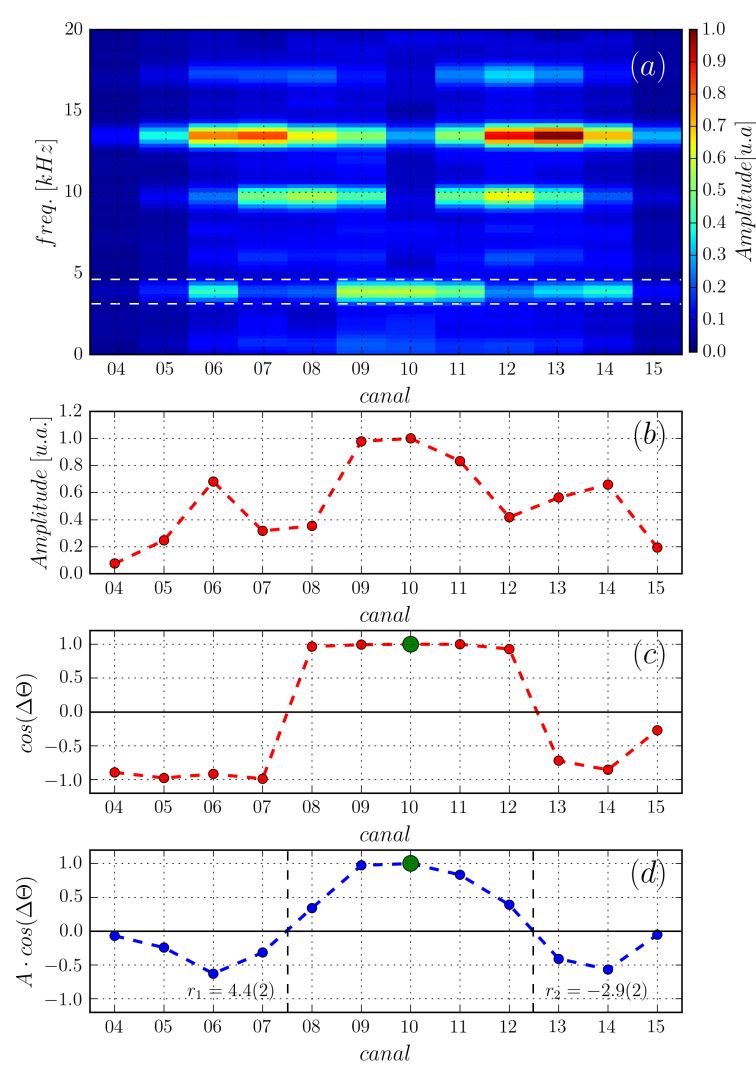
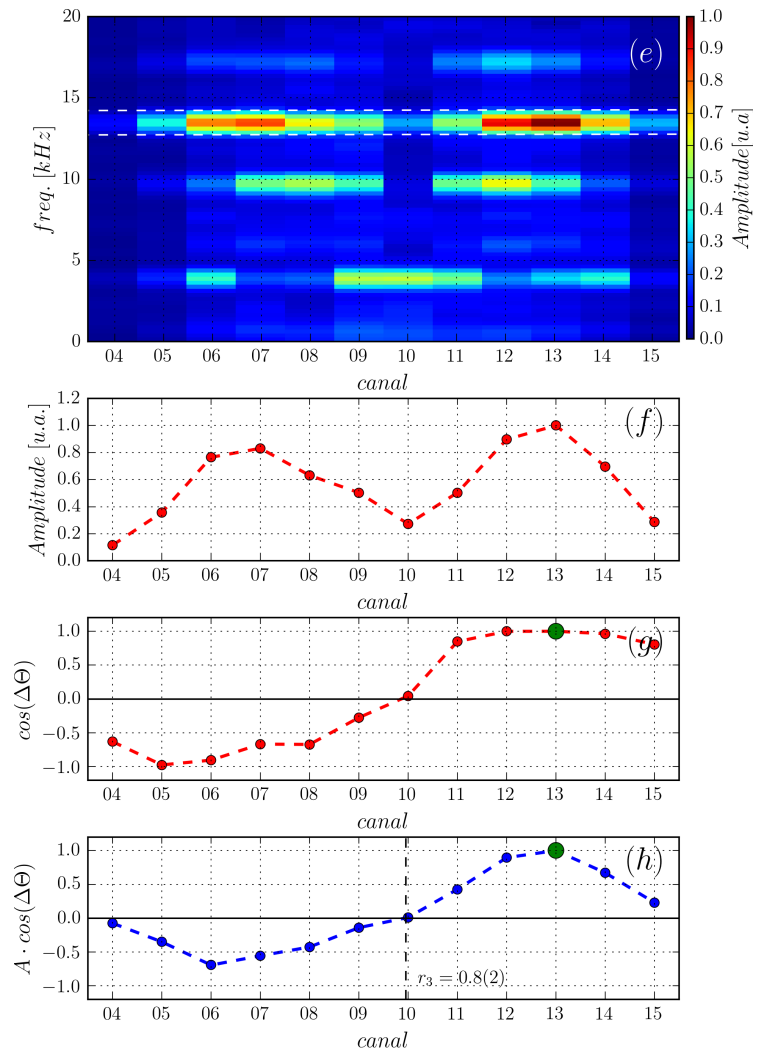

Figura 62 - Análises da distribuição espacial da potência espectral média dos sinais do SXR para o disparo \#28400 no o intervalo de tempo de 75 à $80 \mathrm{~ms}$ para os canais 4 à 15 . Em (a) até (d) estão os resultados referentes à $f_{R E L}$ e em (e) à (f) os resultados referentes à $f_{P R E}$. 
Uma diferença notável é que as componentes de frequências satélites da $f_{P R E}$ são mais intensas, com potência espectral comparável à própria $f_{P R E}$, conforme pode ser visto nos gráficos 62(a) e 62(e). Outra diferença notável é a frequência da relaxação do centro, que é muito superior à observada nos disparos com baixa atividade MHD. Nesse disparo foram encontrados $f_{R E L}=(3,87 \pm 0,12) k H z$ e $f_{P R E}=(13,47 \pm 0,12) k H z$, acompanhada das frequências satélites de $f_{P R E}^{s a t 1}=(17,32 \pm 0,12) k H z$ e $f_{P R E}^{s a t 2}=(9,76 \pm 0,12) k H z$, sendo o espaçamento entre os satélites é da ordem do valor da frequência do dente de serra $f_{R E L}$. Ademais, comportamento da amplitude e fase dos sinais em cada canal apresenta comportamento análogo aos casos anteriormente apresentados.

\subsection{Estudo das interferências das oscilações}

Na seção 5.1 foram realizados estudos experimentais dos sinais produzidos pelas bobinas de Mirnov devido as perturbações magnéticas localizadas nas superfícies racionais e na borda do plasma. Foram determinadas a localização radial e a estrutura espacial dos modos de oscilação na coordenada poloidal. E na seção 5.2 foram tratadas das oscilações do centro da coluna, detectadas pelo sistema SXR, que alteram as propriedades de emissividade óptica do plasma nesta região, mas que também se estendem para além da superfície $q=1$.

Até aqui, pouco foi dito sobre a diversidade espectral dos sinais produzidos por estes diagnósticos, mas em linhas gerais, os sinais das bobinas de Mirnov apresentam poucas componentes de frequência, as quais estão associadas com o movimento das ilhas magnéticas com relação ao referencial do laboratório (que é onde as bobinas estão colocadas). Como devido aos efeitos viscosos é razoável considerar que as ilhas estejam aproximadamente em repouso no referencial do plasma, a frequência das perturbações magnéticas medidas nas bobinas de Mirnov refletem o movimento de rotação do plasma, nas direções toroidal e poloidal. No caso das oscilações na região central da coluna de plasma, foi visto que são perceptíveis duas componentes de frequência principais, uma associada à frequência do crash da dente de serra e outra associada às oscilações precursoras da dente de serra. Mas também foram identificadas componentes satélites à frequência da precursora em situações específicas.

Nesta seção tratar-se-á de um estudo comparativo e semi-quantitativo para entender melhor a diversidade espectral que é comumente encontrada nos sinais produzidos pelos instrumentos ópticos, magnéticos e nos demais diagnósticos do tokamak TCABR e das análises e interpretações físicas dos processos responsáveis por estas características espectrais. 


\subsubsection{Estimativa da frequência pelo espectrograma}

A comparação da frequência de oscilação de dois sinais pode ser efetuada de diversas maneiras, por exemplo localizando a frequência em que ocorre o valor máximo da magnitude absoluta do espectro de Fourier e utilizando testes estatísticos para a aceitação ou rejeição de uma hipótese de igualdade ou desigualdade, dentro de um intervalo de confiança. Na prática os sinais podem conter muitas componentes espectrais ou eles podem estar associados a fenômenos físicos não estacionários, o que dificulta as análises de forma automatizada.

Uma forma de realizar a comparação entre o conteúdo espectral de um sinal em relação a outro é a seguir um ou mais caminhos no plano frequência $\times$ tempo no espectrograma de potência de um sinal tomado como referência, usando o método apresentado na figura 36(d) da seção 4.6.3, sobrepor estes caminhos ao espectrograma do sinal que se deseja analisar e avaliar por inspeção visual o conteúdo espectral relativo ao sinal de referência. Como não é possível atribuir confiabilidade absoluta na seleção manual dos caminhos no espectrograma do sinal de referência, desenvolveu-se um procedimento que a partir de uma estimativa manual da frequência no tempo, produz um refinamento aceitável do valor da frequência das componentes selecionadas nos espectrogramas. O procedimento consiste em considerar cada coluna do espectrograma (que se refere à uma janela de tempo da STFT) como um histograma da potência espectral em termos da frequência, como mostrado na figura 63(a) e (b). Para cada pico do histograma, selecionado manualmente, é ajustado uma parábola da forma $A(f)=a f^{2}+b f+c$, onde $A$ é a magnitude espectral absoluta e $f$ é a frequência. A quantidade $f_{\text {pico }}=-\frac{1}{2} \frac{b}{a}$ refere-se ao valor da frequência em que está localizada o valor máximo da potência espectral, usando o modelo parabólico ao redor da vizinhança do pico. Desta forma, o valor de $f_{\text {pico }}$ constitui uma boa estimativa para o valor da frequência, para a janela de tempo considerada no espectrograma. $\mathrm{O}$ procedimento está ilustrado na figura 63(b).

O processo é repetido para todos os pontos do caminho manual de forma que obtém-se a estimativa da evolução temporal da frequência, como mostrado na figura 63(c).

É importante salientar que a dispersão dos picos de frequência estão relacionados com o efeito do alargamento devido ao janelamento dos dados utilizado no cálculo da STFT e como visto na seção 4.5 o resultado desta operação é a convolução do sinal com a função janela empregada. Sendo assim, a utilização de medidas de dispersão de dados do histograma não constitui uma maneira apropriada para a estimativa das incertezas experimentais do valor da frequência. Uma possibilidade para obter esta estimativa é considerar a resolução máxima em frequência devido à largura da janela de Fourier empregada na construção do espectrograma. Pode-se considerar a incerteza na frequência como sendo a metade da resolução em frequência [67], ou seja, a metade da menor frequência possível de ser representada pela quantidade de amostras contidas na janela 

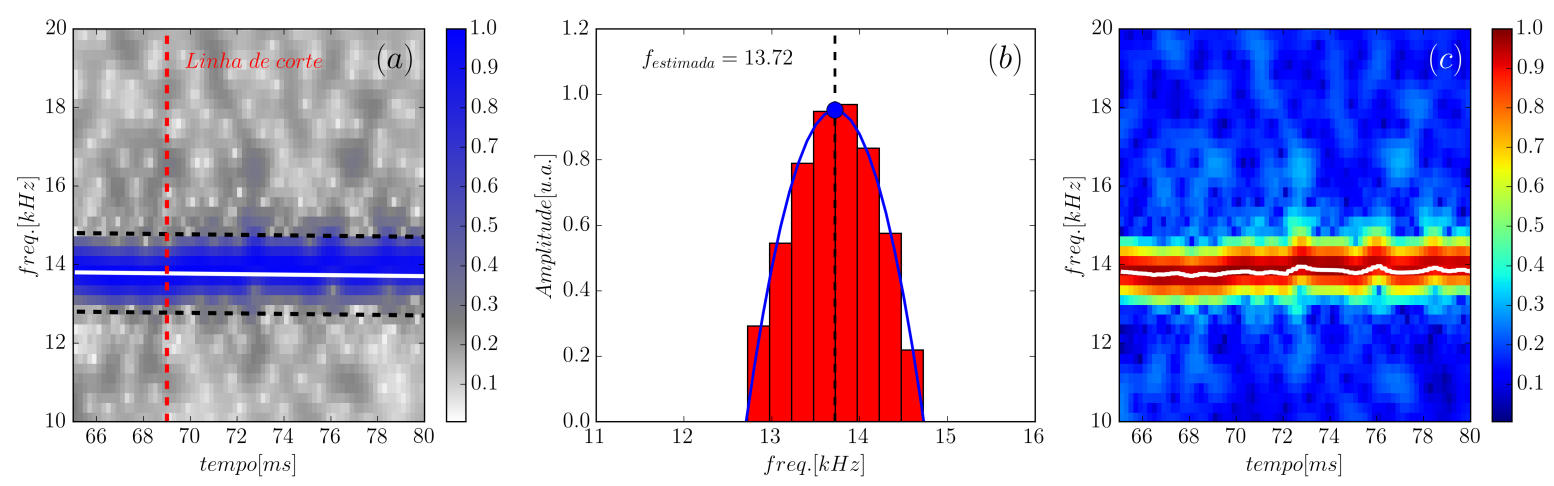

Figura 63 - Refinamento da estimativa da evolução no tempo de uma componente de frequência de um espectrograma. Em (a) espectrograma de um sinal. A linha branca sobreposta constitui uma estimativa manual do valor da frequência no tempo, as linhas pretas delimitam a largura da banda de frequências onde o pico da magnitude será procurado e a linha vertical vermelha especifica o marcador do tempo. Em (b) o histograma de potência espectral para o instante de tempo selecionado e em (c) o valor refinado da componente de frequência no tempo, usando como estimativa a coordenada do ponto de máxima magnitude espectral obtida pelo ajuste parabólico.

e portanto, tem-se que $\sigma_{f} \approx \Delta f / 2=f_{s / 2}$, onde $\Delta f$ é a resolução em frequência, $f_{s}$ é a taxa de amostragem do sinal e $w$ é a largura em número de amostras da janela utilizada no cálculo da STFT.

\subsubsection{Interferências e batimentos}

Para entender melhor a relação entre as componentes satélites, identificadas na seção 5.3.1, com as demais oscilações estudadas (oscilações de Mirnov, dente de serra e precursora de dente de serra) vamos analisar os espectrogramas do sinal das bobinas de Mirnov e um dos canais centrais do SXR (canal 7) para o disparo \#30330 que estão mostrados nos gráficos da figura 64(a) e (b) empregando o método de comparação de frequências pela sobreposição dos caminhos que foi apresentado na seção anterior. A figura 64(a) mostra o espectrograma do sinal da bobina de Mirnov 01 e um caminho em linha de cor verde tracejada selecionada sobre a componente de frequência da ordem de $\approx 15 \mathrm{kHz}$. No gráfico em (b) está mostrado o espectrograma do sinal do canal 7 do SXR e a linha traceja vermelha identifica a frequência principal da oscilação dente de serra, denotada por $f_{R E L}$. Em (c) está o espectrograma do canal 8 do SXR, também central, que será objeto das análises. O mesmo espectrograma em (c) está repetido em (d) mas com a escala de cores escolhida de forma a facilitar a visualização das frequências rasteadas e que estão sobrepostas sobre a figura. Em verde está sobreposto o caminho referente à $f_{M I R}$ e em vermelho o caminho referente a $f_{R E L}$.

O gráfico com a sobreposição mostra que as duas componentes $f_{M I R}$ e $f_{R E L}$ estão presentes no sinal do canal 8 do SXR e mais ainda, o gráfico também mostra que as componentes satélites da $F_{P R E}$ podem ser identificadas pela soma e diferença entre a 

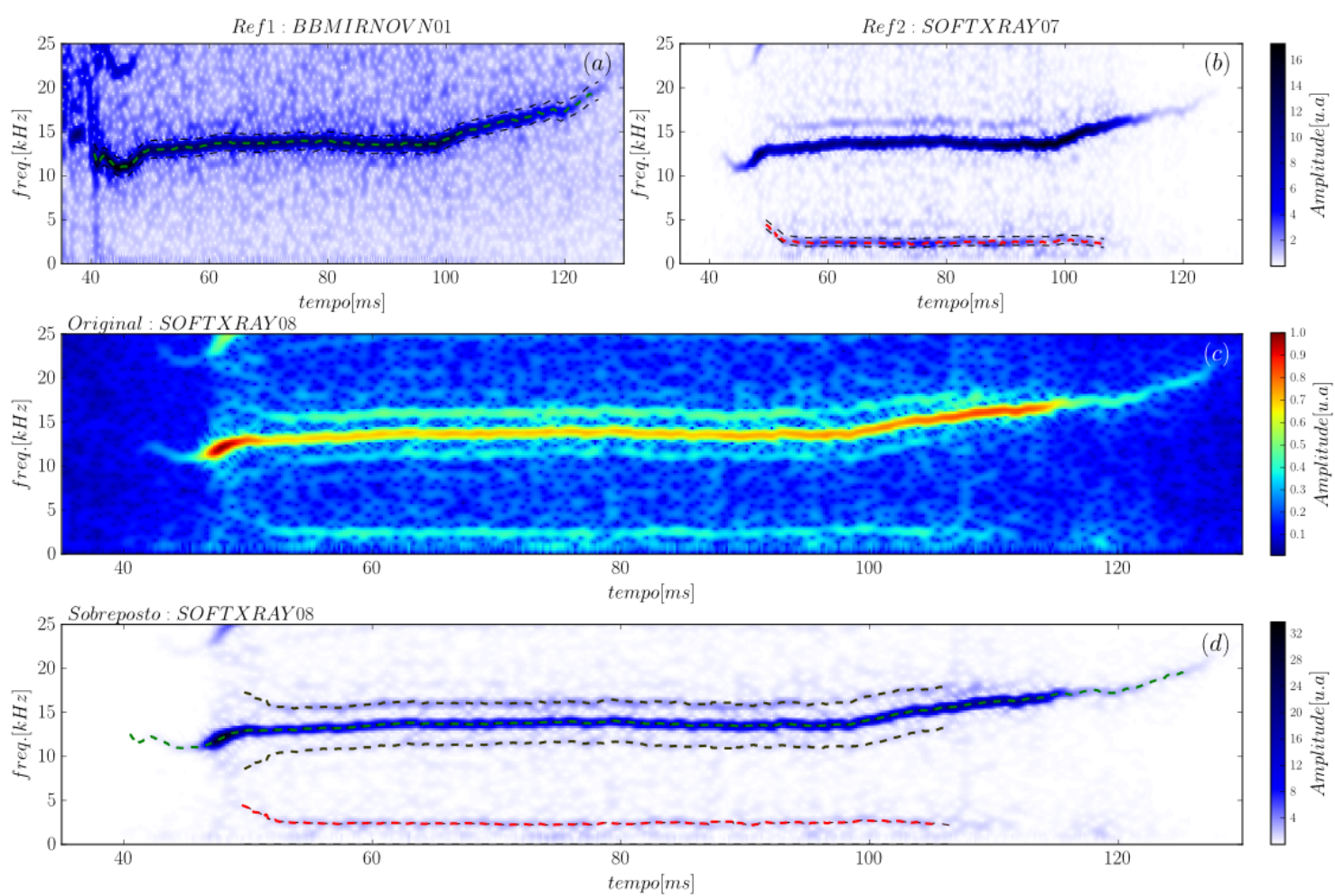

Figura 64 - Análises comparativas das componentes espectrais dos sinais de referência para o disparo \#30330. Em (a) o espectrograma da bobina de Mirnov 01 e o respectivo caminho no plano frequência $\times$ tempo em cor verde, em (b) o espectrograma do canal 07 do SXR e respectivo caminho em cor vermelha, em (c) o espectrograma do sinal a ser comparado, nestes caso o canal 8 do SXR e em (d) o mesmo espectrograma a ser comparado com a sobreposição dos caminhos de frequência das referências.

frequência de Mirnov e a frequência de oscilação da dente de serra $f_{\text {sat }}=f_{M I R} \pm f_{R E L}$.

De forma análoga, esse composição de frequências a partir das frequências base $f_{M I R}$ e $f_{R E L}$ pode ser observada em outros disparos no TCABR, como no caso do \#26136, já analisado nas seções anteriores. A comparação das componentes de frequência estão mostradas nos gráficos da figura 65. Igualmente ao exemplo anterior, os espectrogramas dos sinais de referência estão mostrados em (a) e (b) juntamente com os respectivos caminhos. A comparação é efetuada pela sobreposição das frequências no espectrograma do canal 9 do SXR, também central, como mostrado em (d).

Neste disparo, percebe-se que a diversidade espectral dos sinais do canal analisado é maior que do sinal utilizado no exemplo anterior, visto que o espectrograma do sinal apresentado no gráfico da figura $65(\mathrm{~d})$ estão presentes outras frequências, além das componentes $f_{M I R}, f_{R E L}$ e $f_{M I R} \pm f_{R E L}$. Mas é difícil comparar estas componentes adicionais com as frequências de base, visto que elas não são claramente identificáveis nos espectrograma.

Em alguns disparos essas componentes adicionais são mais facilmente visíveis, como no caso do disparo \#29754, cujas variáveis de equilíbrio estão apresentadas nos gráficos 

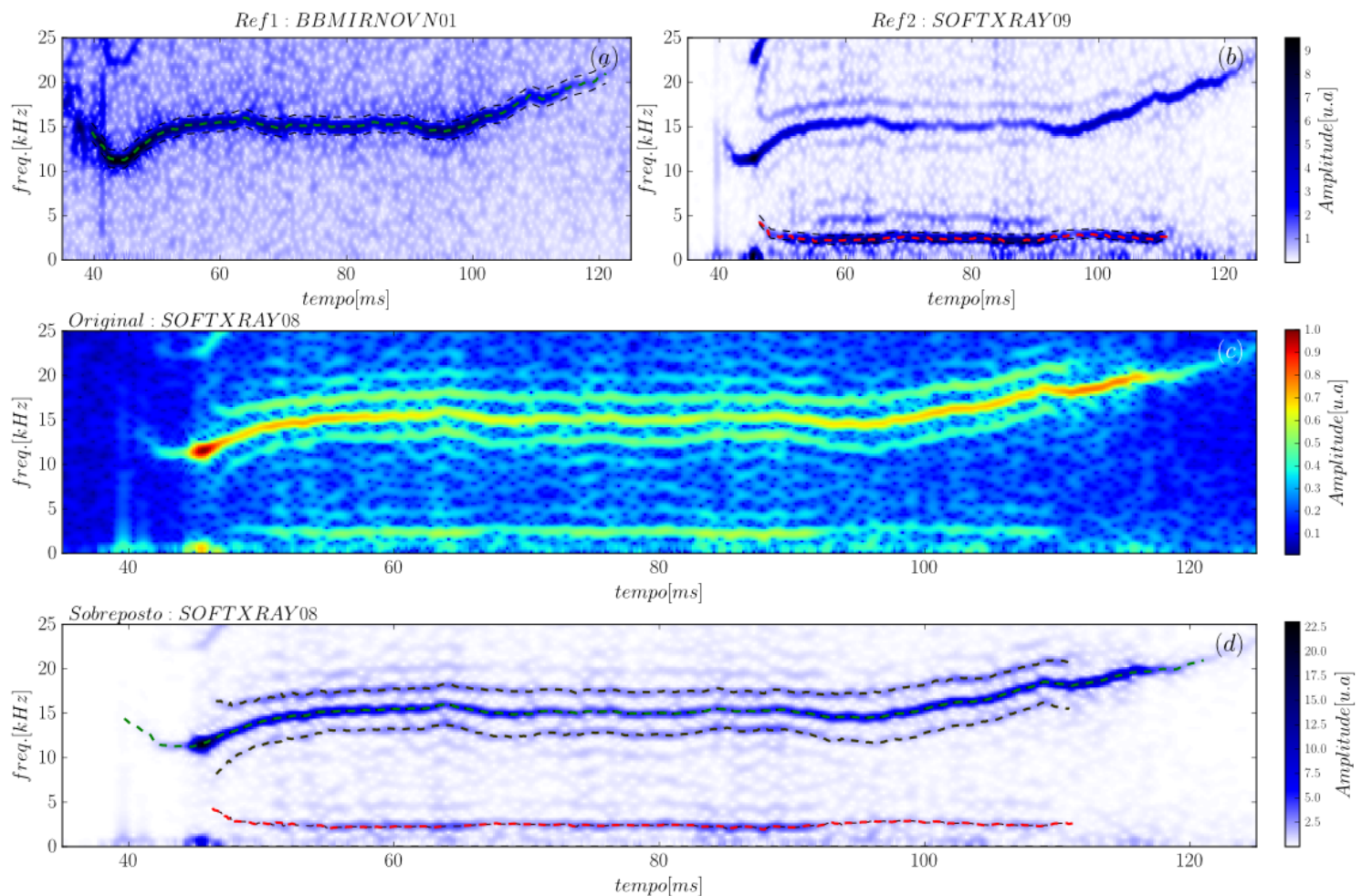

Figura 65 - Análises comparativas das componentes espectrais dos sinais de referência para o disparo \#26136. Em (a) o espectrograma da bobina de Mirnov 01 e o respectivo caminho no plano frequência $\times$ tempo em cor verde, em (b) o espectrograma do canal 09 do SXR e respectivo caminho em cor vermelha, em (c) o espectrograma do sinal a ser comparado, nestes caso o canal 8 do SXR e em (d) o mesmo espectrograma a ser comparado com a sobreposição dos caminhos de frequência das referências.

da figura 66. Este disparo apresenta corrente de plasma $I_{p}=80 \mathrm{kA}$ plana de $42 \sim 90 \mathrm{~ms}$, com densidade eletrônica de $n_{e}=1,5 \times 10^{19} \mathrm{~m}-3$, baixa atividade MHD e pouca emissão de raios-X duros.
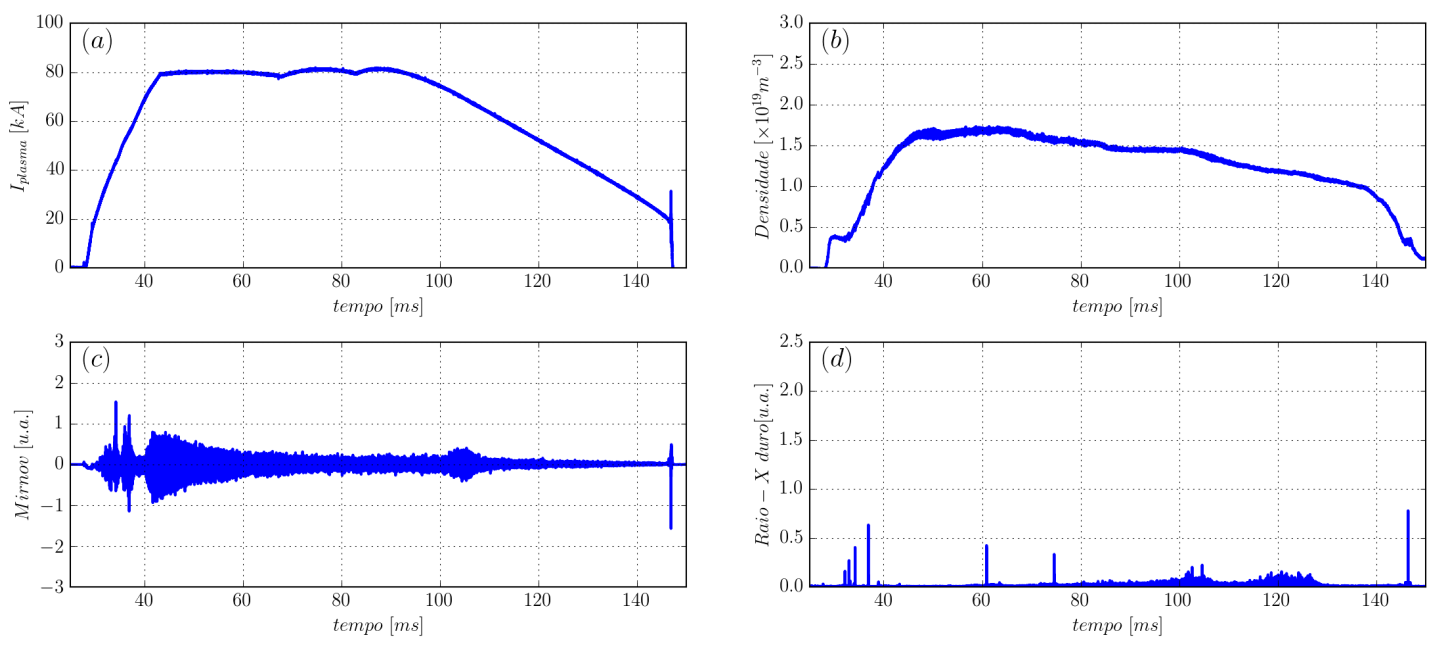

Figura 66 - Variáveis de equilíbrio para o disparo \#29754 do TCABR. Com corrente de plasma em (a), densidade central em (b), sinal da bobina de Mirnov de referência em (c) e sinal da emissão de raios-X duros em (d). 
Para este disparo, as análises de comparação de frequências estão mostradas na figura 67. foram considerados o sinal da bobina de Mirnov 01 e o sinal do canal 10 do SXR como referências de frequência, conforme mostrado nos gráficos em (a) e (b), onde também estão traçados os respectivos caminhos pelas linhas em cor verde e vermelho. $\mathrm{O}$ espectrograma em (c), referente ao sinal do canal 9 do SXR, mostra muitas componentes de frequência distribuídas simetricamente com relação a componente de frequência de $\approx 15 k H z$, com amplitude mais intensa e que está identificada no gráfico como $f_{P R E}$. O espectrograma também mostra a outra componente de frequência de aproximadamente $2,5 k H z$ que dura de de $50 m s$ até o final do disparo e que está identificada como $f_{R E L}$.
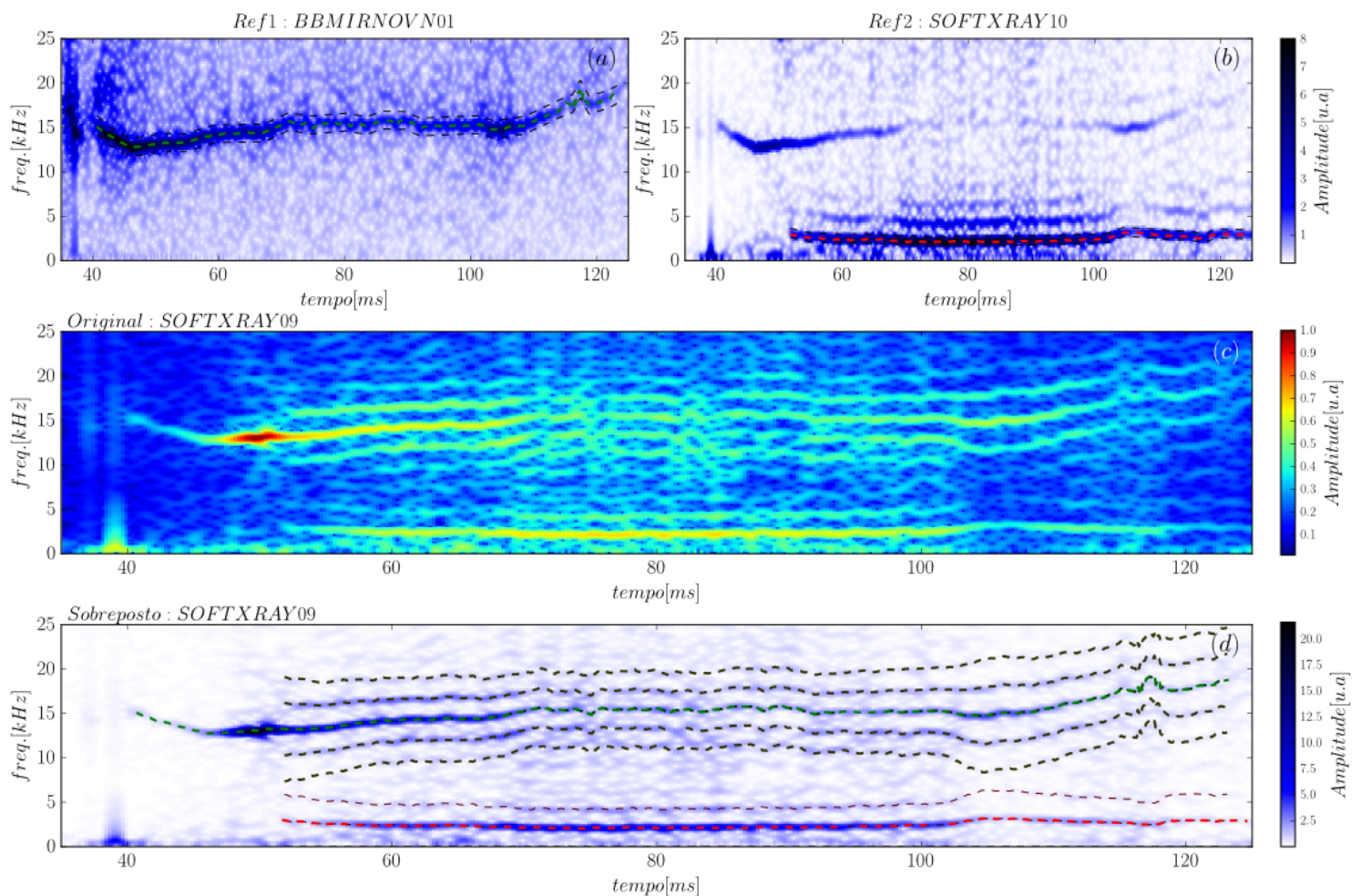

Figura 67 - Análises comparativas das componentes espectrais dos sinais de referência para o disparo \#29754. Em (a) o espectrograma da bobina de Mirnov 01 e o respectivo caminho no plano frequência $\times$ tempo em cor verde, em (b) o espectrograma do canal 10 do SXR e respectivo caminho em cor vermelha, em (c) o espectrograma do sinal a ser comparado, nestes caso o canal 9 do SXR e em (d) o mesmo espectrograma a ser comparado com a sobreposição dos caminhos de frequência das referências.

As componentes de frequência rastreadas nos sinais de referência foram sobrepostas ao espectrograma do sinal do canal 9, como mostrado no gráfico da figura 67(d). Ademais, também foram sobrepostas as frequências de valor $f_{\text {sat }}=f_{M I R} \pm f_{R E L}$ e $f_{\text {sat }}=f_{M I R} \pm 2 f_{R E L}$. Percebe-se que estas linhas casam perfeitamente sobre as componentes espectrais simétricas à $f_{M I R}$.

Situações análogas às mostradas nestes três exemplos (disparos \#30330, \#26136 e \#29754) podem ser encontrados na maioria dos disparos do TCABR. De forma geral, essa 
diversidade espectral encontrada nos sinais produzidos pelos diagnósticos ópticos contém componentes de frequência $f_{M I R}, f_{R E L}$ e demais componentes que podem ser obtidas pela combinação linear de $f_{M I R}$ e $f_{R E L}$ da forma $f=k_{1} f_{M I R} \pm k_{2} f_{R E L}$ onde $k_{1}$ e $k_{2}$ são números inteiros positivos.

Este padrão matemático do valor da frequência das componentes espectrais sugere que as oscilações das propriedades de emissividade do plasma estão sujeitas à fenômenos de interferência como batimentos ou intermodulação entre as oscilações referentes a fenômenos físicos que são, em princípio, completamente distintos; uma delas referente a uma relaxação do centro da coluna de plasma $\left(f_{R E L}\right)$ e outra que governa a rotação das ilhas magnéticas nas superfícies racionais $\left(f_{M I R}\right)$ e também referente às oscilações do modo kink interno $\left(f_{P R E}\right)$, na superfície racional $q=1$. Ademas, estes três exemplos também mostram que a sobreposição da frequência $f_{M I R}$ coincide precisamente, dentro das incertezas do valor experimental, sobre a componente de frequência relativa à oscilação precursora de dente de serra $\left(f_{P R E}\right)$. Isto sugere que, se é que existe diferença do valor da frequência entre $f_{M I R}$ e $f_{P R E}$, essas diferenças são muito pequenas.

As componentes satélites observadas nos espectrogramas desta seção e nas decomposições espaciais efetuadas na seção 5.2 podem ser entendidas como modulação de amplitude, cuja modelagem matemática é efetuada considerando um sinal do tipo:

$$
x(t)=A_{p} \cos \left(2 \pi f_{p} t\right)
$$

onde $x(t)$ é um sinal chamado de portadora, com amplitude $A_{p}$ e frequência $f_{p}$. Se $x(t)$ tem a amplitude modulada, então $A_{p}=A_{p}(t)$ que pode ser escrito genericamente como $A_{p}(t)=A_{0}+a_{m}(t)$, onde $A_{0}$ é a amplitude nominal da portadora e $a_{m}(t)$ é o sinal modulante. Substituindo estas definições na equação (5.2), obtemos:

$$
x(t)=\left[A_{0}+a_{m}(t)\right] \cos \left(2 \pi f_{p} t\right)
$$

Em primeira aproximação, podemos considerar um sinal modulante da forma $a_{m}(t)=a_{m 0} \cos \left(2 \pi f_{m} t\right)$, onde $a_{m 0}$ é a amplitude do sinal modulante e $f_{m}$ é a frequência deste sinal. Substituindo $a_{m}(t)$ na expressão (5.3), obtêm-se:

$$
x(t)=\left[A_{0}+a_{m 0} \cos \left(2 \pi f_{m} t\right)\right] \cos \left(2 \pi f_{p} t\right)=A_{0} \cos \left(2 \pi f_{p} t\right)+a_{m 0} \cos \left(2 \pi f_{m} t\right) \cos \left(2 \pi f_{p} t\right),
$$

que utilizando identidades matemáticas pode ser finalmente escrito da forma:

$$
x(t)=A_{0} \cos \left(2 \pi f_{p} t\right)+\frac{a_{m 0}}{2}\left[\cos \left(2 \pi\left(f_{p}+f_{m}\right) t\right)+\cos \left(2 \pi\left(f_{p}-f_{m}\right) t\right)\right]
$$

Do exposto, o sinal modulado, contém as componentes de frequência $f_{p}, f_{p}+f_{m}$ e $f_{p}-f_{m}$ e, desta forma, aplicando ao caso das frequências $f_{P R E}$ e $f_{R E L}$ podemos considerar que o processo físico envolvido na produção das componentes satélites trata-se de uma 
modulação de amplitude da emissividade. Ademais, as componentes satélites de ordem superior, $f_{\text {sat }}=\left(k_{1} f_{P R E} \pm k_{2} f_{R E L}\right)$, identificadas na seção 5.2, podem ser obtidas de forma análoga, considerando um sinal modulante apropriado. Um modelo alternativo, que leva em conta efeitos de modulação não linear está em [68].

\subsubsection{Interferências em outros sinais}

Até o momento vimos as interferências provocadas pelas frequências base (oscilações de Mirnov e oscilação dente de serra) nos canais do diagnóstico SXR e que elas podem ser observadas na maioria dos disparos do TCABR. Mas estas mesmas componentes podem ser detectadas por vários outros instrumentos, indicando que que as perturbações magnéticas das ilhas nas superfícies racionais e o fenômeno da reconexão magnética na superfície racional $q=1$ podem perturbar todas as outras propriedades do plasma, além da emissividade na região do raio-X moles.

Como forma de exemplificar estes efeitos, vamos analisar os sinais do disparo \#26842, cujas variáveis de equilíbrio encontram-se nos gráficos da figura 68. Este disparo apresenta corrente de plasma de $I_{p}=84 k A$ plana na região de $50 \sim 100 \mathrm{~ms}$, com densidade eletrônica central de $n_{e}=1,1 \times 10^{19} \mathrm{~m}^{-3}$, atividade MHD intensa durante toda a região de platô da corrente de plasma, e também apresenta pouco emissão de raios-X duros.
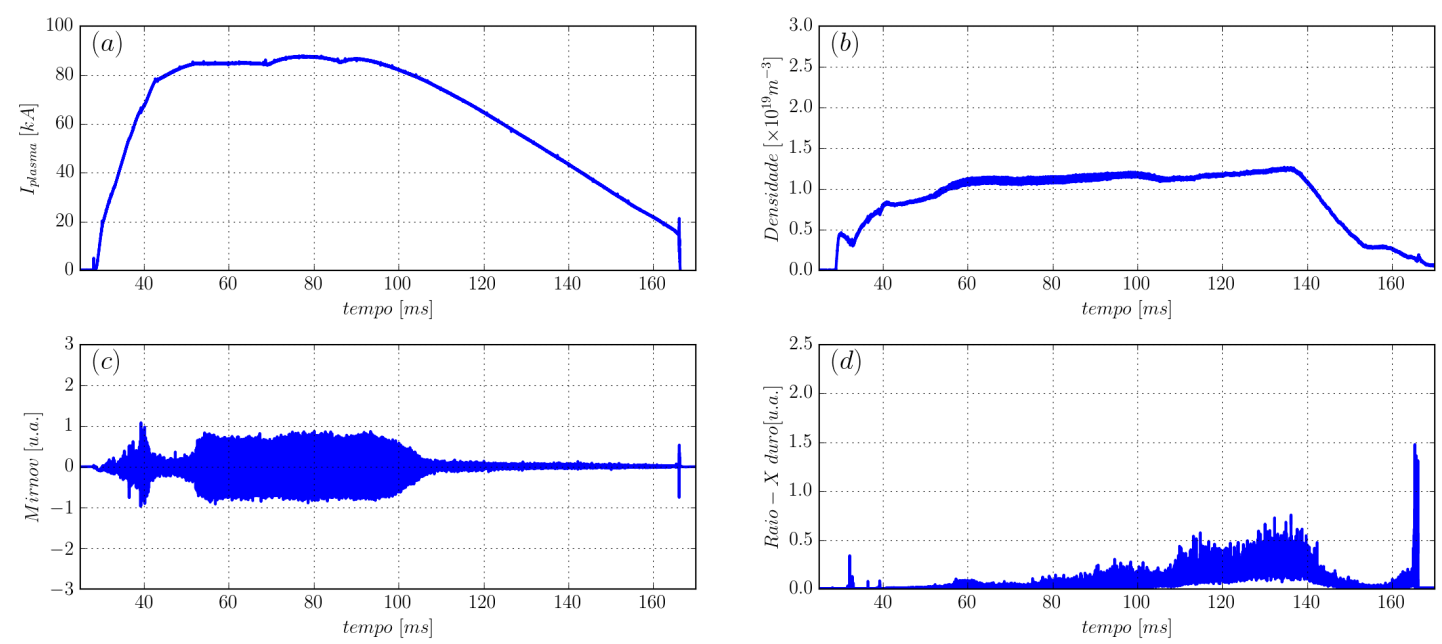

Figura 68 - Variáveis de equilíbrio para o disparo \#26842 do TCABR. Com corrente de plasma em (a), densidade central em (b), sinal da bobina de Mirnov de referência em (c) e sinal da emissão de raios-X duros em (d).

As análises comparativas das componentes de frequência para este disparo foram efetuadas tomando as frequências rastreadas nos espectrogramas da bobina de Mirnov $01 \mathrm{e}$ do canal 8 do SXR, conforme indicado na figura 69(a) e (b), respectivamente. O gráfico em (c) mostra o espectrograma original do sinal do canal 10 do SXR enquanto que o gráfico em (d) mostra o espectrograma deste sinal com a a sobreposição das frequências de base. 

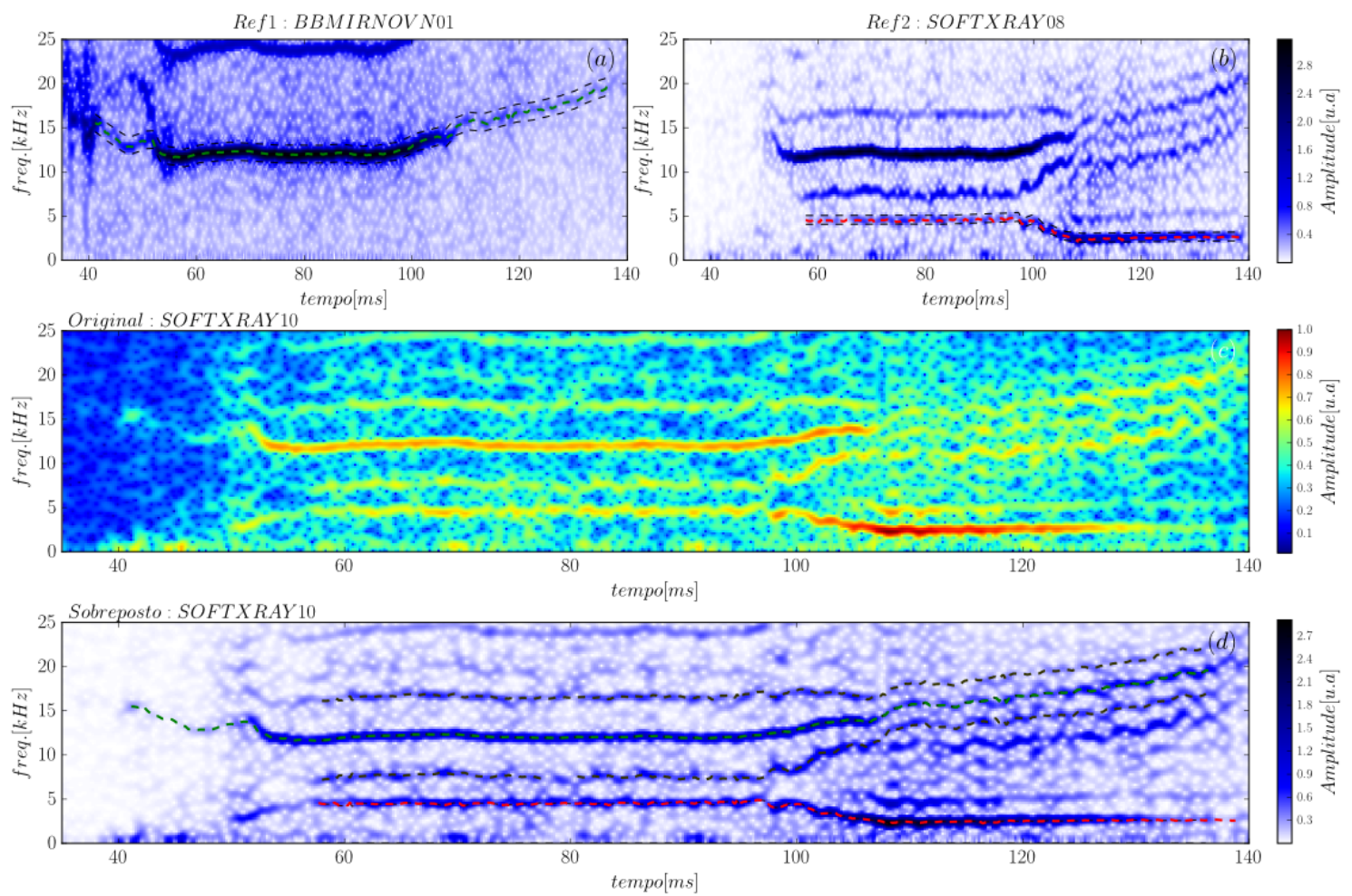

Figura 69 - Análises comparativas das componentes espectrais dos sinais de referência para o disparo \#26842. Em (a) o espectrograma da bobina de Mirnov 01 e o respectivo caminho no plano frequência $\times$ tempo em cor verde, em (b) o espectrograma do canal 8 do SXR e respectivo caminho em cor vermelha, em (c) o espectrograma do sinal a ser comparado, nestes caso o canal 10 do SXR e em (d) o mesmo espectrograma a ser comparado com a sobreposição dos caminhos de frequência das referências.

O que é notável nestes espectrogramas é que, enquanto a atividade MHD é intensa, o valor da frequência da dente de serra é $f_{R E L} \approx 4,6 \mathrm{kHz}$ estável durante o intervalo de $50 \sim 100 \mathrm{~ms}$. quando a intensidade da atividade MHD se torna reduzida, como indicado pela magnitude espectral do sinal de Mirnov, a frequência da dente de serra cai para $f_{R E L} \approx 2,5 k H z$ e permanece neste valor até o final do disparo. Este comportamento é comumente observado durante o crescimento de ilhas magnéticas e mudanças de atividade MHD baixa para intensa e vice-versa. Para este disparo, componentes de frequência $f_{M I R}$ e $f_{P R E}$ são detectáveis nos demais diagnósticos da máquina, como exemplificado para os sinais do detector de raios-X duros (HXR) e para a medida de densidade no centro (NE03), conforme indicado nos gráficos da figura 70. Essa mostra em (a) e (c) respectivamente o espectrograma do sinal do detector de raios-X duros e o mesmo espectrograma com a sobreposição dos caminhos $f_{M I R}, f_{R E L}$ e $2 f_{M I R}$.

A emissão de raios-X duros está associada com a desestabilização das órbitas dos elétrons runaway que se formaram no início da formação da coluna de plasma. O que é de certa forma surpreendente é que, durante o período de atividade MHD intensa, a emissão de raios-X duros se dá predominantemente na frequência das ilhas magnéticas $f_{M I R}$ e 

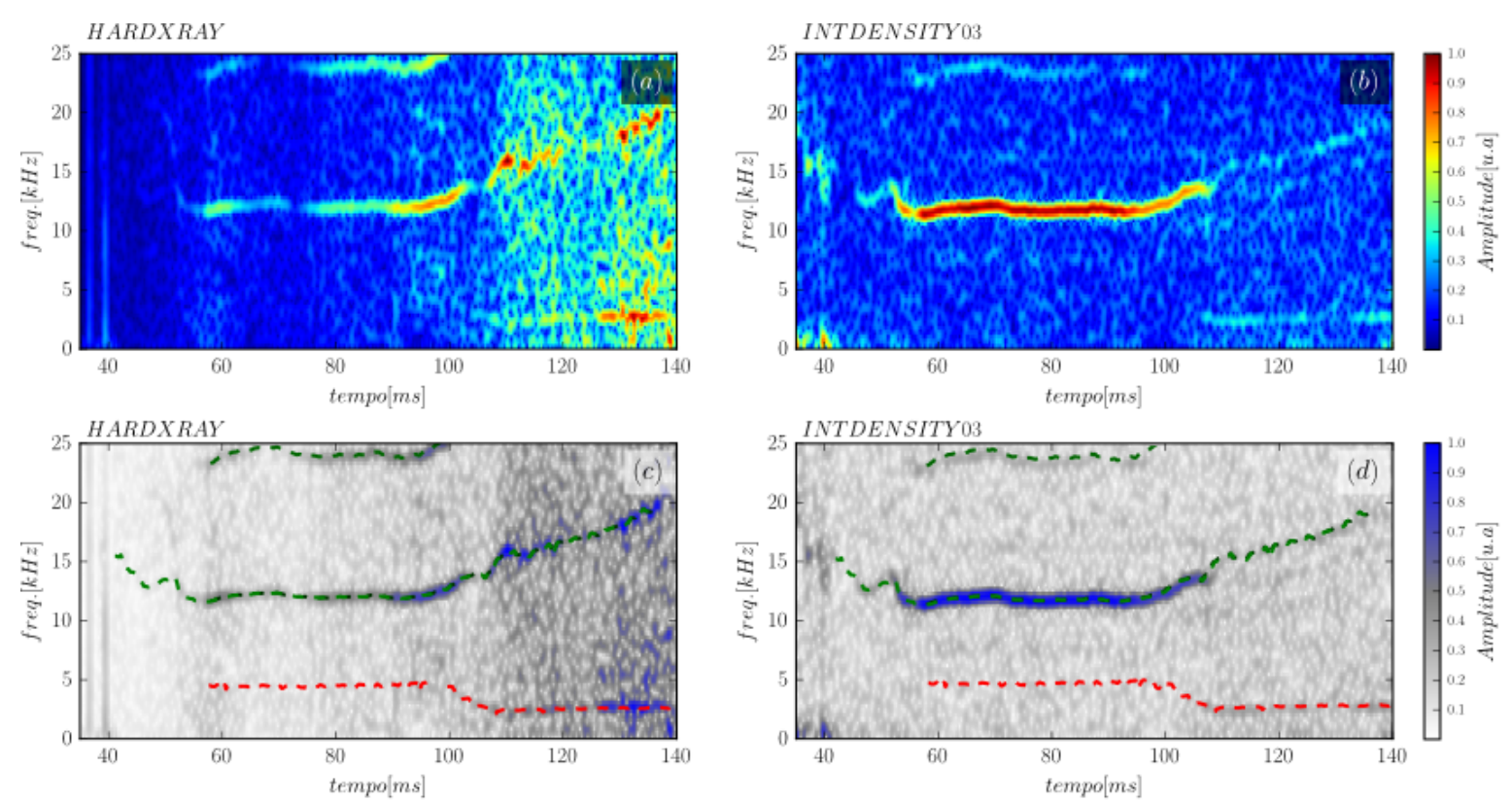

Figura 70 - Análises comparativas das componentes espectrais dos sinais de referência para o disparo \#29754 para outros sinais. Em (a) e (c) os espectrogramas do sinal de emissão de raios-X duros (HARDXRAY) respectivamente com e sem sobreposição da componentes de referência e em (b) e (d) os espectrogramas do sinal de densidade eletrônica a $-1 \mathrm{~cm}$ da posição central da coluna (NE03), respectivamente com e sem sobreposição.

que, quando a atividade MHD diminui fortemente a emissão de raios-X duros passa a ser dominada pela frequência da dente de serra $f_{R E L}$.

Já nos gráficos apresentados na figura 70(b) e (d) estão mostrados respectivamente os espectrogramas sem e com sobreposição das frequências de base para o sinal do interferômetro na corda mais central ( $-1 \mathrm{~cm}$ do centro da coluna). Os gráficos mostram uma intensa perturbação na densidade na frequência $f_{M I R}$, com a presença também da segunda harmônia $2 f_{M I R}$. Somente ao final do disparo a componente $f_{R E L}$ torna-se visível no espectrograma, mas com baixa intensidade.

Outro exemplo de que as perturbações base são também detectáveis nos demais diagnósticos pode ser visto para o disparo \#30920, cujas variáveis de equilíbrio encontramse nos gráficos da figura 71. A corrente de plasma é $I_{p}=85 k \mathrm{~A}$, plana no intervalo de $40 \sim 95 \mathrm{~ms}$, com densidade eletrônica no centro de $n_{e}=2,4 \times 10^{19} \mathrm{~m}^{-3}$, intensidade MHD moderada e baixa emissão de raios-X duros.

O estudo da comparação das componentes de frequência para este disparo estão mostrados nos gráficos da figura 72. Em (a) e (b) respectivamente, estão apresentados os espectrogramas dos sinais da bobina de Mirnov 01 e do canal 10 do SXR, juntamente com os caminhos das frequências de base $f_{M I R}$ e $f_{R E L}$, assinaladas pelas linhas tracejadas em verde e vermelho. As comparações das frequências base foram efetuadas sobre o espectrograma do sinal do canal 12 do SXR e indicam a presença de ambas as componentes 

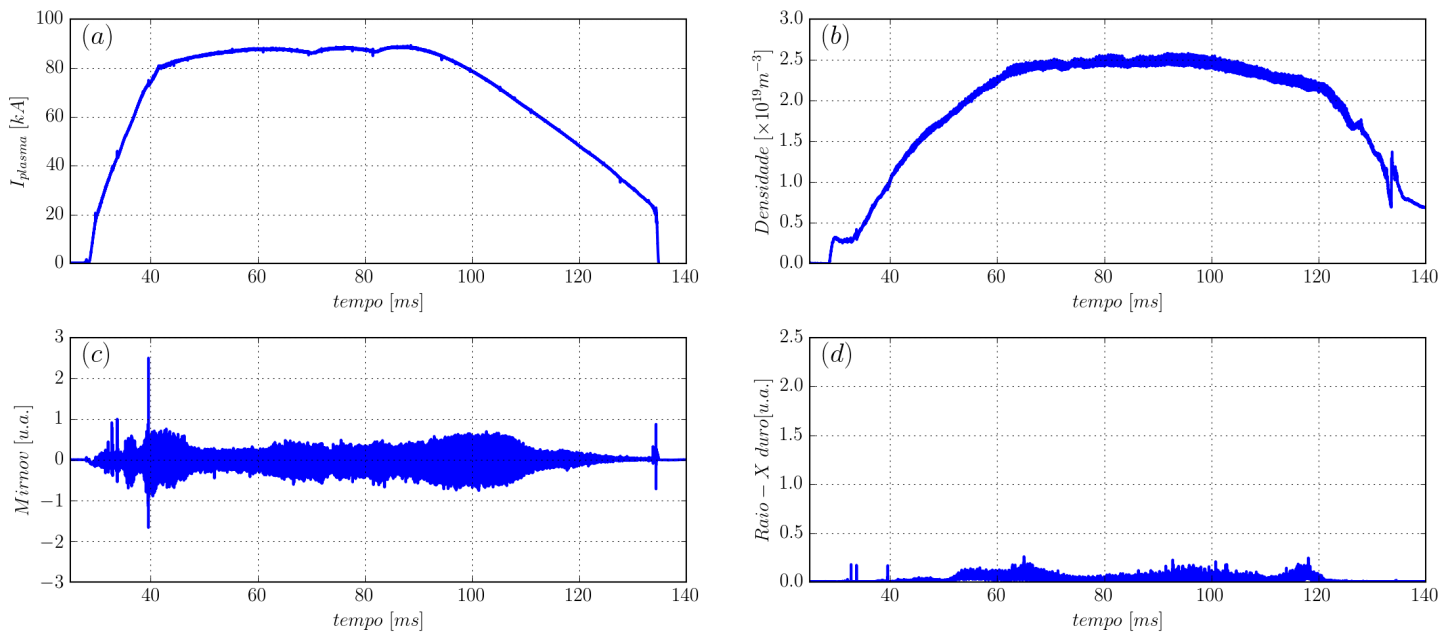

Figura 71 - Variáveis de equilíbrio para o disparo \#30920 do TCABR. Com corrente de plasma em (a), densidade central em (b), sinal da bobina de Mirnov de referência em (c) e sinal da emissão de raios-X duros em (d).

$f_{M I R}$ e $f_{R E L}$, esta última acompanha por frequências satélites $f_{M I R} \pm f_{R E L}$, conforme indicado no gráfico da figura $72(\mathrm{~d})$.
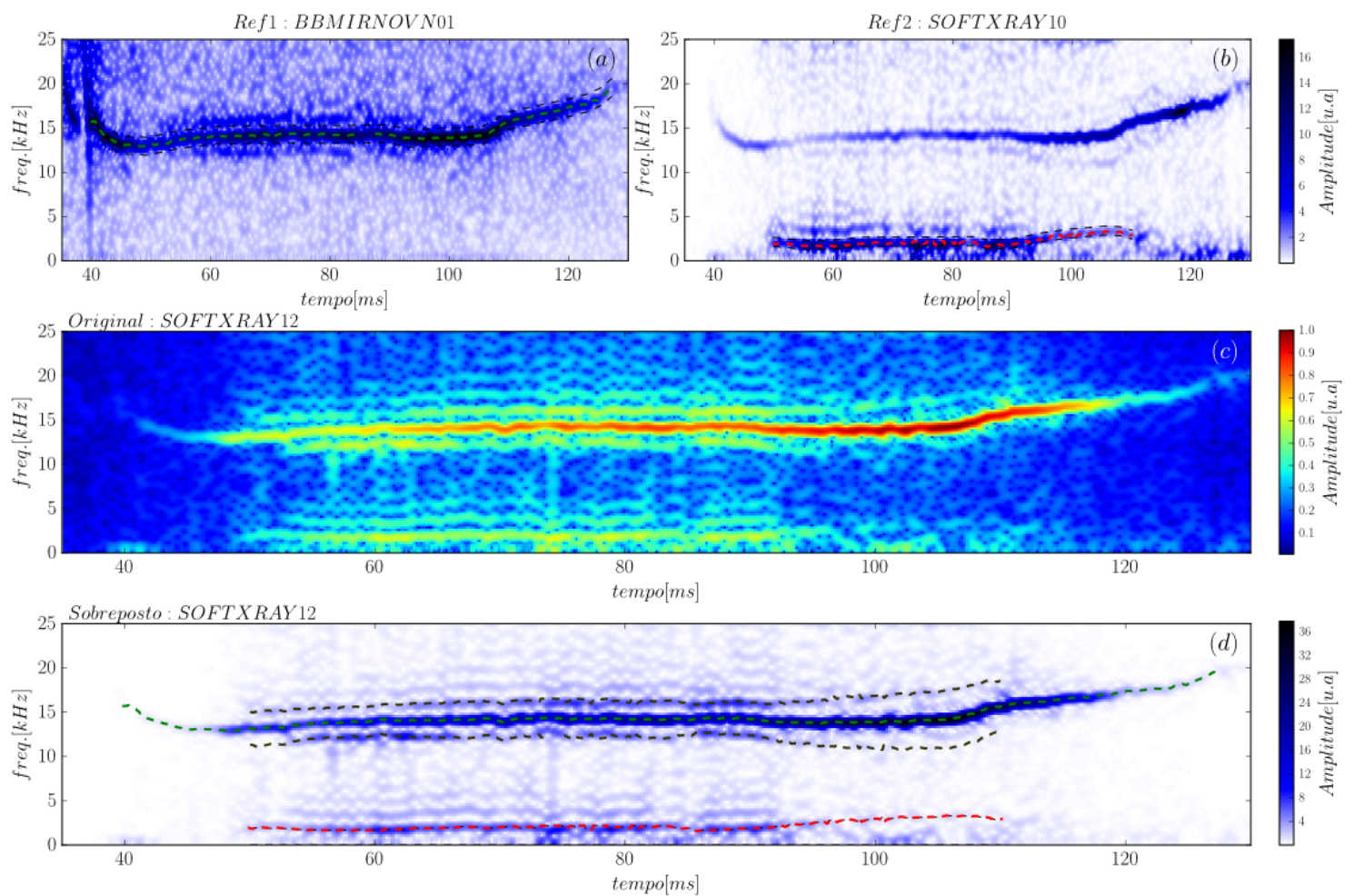

Figura 72 - Análises comparativas das componentes espectrais dos sinais de referência para o disparo \#30920. Em (a) o espectrograma da bobina de Mirnov 01 e o respectivo caminho no plano frequência $\times$ tempo em cor verde, em (b) o espectrograma do canal 10 do SXR e respectivo caminho em cor vermelha, em (c) o espectrograma do sinal a ser comparado, nestes caso o canal 12 do SXR e em (d) o mesmo espectrograma a ser comparado com a sobreposição dos caminhos de frequência das referências. 
Para mostrar a interferência em outros diagnósticos, os gráficos da figura 73 mostram os espectrogramas originais e sobrepostos para os sinais do HXR e para a bobina de Mirnov 01 (que também foi utilizada como sinal de referência).
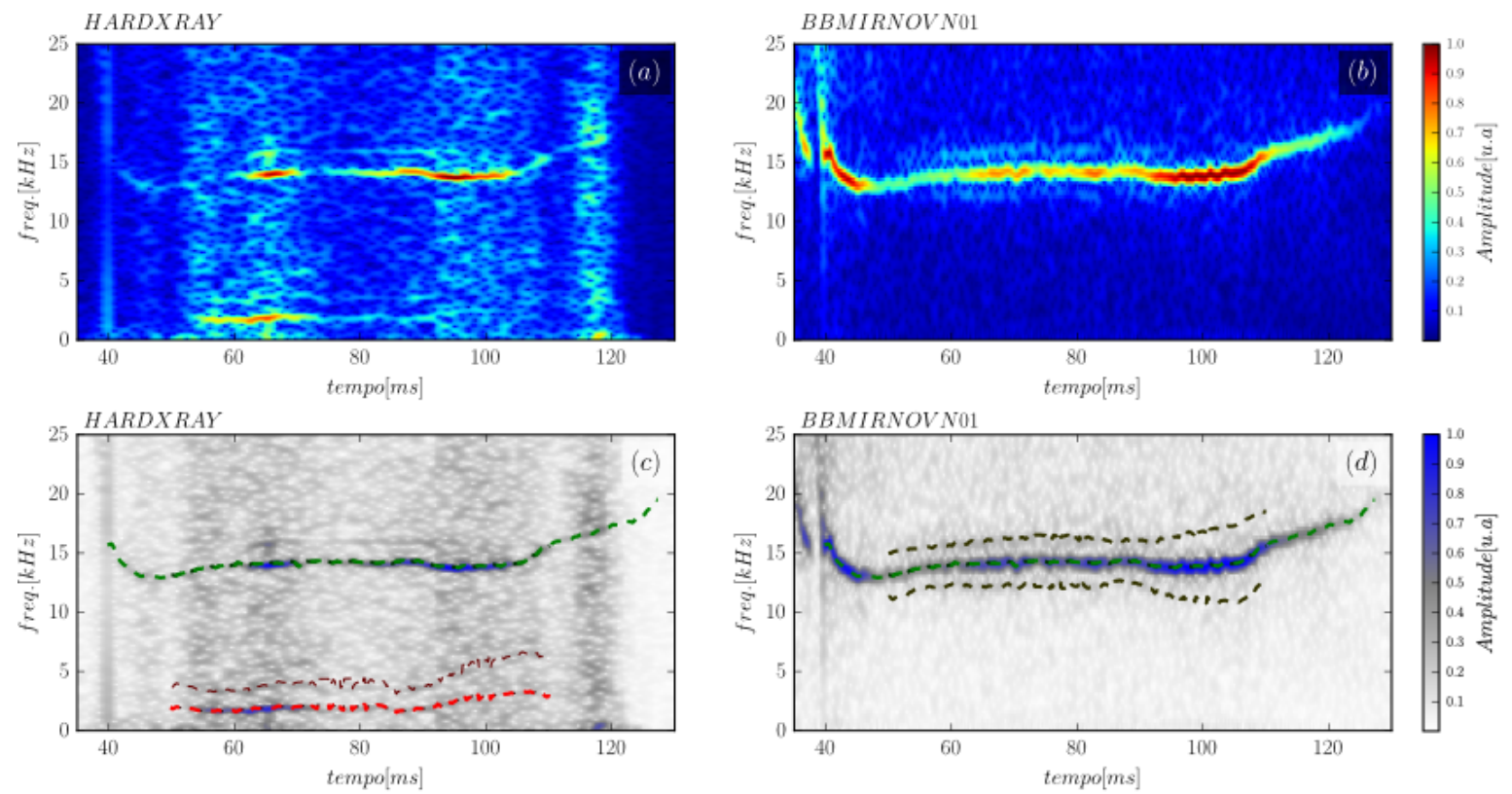

Figura 73 - Análises comparativas das componentes espectrais dos sinais de referência para o disparo \#30920 para outros sinais. Em (a) e (c) os espectrogramas do sinal de emissão de raios-X duros (HARDXRAY) respectivamente com e sem sobreposição da componentes de referência e em (b) e (d) os espectrogramas do sinal da própria Mirnov 01, respectivamente com e sem sobreposição. O sinal da Mirnov apresenta as frequências de $f_{M I R} \pm f_{R E L}$.

Os gráficos (a) e (c) indicam a presença da harmônica $2 f_{R E L}$, além da própria $f_{R E L}$ e da $f_{M I R}$, normalmente encontradas. Nos gráficos (b) e (c) referente ao sinal da bobina de Mirnov 01, é notável a presença de duas componentes satélites $f_{M I R} \pm f_{R E L}$, o que não é comum de ser encontrado nos disparos. A explicação física para o aparecimento das satélites nas perturbações magnéticas medidas pelas bobinas de Mirnov estão relacionadas com o transporte de partículas e impurezas do centro da coluna de plasma para as regiões periféricas a cada crash da dente de serra, visto que as partículas expulsas da região central podem atingir a posição das ilhas. Considerando que a concentração de impurezas da região central seja muito diferente daquela na região das ilhas, cada vez que o plasma expelido pela região central chega às ilhas, ela modifica a característica das ilhas, alterando sua intensidade. Isso poderia explicar a variação do tamanho das ilhas magnéticas. Desta forma, a variação do tamanho das ilhas que ocorre de forma síncrona com a $f_{R E L}$, explicando o aparecimento das satélites no espectrograma. 


\subsubsection{Estudo das frequências durante o acoplamentos de ilhas}

Na seção 5.1.4 foram estudados os acoplamentos de ilhas e foi visto que após a atividade MHD das ilhas magnéticas aumentar de intensidade a frequência de oscilação das ilhas magnéticas cai rapidamente, se estabilizando em um novo valor. Nas análises comparativas das frequências de base para o exemplo do disparo \#28754, estudado na seção 5.3.2, já foi visto que na transição de um regime de alta para baixa atividade MHD o valor da frequência de oscilação da dente de serra caiu de $f_{R E L} \approx 4,6 \mathrm{kHz}$ para $f_{R E L} \approx 2,5 k H z$, enquanto que a frequência de oscilação das perturbações magnéticas aumentou simultaneamente com a diminuição da intensidade da atividade.

Agora vamos estudar o comportamento das frequências de base nos casos em que a variação da intensidade da atividade MHD está associada com o acoplamento de ilhas magnéticas. Por exemplo, vamos considerar o disparo \#25911, cujas variáveis de equilíbrio já foram apresentadas nos gráficos da figura 50. As análises comparativas das frequências de base para este disparo estão mostradas nos gráficos da figura 74. Em (a) e (b) estão mostrados respectivamente os espectrogramas dos sinais da bobina de Mirnov 01 e do canal 9 do SXR, juntamente com os caminhos das frequências de base, assinalados pelas linhas tracejadas. Em (c) e (d) estão mostrados os espectrogramas do sinal do canal 10 do SXR sem e com a sobreposição dos caminhos das frequências de base. O gráfico em (d) revela que estão presentes as componentes $f_{M I R}, f_{R E L}, 2 f_{R E L}$ e $f_{M I R} \pm f_{R E L}$.

É interessante anotar que o valor da frequência de oscilação da dente de serra antes do acoplamento era $f_{R E L} \approx 2,5 k H z$ e subiu para $f_{R E L} \approx 4,8 k H z \log$ após ao acoplamento. A frequência das oscilações de Mirnov que era estável com valor $f_{M I R} \approx 15 \mathrm{kHz}$ antes do acoplamento sofreu um rápido decréscimo no momento em que acontece o acoplamento, caindo para $f_{M I R} \approx 12,5 k H z$. As frequências $f_{R E L}$ e $f_{M I R}$ se mantiveram estáveis nestes valores até aproximadamente $95 \mathrm{~ms}$, instante de tempo em que a atividade MHD começou a perder intensidade. Logo que os níveis das perturbações atingiram os patamares anteriores ao acoplamento, a $f_{R E L}$ voltou a um valor próximo à $2,5 k H z$ e a $f_{M I R}$ subiu continuamente de valor, em parte porque a partir de $100 \mathrm{~ms}$ a corrente de plasma já começava a se extinguir e desta forma, a frequência $f_{M I R}$ não se estabilizou.

Este exemplo mostra um fenômeno relativamente comum nos disparos do TCABR, quando ocorrem acoplamentos de modos MHD; sempre que as frequências das perturbações magnéticas caem de valor, a frequência de oscilação da relaxação da superfície $q=1$ aumenta de valor por um fator de aproximadamente 2. Também é interessante notar que as componentes $f_{M I R}+f_{R E L}$ e $f_{M I R}-f_{R E L}$ descrevem muito bem o comportamento das frequências satélites, como visualizadas nos gráficos da figura 74(d).

Um outro exemplo interessante para o estudo comparativo das frequências base é o caso do disparo \#27005, cujas variáveis de equilíbrio já foram apresentadas nos gráficos da 

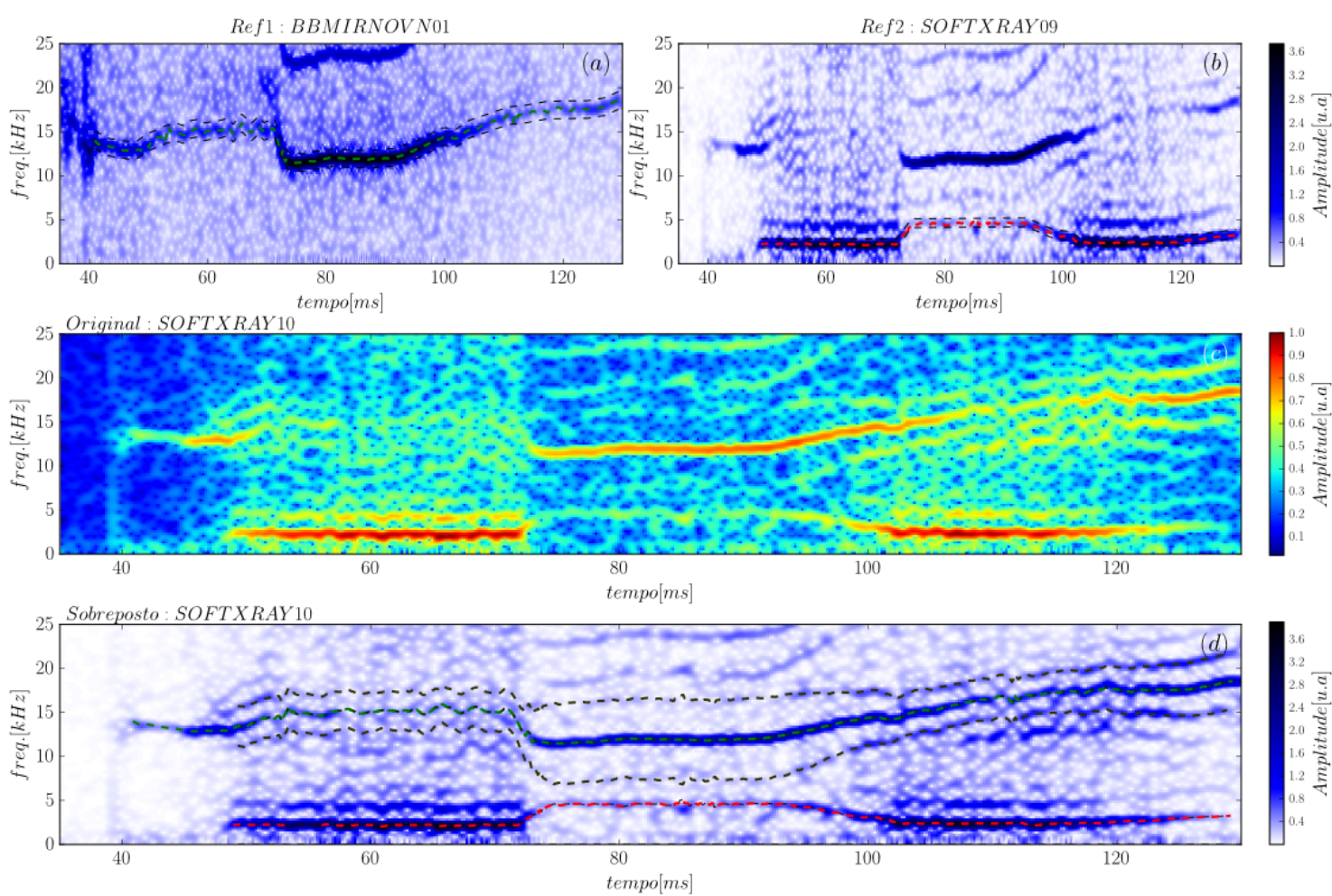

Figura 74 - Análises comparativas das componentes espectrais dos sinais de referência para o disparo \#25911. Em (a) o espectrograma da bobina de Mirnov 01 e o respectivo caminho no plano frequência $\times$ tempo em cor verde, em (b) o espectrograma do canal 9 do SXR e respectivo caminho em cor vermelha, em (c) o espectrograma do sinal a ser comparado, nestes caso o canal 10 do SXR e em (d) o mesmo espectrograma a ser comparado com a sobreposição dos caminhos de frequência das referências.

figura 52. Ocorreu um acoplamento de modos próximo à $55 \mathrm{~ms}$ depois da qual a frequência de oscilação do sinal de Mirnov caiu para $\approx 12 k H z$, como pode ser visto no espectrograma da figura $75(\mathrm{a})$.

Na figura 75(b) está apresentado o espectrograma do canal 9 do SXR e está assinalado pela linha tracejada em vermelho a frequência de oscilação da dente de serra. Este disparo apresenta duas quedas abruptas na frequência das oscilações devidas às ilhas magnéticas, concomitantemente aos incrementos da $f_{R E L}$, como indicado no espectrograma com sobreposição dos caminhos, mostrado na figura $75(\mathrm{~d})$. Este exemplo é bom para demonstrar o caráter repetitivo do comportamento da frequência $f_{R E L}$ quando ocorrem variações da frequência de oscilação das perturbações magnéticas ressonantes (oscilações de Mirnov). Novamente, a cada queda do valor de $f_{M I R}$ (nos instantes de $60 \mathrm{~ms}$ e de $78 \mathrm{~ms}$ ) a $f_{R E L}$ sofreu um incremento no valor e após a diminuição da intensidade da atividade MHD, o valor dessa frequência voltou ao valor original de $f_{R E L} \approx 2,5 \mathrm{kHz}$ anterior ao acoplamentos. 

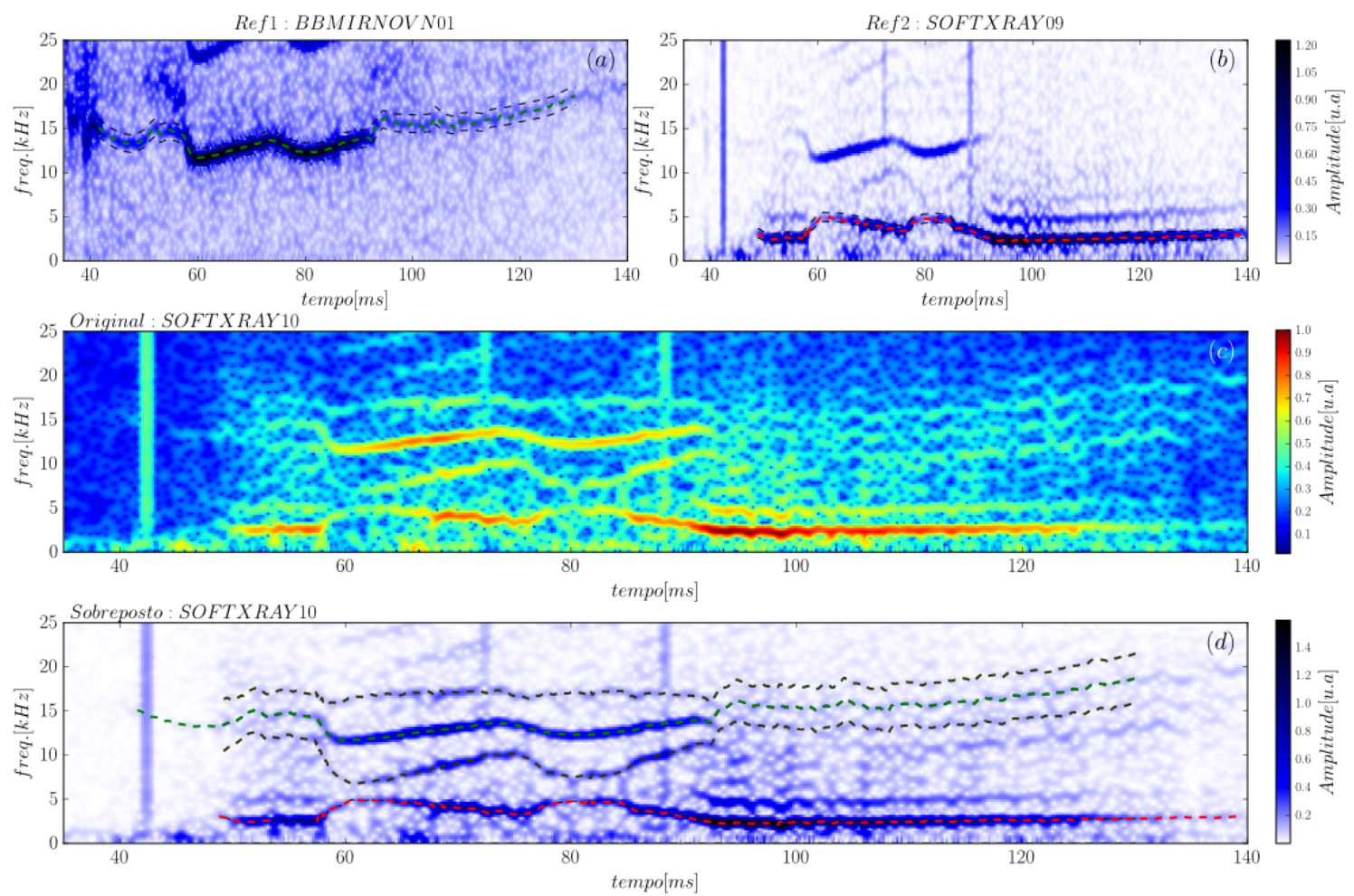

Figura 75 - Análises comparativas das componentes espectrais dos sinais de referência para o disparo \#27005. Em (a) o espectrograma da bobina de Mirnov 01 e o respectivo caminho no plano frequência $\times$ tempo em cor verde, em (b) o espectrograma do canal 9 do SXR e respectivo caminho em cor vermelha, em (c) o espectrograma do sinal a ser comparado, nestes caso o canal 10 do SXR e em (d) o mesmo espectrograma a ser comparado com a sobreposição dos caminhos de frequência das referências. 



\section{Discussões e conclusão}

Este trabalho contemplou um estudo relativamente amplo, mas não exaustivo, sobre instabilidades magneto-hidrodinâmicas no plasma confinado no tokamak TCABR. Efetuou-se uma revisão inicial da técnica de confinamento magnético de plasma, passando superficialmente sobre os problemas relacionados com as derivas responsáveis pela degradação do confinamento, como estas questões são resolvidas num tokamak para obter uma configuração de equilíbrio favorável. Em função da topologia dos campos e através da equação de difusão de campos magnéticos em meios com resistividade não nula, foram estudadas as origens das perturbações de ruptura, explorados os motivos pelos quais essas perturbações crescem nas proximidades das superfícies racionais e de que maneira elas desempenham forte influência em todas as propriedades físicas do plasma. O uso de um modelo para a perturbação magnética provocada por modos MHD (equação 2.24) permitiu decompor as perturbações em componentes espaciais e temporais e com isso, a descrição espacial que diferencia os modos Tearing e Kink foram apresentadas. Com o uso desse modelo, também pôde-se justificar o emprego de alguns métodos de tratamento de dados, em especial à análise espectral e ajuste por mínimos quadrados. Munidos destas ferramentas, várias situações representativas foram analisadas em detalhes de forma que a estrutura espacial das ilhas (modos tearing e kink de borda) e oscilações de centro da coluna de plasma (modo kink interno e relaxação do centro) foram determinadas para as situações usualmente denominadas como "baixa" e "alta" atividade MHD.

Na seção 5.1 várias das propriedades das ilhas magnéticas, como posição radial e número de onda poloidal foram determinadas experimentalmente e os resultados indicaram que a rotação dos sistemas de ilhas se dá no sentido positivo da coordenada poloidal, tendo em vista que não foram encontrados número de onda $m<0$. A explicação física mais provável, aventada no texto, é que a situação deve-se a efeitos viscosos do plasma circundante que rapidamente amorteceriam movimentos contrários ao sentido de rotação da coluna.

As decomposições espaciais das instabilidades MHD medidas pelas bobinas de Mirnov mostraram que a configuração de modos não é, em geral, estática no tempo, conforme visto nos gráficos da figura 47. Essas análises mostraram que no início dos disparos temos uma situação de acomodamento que é normalmente composta por uma sucessão decrescente de modos com números de onda poloidal mais elevados, $m=(7,6,5,4)$, cujo modo dominante num dado instante de tempo está relacionado com o valor do fator de segurança na borda e, portanto, tratam-se de modos kink de borda que são exitados dependendo do valor da corrente de plasma. Após os instantes iniciais da formação da coluna de plasma, a corrente se estabiliza no valor de platô e os modos $m=(2,3,4)$ 
relacionados com modos de ruptura (tearing modes) se consolidam, crescem e governam a intensidade e frequência das perturbações magnéticas medidas pelas bobinas de Mirnov. Nesta região vários fenômenos podem acontecer, de maneira que o particionamento das análises em grupos de disparos de baixa e alta atividade MHD permitiu traçar um panorama das possíveis formas de evolução das instabilidades.

Para disparos que apresentam baixa intensidade das perturbações medidas pelas bobinas (denominados como sendo de "baixa atividade MHD"), dois tipos de oscilações do centro da coluna de plasma foram identificadas, utilizando análises espectrais com resolução espacial dos sinais produzidos pelo diagnóstico SXR que detecta a emissividade do plasma na região do U.V. e dos raios-X moles, conforme explorado na seção 5.2. Uma delas, identificada como oscilação dente de serra, apresenta frequência na faixa de 2 à $3 k H z$ cuja característica espacial marcante é que a emissividade dos pontos internos a superfície $q=1$ variam conjuntamente e em contra-fase com relação a variação da emissividade na região externa à esta superfície. A outra oscilação presente na região central, identificada como a componente precursora da dente de serra, apresenta frequência na faixa de 10 à $20 k H z$, cuja característica espacial marcante é que a variação da emissividade do plasma em lados opostos do centro da coluna estão em contra-fase (isto é, quando as emissões aumentam de um lado elas diminuem do lado oposto e vice-versa) e, desta forma, pode ser identificada como um modo kink localizado na superfície racional $q=1$. Ambas as oscilações estão de acordo com o modelo de Kadomtsev, apresentado na seção 2.3.4, que descreve o mecanismo de relaxação do centro da coluna. Essas oscilações são comuns e, de fato, são encontradas em todos os tokamaks. Ademais, foram identificadas outras oscilações, com frequências satélites à oscilação precursora da dente de serra, que tem a mesma estrutura espacial da oscilação precursora. Nesta situação de baixa atividade MHD somente as satélites inferiores foram detectadas e com magnitude espectral baixa quando comparadas com a precursora.

Já para atividade MHD de alta intensidade medida pelas bobinas de Mirnov, o comportamento espacial das oscilações do centro da coluna não deixa de ser análogo ao caso anterior, mas apresenta diferenças significativas no valor da frequência da oscilação dente de serra que, para esta situação, fica na faixa de 4 à $5 k H z$. Com relação às frequências satélites, diferentemente do caso com MHD de baixa intensidade, estas apresentam magnitude espectral comparável à própria precursora e, tanto as satélites inferiores quanto as superiores estão presentes.

As análises efetuadas na seção 5.3, dão conta que para ambos os casos (MHD de alta e baixa intensidade), as frequências das componentes satélites estão espaçadas da precursora por valores múltiplos inteiros da frequência da dente de serra. Ademais, as mesmas análises mostraram que a frequência das oscilações dente de serra está de alguma forma relacionadas com as características da atividade MHD relativas às ilhas (intensidade 
e frequência medidas pelas bobinas de Mirnov) como demostrado para o exemplos de acoplamentos de modos presentes nos disparos \#25911 e \#27005, analisados na seção 5.1.4, tendo em vista que após o acoplamento, a frequência do sistema de ilhas caiu e a intensidade da atividade aumentou enquanto que a frequência da oscilação dente de serra continuamente variou de um valor dentro da faixa típica para disparos de baixa intensidade MHD para um outro valor dentro da faixa típica para disparos de alta intensidade. É importante frisar que realmente se trata de um incremento na frequência da oscilação dente de serra e não de uma nova perturbação de centro, visto que o incremento é contínuo e que as análises espaciais das componentes de frequência revelam que a estrutura espacial possui as mesmas características de uma relaxação do centro da coluna, como pode ser notado comparando-se as figuras $61(\mathrm{a}-\mathrm{d})$ e $62(\mathrm{a}-\mathrm{d})$.

Com esse quadro de resultados experimentais, é possível construir um sinótico das oscilações MHD em um disparo típico do TCABR: no início da formação da coluna de plasma é esperado uma sucessão de instabilidades do tipo kink de borda com número de onda poloidal decrescente, variando de $m=7$ até $m=4$ ou $m=3$. Após a estabilização do platô da corrente de plasma, em disparos com baixa atividade MHD o que se observa é uma composição de modos tearing com $m=(2,3,4)$. Outra situação possível ocorre quando há crescimento da atividade MHD durante a região de platô que muitas vezes acontece devido ao aparecimento de perturbações do tipo kink de borda (nos exemplos estudados, com $m=3$ ) o qual pode se acoplar com os modos tearing presentes no disparo, caso em que a intensidade da atividade MHD será fortemente aumentada, conjuntamente com a queda na frequência das oscilações de Mirnov e o aumento da frequência da relaxação do centro da coluna.

Como continuação deste trabalho, assinala-se que algumas questões encontradas não foram explicadas e, portanto, permanecem em aberto e necessitam de tratamento futuro, dentre as quais podemos citar; 1) a compreensão dos mecanismos físicos associados à assimetria das componentes satélites encontradas na situação de atividade MHD de baixa intensidade, visto que somente as satélites inferiores à frequência da precursora da dente de serra foram observadas, 2) esclarecer o motivo pelo qual o processo de reconexões magnéticas na superfície racional $q=1$ é facilitado quando a intensidade da atividade MHD medida pelas bobinas de Mirnov é elevada, tendo em vista que o intervalo de tempo entre as relaxações do centro diminui, implicando na maior frequência das relaxações associadas ao dente de serra e 3) sabendo que as relaxações do centro da coluna desempenham um papel central no transporte de partículas e impurezas do centro para as regiões periféricas, é necessário ampliar a compreensão do processo de intensificação da atividade MHD devido a concentração de impurezas e, em contrapartida, entender como as ilhas magnéticas influenciam no transporte de impurezas.

Ademais, este trabalho se soma aos esforços anteriores efetuados no laboratório 
para melhorar a compreensão dos fenômenos magneto-hidrodinâmicos presentes no plasma do TCABR. Dentre as dissertações e teses que foram importantes para este trabalho valem a pena citar: 1) A tese de doutoramento do Dr. Erich Saetone, que estudou as oscilações de Mirnov com o emprego de um conjunto de 24 bobinas de Mirnov numa configuração circular e com distribuição não uniforme das bobinas e que utilizou análise de Fourier no tratamento dos dados [69]; 2) A dissertação de mestrado do Sr. Victor Cominato, estudo sobre instabilidade magneto-hidrodinâmicas utilizando um sistema bolométrico via análise espectral [24]; 3) A tese de doutoramento do Dr. Antônio Fonseca, sobre emissão ciclotrônica do qual o método proposto permitiu a determinação direta da posição e largura das ilhas magnéticas [70] e 4) A tese de doutoramento do Dr. Omar Najera, sobre o perfil tomográfico da emissão da linha $H \alpha$ [71].

Dois pontos com relação a este trabalho merecem ser destacados, um deles refere-se à implementação de códigos computacionais em linguagem Python como uma forma de possibilitar as análises dos dados experimentais. De fato, muitas das rotinas já se encontravam disponíveis para o Matlab, mas um entendimento profundo das técnicas não deve se limitar apenas à sua utilização, sendo que, de um ponto de vista pessoal, certos detalhes do conhecimento só são obtidos quando a sequência de desenvolvimento é efetuado passo à passo, desde dos conceitos mais básicos até que se obtenha uma visão mais global do problema em tela. O outro destaque diz respeito ao projeto e construção do amplificador do sistema SXR efetuado durante o transcorrer deste trabalho. Uma importante evolução no amplificador do sistema SXR em relação ao precedente é a capacidade do novo sistema de operar com os sensores em modo fotocorrente o que lhe confere uma resposta mais rápida, apesar de apresentar maior nível de ruído e sensibilidade a interferências. Em contrapartida, possibilita futuros estudos das instabilidades de frequência mais altas $(\sim 500 \mathrm{kHz})$ como as "TAE - Toroidal Alfvèn Eigenmode".

Estes pontos vão ao encontro com a tradição do laboratório no desenvolvimento de novos diagnósticos e de instrumentação para o estudo de plasmas confinados em tokamaks. Esta é uma característica importante do grupo de física de plasmas do IFUSP, visto que corrobora com a produção de novos resultados experimentais localmente e também auxilia nas colaborações internacionais das quais o grupo faz parte. A veia do desenvolvimento de instrumentação é uma importante vertente da atividade de pesquisa do grupo que deve continuar a ser estimulada. 


\section{Referências}

[1] F. Chen, Introduction to Plasma Physics and Controlled Fusion. No. v. 1, Springer, 2006.

[2] D. Meade, "50 years of fusion research," Nuclear Fusion, vol. 50, no. 1, p. 014004, 2010 .

[3] M. L. K. T. M. Kikuchi, Fusion Physics. International Atomic Energy Agency, 2012.

[4] H. A. Bethe, "Energy Production in Stars," Phys. Rev., vol. 55, p. 103, Jan 1939.

[5] E. M. Burbidge, G. R. Burbidge, W. A. Fowler, and F. Hoyle, "Synthesis of the Elements in Stars," Reviews of Modern Physics, vol. 29, p. 547, 1957.

[6] M. Kamionkowski and J. N. Bahcall, "The Rate of the proton proton reaction," Astrophys. J., vol. 420, p. 884, 1994.

[7] H.-S. Bosch and G. M. Hale, "Improved formulas for fusion cross-sections and thermal reactivities," Nuclear Fusion, vol. 32, p. 611, Apr. 1992.

[8] W. Horton, Turbulent Transport in Magnetized Plasmas. World Scientific Publishing Company, 2012.

[9] T. Nicolas, H. Lütjens, J.-F. Luciani, X. Garbet, and R. Sabot, "Impurity behavior during sawtooth activity in tokamak plasmas," Physics of Plasmas, vol. 21, no. 1, p. 012507, 2014.

[10] M. Nave, J. Rapp, T. Bolzonella, R. Dux, M. Mantsinen, R. Budny, P. Dumortier, M. von Hellermann, S. Jachmich, H. Koslowski, G. Maddison, A. Messiaen, P. MonierGarbet, J. Ongena, M. Puiatti, J. Strachan, G. Telesca, B. Unterberg, M. Valisa, P. de Vries, and c. t. t. J.-E. Workprogramme, "Role of sawtooth in avoiding impurity accumulation and maintaining good confinement in JET radiative mantle discharges," Nuclear Fusion, vol. 43, no. 10, p. 1204, 2003.

[11] G. D. Lehner T., La Fusion par Confinement Magnetique. Les Editions de Physique, 1984.

[12] R. B. White, The Theory of Toroidally Confined Plasma. Imperial College Press, 2006.

[13] J. P. Freidberg, "Ideal magnetohydrodynamic theory of magnetic fusion systems," Rev. Mod. Phys., vol. 54, p. 801, Jul 1982. 
[14] J. P. Freidberg, Ideal Magnetohydrodynamics. Springer, 1987.

[15] N. Cruz, J. Moret, S. Coda, B. P. Duval, H. B. Le, A. P. Rodrigues, C. A. F. Varandas, C. M. B. A. Correia, and B. S. Goncalves, "An optimal real-time controller for vertical plasma stabilization," ArXiv e-prints, June 2014.

[16] F. Sartori, A. Barbalace, A. Batista, T. Bellizio, P. Card, G. D. Tommasi, P. M. Cullen, A. Neto, F. Piccolo, R. Vitelli, and L. Zabeo, "The $\{$ PCU $\}\{$ JET $\}$ Plasma Vertical Stabilization control system," Fusion Engineering and Design, vol. 85, no. 3-4, p. 438, 2010. Proceedings of the 7th IAEA Technical Meeting on Control, Data Acquisition, and Remote Participation for Fusion Research.

[17] D. D. Schnack, Lectures in Magnetohydrodynamics: With an Appendix on Extended MHD. Lecture Notes in Physics, Berlin, Heidelberg: Springer, 2009.

[18] M. D. Kruskal and R. M. Kulsrud, "Equilibrium of a Magnetically Confined Plasma in a Toroid," Physics of Fluids, vol. 1, no. 4, p. 265, 1958.

[19] V. D. Shafranov, "Equilibrium of a toroidal pinch in a magnetic field," Soviet Atomic Energy, vol. 13, no. 6, p. 1149, 1963.

[20] P. Bellan, Fundamentals of Plasma Physics. Cambridge University Press, 2006.

[21] J. D. Callen, Fundamentals of Plasma Physics. University of Wisconsin, Madison, 2006.

[22] M. J.D. and H. R.D., Plasma Confinement. Addison-Wesley, 1991.

[23] A. Boozer, Plasma confinement. No. v. 13 in Encyclopedia of Physical Science and Technology, Academic Press, 1992.

[24] V. C. Theodoro, "Estudo espectral das instabilidades MHD no tokamak TCABR," Mestrado, Universidade de São Paulo - USP, 2013.

[25] E. Witrant, E. Joffrin, S. Brémond, G. Giruzzi, D. Mazon, O. Barana, and P. Moreau, "A control-oriented model of the current profile in tokamak plasma," Plasma Physics and Controlled Fusion, vol. 49, no. 7, p. 1075, 2007.

[26] Z. O. Guimarães-Filho, T. S. Team, and F. Team, "Characterization of energetic particle driven modes by spectral analysis in Tore Supra and FTU tokamaks," AIP Conference Proceedings, vol. 1478, no. 1, p. 129, 2012.

[27] C. Cheng, "Kinetic extensions of magnetohydrodynamics for axisymmetric toroidal plasmas," Physics Reports, vol. 211, no. 1, p. 51, 1992. 
[28] M. A. Van Zeeland, G. J. Kramer, M. E. Austin, R. L. Boivin, W. W. Heidbrink, M. A. Makowski, G. R. McKee, R. Nazikian, W. M. Solomon, and G. Wang, "Radial Structure of Alfvén Eigenmodes in the DIII-D Tokamak through Electron-CyclotronEmission Measurements," Phys. Rev. Lett., vol. 97, p. 135001, Sep 2006.

[29] A. H. Boozer and N. Pomphrey, "Current density and plasma displacement near perturbed rational surfaces," Physics of Plasmas, vol. 17, no. 11, p. 110707, 2010.

[30] R. Fitzpatrick, "Helical temperature perturbations associated with tearing modes in tokamak plasmas," Physics of Plasmas, vol. 2, no. 3, p. 825, 1995.

[31] J. Wesson and D. Campbell, Tokamaks. International Series of Monographs on Physics, OUP Oxford, 2011.

[32] M. de Bock, Understanding and controlling plasma rotation in tokamaks. PhD thesis, 2007.

[33] R. Fitzpatrick, "Braking of tearing mode rotation by ferromagnetic conducting walls in tokamaks," Physics of Plasmas, vol. 22, no. 9, p. 092506, 2015.

[34] R. Fitzpatrick, "Interaction of tearing modes with external structures in cylindrical geometry (plasma)," Nuclear Fusion, vol. 33, no. 7, p. 1049, 1993.

[35] F. Waelbroeck, "Theory and observations of magnetic islands," Nuclear Fusion, vol. 49, no. 10, p. 104025, 2009.

[36] B. B. Kadomtsev, "Disruptive instability in Tokamaks," Fizika Plazmy, vol. 1, p. 710, Sept. 1975.

[37] I. T. Chapman, "Controlling sawtooth oscillations in tokamak plasmas," Plasma Physics and Controlled Fusion, vol. 53, no. 1, p. 013001, 2011.

[38] J. A. Bittencourt, Fundamentals of Plasma Physics. third ed., 2004.

[39] M. Rosenbluth, R. Dagazian, and P. Rutherford, "Nonlinear properties of the internal $\mathrm{m}=1$ kink instability in the cylindrical tokamak," Phys. Fluids, v. 16, no. 11, p. 1894, Nov 1973.

[40] B. Kadomtsev, Tokamak Plasma: A Complex Physical System. Plasma Physics Series, IOP Publishing, 1992.

[41] I. Nascimento, Y. Kuznetsov, J. Severo, A. Fonseca, A. Elfimov, V. Bellintani, M. Machida, M. Heller, R. Galvão, E. Sanada, and J. Elizondo, "Plasma confinement using biased electrode in the TCABR tokamak," Nuclear Fusion, vol. 45, no. 8, p. 796, 2005. 
[42] Z. O. Guimarães-Filho, I. L. Caldas, R. L. Viana, I. C. Nascimento, Y. K. Kuznetsov, and J. Kurths, "Recurrence quantification analysis of turbulent fluctuations in the plasma edge of Tokamak Chauffage Alfvén Brésilien tokamak," Physics of Plasmas, vol. 17, no. 1, p. 012303, 2010.

[43] Z. O. Guimarães-Filho, I. L. Caldas, R. L. Viana, M. V. A. P. Heller, I. C. Nascimento, Y. K. Kuznetsov, and R. D. Bengtson, "Electrostatic turbulence driven by high magnetohydrodynamic activity in Tokamak Chauffage Alfvén Brésilien," Physics of Plasmas, vol. 15, no. 6, p. 062501, 2008.

[44] I. Nascimento, Y. Kuznetsov, Z. Guimarães-Filho, I. E. Chamaa-Neto, O. Usuriaga, A. Fonseca, R. Galvão, I. Caldas, J. Severo, I. Semenov, C. Ribeiro, M. Heller, V. Bellintani, J. Elizondo, and E. Sanada, "Suppression and excitation of MHD activity with an electrically polarized electrode at the TCABR tokamak plasma edge," Nuclear Fusion, vol. 47, no. 11, p. 1570, 2007.

[45] J. Severo, I. Nascimento, Y. Kuznetsov, R. Galvão, Z. Guimarães-Filho, F. Borges, O. Usuriaga, J. Elizondo, W. de Sá, E. Sanada, and M. Tendler, "Temporal behaviour of toroidal rotation velocity in the TCABR tokamak," Nuclear Fusion, vol. 49, no. 11, p. 115026, 2009.

[46] J. Severo, I. Nascimento, V. Tsypin, and R. Galvão, "Plasma residual rotation in the TCABR tokamak," Nuclear Fusion, vol. 43, no. 10, p. 1047, 2003.

[47] "Dados públicos TCABR disponível em: http://tcabrcl.if.usp.br/tcabrWiki/index.php/Theses - data de acesso:," Mar. 2016.

[48] R. M. O. Galvão, C. H. S. Amador, W. A. H. Baquero, F. Borges, I. L. Caldas, N. A. M. Cuevas, V. N. Duarte, A. G. Elfimov, J. I. Elizondo, A. M. M. Fonseca, T. M. Germano, G. G. Grenfell, Z. O. Guimarães-Filho, J. L. Jeronimo, Y. K. Kuznetsov, M. A. M. Manrique, I. C. Nascimento, C. J. A. Pires, P. G. P. Puglia, A. P. Reis, G. Ronchi, L. F. Ruchko, W. P. de Sá, R. J. F. Sgalla, E. K. Sanada, J. H. F. Severo, V. C. Theodoro, and D. L. Toufen, "Report on recent results obtained in TCABR," Journal of Physics: Conference Series, vol. 591, no. 1, p. 012001, 2015.

[49] A. Cheetham, A. Heym, F. Hofmann, K. Hruska, R. Keller, A. Lietti, J. Lister, A. Pochelon, H. Ripper, S. R., and A. Simik, "The TCA Tokamak - Project Report," tech. rep., Centre de Recherches en Physique des Plasmas, Lausanne, Switzerland, Jan. 1980.

[50] M. Araujo, V. A., and O. K.A., "Toroidal geometry and plasma column displacement corrections in the analysis of Mirnov oscillations," Brazilian Journal of Physics, vol. 32, p. 131, 032002 . 
[51] M. Kikuchi, "A note on the Mirnov signal analysis in tokamaks," Nuclear Fusion, vol. 26, no. 1, p. 101, 1986.

[52] U. Bakshi and A. Godse, Electronic Devices and Circuits. Technical Publications, 2008.

[53] T. M. Germano, A. Vannucci, L. Ruchko, A. Reis, R. M. Galvao, and I. C. Nascimento, "Upgrade of the TCABR soft X-ray system," 9 Brazilian meeting on plasma physics, 2007.

[54] EIA/ECA-310 - Cabinets, Racks, Panels, and Associated Equipment, Revision E ed., Dec. 2005.

[55] J. Graeme, Photodiode Amplifiers: OP AMP Solutions. Gain technology, McGraw-Hill Education, 1996.

[56] O. D. Corporation, AXUV/SXUV/UVG: Salient Applications, 2013.

[57] E. O. Brigham, The fast Fourier transform and its applications. Englewood Cliffs, New Jersey: Prentice-Hall, 1988.

[58] M. A. Kramer, An Introduction to Field Analysis Techniques: The Power Spectrum and Coherence. Department of Mathematics and Statistics - Boston University, 2013.

[59] S. J. Orfanidis, Introduction to Signal Processing. Upper Saddle River, NJ, USA: Prentice-Hall, Inc., 1995.

[60] K. R. Rao, D. N. Kim, and J.-J. Hwang, Fast Fourier Transform - Algorithms and Applications. Springer Publishing Company, Incorporated, 1st ed., 2010.

[61] Widrow, B., Baudrenghien, P., Vetterli, M. and Titchener, P. F., "Fundamental relations between the LMS algorithm and the DFT," IEEE Transactions on Circuits and Systems, vol. 34, no. 7, p. 814, 1987.

[62] N. P. Basse, S. Zoletnik, G. Y. Antar, J. Baldzuhn, A. Werner, and t. W.-A. Team, "Characterization of turbulence in L- and ELM-free H-mode Wendelstein 7-AS plasmas," Plasma Physics and Controlled Fusion, vol. 45, no. 4, p. 439, 2003.

[63] P. Stoica and R. Moses, Spectral Analysis of Signals. Pearson Prentice Hall, 2005.

[64] S. M. "Kay and S. L. Marple, "Spectrum Analysis - A Modern Perspective," Proceedings of the IEEE, vol. 69, no. 11, p. 1379, 1981.

[65] S. da Graça, G. D. Conway, P. Lauber, M. Maraschek, D. Borba, S. Günter, L. Cupido, K. Sassenberg, F. Serra, M. E. Manso, t. C. reflectometry group, and t. A. U. Team, "Localization of MHD and fast particle modes using reflectometry in ASDEX Upgrade," Plasma Physics and Controlled Fusion, vol. 49, no. 11, p. 1849, 2007. 
[66] S. L. Marple, Digital Spectral Analysis With Applications. Australia, Sydney: Prentice Hall, 1987.

[67] Joint Committee for Guides in Metrology, "JCGM 100: Evaluation of Measurement Data - Guide to the Expression of Uncertainty in Measurement," tech. rep., JCGM, 2008.

[68] Hole, MJ and Appel, LC, "A modulation model for mode splitting of magnetic perturbations in the Mega Ampere Spherical Tokamak," Plasma Physics and Controlled Fusion, vol. 51, no. 4, p. 045002, 2009.

[69] E. A. S. Olschewki, Construção e utilização de um limitador ergódico magnético no tokamak TCABR. Doutorado, Universidade de São Paulo - USP, 2004.

[70] A. M. M. Fonseca, Emissão Eletrociclotrônica no Tokamak TCABR: Um Estudo Experimental. Doutorado, Universidade de São Paulo - USP, 2005.

[71] O. C. U. Najera, Tomografia de emissão H-alfa no tokamak TCABR. Doutorado, Universidade de São Paulo - USP, 2006. 


\section{ANEXO A - Projeto amplificador do SXR}

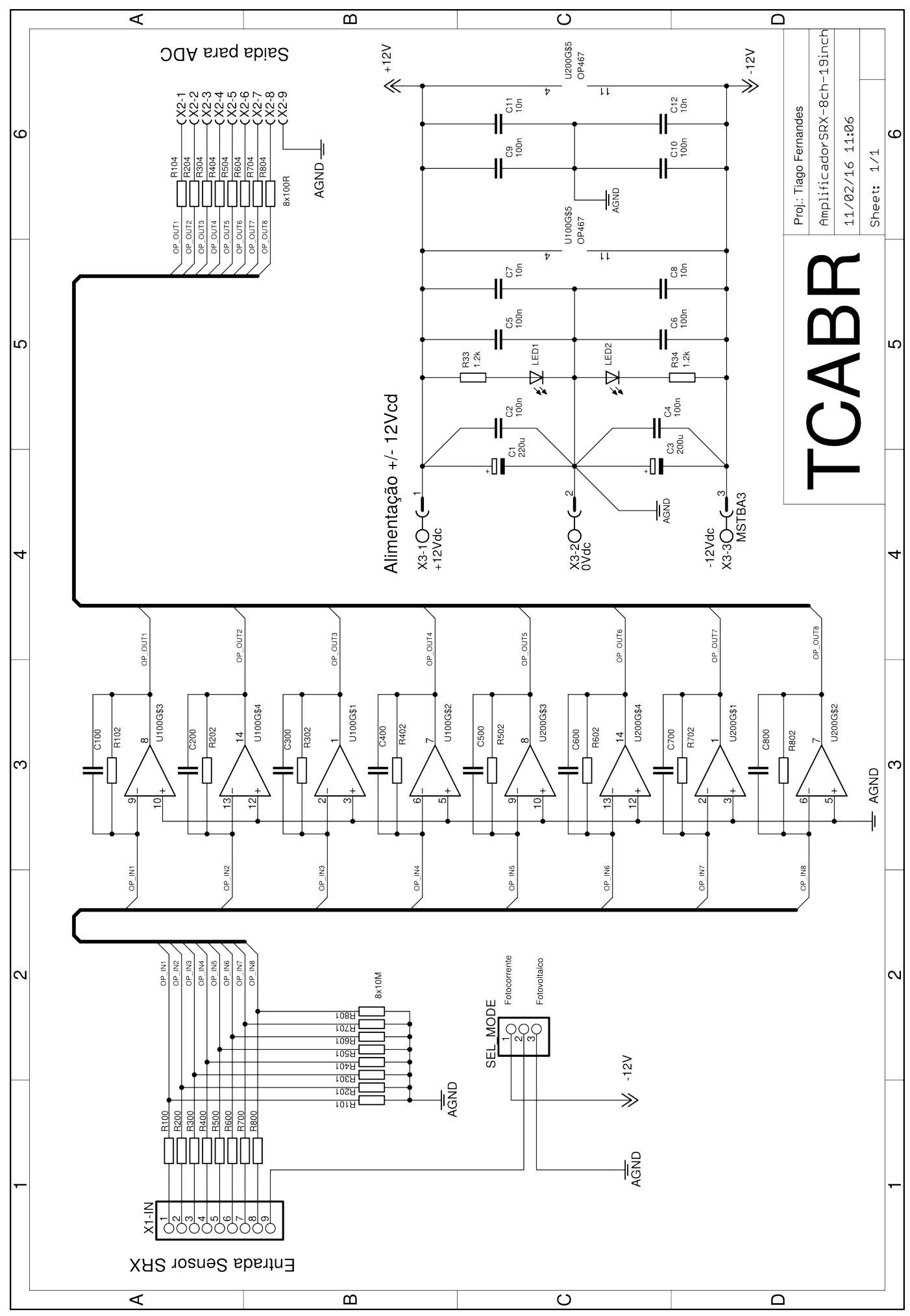

Figura 76 - Diagrama do circuito eletrônico completo do novo amplificador de sinais do sistema SXR do TCABR. 
A.1 Desenho da Placa de circuito impresso

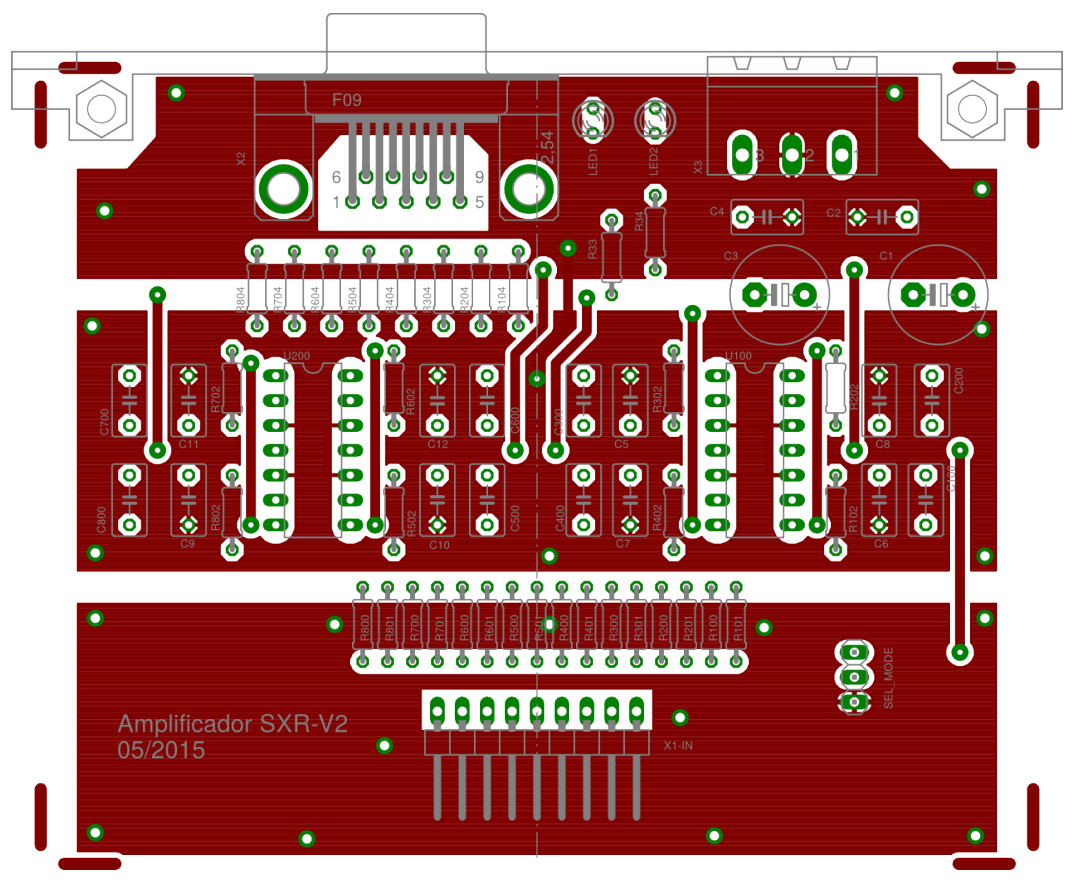

(a)

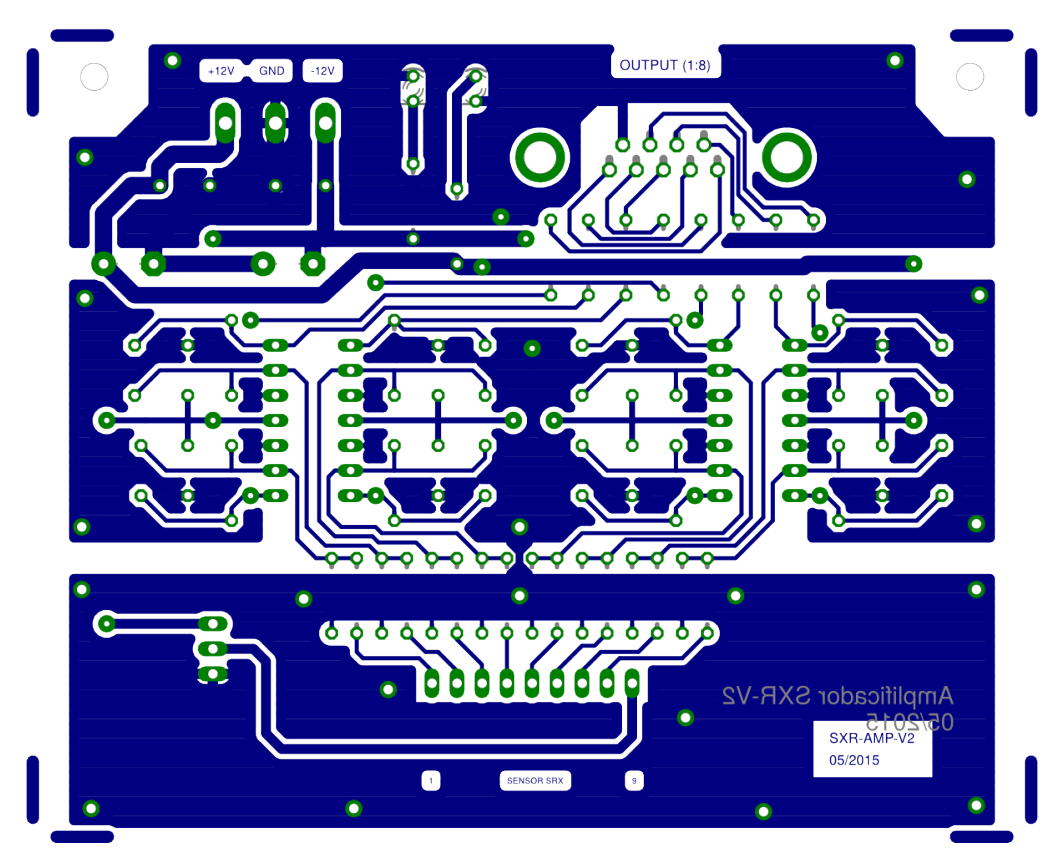

(b)

Figura 77 - Desenho em escala natural da parte superior em (a) e inferior em (b) da placa de circuito impresso do novo amplificador do sistema SXR do TCABR. 


\section{A.2 Projeto mecânico}

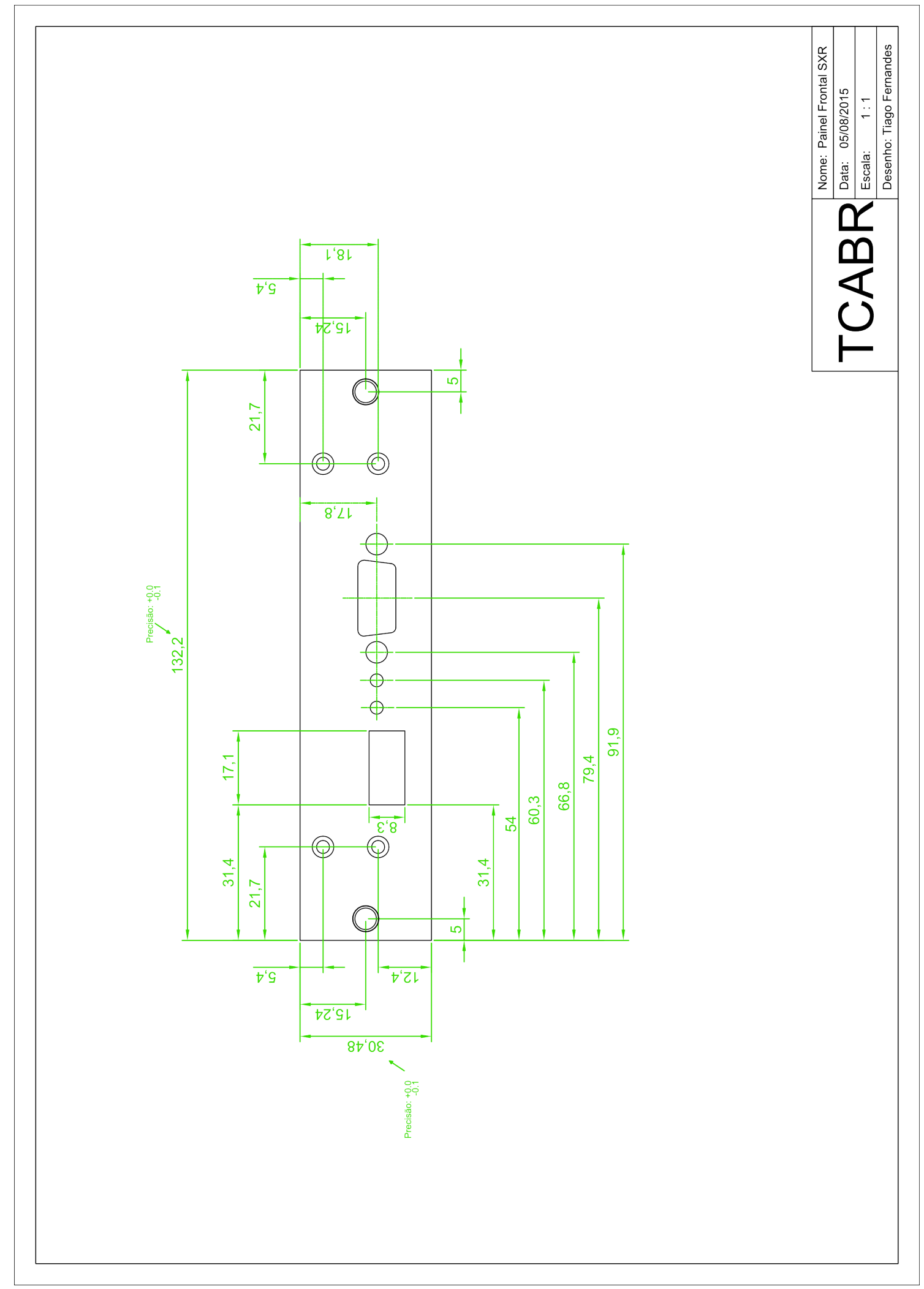

Figura 78 - Lâminas frontais do módulos eletrônicos do sistema SXR do TCABR. 


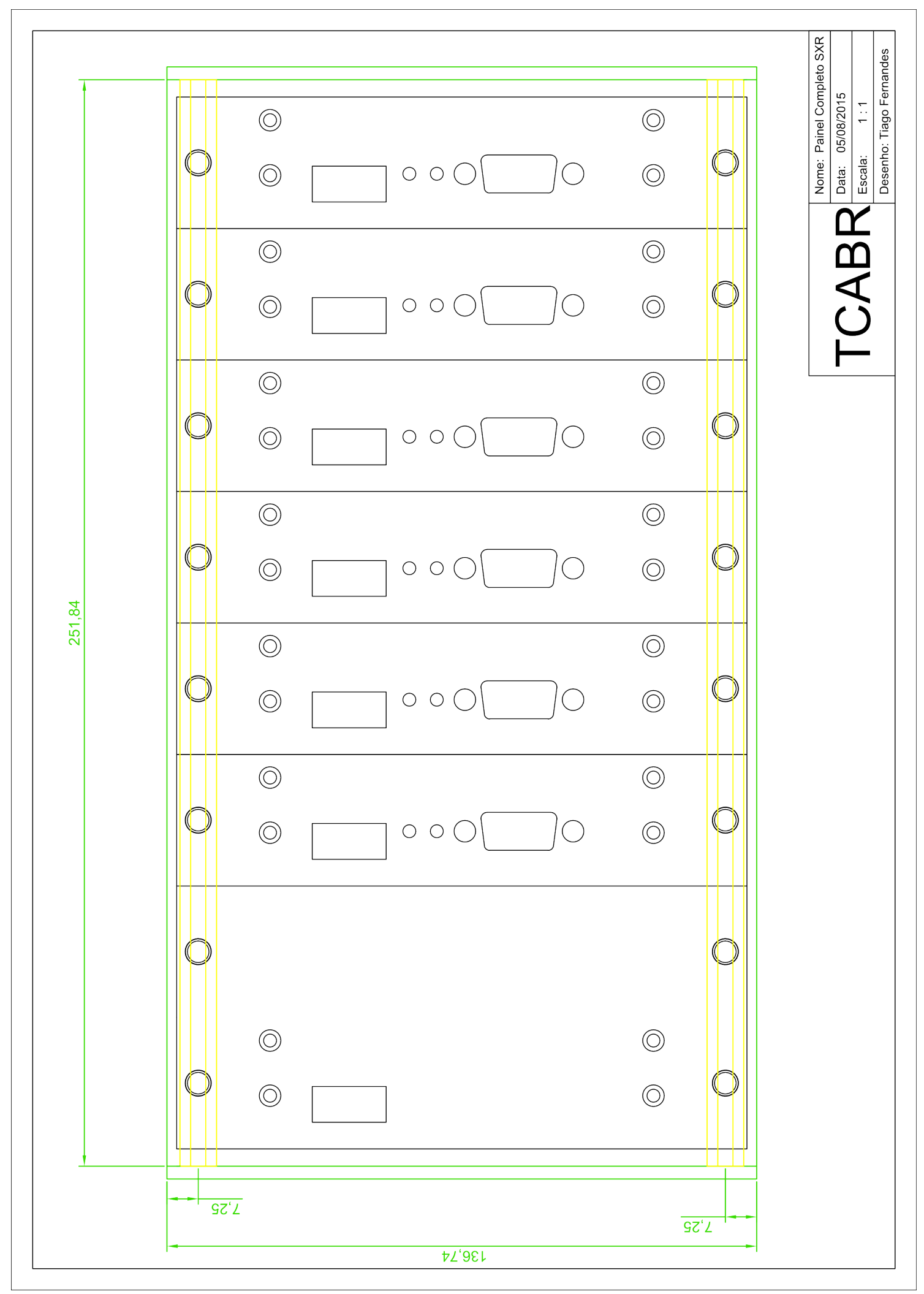

Figura 79 - Vista frontal do bastidor do sistema SXR do TCABR.. 


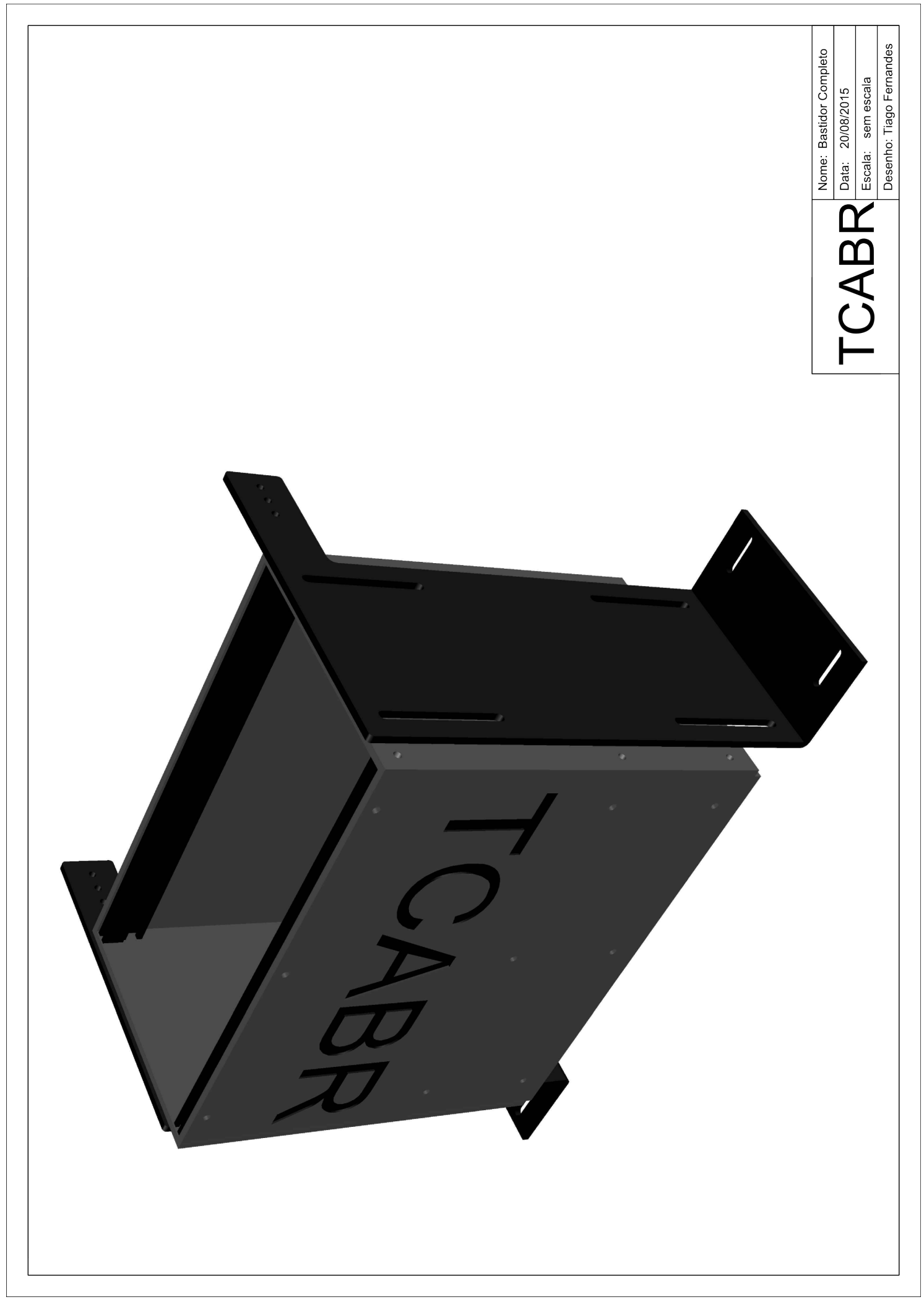

Figura 80 - Vista 3D do bastidor do sistema SXR do TCABR. 